Portland State University

PDXScholar

$5-12-2021$

\title{
Chemical Characterization of Toxicologically Relevant Molecules in Cannabis Concentrates and Vaporizer Aerosols
}

Jiries Meehan-Atrash

Portland State University

Follow this and additional works at: https://pdxscholar.library.pdx.edu/open_access_etds

Part of the Chemistry Commons

Let us know how access to this document benefits you.

Recommended Citation

Meehan-Atrash, Jiries, "Chemical Characterization of Toxicologically Relevant Molecules in Cannabis Concentrates and Vaporizer Aerosols" (2021). Dissertations and Theses. Paper 5687.

https://doi.org/10.15760/etd.7560

This Dissertation is brought to you for free and open access. It has been accepted for inclusion in Dissertations and Theses by an authorized administrator of PDXScholar. Please contact us if we can make this document more accessible: pdxscholar@pdx.edu. 
Chemical Characterization of Toxicologically Relevant Molecules in Cannabis Concentrates and Vaporizer Aerosols

\author{
by \\ Jiries Meehan-Atrash \\ requirements for the degree of \\ Doctor of Philosophy \\ in \\ Chemistry \\ Dissertation Committee: \\ Robert M. Strongin, Chair \\ David H. Peyton \\ Dean B. Atkinson \\ Andrew Rice
}

A dissertation submitted in partial fulfillment of the

Portland State University

2021 
(C) 2021 Jiries Meehan-Atrash 


\section{Abstract}

Consumption of cannabis concentrates using the relatively novel non-combustion methods dabbing and vaping has steadily grown in popularity as cannabis legalization in North America has allowed increased access to sophisticated cannabis products and technology. In order to assess the safety of these products, it is necessary to gain a chemical understanding of the decomposition reactions that occur when the active ingredients are heated in the conditions seen when dabbing or vaping. This dissertation contains a manuscript that details efforts to structurally characterize a toxic cannabis concentrate adulterant, and three manuscripts that studied the chemical decomposition of the two primary cannabis concentrate ingredients, the psychoactive $\Delta^{9}$-tetrahydrocannabinol (THC) and aromatic terpenoids. The known airway toxicant pine rosin or colophony was identified as a major component of a cannabis extract adulterant using liquid chromatography-mass spectrometry and nuclear magnetic resonance spectroscopy (NMR). Though this agent has previously been identified as a hashish adulterant in Europe, this was the first report of its use in North America. THC and cannabis terpenoids were shown to decompose to generate potentially harmful levels of known toxicants such as methyl vinyl ketone, 1,3-butadiene, methacrolein, benzene, toluene, and a slew of other volatile organic compounds (VOCs) with unknown health impacts. Characterization and quantification methods for such VOCs 
using NMR and automated thermal desorption-gas chromatography-mass spectrometry are presented. Given the lack of previous understanding related to THC and cannabis terpenoid (e.g. $\beta$-myrcene) decomposition when heated to the temperatures seen during dabbing and vaping $\left(250-400{ }^{\circ} \mathrm{C}\right)$, special attention is paid to the chemical mechanisms that occur. $\beta$-Myrcene decomposition was studied by characterizing the VOCs released when dabbing a site-specifically deuterated isotopologue of this molecule. THC decomposition was studied by characterizing its dabbing and vaping-released VOCs, and comparing these to a structurally similar cannabinoid, cannabinol. Chemical mechanisms that account for large shares of the VOCs released by these molecules are described. Curiously, THC and $\beta$-myrcene share a common reactive intermediate that is the source of isoprene, 2-methyl-2-butene, 3methylcrotonaldehyde, and 3-methyl-1-butene, and it was shown that the relative proportions of these four VOCs is temperature dependent. It was shown that the ratio of the two primary cannabis concentrate ingredients, THC and terpenoids, impacts the release of VOCs and transfer of active ingredients. Specifically, increasing the mass percent of $\beta$-myrcene in THC for a synthetic cannabis oil from $7 \%$ to $14 \%$ led to significant decreases in the the release of degradants and carcinogens such as benzene, 1,3-butadiene, and isoprene, and more efficient transfer of THC when vaping. However, the opposite effect was observed for dabbing: increased mass percent of this terpene led to an increased release of degradation products. In addition to these insights, a novel quantitative risk assessment model for cannabis inhalation was described that allowed for preliminary determination of the relative cancer and noncancer chronic health risks associated with dabbing, vaping, and smoking cannabis. Further chemical and toxicological characterization of other aerosol components will 
allow the expansion of this model to provide an accurate description of the chronic health impacts associated with these cannabis consumption modalities. 


\section{Acknowledgments}

The completion of my dissertation merits many acknowledgements of individuals who supported my educational and professional journey. From Portland State University, I must acknowledge my committee chair, advisor, and friend, Robert M. Strongin for his unwavering support and jovial mentorship undeterred by a student with a unique and difficult set of goals. Additionally, David H. Peyton for instilling his rigorous approach to scientific scholarship. My gratitude extends to Wentai Luo for providing advice and assistance with experimental design and instrumentation. I thank my instructor and committee member, Dean Atkinson, for his teachings of crucial concepts in atmospheric chemistry and programming. Special thanks are given to Theresa McCormick for her instruction and support during the start of my graduate studies. Lastly, James Pankow for demonstrating the importance of maintaining high moral integrity in the midst of questionable science. From my undergraduate institution, I would like to recognize Franz Folmer-Andersen for fostering my path into organic chemistry and scientific research, and Megan Ferguson for her teachings in analytical and instrumental chemistry, but most critically, Microsoft Excel. Finally, I must acknowledge my high school chemistry instructor, Carmen Redondo González, for inspiring my pursuit of chemistry.

I owe much gratitude to my parents and family who consciously put forth the 
strongest effort to provide the intellectual stimulation necessary to ensure my success as a scientist. Many thanks to my mother, Maureen Meehan, for providing me with every opportunity to learn and expand my knowledge. My father, Jiries Atrash, I thank you for instilling your resolve and strong work ethic. My uncle, Bill O'Connor, I thank you for engaging me with intellectual and philosophical conversation starting at the youngest age. Special thanks must also go out to Michael and Eleonora Kennedy for the crucial role they played in starting my career as a scientist.

Of my colleagues, friends, and collaborators, I recognize Anna K. Duell, Kevin J. McWhirter, and Alisha Ortiz for collectively ensuring our experiments proceeded with the highest quality data. I thank David Sarlah for providing materials that were instrumental for elucidating terpene degradation mechanisms detailed herein. To the Strongin group members, the department support staff, and my friends in Portland, I thank you for being the network and support system I needed to succeed. Importantly, I thank must Miguel Perdiguero for his suggestion of utilizing $\mathrm{AT}_{\mathrm{E}} \mathrm{X}$ to write this document; mi amigo, te tengo que dar la razón que ésta es la mejor forma de escribir algo así de complejo. Many thanks to Violet, Andrew, Chip, and Mike of Rogue Hall (a.k.a. Science Building 3) and all the other bartenders and baristas around Portland whose establishments served as a second workstation during the production of my manuscripts. Finally, I thank the DJs and musicians who set the fast pace and upbeat mood I craved during long hours in the lab.

Last but certainly not least, I thank my loving and beautiful wife, Brooke Sergas and our mischievous and lovingly annoying cat, Creepy "Crepuscular" Sergas for always being there when times were hard and to celebrate when times were good. This is for you. 


\section{Table of Contents}

Abstract $\quad$ i

Acknowledgments $\quad$ iv

List of Tables $\quad$ xiii

List of Figures $\quad$ xiv

List of Schemes $\quad$ xvii

1 Introduction 1

1.1 The basics of cannabis and its derivatives . . . . . . . . . . . . 1

1.1.1 Botanical and taxonomic considerations . . . . . . . . . . 1

1.1.2 Cannabinoids and terpenoids ............. 2

1.1.3 Cannabis concentrates: an explosively diverse selection . . . . 5

1.1.4 Cannabis concentrate adulterants . . . . . . . . . . . . 7

1.2 The historical context of cannabis intoxication by inhalation . . . . 8

1.2.1 Historical and archaeological evidence from millennia past . . 8

1.2.2 The emergence of hashish . . . . . . . . . . . . . . 9

1.2.3 Cannabis' dance with tobacco and the emergence of the joint . 10 
1.3 Contemporary cannabis inhalation methods: smoking, vaping and dab-

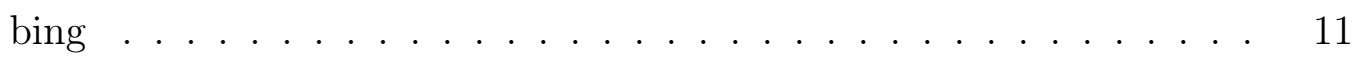

1.3.1 Cannabis smoking . . . . . . . . . . . . . . 11

1.3.2 Cannabis flower vaping . . . . . . . . . . . . . . . . 12

1.3.3 Cannabis extract vaping using cannabis e-cigarettes . . . . . 13

1.3.4 Dabbing . . . . . . . . . . . . . . . . . 15

1.4 Thermal degradation reactions of cannabinoids: prior work . . . . . 17

1.5 Prior work characterizing thermal degradation of $\beta$-myrcene, a fundamental cannabis terpene . . . . . . . . . 21

1.6 Summary . . . . . . . . . . . . . . . . . . . . . . 24

1.7 References . . . . . . . . . . . . . . . . . . . . 25

2 Pine rosin identified as a toxic cannabis extract adulterant 43

2.1 Abstract . . . . . . . . . . . . . . . . . 44

2.2 Introduction . . . . . . . . . . . . . . . . 45

2.3 Materials and methods . . . . . . . . . . . . . . . . 47

2.4 Results and discussion $\ldots \ldots \ldots \ldots$

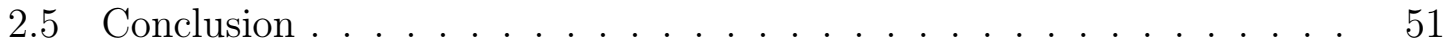

2.6 CRediT authorship contribution statement . . . . . . . . . . 51

2.7 Acknowledgements . . . . . . . . . . . . . . . . . . . 52

2.8 References . . . . . . . . . . . . . . . . . . . . . . . . . 52

3 Toxicant formation in dabbing: The terpene story 56

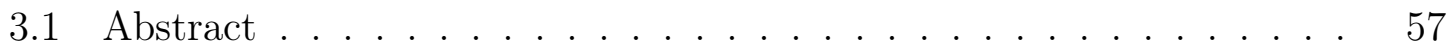

3.2 Introduction $\ldots \ldots \ldots \ldots \ldots \ldots \ldots \ldots \ldots$ 
3.3 Results and discussion . . . . . . . . . . . . . . . . . . 62

3.3.1 Sample generation and product identification . . . . . . . 62

3.3 .2 Product quantification . . . . . . . . . . . . . . 65

3.3 .3 Degradant toxicology . . . . . . . . . . . . . . . . 66

3.3.4 Degradant formation mechanism _ . . . . . . . . . 66

3.3 .5 Limitations . . . . . . . . . . . . . . . . . . . . 67

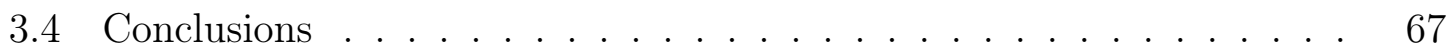

3.5 Methods . . . . . . . . . . . . . . . . . 68

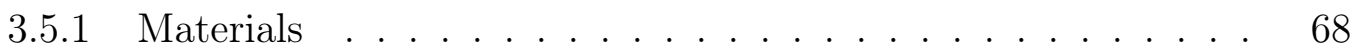

$3.5 .2 \quad$ NMR experiments . . . . . . . . . . . . . . . . . 68

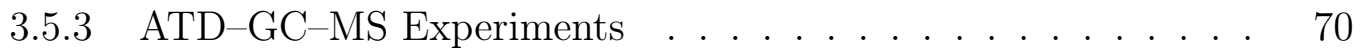

3.6 Author information . . . . . . . . . . . . . . . . . . 70

3.6 .1 Corresponding author $\ldots \ldots \ldots \ldots \ldots$

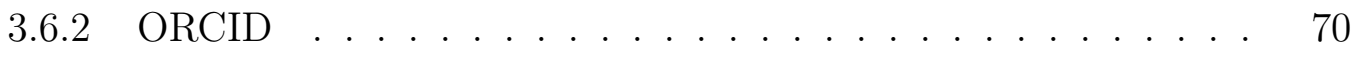

3.6.3 Author contributions . . . . . . . . . . . . . . . 71

3.6 .4 Funding . . . . . . . . . . . . . . . . . 71

3.7 Acknowledgements . . . . . . . . . . . . . . . . . 71

3.8 Abbreviations . . . . . . . . . . . . . . . . . . . 71

3.9 References . . . . . . . . . . . . . . . . . . . . . . . . . 72

4 Aerosol gas-phase components from cannabis e-cigarettes and dab$\begin{array}{ll}\text { bing: mechanistic insight and quantitative risk analysis } & 77\end{array}$

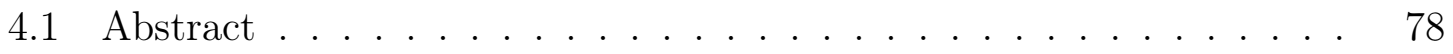

4.2 Introduction . . . . . . . . . . . . . . . . . . . . . 79

4.3 Results . . . . . . . . . . . . . . . . . 84 
4.4 Discussion . . . . . . . . . . . . . . . . . . . . . . . . 87

4.5 Conclusions . . . . . . . . . . . . . . . . . . . 90

4.6 Methods and materials . . . . . . . . . . . . . . . . . . . 92

4.6 .1 Materials . . . . . . . . . . . . . . . . . . . . . . . 92

4.6.2 Sample collection for dabbing . . . . . . . . . . . . . . . 93

4.6.3 Sample collection for CV vaping . . . . . . . . . . . . . . . 93

4.6.4 Adsorption/thermal desorption gas chromatographymass spectrometry . . . . . . . . . . . . . . . 94

4.6.5 Quantification of components from CV vaping and dabbing. . 95

4.6.6 Cannabis smoke component literature review . . . . . . . . 96

4.6.7 Quantitative risk assessment . . . . . . . . . . . . . 97

4.6.8 Quantitative risk assessment for cancer effects . . . . . . . . 97

4.6.9 Quantitative risk assessment for noncancer effects . . . . . . 99

4.7 Author information . . . . . . . . . . . . . . . . . 99

4.7 .1 Corresponding author . . . . . . . . . . . . . . . . . 99

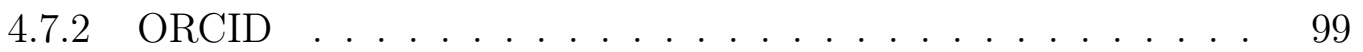

4.7 .3 Author contributions . . . . . . . . . . . . . . . 100

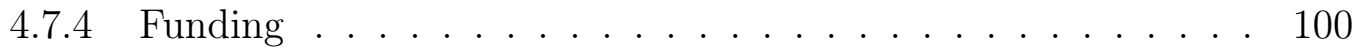

4.7 .5 Notes . . . . . . . . . . . . . . . . . 100

4.8 Acknowledgements . . . . . . . . . . . . . . . . 100

4.9 Abbreviations . . . . . . . . . . . . . . . . . . . . . . . . . 101

4.10 References . . . . . . . . . . . . . . . . . . . . 102

5 The influence of terpenes on the release of volatile organic compounds and active ingredients to cannabis vaping aerosols 114 


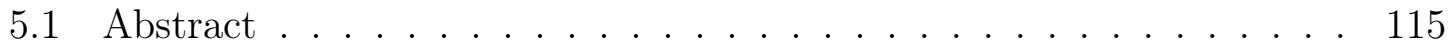

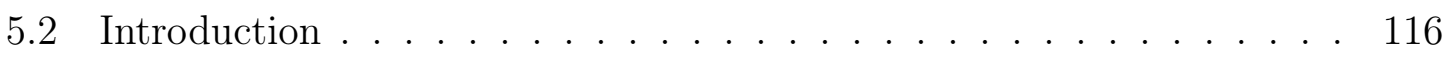

5.3 Materials and methods . . . . . . . . . . . . . . . . . . . . 119

5.3.1 Synthetic cannabis oil $(\mathrm{SCO}) \ldots \ldots \ldots$

$5.3 .2 \quad$ Dabbing and vaping . . . . . . . . . . . . . . . . . . . . 119

5.3 .3 Aerosols gas phase analysis . . . . . . . . . . . . . . 120

5.3 .4 THC transfer analysis . . . . . . . . . . . . . . . . 121

5.3.5 Data analysis and statistics _. . . . . . . . . . 121

5.4 Results and discussion . . . . . . . . . . . . . . . . . 122

5.4.1 The thermal degradation of $\beta$-myrcene $\ldots \ldots \ldots \ldots$

5.4.2 Thermal degradation of $\Delta^{9}$-tetrahydrocannabinol . . . . . . 124

5.4.3 Increased terpene content leads to elevated release of degradation products for dabbing $\ldots \ldots \ldots \ldots$

5.4.4 Increased terpene content in cannabis oil decreases degradation and increases transfer of starting materials for cannabis e-cigarette vaping . . . . . . . . . . . . . . . . . . . . . . 129

5.4.5 Applied electrical power increases degradation products and decreases transfer of starting materials for cannabis e-cigarette vaping . . . . . . . . . . . . . . . . . . . 131

5.4.6 Terpene and power levels influence the major degradation pathway of THC and $\beta$-myrcene during cannabis e-cigarette vaping 132

5.4 .7 Conclusions . . . . . . . . . . . . . . . . . . . . . . 134

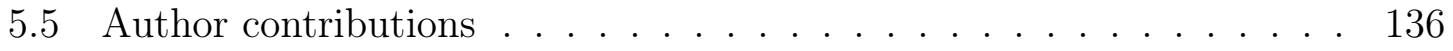

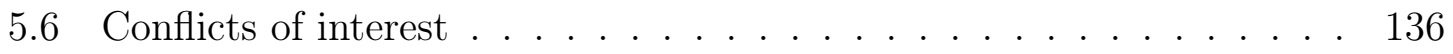


5.7 Acknowledgements . . . . . . . . . . . . . . 136

5.8 References . . . . . . . . . . . . . . . . . . . . 136

6 Overall conclusions $\quad 142$

6.1 References . . . . . . . . . . . . . . . . . . . . . . . . 144

7 Appendix A: Supporting Information to Pine rosin identified as a toxic cannabis extract adulterant 145

7.1 Quantitative NMR . . . . . . . . . . . . . . . . 145

7.2 Semi-preparative HPLC . . . . . . . . . . . . . . . 145

7.3 HPLC-ESIMS . . . . . . . . . . . . . . . . . 146

7.4 References . . . . . . . . . . . . . . . . . . . . . 148

8 Appendix B: Supporting Information to Toxicant formation in dabbing: The terpene story 150

8.1 Experimental setups $\ldots \ldots \ldots \ldots \ldots$

8.2 ATD-GC-MS Conditions . . . . . . . . . . . . . . . 151

8.3 Temperature measurements . . . . . . . . . . . . . . . . 152

8.4 NMR conditions . . . . . . . . . . . . . . . . . . . . . . . 153

8.5 Toxicant levels generated in myrcene NMR experiments . . . . . . . 154

8.6 Product identification by spiking $\ldots \ldots \ldots \ldots \ldots \ldots$

8.7 Sample chromatograms and mass spectra of select degradants . . . . . . . . . . . . . . . . . . 162

9 Appendix C: Supporting Information to Aerosol gas-phase components from cannabis e-cigarettes and dabbing: mechanistic insight 
and quantitative risk analysis

10 Appendix D: Supporting Information to The influence of terpenes on the release of volatile organic compounds and active ingredients to cannabis vaping aerosols

10.1 Scheduled substance usage $\ldots \ldots \ldots \ldots \ldots$

10.2 Synthesis of $\beta$-myrcene- $d_{6} \ldots \ldots \ldots \ldots \ldots$

10.3 Synthetic cannabis oil . . . . . . . . . . . . . . . . . 176

10.4 Cartridge vaping experiments $\ldots \ldots \ldots \ldots \ldots \ldots$

10.5 THC delivery analysis . . . . . . . . . . . . . . . . . . 179

10.6 HPLC-UV methodology . . . . . . . . . . . . . . . . . . . . . . 179

10.7 ATD-GC-MS methodology . . . . . . . . . . . . . . . 180

10.8 VOC quantification by ATD-GC-MS . . . . . . . . . . 181

10.9 Chemical mechanism modelling . . . . . . . . . . . . . . . 182

10.10 Mass spectra . . . . . . . . . . . . . . . . 183

10.11 Chromatograms . . . . . . . . . . . . . . 187

10.12 Identified compounds . . . . . . . . . . . . . . . . . 188

$10.13 \mathbf{1 a}$ and $\mathbf{1} \mathbf{b}$ product distribution as a function of applied power . . . . 194

10.14 References . . . . . . . . . . . . . . . . . 196 


\section{List of Tables}

2.1 Components identified in CEA by nuclear magnetic resonance (NMR) spectroscopy and HPLC-ESIMS, and approximate \% masses in the sample were determined by Q-NMR. . . . . . . . . . . . . . . 50

3.1 Methacrolein (MC) and benzene levels produced per mg terpene starting material when vaporized at the highest temperature range investigated, ca. $550{ }^{\circ} \mathrm{C}\left(T_{\mathrm{i}}\right)-500{ }^{\circ} \mathrm{C}\left(T_{\mathrm{f}}\right)$ using single replicate experiments

4.1 Selected GP components identified in dabbing and CV vaping using

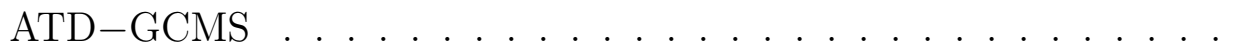

4.2 Hazard index and excess lifetime cancer risk for smoking, dabbing, and vaping at 3 voltages. . . . . . . . . . . . . . . .

5.1 CEC vaping experiments in which both terpene content and power level were studied to probe their effect on yields of active ingredients and degradation products. For the experiments wherein $\%$ mass $\beta$ myrcene was the variable, power level was kept at a constant $10 \mathrm{~W}$. For the experiments wherein power level was varied, $\%$ mass $\beta$-myrcene in CVL was $14 \%$. . . . . . . . . . . . . . . . . . 130 


\section{List of Figures}

1.1 Major chemical transformations of $\Delta^{9}$-tetrahydrocannabinolic acid (THCA) that include decarboxylation to THC, double bond isomerization to the $\Delta^{8}$ isomer, and cyclization to the $p$-menthyl ring. . . . . . . . . . . 3

1.2 Four terpenoids that represent four common structure types present in cannabis volatile oil: the acyclic monoterpene $\beta$-myrcene, the monoterpene alcohol linalool, the cyclic monoterpene d-limonene, and the sesquiterpene $\beta$-caryophyllene. . . . . . . . . . . . . . . . . . . . . 4

1.3 Arrow-pushing mechanism for the conversion of CBD to THC, a reaction first described by Adams et al. ${ }^{116}$ to occur by hydrochloric acid catalysis in ethanol, confirmed to occur during smoking by Mikeš and Waser. ${ }^{114}$ and Quarles et al., ${ }^{118}$ and during pyrolysis by Kuppers et al. ${ }^{119} 18$

1.4 Cracking products described in Kuppers et al. $\left(1975\right.$ b). ${ }^{124}$. . . . . . 20

1.5 Later-eluting products identified by the Utrecht group. . . . . . . . . 21

1.6 a) The structures of $\beta$-myrcene and $\alpha$-myrcene; b) $\beta$-myrcene decomposition mechanism proposed by Kolichescki et al.; ${ }^{141}$ c) the decomposition mechanism proposed by Stolle and Ondruschka ${ }^{142}$ in response to Kolichescki et al. ${ }^{141} \ldots \ldots \ldots . \ldots \ldots 22$ 
2.1 Cannabis extract thickener provided in a glass syringe. . . . . . . . . 48

2.2 Overlaid ${ }^{1} \mathrm{H}$ NMR spectra of CEA (top, maroon) and commerciallyavailable gum rosin (bottom, green) from Sigma Aldrich (CAS no.

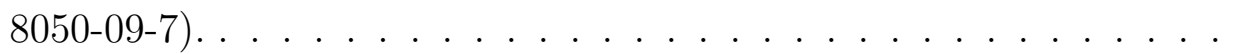

3.1 MC (ng) generated in a $40 \mathrm{mg}$ dab using myrcene as a model terpene assuming a $5.9 \%$ concentration of terpenes in BHO. Temperature values represent the $T_{\mathrm{m}}$ for each TR. Error bars are determined at the 95\% confidence level using the standard deviation of the three replicates taken at each TR. At the lowest TR, MC was not detected by

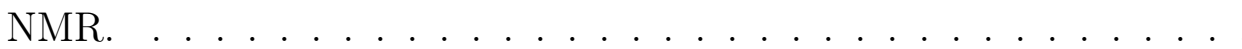

4.1 Relevant cannabinoids . . . . . . . . . . . . . . . . . . . 79

4.2 Cannabidiol degradation products . . . . . . . . . . . . . . 82

4.3 Experimental setups used for dabbing (top) and CV (bottom) vapor collection by ATD-GCMS. Components depicted are: $a$, e-nail; $b$, CFP holder; $c$, 3-way stopcock; $d$, ATD cartridge; e, mass flow meter; $f$, flow control valve; $g$, vacuum source; $h$, by-pass line; $i, \mathrm{CV} ; j, \mathrm{CSM}$.

5.1 Chemical structures of $\Delta^{9}$-tetrahydrocannabinol (THC), cannabinol $(\mathrm{CBN})$, and $\beta$-myrcene shown with carbons numbered. . . . . . . . 117

5.2 Proposed mechanism for the thermal degradation of $\beta$-myrcene- $d_{6}$. The natural isotopologues of these reactions products compose $30 \%$ of the $\mathrm{VOC}_{N T}$ observed for $\beta$-myrcene. . . . . . . . . . . . . . . . . 123 
5.3 The proposed reaction scheme for a major thermal degradation pathway of THC which accounts for $22 \pm 6 \%$ of $\mathrm{VOC}_{\mathrm{T}}$ when THC is vaporized alone in a CEC at $10 \mathrm{~W}$, and $18 \pm 4 \%$ of $\mathrm{VOC}_{\mathrm{T}}$ when THC is vaporized alone by dabbing at $370{ }^{\circ} \mathrm{C}$. . . . . . . . . . . . . 125

5.4 Comparative levels of major degradation products and their deuterated isotopologues encountered in the aerosol GP from dabbing pure THC (0\% $\beta$-myrcene- $\left.d_{6}\right)$, THC with $5 \% \beta$-myrcene- $d_{6}$, and THC with $9 \%$ $\beta$-myrcene- $d_{6}$. Error bars are SEM. . . . . . . . . . . . . . . . . 128

5.5 The relationship between applied power to $1 \mathrm{a}: 1 \mathrm{~b}$ (a) and $\%$ mass $\beta$ myrcene to $1 \mathrm{a}: 1 \mathrm{~b}(\mathrm{~b})$. $1 \mathrm{a}: 1 \mathrm{~b}$ is calculated as the quotient of the selected ion chromatogram integrations of the moleculear ions for $\mathbf{1 a}$ products, 3MCA $(m / z=84 \mathrm{amu})$ and 2M2B $(m / z=70 \mathrm{amu})$, with 1b products, isoprene $(m / z=67 \mathrm{amu})$ and $3 \mathrm{M} 1 \mathrm{~B}(\mathrm{~m} / z=70 \mathrm{amu}) . \quad 133$ 


\section{List of Schemes}

3.1 Terpene degradation products identified via GC-MS analysis; 1, methacrolein;

2, methyl vinyl ketone; 3, hydroxyacetone; 4, 3-methylfuran; 5, 2methylnapthalene; 6, 1,3-butadiene; 7, 1-methylcyclohexa-1,4-diene; 8, benzene. These and other related products were produced from pure samples of each of limonene, linalool and myrcene. . . . . . . . . . . . 64 


\section{Introduction}

\subsection{The basics of cannabis and its derivatives}

\subsubsection{Botanical and taxonomic considerations}

Cannabis sativa L. is an annual, flowering dioecious plant that originated in Central Asia. ${ }^{1}$ Pistillate cannabis plants exhibit gynoecium, flowers, covered in microscopic structures called trichomes ${ }^{2}$ that produce a unique class of molecules: cannabinoids. ${ }^{3}$ The pharmacological activity of these compounds ${ }^{4}$ has made this species unique among human domesticates as a plant that serves both as a prime material and a drug. ${ }^{1}$ Cannabis is among the top three most consumed psychoactive substances globally after alcohol and tobacco. ${ }^{5}$ As one of mankind's oldest crops, it has seen continuous cultivation for over 12,000 years $^{6}$ with diverse uses in textiles, sustenance, and as a medicine, an entheogen, and a recreational drug. ${ }^{1}$ Its fecundity and hardiness as a crop allowed it to follow the spread of human civilization around the globe, and feral strains of this plant can be found on every inhabited continent. ${ }^{7}$

The formal taxonomic classification devised by Small and Cronquist in 1976 for C. sativa divides it into two subspecies: sativa and indica. ${ }^{8}$ C. sativa subsp. sativa (i.e. hemp) produces $<0.3 \% \mathrm{~m} / \mathrm{m}$ the plant's psychoactive constituent $\Delta^{9}$ tetrahydrocannabinol (THC), and is subdivided into two varieties: sativa and spon- 
tanea that have domestication and wild-type traits, respectively. ${ }^{8}$ C. sativa subsp. indica is characterized by having $>0.3 \% \mathrm{~m} / \mathrm{m}$ THC and is also subdivided into two varieties: indica, domesticated, and kafiristanica, wild-type. ${ }^{8}$ Commonly referred to as marijuana, ganja, pot, weed, or simply cannabis in English, C. sativa subsp. indica var. indica encompasses the group of cultivars or strains associated with drug cannabis. These cultivars have been subjected to extensive selective breeding over millennia to produce high levels of THC for its intoxicating effect, and terpenoids for their characteristic aroma. ${ }^{9}$

\subsubsection{Cannabinoids and terpenoids}

Cannabinoids, often referred to as phytocannabinoids to differentiate them from synthetic $^{10}$ or anthropogenic ${ }^{11}$ cannabinoids, are isoprenylated resorcinyl polyketide molecules present in all C. sativa. Cannabinoids are biosynthesized as cannabinoid acids, ${ }^{12-14}$ with an aryl carboxy group at the 2-position of the resorcinol ring. ${ }^{15} \Delta^{9}$ Tetrahydrocannabinolic acid (THCA) and cannabidiolic acid (CBDA) are the two most abundant cannabinoids produced by all C. sativa,${ }^{16}$ with only rare exceptions. ${ }^{17}$ Cannabinoids primarily act on the G-protein coupled receptors cannabinoid receptor $1\left(\mathrm{CB}_{1} \mathrm{R}\right)$ and cannabinoid receptor $2\left(\mathrm{CB}_{2} \mathrm{R}\right)^{18}$ that form part of the endocannabinoid system, an endogenous lipid-mediated system of the body which primarily consists of cannabinoid receptors, endocannabinoids, and their degradative enzymes. ${ }^{11}$ $\mathrm{CB}_{1} \mathrm{Rs}$ are abundantly expressed in the central nervous system and their activation by $\mathrm{THC}$, a $\mathrm{CB}_{1} \mathrm{R}$ and $\mathrm{CB}_{2} \mathrm{R}$ partial agonist, is responsible for the psychoactive effect of cannabis. ${ }^{19}$ 
<smiles>CCCCCCCc1cc2c(c(O)c1C(=O)O)C1C=C(C)CCC1C(C)(C)O2</smiles>

$\Delta^{9}$-Tetrahydrocannabinolic acid $\Delta$ or $h v$<smiles>CCCCCCc1cc2c(c(O)c1C(=O)O)C1CC(C)=CCC1C(C)(C)O2</smiles>
$\Delta^{8}$-Tetrahydrocannabinolic acid<smiles>CCCCCc1cc2c(c(O)c1C(=O)O)-c1cc(C)ccc1C(C)(C)O2</smiles>

Cannabinolic acid

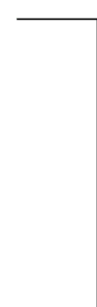

$\mid \begin{aligned} & \mathrm{CO}_{2} \\ & \stackrel{\Delta}{\Delta}\end{aligned}$<smiles>CCCCCCc1cc(O)c2c(c1)OC(C)(C)C1CCC(C)=CC21</smiles>
$\Delta^{9}$-Tetrahydrocannabinol $\Delta$ or $h v$<smiles>CCCCCCc1cc(O)c2c(c1)OC(C)(C)C1CC=C(C)CC21</smiles>

$\Delta^{8}$-Tetrahydrocannabinol<smiles>CCCCCCCCCCSc1cc(O)c2c(c1)OC(C)(C)c1ccc(C)cc1-2</smiles>

Cannabinol

Figure 1.1: Major chemical transformations of $\Delta^{9}$-tetrahydrocannabinolic acid (THCA) that include decarboxylation to THC, double bond isomerization to the $\Delta^{8}$ isomer, and cyclization to the $p$-menthyl ring.

The diversity among minor cannabinoids is great, with over 150 recorded to date. ${ }^{20}$ This diversity owes itself to the many modulations possible in the convergent mevalonate and polyketide biosynthetic pathways, in addition to thermal- and radiationinduced chemical transformations that occur in situ during growth and storage. ${ }^{21}$ Figure 1.1 displays the major degradation and reaction pathways that occur after 
THCA biosynthesis, which include decarboxylation to the psychoactive THC, double bond isomerization to the $\Delta^{8}$ isomer, and full cyclization of the $p$-menthyl ring to cannabinol (CBN). A 2019 analysis of cannabis potency in the United States of America using Drug Enforcement Agency narcotics seizures indicates that, in 2017, the average THC level in domestic drug cannabis is $17 \%,{ }^{22}$ but levels as high as $30 \%$ have been reported. ${ }^{23}$

Aroma has long had been a defining characteristic of $C$. sativa, and this organoleptic property has been shown to have a significant impact on consumer perceptions of the quality of a cannabis product. ${ }^{24}$ Responsible for this aroma are terpenoids, of which more than 60 have been identified to exist in its essential oil. ${ }^{25}$ Proponents of medical cannabis have asserted that terpenoids contribute to cannabis' medicinal effect by way of the so-called "entourage effect," ${ }^{26-27}$ a theory that has been called into question by several researchers. ${ }^{28-29}$ Figure 1.2 displays four terpenoids that represent four of the common structures types present in the volatile oil: the acyclic monoterpene $\beta$-myrcene, the cyclic monoterpene $d$-limonene, the terpene alcohol linalool, and the sesquiterpene $\beta$-caryophyllene. ${ }^{25}$

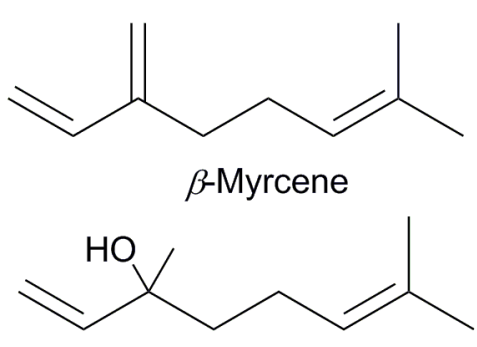

Linalool

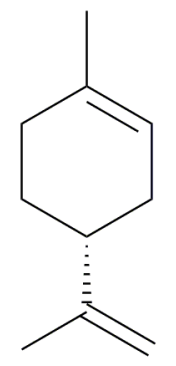

$d$-Limonene

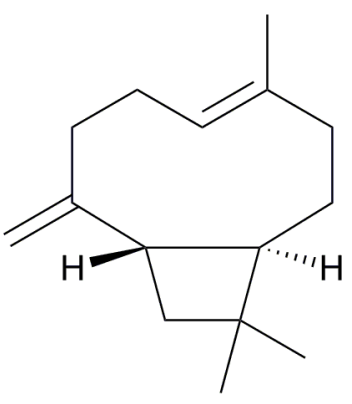

$\beta$-Caryophyllene

Figure 1.2: Four terpenoids that represent four common structure types present in cannabis volatile oil: the acyclic monoterpene $\beta$-myrcene, the monoterpene alcohol linalool, the cyclic monoterpene d-limonene, and the sesquiterpene $\beta$-caryophyllene. 


\subsubsection{Cannabis concentrates: an explosively diverse selection}

A cannabis concentrate is any solid or liquid substance in which the pharmacologically active and economically desirable agents in cannabis have been extracted, and are often an order of magnitude higher in concentration than in cannabis plant material. The term concentrate is a relatively novel term used in the cannabis industry coined to encompass the many types cannabis extracts and derivatives thereof that exist in today's market. ${ }^{30}$ Hashish, the oldest type of cannabis concentrate (vide infra), is manufactured by any process that mechanically removes cannabis trichomes from the plant material (i.e. sifting) followed by mechanical compression and/or heating to form a solid. ${ }^{1}$ Hashish is a major commodity in the global drug trade with over 1,300 metric tons seized in $2018 .^{31}$ Hashish may be consumed alone with a pipe but is typically mixed with tobacco and hand-rolled into cigarettes. ${ }^{1}$

Some of the earliest reports of solvent-extracted cannabis concentrates (hashish, hash, or honey oil) in the United States date back to the mid $1970 \mathrm{~s}^{32}$ to early $1980 \mathrm{~s}^{33}$ Potency of confiscated hash oil samples randomly fluctuated from the $1980 \mathrm{~s}^{34}$ through the $2000 \mathrm{~s}^{34-36}$ and didn't exhibit meaningful increases in THC content until the turn of the 2010s decade. ${ }^{22}$ This time period is also coincident with increases in search engine queries related to hash oil and dabbing (a hash oil consumption technique, vide infra $)^{37}$ and case reports of hospitalizations due to burn injuries related to butane explosions during hash oil production. ${ }^{38}$ Butane is indeed one of the most common solvents used for the production of hash oil, most often referred to as butane hash oil (BHO). ${ }^{39-40}$

As the state-level legal cannabis market in the United States has proliferated in the latter half of the 2010s decade, two other advanced cannabis extraction methods 
are increasingly common: supercritical fluid extraction $(\mathrm{SFE})^{41}$ and vacuum distillation (VD). ${ }^{42}$ While SFE is an extraction technique for isolating cannabinoids and terpenoids from cannabis plant material, VD is an extract refinement technique for $\mathrm{BHO}$ or SFE that separates cannabinoids and terpenoids from other potentially undesirable components present in crude extract. ${ }^{42}$ Cannabis extracts made with SFE and VD may be consumed alone by dabbing, but are often introduced into cannabis e-cigarettes. ${ }^{39}$

In 2017, researchers at the University of Toronto that sourced cannabis from a Canadian licensed cannabis producer used liquid chromatography-mass spectrometry (LC-MS) to analyze an extract made using SFE without any further refinement. ${ }^{43}$ The authors qualitatively identified 62 distinct compounds, up to 23 of which were cannabinoids. ${ }^{43}$ Other identified compounds included terpenes, fatty acids, flavanols, steroids, and chlorophyll. ${ }^{43}$ A 2016 report that analyzed the content of a black market cannabis oil made for vaping, sourced from the US Department of Justice, using gas chromatography-mass spectrometry (GC-MS) and LC-MS identified the presence of cannabinoids, terpenoids, and propylene glycol without any further compounds present. ${ }^{44}$ These two studies highlight the differences that may exist between modern cannabis concentrates depending on their intended mode of consumption. While unrefined concentrates that have not undergone decarboxylation are suitable for dabbing (vide infra), concentrates made for vaping (vide infra) undergo refinement and purification in order to be amenable for use in e-cigarettes, and may or may not include a solvent such as propylene glycol or medium chain triglyceride oil to reduce viscosity. ${ }^{45}$ 


\subsubsection{Cannabis concentrate adulterants}

An omnipresent concern for cannabis concentrate consumers is adulteration. Many sporadic cases of hashish adulteration in Europe with substances such as glass beads, soil, paraffin wax, glue, pine rosin etc. indicate non-cannabis substances may be added to increase profitability for manufacturers, and in some cases, additional psychoactive drugs are added presumably to mask the fact the hashish has been cut by synthetically increasing its narcotic effect. ${ }^{46-47}$ Though the transatlantic hashish trade has not meaningfully supplied North American consumers for decades ${ }^{46}$ the increasing market share of domestic hash oil compared to cannabis ${ }^{35}$ has created similar adulteration concerns in the United States.

The e-cigarette and vaping product use-associated lung injury (EVALI) outbreak which resulted in 68 deaths and 2,807 hospitalizations in 2019 and $2020^{48}$ emphasizes the gravity of this issue. EVALI was associated with cannabis e-cigarettes, and vitamin E acetate (VEA) was suggested as a causative agent by the Centers for Disease Control, ${ }^{49}$ prompted by its identification in bronchoalveolar lavage fluids of EVALI patients. ${ }^{50} \mathrm{~A}$ hydrogen bonded complex between VEA and THC, linking the carbonyl group of the former and the hydroxyl group of the latter, was described using Fourier transform infrared (IR) spectroscopy, nuclear magnetic resonance spectroscopy (NMR) and direct analysis in real time mass spectrometry (DART-MS) and it was hypothesized this complex may play a role in the pathogenesis of EVALI. ${ }^{50} \mathrm{In}$ another study, ketene, a highly toxic gas, was identified as a degradation product of VEA, and authors suggested exposure to this chemical may be a mechanism for lung injuries in EVALI patients. ${ }^{51}$

Though VEA was identified as a potential causative agent in the EVALI outbreak, 
this compound was not the only adulterant identified in cannabis e-cigarettes. Duffy et al. analyzed confiscated EVALI vaporizer cartridges using GC-MS and LC-MS, and detected a slew of other diluents/adulterants including medium chain triglyceride oil, squalane, triethyl citrate, etc. ${ }^{52}$ In another study published just prior to the EVALI outbreak, Poklis et al. detected 5-fluoro-MDMB-PINACA, a synthetic cannabinoid, ${ }^{53}$ and dextromethorphan, a psychoactive antitussive found in cough syrup, ${ }^{54}$ in commercial CBD e-cigarette liquids using DART-MS. ${ }^{55}$

Identifying vaporizer adulterants in e-cigarette liquid and in biological matrices is a continuing analytical challenge that requires advanced instrumentation and perseverance. Despite the legal and regulatory considerations that make it difficult to obtain grey or black market samples, the EVALI outbreak highlights the importance of this work for public health.

\subsection{The historical context of cannabis intoxication by inhala- tion}

\subsubsection{Historical and archaeological evidence from millennia past}

The first historical account of cannabis use for a psychoactive effect was by the Greek historian Herodotus ("Father of History"56) as early as the $5^{\text {th }}$ Century BCE by the Scythians,${ }^{57}$ an ancient group of Eurasian nomads. ${ }^{58}$ Herodotus detailed how Scythians would "bathe" in hemp vapors, letting its seeds smolder on red hot stones in sunken tents, causing a "howling joy." 57 In 2019, wooden braziers (small wooden containers used in ritualistic burning) recovered from the Jirzankal Cemetery, ca. 500 
BCE, in the Pamir Plateau in China were analyzed for the presence of cannabinoids. ${ }^{59}$ Wood from the inside of the brazier, burnt stones, and an ancient cannabis reference sample recovered from the site were extracted analyzed by GC-MS, which revealed detectable quantities of $\mathrm{CBN} .{ }^{59}$

The first evidence of a pipe used for cannabis was discovered in Ethiopia in 1971 and radiocarbon dated to $1320 \pm 80 \mathrm{CE} \cdot{ }^{60}$ After collection by archaeologists, samples were sent to New York and analyzed by thin layer chromatography (TLC), a standard method for cannabis analysis in forensic chemistry at the time.${ }^{60}$ Residues from the pipe were collected, extracted, spotted on TLC plates, eluted in benzene, and developed with Fast Blue B salt. ${ }^{60}$ Archaeological samples showed spots with $R_{\mathrm{f}}$ values higher than those seen in street marijuana samples, which were known to contain THC, CBD, and CBN. However, samples extracted from modern cannabis pipes displayed faint spots with the same $R_{\mathrm{f}}$ values as those in the ancient pipes, which lead the authors to conclude these were unidentified cannabinoid decomposition products. ${ }^{60}$

\subsubsection{The emergence of hashish}

The first cannabis preparation made to concentrate its psychoactive material was hashish, said to have originated in India or Nepal. ${ }^{61-62}$ Though archaeological evidence is lacking, legends of cannabis resin sticking to the hands of cultivators that formed it into balls by hand has gone undoubted by historians as a simple discovery by accident. ${ }^{61-62}$ The first historical account of hashish consumption was by Marco Polo, and is associated with the legend of the Old Man of the Mountain, the $11^{\text {th }}$ Century Arab ruler Hasan-i Sabah. ${ }^{6}$ Marco Polo's story, never verified and likely false, asserted that Sabah enticed would-be assassins with a hashish-infused drink. ${ }^{6}$ Indeed, 
the extensive history linking hashish to early Islam and Arab culture involve oral consumption, not smoking. ${ }^{61,63}$

Ancient ritualistic hemp vapor bathing appears to have faded out in Europe with the rise of Christianity, ${ }^{6,63}$ and added to the fact that most feral cannabis of the continent produces only low levels of $\mathrm{THC}^{8}$ cannabis intoxication was not common in Europe until the return of Napoleon Bonaparte's troops from Egypt. ${ }^{6,63}$

\subsubsection{Cannabis' dance with tobacco and the emergence of the joint}

Nicotine has been positively identified by LC-MS in residues extracted from tobacco pipes from the Colombia Plateau, suggesting that tobacco smoking by Indigenous North Americans went as far back as 2500 BCE. ${ }^{64}$ Tobacco stuffed into phragmites reeds, both identified by morphological and anatomical examination, uncovered in the Red Bow Cliff Dwelling in Arizona (1325-1400 CE) is some of the first evidence of human use of cigarettes for smoking. ${ }^{65}$ Spanish colonial contact with the Americas sparked an almost immediate interest in tobacco, and its use quickly spread through Europe. ${ }^{66}$ As European and Middle Eastern hashish consumption in social circles with existing habitual tobacco use surged, hashish smoking saw its biggest push, supplanting oral consumption. ${ }^{61,63}$ To this day, cannabis and tobacco are two of the most frequently co-consumed drugs of abuse. ${ }^{67}$

Pipe smoking and snuff were the most popular routes of administration for tobacco in Central Europe, but maize-wrapped papelate cigarettes spread from Spanish soldiers into France as early as the $17^{\text {th }}$ Century. ${ }^{66}$ Pierre Lacroix invented the modern rolling paper in 1660, and rising demand for his high quality rolling papers led to the 
creation of the Lacroix Rolling Paper Company, now known as Rizla. ${ }^{68}$ Paired with the rise of machine-manufactured tobacco cigarettes in the $20^{\text {th }}$ Century, ${ }^{66}$ the rolling paper facilitated not only handmade cigarettes, but the emergence of the marijuana cigarette or joint. ${ }^{61,63}$

\subsection{Contemporary cannabis inhalation methods: smoking, va- ping and dabbing}

\subsubsection{Cannabis smoking}

Smoking, by pipe or cigarette, to this day remains the most popular consumption method for cannabis. ${ }^{69-71}$ THCA present in the plant material decarboxylates during combustion, ${ }^{72}$ and transfer of $\mathrm{THC}$, which has a boiling point of approximately $416^{\circ} \mathrm{C},{ }^{73}$ to the resultant aerosol occurs with an efficiency of $50 \%$ on a mole-to-mole basis with respect to the THCA starting material. ${ }^{74}$ Different machine puffing protocols, preparation methods, and the inclusion of tobacco in the cannabis smoking vehicle influence the yield of THC significantly. ${ }^{74-75}$

In a sui generis systematic literature review conducted in Meehan-Atrash et al. (2019a), ${ }^{39} 92$ distinct cannabis smoke components were identified and quantitated as combustion/pyrolysis byproducts from seven different studies in the scientific literature. ${ }^{76-82}$ Polynuclear aromatic hydrocarbons (PAHs), consistent with hightemperature conditions ${ }^{83}$ also encountered in tobacco smoke, ${ }^{84}$ are present, including carcinogens such as benzo[b]fluoranthene and benzo[a]pyrene. Familiar volatile organic compounds (VOCs) such as acrolein, benzene, butyaldehyde, butadiene, isoprene, styrene, and toluene are also present, as are a range of phenols, quinones, 
aldehydes, and carbon monoxide. ${ }^{76-82}$ As detailed in Bloor et al. ${ }^{76}$ cannabis smoke may contain high levels of ammonia and hydrogen cyanide, and other studies have identified other nitrogenous compounds such as acrylonitrile, 2-aminonaphthalene, 4-aminobiphenyl, methylethylnitrosamine, and NOx. ${ }^{76-82}$

The only systematic review of the medical literature to ever assess the association with cannabis-only consumption with function of the respiratory tract was conducted by Meehan Atrash et al. (2019b). ${ }^{85}$ This review identified that chronic cannabisonly smoking was associated with increased airway resistance, respiratory symptoms and distress, and decrease in lung density. ${ }^{85}$ In vitro studies reviewed also associated cannabis smoke condensate and/or cannabinoids with airway hyperreactivity, genotoxicity, cytotoxicity, and negative impacts on lung surfactant. ${ }^{85}$ Cannabis smoke components identified as having the respiratory system as a target organ for the their non-cancer chronic toxicity ${ }^{39}$ may contribute to these observations.

\subsubsection{Cannabis flower vaping}

The first electronic cigarette, or e-cigarette, was conceived by Chinese pharmacist and inventor Hon Lik and first filed for patent in 2003. ${ }^{86}$ Electronic cigarettes for the consumption of nicotine slowly gained in popularity over the course of a decade, began to make their first appearances in the scientific literature before the start of the 2010 s decade,${ }^{87}$ and are now hugely popular. The application of this technology to cannabis consumption is paired with the proliferation of cannabis extracts which,

coincidentally, saw their largest increase in global seizures in 2004, having doubled from $2003 .^{88}$

Though "cannabis vaping" is often grouped as one practice in epidemiological 
work, ${ }^{39}$ vaping cannabis can take many forms. The use of vaporization to consume cannabis flower, not cannabis concentrates, was reported in the literature as early as $2001,{ }^{89}$ predating the invention of the nicotine e-cigarette. Cannabis flower vaping generally consists of a handheld or tabletop device which generates hot air that is blown over milled cannabis flower to create an aerosol that is inhaled by the user. ${ }^{78,90}$ The work by Gieringer et al. was the first to characterize the aerosol components emitted by a cannabis flower vaporizer. ${ }^{78}$ In this paper, aerosol generated from a Volcano $(\mathrm{R}$ tabletop vaporizer was transferred directly to a $250 \mathrm{~mL}$ volatile gas trap, from which a headspace syringe was used to inject $2 \mathrm{~mL}$ of gas directly into the GC-MS injection port for analysis without preconcentration. ${ }^{78}$ The inside surface of the volatile gas trap was rinsed with methanol for collection of the aerosol particulate matter and also analyzed. ${ }^{78}$ The authors reported that both particulate and gas samples only contained cannabinoids and terpenes, which led them to conclude vaporizing with a Volcano@ suppressed the formation of harmful degradation products. ${ }^{78}$ Interest in cannabis flower vaporization as a route of pulmonary medical cannabis administration led to a brief flurry of papers characterizing aerosolization parameters of the Volcano $\cap,{ }^{91}$ in vitro studies, ${ }^{92}$ and even some small pre-clinical trials with human volunteers ${ }^{93-95}$ but no further attention to the potential presence of VOCs or other degradants in the aerosol was given after Gieringer et $a l^{78}$

\subsubsection{Cannabis extract vaping using cannabis e-cigarettes}

A second class of cannabis vaping may be defined as the use of any type of electrical device, any "cannabis e-cigarette," to vaporize a cannabis concentrate. ${ }^{39}$ In general, two types of cannabis e-cigarettes exist, top loading vaporizers (TLVs) and cartridge 
vaporizers (CV) ${ }^{39}$ TLVs consist of an exposed atomizer containing a resistively-heated coil upon which a user manually places any cannabis extract, and an attached mouthpiece allowing direct inhalation of the aerosol. ${ }^{39} \mathrm{CVs}$ also use a resistively-heated element to vaporize cannabis concentrate, but the atomizer is embedded within a cartridge that contains the concentrate. ${ }^{39}$

Though the earliest report mentioning the use of an e-cigarette to consume cannabis was in $2011,{ }^{96}$ the two first studies to focus on this topic appeared in $2014^{97}$ and $2015,{ }^{98}$ an internet survey and literature review, respectively. These reports indicated that TLV and CV usage was in an early stage with a considerable "do it yourself" aspect, with mentions of mixing cannabis extracts with glycerol and/or propylene glycol (two solvents used in nicotine e-cigarettes ${ }^{99}$ ) and even self-manufacture of the cannabis extract. $^{97-98}$

The first investigation into the release of harmful degradation products from cannabis extract vaping was published in Varlet et al. ${ }^{100}$ In this study, the authors made BHO, mixed it with propylene glycol, and vaped it in a standard nicotine ecigarette. ${ }^{100}$ The authors measured VOCs released from the aerosol by passing the aerosol through an activated charcoal filter, which was later eluted with carbon disulfide for analysis by GC-MS. ${ }^{100}$ They also measured carbonyls by passing the aerosol through cartridges coated in 2,4-dinitrophenylhydrazine (2,4-DNPH) (an aldehyde derivatizing agent used for quantifying carbonyls in tobacco cigarette and e-cigarette aerosols ${ }^{101}$ ) eluting any formed aldehyde-2,4-DNPH hydrazones with acetonitrile for analysis by high performance liquid chromatography with ultraviolet-visible spectroscopy (HPLC-UV). ${ }^{100}$ The authors were not able to detect any VOCs and only two carbonyls, formaldehyde and acetaldehyde. ${ }^{100}$ They also reported difficulties when 
dissolving $\mathrm{BHO}$ in propylene glycol and were only able to make stable solutions of $\mathrm{BHO}$ in propylene glycol of levels of up to $10 \%$, and questioned the usefulness of vaping cannabis with an e-cigarette as it was not likely to deliver an active dose of THC. ${ }^{100}$

Currently, vaporizing cannabis is one of the most common non-smoking cannabis inhalation methods, with one study reporting that $21.8 \%$ of past-30-day cannabisconsuming Colorado high school students reported past-30-day cannabis vaporizing as a use mode in $2015,{ }^{102}$ and another reported that $19.5 \%$ of surveyed cannabis users from 12 US states from 2016 reported past-month vaping. ${ }^{71}$ These studies differentiated vaping from dabbing but did not differentiate cannabis flower and concentrate vaping.

\subsubsection{Dabbing}

Dabbing could be considered another form of cannabis vaping, as the MerriamWebster definition of vape: "to inhale vapor through the mouth from a usually battery-operated electronic device (such as an electronic cigarette) that heats up and vaporizes a liquid or solid"103 technically allows inclusion of this method under the vaping umbrella. However, differences between the e-cigarette and dabbing apparatus warrant separation of this method into a class of its own. In its simplest form, dabbing, or the act of taking or doing a dab, is flash vaporization of a small amount of cannabis oil, a dab, when contacted with a heated surface. ${ }^{39-40}$ The heated surface may be a small piece of titanium, ceramic, quartz, or glass often called a nail that is attached to a water pipe, pipe, or straw through which the user inhales. ${ }^{39-40}$ Most

commercially-available nails are made to be heated with a crème brûlée torch, ${ }^{104}$ but 
electrically-heated nails, e-nails, are also commonplace. ${ }^{39}$

Exactly when dabbing emerged as a usage mode for cannabis is unknown, but its first mention in the literature was in a 2014 internet survey that assessed user perceptions of the method, and concluded that dabbing appeared to lead to increase drug tolerance to THC, and that the method is more dangerous than other usage modes. ${ }^{105}$

Despite the lack of research on dabbing, two studies have investigated cannabinoid transfer and THCA decarboxylation efficiency during dabbing. A 2015 study performed partly by members of a cannabis industry-associated testing laboratory assessed the transfer efficiency of cannabinoids during dabbing. ${ }^{104}$ In Raber et al., a "mechanical lung system" was used to pull aerosol generated from $40 \mathrm{mg}$ dabs applied to a nail heated to an estimated $300{ }^{\circ} \mathrm{C}$ through two chilled methanol traps which were subsequently analyzed by HPLC-UV for cannabinoid detection. ${ }^{104}$ The authors did not discuss further details on the quantification methodology, and it is not clear how impinger solvent losses were accounted for. ${ }^{104}$ The authors reported that $50 \%$ of the available THC was transferred depending on the type of cannabis extract used, and that the decarboxylation of THCA present in the starting material was $>90 \% .{ }^{104}$

A 2019 study by Swiss and German forensic chemists performed similar dabbing experiments that consisted of placing $160-230 \mathrm{mg}$ portions of cannabis extract onto a nail heated to an unknown temperature, and the resulting aerosol was passed through two in-series liquid $\mathrm{N}_{2}$-cooled aerosol traps filled with glass boiling chip granules. ${ }^{106}$ After this, the aerosol traps were rinsed with methanol, the solvent evaporated in vacuo, the residue reconstituted in a known volume of methanol, and the solution analyzed by HPLC-UV. ${ }^{106}$ Though liquid impingers, such as those reported in Raber 
et al. ${ }^{104}$ for the analysis of cannabis and tobacco smoke aerosols have been reported many times in the literature ${ }^{106}$ the use of chilled glass boiling chip granules for aerosol capture represents a novel method. Hädener et al. reported a decarboxylation efficiency of $>99 \%$, and a THC transfer of $75.5 \%,{ }^{106}$ slightly higher than that reported by Raber et al. Both studies conclude that unrecovered THC is likely lost to sidestream smoke, adsorption on the experimental setup, or to thermal degradation.

Though the first user survey indicated user hesitation about dabbing, ${ }^{105}$ dabbing has emerged as an incredibly popular cannabis concentrate consumption technique. In 2015, 4.3\% of past-30-day cannabis-consuming Colorado high school students reported past-30-day dabbing, ${ }^{102}$ and in 2016, $14.6 \%$ of surveyed cannabis users in 12 US states reported past-month dabbing. ${ }^{71}$

\subsection{Thermal degradation reactions of cannabinoids: prior work}

Studies directed at characterizing degradation and oxidation reactions that occur during cannabis or cannabis concentrate processing and storage appear in the literature with some degree of regularity, ${ }^{107-112}$ but publications describing high temperature thermal degradation reactions of cannabinoids are scarce, with the entirety of this work dating back to the 70 s and 80 s. $^{113}$

One of the first instances of chemists studying cannabinoid reactions that occur during smoking was in 1971 by Mikeš and Waser. ${ }^{114}$ This work was motivated by a consistent pharmacological observation that hashish was more potent when smoked then when ingested orally. ${ }^{114}$ Though it is now known that orally ingested and smoked cannabis produce similar subjective effects despite a starkly different pharmacokinetic profile, ${ }^{115}$ Mikeš and Waser hypothesized that CBD, a ubiquitous component 
of hashish often present in a one-to-one ratio with $\mathrm{THC}$, isomerized to $\mathrm{THC}$ during smoking. ${ }^{114}$ For their experiments, Mikeš and Waser added THC, CBD, or hashish to a tobacco cigarette, smoked the cigarettes with a machine smoking device, collected the aerosol particulate matter on filters, extracted the filters with ether, then injected the extract onto a GC-MS system for analysis. ${ }^{114}$ In 1941, Adams et al. ${ }^{116}$ first described the acid-catalyzed cyclization of CBD to tetrahydrocannabinols, as it was known (the exact structure of THC was not described until 1963 by Mechoulam and Shvo and in 1964 by Šantavý et al., independently of each other ${ }^{117}$ ), and Mikeš and Waser postulated this same reaction (Figure 1.3) could take place during smoking, catalyzed by some smoke-borne acid. ${ }^{114}$ Soon thereafter, Quarles et al. in 1973 pointed out this reaction would only take place if CBD was combusted in the presence of tobacco, with a measured $\mathrm{pH}$ of 5.72 , and would not take place when combusting CBD-only cannabis of $\mathrm{pH} 8.14 .{ }^{118}$

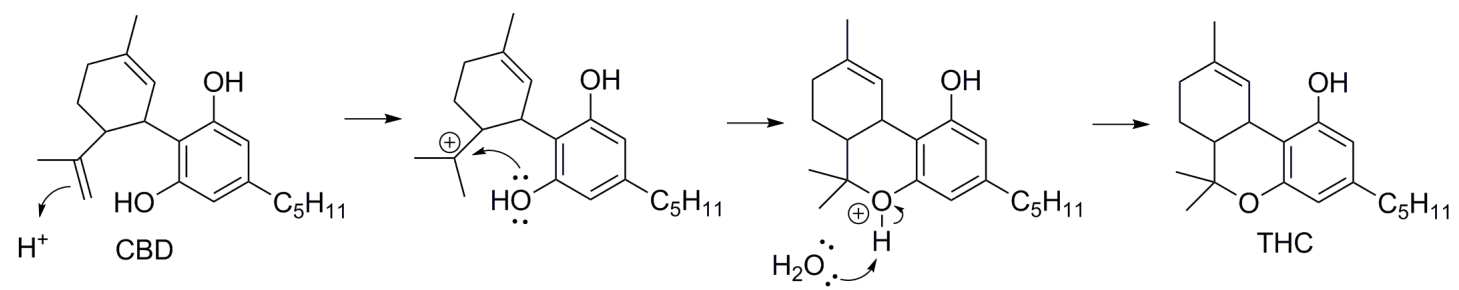

Figure 1.3: Arrow-pushing mechanism for the conversion of CBD to THC, a reaction first described by Adams et al. ${ }^{116}$ to occur by hydrochloric acid catalysis in ethanol, confirmed to occur during smoking by Mikeš and Waser. ${ }^{114}$ and Quarles et al., ${ }^{118}$ and during pyrolysis by Kuppers et al. ${ }^{119}$

After the apparent resolution of the CBD-to-THC conversion issue, cannabinoid pyrolysis was studied by two groups of organic and analytical chemistry researchers at the University of Utrecht between $1973^{120}$ and $1978 .{ }^{121}$ With the overarching goal of identifying molecules of toxicological concern, the group initially studied cannabis 
smoke, but decided to simplify the system and conduct pyrolysis/combustion studies with a single cannabinoid: CBD. ${ }^{113}$ This molecule was chosen in part due to it being a crystalline solid $\left(\mathrm{mp}=67.5 \pm 0.3{ }^{\circ} \mathrm{C}^{122}\right.$ ) that is easier to handle than $\mathrm{THC}$, which is an extremely sticky, sappy oil at room temperature $\left(\mathrm{mp}=r t^{123}\right)$, and in part because it was, perhaps at the time, the most abundant cannabinoid in most cannabis preparations. ${ }^{113}$

The Utrecht researchers performed aerobic and anaerobic pyrolysis experiments by passing air or $\mathrm{N}_{2}$ through a heated quartz tube containing $\mathrm{CBD}$ to $700{ }^{\circ} \mathrm{C}$, and collected pyrolysates in a $-80^{\circ} \mathrm{C}$ cold trap ${ }^{119-120,124-127}$ Degradation products were isolated by preparative GC and TLC, and structural assignments were performed using mass spectrometry, ${ }^{1} \mathrm{H}$ NMR, and optical rotation measurements. ${ }^{119-120,124-127}$ They identified many CBD degradation products and divided them into two groups based on their relative elution order with respect to $\mathrm{CBD}$ in the $\mathrm{GC}-\mathrm{MS}$ chromtograms of pyrolysate samples: early-eluting products (referred to as cracking products), and later-eluting products. ${ }^{113}$

A selection of the cracking products identified in Kuppers et al. $(1975 \mathrm{~b})^{124}$ are displayed in Figure 1.4. Readily apparent is the intact 5-pentylresorcinol moiety in all these products, which suggests thermal degradation of CBD is initiated on the terpenoid moiety. Products more volatile than these (VOCs such as isoprene, butadiene, benzene, etc.) may have evaporated before sample collection, or may have been overwhelmed by the solvent peak (pentane ${ }^{120}$ ) in the GC-MS chromtogram. In one chromatogram, the first peak coming off the tail of the solvent front is highlighted as a potential degradation product, but the authors did not investigate its structure. ${ }^{124}$ 


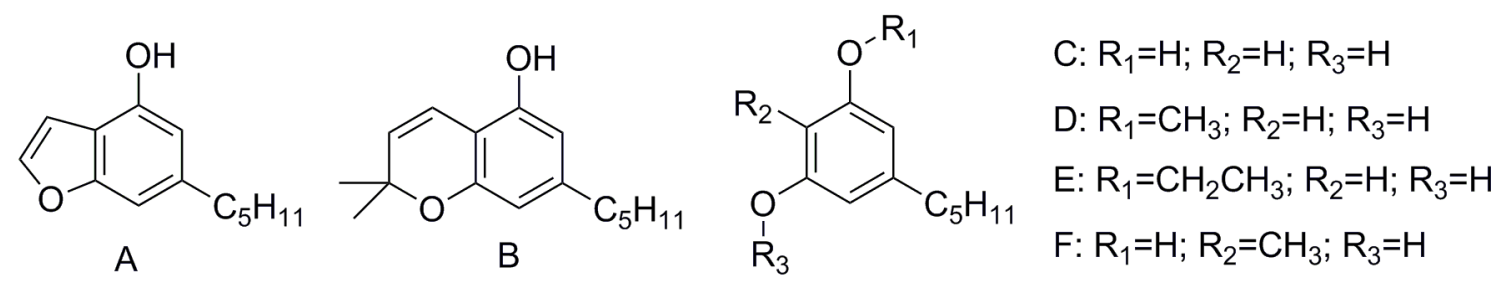

Figure 1.4: Cracking products described in Kuppers et al. (1975 b). ${ }^{124}$

Later-eluting products identified by the Utrecht group are displayed in Figure 1.5. In their fist paper, cannabielsoin was identified as the major product on aerobic pyrolysis of CBD, ${ }^{119}$ and several years later, a product dubbed 314/271 (the $m / z$ of its two most abundant fragment ions) was identified as the main anaerobic pyrolysis product. ${ }^{126}$ The researchers noted that other products were visible in GC-MS chromatograms of aerobic pyrolysis experiments, but all were more easily identifiable in $\mathrm{O}_{2}$-free experiments. ${ }^{113}$ Given the discrepancy between these two experimental conditions, the group monitored the mainstream smoke of a cigarette using a polarographic $\mathrm{O}_{2}$ sensor and determined that anaerobic conditions were a better recreation of reality. ${ }^{121}$ In all cases, the 5-pentylresorcinol moiety remains intact, a further indication that reactions involving the terpenoid moiety occur with relative ease. 


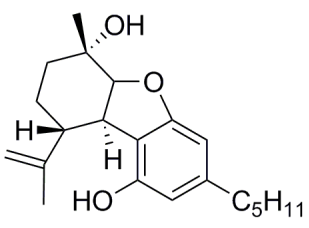

Cannabielsoin

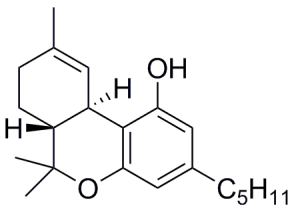

$\mathrm{THC}$

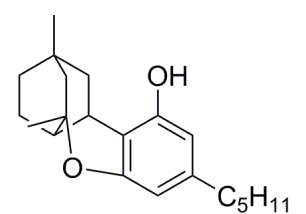

"314/108"

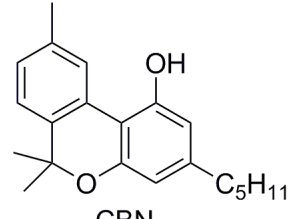

CBN

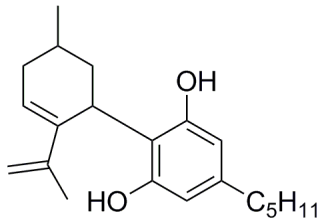

$\Delta^{4}-\mathrm{CBD}$

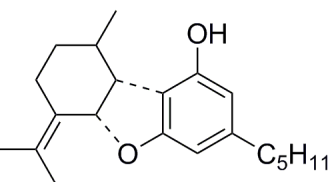

"314/271"

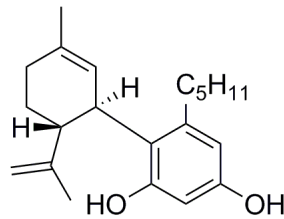

Abnormal CBD

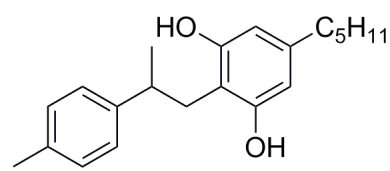

2-[2-(p-tolyl)propyl]olivetol

Figure 1.5: Later-eluting products identified by the Utrecht group.

\subsection{Prior work characterizing thermal degradation of $\beta$-myrcene, a fundamental cannabis terpene}

Myrcene is a C10 monoterpene terpene first isolated in 1895 from Myrcia acris (bay oil). ${ }^{128}$ Myrcene exists as two isomers governed by the position of the double bond on the isopropylidene/isopropenyl moiety: $\beta$-myrcene and $\alpha$-myrcene (Figure 1.6a). The position of the double bond in the naturally-occurring isomer, $\beta$-myrcene, was first reported in 1924 by Ruicka and Stoll, who rationalized this after only detecting succinic acid after oxidizing myrcene ozonolysis products with chromic acid, ${ }^{129}$ a result that was later confirmed by IR and NMR spectroscopy. ${ }^{128}$

Though comprehensive metabolic profiling of cannabis products is difficult mainly due to cannabis' legal status, many existing reports that detail the composition of cannabis essential oil note $\beta$-myrcene as one of the most abundant terpenes present in both drug ${ }^{131-135}$ and hemp ${ }^{136-137}$ cannabis. One study reported $\beta$-myrcene was the most abundant terpene of the sample of drug cannabis studied, representing $33 \% \mathrm{~m} / \mathrm{m}$ 
of distilled essential oil, nearly double the next most abundant terpene, $d$-limonene. ${ }^{25}$

The earliest work to partially characterize the thermal degradation of $\beta$-myrcene is in doctoral thesis of Ioan Prodrom published in 1913 at the Swiss Federal Institute of Technology. ${ }^{138}$ In this body of work, reactions of terpenes and other hydrocarbons were explored, and it was observed that $\beta$-myrcene produced good yields of isoprene (39\%) when pyrolyzed by passing current through a platinum wire submerged in the terpene. ${ }^{138}$ However, the isoprene was of lower quality than that derived from limonene, and it was suggested this may have been due to impurities in the starting material. ${ }^{138}$ In 1946, Davis et al. performed similar pyrolysis experiments geared toward determining which of seven terpenes would be an ideal source of isoprene for the manufacture of synthetic rubber. ${ }^{139}$ Davis et al. also pyrolyzed the terpenes using a resistively-heated wire (nickel-chromium in this case). ${ }^{139} \beta$-Myrcene had the third highest yield of isoprene (21\%), after $\beta$-pinene (23\%), and $d$-limonene (54\%). ${ }^{139}$ The resemblance of these early $20^{\text {th }}$ Century pyrolytic reactors with that of a modern e-cigarette is uncanny.

a)
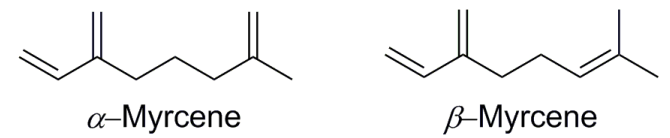

b)

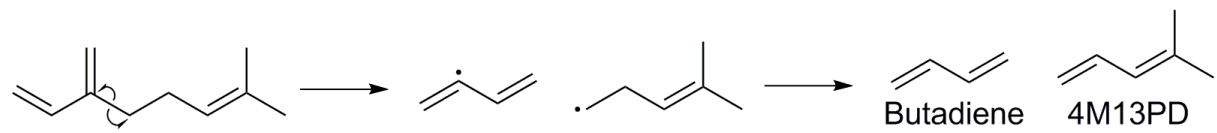

c)

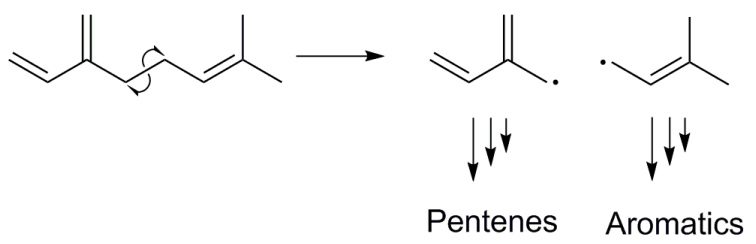

Figure 1.6: a) The structures of $\beta$-myrcene and $\alpha$-myrcene; b) $\beta$-myrcene decomposition mechanism proposed by Kolichescki et al.; ${ }^{141}$ c) the decomposition mechanism proposed by Stolle and Ondruschka ${ }^{142}$ in response to Kolichescki et al. ${ }^{141}$ 
Though initially isolated from natural products such as bay oil, this is not economical, and currently the most common source of $\beta$-myrcene production is by pyrolysis of $\beta$-pinene. ${ }^{128}$ This method has been refined since it was first patented in $1947,{ }^{130}$ and the highest reported yield thus far is $85 \% \cdot{ }^{141}$ In 2007, Kolicheski et al. developed a theoretical equilibrium model for the reaction and determined it should, in theory, have a yield of $93.5 \%{ }^{141}$ The authors analyzed degradation products of the reaction by $\mathrm{GC}-\mathrm{MS}$ and theorized that degradation of $\beta$-myrcene via alkyl radicals accounted for the decreased yields. ${ }^{141}$ They proposed a degradation mechanism for $\beta$-myrcene (Figure 1.6b) that would primarily yield butadiene and 4-methyl-1,3-pentadiene, and though they did not detect these products, Kolicheski et al. detected several products they reported as known degradation products of butadiene (benzene, xylenes, ethylbenzene, etc.) and two 4-methyl-1,3-pentadiene constitutional isomers. ${ }^{141}$ Approximately six months after this publication was made available, the same journal published a critical commentary to this paper that pointed out that the bond homolysis in Figure 1.6b proposed by Kolicheski et al. is unlikely given the relative instability of primary and vinyl radicals this forms. ${ }^{142}$ Stolle and Ondruschka instead proposed the mechanism shown in Figure 6c which yields two relatively more stable allylic radicals, and suggested these radicals are precursors for isopentene, pentene, and aromatic hydrocarbons. ${ }^{142}$

Since then, a further theoretical and experimental study on the synthesis of $\beta$ myrcene from $\beta$-pinene was published by Zheng et al. in 2017. ${ }^{143}$ Perhaps on the suggestion of Stolle and Ondruschka, ${ }^{142}$ these authors characterized pyrolysis products for not only $\beta$-pinene, but also $d$-limonene and $\beta$-myrcene. ${ }^{143}$ Zheng et al. characterized and quantitated degradants by $\mathrm{GC}-\mathrm{MS}$, proposed reaction mechanisms, and 
developed a kinetic model that showed good agreement with experimental data. ${ }^{143}$ Products of $\beta$-myrcene pyrolysis they reported include products that maintain the same number of carbon atoms as $\beta$-myrcene formed by intramolecular ene reactions as well as a number of C4, C5, and C6 degradation products. ${ }^{143}$

\subsection{Summary}

Detailed knowledge that is not only grounded in science but in touch with historic and current user habits is essential for performing research that seeks to advance our knowledge of the chemical processes that underlie cannabis consumption by any route. Though cannabis flowers are readily consumable by smoking in cigarettes or pipes, since ancient times cannabis concentrates have been an important vehicle for the plant's intoxicating principle. ${ }^{61-62}$ Adulteration of hashish is a chronic issue extensively reported on in Europe, ${ }^{46-47}$ and though hashish from Morocco does not currently make its way across the Atlantic Ocean in a meaningful way, ${ }^{46}$ adulteration concerns of cannabis concentrates manufactured in North America have quickly arisen. ${ }^{52,55,144}$ Indeed, the deadly outbreak of cannabis-e-cigarette-originated lung injury known as EVALI is suggested to have have been caused by an adulterant. ${ }^{49}$

Part of the body of work presented herein is a manuscript published in Forensic Science International titled "Pine rosin identified as a toxic cannabis extract adulterant" that details efforts to identify a cannabis concentrate adulterant for which there is evidence that the main substance it contains, pine rosin or colophony, was or may continue to be in use in the black market. ${ }^{144}$ The hope is that this work provides awareness to medical professionals, forensic scientists, and law enforcement agencies about the potential presence of this substance, which is not safe to inhale, in cannabis 
concentrates.

Despite the popularity of cannabis concentrate consumption by vaping and dabbing, prior efforts to examine the chemical processes that occur during consumption by these methods is scarce. Prior to the publication of the manuscripts herein, little work existed on the characterization of any harmful or potentially harmful components of cannabis concentrate vaping aerosols, and the chemical understanding of THC and terpene degradation in the context of these consumption methods was loose or nonexistent. The other published manuscripts presented herein ("Toxicant Formation in Dabbing the Terpene Story," 40 "Aerosol Gas-Phase Components from Cannabis ECigarettes and Dabbing: Mechanistic Insight and Quantitative Risk Analysis," 39 and "The influence of terpenes on the release of volatile organic compounds and active ingredients to cannabis vaping aerosols" ${ }^{45}$ ) represent a progression in understanding of cannabis concentrate inhalation methods, chemical composition of the extracts, degradation mechanisms, and analysis methods. This work is only a first pass at assessing the safety of these novel cannabis consumption methods, a task that must be continued by chemists, aerosol scientists, toxicologists, and clinicians alike.

\subsection{References}

(1) Cervantes, J., The Cannabis Encyclopedia. Van Patten Publishing: 2015.

(2) Reed, J. Morphology of cannabis sativa L. State University of Iowa, Iowa City, USA, 1914.

(3) Turner, J. C.; Hemphill, J. K.; Mahlberg, P. G., Quantitative determination of cannabinoids in individual glandular trichomes of Cannabis sativa L. (cannabaceae). Amer. J. Bot. 1978, 65 (10), 1103-6. 
(4) Raymon, L. P.; Walls, H. C., Pharmacology of Cannabinoids. In Marijuana and the Cannabinoids, Elsohly, M. A., Ed. Humana Press: Totowa, NJ, 2007.

(5) World Drug Report. World Drug Report 2020, (United Nations publications, Sales No. E.20.XI.6).

(6) Warf, B., High Points: An Historical Geography of Cannabis. Geogr. Rev. 2019, 104 (4), 414-38.

(7) Kuddus, M.; Ginawi, I.; AlHazimi, A., Cannabis sativa: An ancient wild edible plant of India. Emir. J. Food Agric. 2013, 25 (10), 736-45.

(8) Small, E.; Cronquist, A., A Practical and Natural Taxonomy for Cannabis. Taxon 1976, 25 (4), 405-35.

(9) Brenneisen, R., Chemistry and Analysis of Phytocannabinoids and Other Cannabis Constituents. In Marijuana and the Cannabinoids, ElSohly, M. A., Ed. Humana Press: 999 Riverview Drive, Suite 208 Totowa, New Jersey 07512, 2007.

(10) Costain, W. J.; Rasquinha, I.; Comas, T.; Hewitt, M.; Aylsworth, A.; Rouleau, Y.; Marleau, V.; Soo, E. C.; Tauskela, J. S., Analysis of the pharmacological properties of JWH-122 isomers and THJ-2201, RCS-4 and AB-CHMINACA in HEK293T cells and hippocampal neurons. Eur. J. Pharmacol. 2018, 823, 96-104.

(11) Martin, B., The Endocannabinoid System and the Therapeutic Potential of Cannabinoids. In Marijuana and the Cannabinoids, ElSohly, M., Ed. Humana Press: Totowa, New Jersey, 2007.

(12) Sirikantaramas, S.; Taura, F.; Y., T.; Ishikawa, Y.; Morimoto, S.; Shoyama, Y., Tetrahydrocannabinolic acid synthase, the enzyme controlling marijuana psychoactivity, is secreted into the storage cavity of the glandular trichomes. Plant Cell Physiol. 2005, $46(9), 1578-82$. 
(13) Taura, F.; Morimoto, S.; Shoyama, Y., Purification and characterization of cannabidiolic-acid synthase from Cannabis sativa L.. Biochemical analysis of a novel enzyme that catalyzes the oxidocyclization of cannabigerolic acid to cannabidiolic acid. J. Biol. Chem. 1996, 271 (29), 17411-6.

(14) Taura, F.; Morimoto, S.; Shoyama, Y.; Mechoulam, R., First direct evidence for the mechanism of $\Delta^{1}$-tetrahydrocannabinolic acid biosynthesis. J.Am. Chem. Soc. 1995, $117(38), 9766-7$.

(15) Hazekamp, A.; Peltenburg, A.; Verpoorte, R.; Giroud, C., Chromatographic and Spectroscopic Data of Cannabinoids from Cannabis sativa L. J. Liq. Chromatogr. Relat. Technol. 2007, 28 (15), 2361-82.

(16) de Meijer, E. P.; Bagatta, M.; Carboni, A.; Crucitti, P.; Moliterni, V. M.; Ranalli, P.; Mandolino, G., The inheritance of chemical phenotype in Cannabis sativa L. Genetics 2003, 163 (1), 335-46.

(17) de Meijer, E. P. M.; Hammond, K. M., The inheritance of chemical phenotype in Cannabis sativa L. (II): Cannabigerol predominant plants. Euphytica 2005, 145 (1-2), 189-98.

(18) Lu, H. C.; Mackie, K., An Introduction to the Endogenous Cannabinoid System. Biol. Psychiatry 2016, 79 (7), 516-25.

(19) Pertwee, R., The diverse CB1 and CB2 receptor pharmacology of three plant cannabinoids: $\Delta^{9}$-tetrahydrocannabinol, cannabidiol and $\Delta^{9}$-tetrahydrocannabivarin. Br. J. Pharmacol. 2008, 153, 199-215.

(20) Citti, C.; Linciano, P.; Russo, F.; Luongo, L.; Iannotta, M.; Maione, S.; Lagana, A.; Capriotti, A. L.; Forni, F.; Vandelli, M. A.; Gigli, G.; Cannazza, G., A novel phytocannabinoid isolated from Cannabis sativa L. with an in vivo cannabimimetic 
activity higher than $\Delta^{9}$-tetrahydrocannabinol: $\Delta^{9}$-Tetrahydrocannabiphorol. Sci. Rep. 2019, 9 (1), 20335.

(21) Hanuš, L. O.; Meyer, S. M.; Muñoz, E.; Taglialatela-Scafati, O.; Appendino, G., Phytocannabinoids: a unified critical inventory. Nat. Prod. Rep. 2016, 33 (12), 1357-92.

(22) Chandra, S.; Radwan, M. M.; Majumdar, C. G.; Church, J. C.; Freeman, T. P.; Elsohly, M. A., New trends in cannabis potency in USA and Europe during the last decade (2008-2017). Eur. Arch .Psychiatry Clin. Neurosci. 2019, 269, 5-15.

(23) Swift, W.; Wong, A.; Li, K. M.; Arnold, J. C.; McGregor, I. S., Analysis of cannabis seizures in NSW, Australia: cannabis potency and cannabinoid profile. PLoS One 2013, 8 (7), e70052.

(24) Gilbert, A. N.; DiVerdi, J. A., Consumer perceptions of strain differences in Cannabis aroma. PLoS One 2018, 13 (2), e0192247.

(25) Ross, S. A.; ElSohly, M. A., The volatile oil composition of fresh and air-dried buds of Cannabis sativa. J. Nat. Prod. 1996, 59 (1), 49-51.

(26) Russo, E. B., Taming THC: potential cannabis synergy and phytocannabinoidterpenoid entourage effects. Br. J. Pharmacol. 2011, 163 (7), 1344-64.

(27) Koltai, H.; Namdar, D., Cannabis Phytomolecule 'Entourage': From Domestication to Medical Use. Trends Plant Sci. 2020, 25(10), 976-84.

(28) Piomelli, D., Waiting for the Entourage. Cannabis Cannabinoid Res 2019, 4 (3), 137-8.

(29) Finlay, D. B.; Sircombe, K. J.; Nimick, M.; Jones, C.; Glass, M., Terpenoids From Cannabis Do Not Mediate an Entourage Effect by Acting at Cannabinoid Receptors. Front. Pharmacol. 2020, 11, 359 . 
(30) Concentrates. https://weedmaps.com/learn/dictionary/concentrates/ (accessed March 17).

(31) World Drug Report 2020. https://wdr.unodc.org/wdr2020/index.html (accessed March 17).

(32) Drugs, booze and sex: a look at the problems. Association News Jul 12, 1975, pp 69-71.

(33) Bachman, J. G.; Johnston, L. D.; O’Malley, P. M., Smoking, drinking, and drug use among American high school students: correlates and trends, 1975-1979. Am J Public Health 1981, 71 (1), 59-69.

(34) ElSohly, M. A.; Ross, S. A.; Mehmedic, Z.; Arafat, R.; Yi, B.; Banahan, B. F., Potency Trends of $\Delta^{9}$-THC and Other Cannabinoids in Confiscated Marijuana from 1980-1997. J. Forensic Sci. 2000, 45 (1), 24-30.

(35) ElSohly, M. A: Mehmetic, Z.; Foster, S.; Gon, C.; Chandra, S.; Church J. C., Changes in Cannabis Potency over the Last Two Decades (1995-2014) - Analysis of Current Data in the United States. Biol. Psychiatry 2016, 79 (7), 613-19. (36) Mehmedic, Z.; Chandra, S.; Slade, D.; Denham, H.; Foster, S.; Patel, A. S.; Ross, S. A.; Khan, I. A.; ElSohly, M. A., Potency trends of $\Delta^{9}-$ THC and other cannabinoids in confiscated cannabis preparations from 1993 to 2008. J. Forensic Sci. 2010, 55 (5), 1209-17.

(37) Zhang, Z.; Zheng, X.; Zeng, D. D.; Leischow, S. J., Tracking Dabbing Using Search Query Surveillance: A Case Study in the United States. J. Med. Internet Res. 2016, 18 (9), e252.

(38) Jensen, G.; Bertelotti, R.; Greenhalgh, D.; Palmieri, T.; Maguina, P., Honey oil burns: a growing problem. J .Burn Care Res. 2015, 36 (2), e34-7. 
(39) Meehan-Atrash, J.; Luo, W.; McWhirter, K. J.; Strongin, R. M., Aerosol GasPhase Components from Cannabis E-Cigarettes and Dabbing: Mechanistic Insight and Quantitative Risk Analysis. ACS Omega 2019, 4 (14), 16111-20.

(40) Meehan-Atrash, J.; Luo, W.; Strongin, R. M., Toxicant Formation in Dabbing: The Terpene Story. ACS Omega 2017, 2 (9), 6112-7.

(41) Qamar, S.; Torres, Y. J. M.; Parekh, H. S.; Robert Falconer, J., Extraction of medicinal cannabinoids through supercritical carbon dioxide technologies: A review. J. Chromatogr. B. 2021, 1167, 122581.

(42) Distillate. https://weedmaps.com/learn/dictionary/distillate/ (accessed January 13,2020$)$.

(43) Lewis, M. M.; Yang, Y.; Wasilewski, E.; Clarke, H. A.; Kotra, L. P., Chemical Profiling of Medical Cannabis Extracts. ACS Omega 2017, 2 (9), 6091-103.

(44) Peace, M. R.; Stone, J. W.; Poklis, J. L.; Turner, J. B.; Poklis, A., Analysis of a Commercial Marijuana e-Cigarette Formulation. J. Anal. Toxicol. 2016, 40 (5), $374-8$.

(45) Meehan-Atrash, J.; Luo, W.; McWhirter, K. J.; Dennis, D. G.; Sarlah, D.; Jensen, R. P.; Afreh, I.; Jiang, J.; Barsanti, K. C.; Ortiz, A.; Strongin, R. M., The influence of terpenes on the release of volatile organic compounds and active ingredients to cannabis vaping aerosols. RSC Advances 2021, 11 (19), 11714-23.

(46) Chouvy, P. A., The Supply of Hashish to Europe. European Monitoring Center for Drugs and Drug Addiction: Lisbon, Portugal, 2015.

(47) Perez-Moreno, M.; Perez-Lloret, P.; Gonzalez-Soriano, J.; Santos-Alvarez, I., Cannabis resin in the region of Madrid: Adulteration and contamination. Forensic Sci. Int. 2019, 298, 34-8. 
(48) CDC Outbreak of Lung Injury Associated with the Use of E-Cigarette, or Vaping, Products. https://www.cdc.gov/tobacco/basic_information/e-cigarettes/severe-lungdisease.html (accessed March 18, 2021).

(49) Lewis, N.; McCaffrey, K.; Sage, K.; Cheng, C.-J.; Green, J.; Goldstein, L.; Campbell, H.; Ferrell, D.; Malan, N.; LaCross, N.; Maldonado, A.; Board, A.; Hanchey, A.; D., H.; Callahan, S.; Aberegg, S.; Risk, I.; Willardson, S.; Carter, A.; Nakashima, A.; Duncan, J.; Burnett, C.; Atkinson-Dunn, R.; Dunn, A., E-cigarette Use, or Vaping, Practices and Characteristics Among Person with Associated Lung Injury - Utah, April-October 2019. MMWR Morb. Mortal. Wkly. Rep. 2019, 68, 953-6.

(50) Lanzarotta, A.; Falconer, T. M.; Flurer, R.; Wilson, R. A., Hydrogen Bonding between Tetrahydrocannabinol and Vitamin E Acetate in Unvaped, Aerosolized, and Condensed Aerosol e-Liquids. Anal. Chem. 2020, 92 (3), 2374-8.

(51) Wu, D.; O'Shea, D. F., Potential for release of pulmonary toxic ketene from vaping pyrolysis of vitamin E acetate. Proc. Natl. Acad. Sci. USA 2020, 117 (12), $6349-55$.

(52) Duffy, B.; Li, L.; Lu, S.; Durocher, L.; Dittmar, M.; Delaney-Baldwin, E.; Panawennage, D.; LeMaster, D.; Navarette, K.; Spink, D., Analysis of CannabinoidContaining Fluids in Illicit Vaping Cartridges Recovered from Pulmonary Injury Patients: Identification of Vitamin E Acetate as a Major Diluent. Toxics 2020, 8 (1). (53) Mogler, L.; Franz, F.; Rentsch, D.; Angerer, V.; Weinfurtner, G.; Longworth, M.; Banister, S. D.; Kassiou, M.; Moosmann, B.; Auwarter, V., Detection of the recently emerged synthetic cannabinoid 5F-MDMB-PICA in 'legal high' products and human urine samples. Drug Test. Anal. 2018, 10 (1), 196-205.

(54) Eccles, R., What is the Role of Over 100 Excipients in Over the Counter (OTC) 
Cough Medicines? Lung 2020, 198 (5), 727-34.

(55) Poklis, J. L.; Mulder, H. A.; Peace, M. R., The unexpected identification of the cannabimimetic, 5F-ADB, and dextromethorphan in commercially available cannabidiol e-liquids. Forensic Sci Int 2019, 294, e25-e27.

(56) Luce, T. J., The Greek Historians. Routledge: London, England, 1997.

(57) Herodotus, The Histories. Godley, A. D., Ed. Harvard University Press: Cambridge, MA, 1920.

(58) Harmatta, J., History of Civilizations of Central Asia: The Development of Sedentary and Nomadic Civilizations, 700 B. C. to A. D. 250. UNESCO: Paris, France, 1994; Vol. 2.

(59) Ren, M.; Tang, Z.; Wu, X.; Spengler, R.; Jiang, H.; Yang, Y.; Boivin, N., The origins of cannabis smoking: Chemical residue evidence from the first millenium $\mathrm{BCE}$ in the Pamirs. Sci. Adv. 2019, 5, eeaw1391.

(60) Van Der Merwe, N. J., Cannabis Smoking in the 13th-14th Century Ethiopia: Chemical Evidence. In Cannabis and Culture, Rubin, V., Ed. De Gruyter: The Hague, The Netherlands, 1975.

(61) Chasteen, J. H., Getting High, Marijuana through the Ages. Rowman \& Littlefield: London, United Kingdom, 2016.

(62) Fisher, J., Cannabis in Nepal: An Overview. In Cannabis and Culture, Rubin, V., Ed. De Gruyter: The Hague, The Netherlands, 1975.

(63) Booth, M., Cannabis: A History. Picador: New York, NY, 2003.

(64) Tushingham, S.; Snyder, C. M.; Brownstein, K. J.; Damitio, W. J.; Gang, D. R., Biomolecular archaeology reveals ancient origins of indigenous tobacco smoking in North American Plateau. Proc. Natl. Acad. Sci. USA 2018, 115 (46), 11742-7. 
(65) Adams, K. R., Prehistoric reedgrass (phragmites) "cigarettes" with tobacco (Nicotiniana) contents: A case study from Red Bow Cliff Dwelling, Arizona. J. Ethnobiol. 1990, 10, 123-39.

(66) Goodman, J., Tobacco in History. The Cultures of Dependence. Routledge: London, England, 1993.

(67) Gravely, S.; Driezen, P.; Smith, D. M.; Borland, R.; Lindblom, E. N.; Hammond, D.; McNeill, A.; Hyland, A.; Cummings, K. M.; Chan, G.; Thompson, M. E.; Boudreau, C.; Martin, N.; Ouimet, J.; Loewen, R.; Quah, A. C. K.; Goniewicz, M. L.; Thrasher, J. F.; Fong, G. T., International differences in patterns of cannabis use among adult cigarette smokers: Findings from the 2018 ITC Four Country Smoking and Vaping Survey. Int. J. Drug Policy 2020, 79, 102754.

(68) The Rizla Story. https://www.rizla.com/history/ (accessed March 11).

(69) Hazekamp, A.; Ware, M. A.; Muller-Vahl, K. R.; Abrams, D.; Grotenhermen, F., The Medicinal Use of Cannabis and Cannabinoids-An International Cross-Sectional Survey on Administration Forms. J. Psychoac. Drugs 2013, 45 (3), 199-210.

(70) Azofeifa, A.; Mattison, M. E.; Schauer, G.; McAfee, T.; Grant, A.; Lyerla, R., National Estimates of Marijuana Use and Related Indicators - National Survey on Drug Use and Health, United States, 2002-2014; Centers for Disease Control and Prevention: Atlanta, GA, 2016.

(71) Schauer, G. L.; Njai, R.; Grant-Lenzy, A. M., Modes of marijuana use - smoking, vaping, eating, and dabbing: Results from the 2016 BRFSS in 12 States. Drug Alcohol Depend. 2020, 209, 107900.

(72) Dussy, F. E.; Hamberg, C.; Luginbuhl, M.; Schwerzmann, T.; Briellmann, T. A., Isolation of $\Delta^{9}$-THCA-A from hemp and analytical aspects concerning the determi- 
nation of $\Delta^{9}$-THC in cannabis products. Forensic Sci. Int. 2005, 149 (1), 3-10.

(73) Lovestead, T. M.; Bruno, T. J., Determination of Cannabinoid Vapor Pressures to Aid in Vapor Phase Detection of Intoxication. Forensic Chem. 2017, 5, 79-85.

(74) Van der Kooy, F.; Pomahacova, B.; Verpoorte, R., Cannabis smoke condensate I: the effect of different preparation methods on tetrahydrocannabinol levels. Inhal. Toxicol. 2008, 20 (9), 801-4.

(75) Van der Kooy, F.; Pomahacova, B.; Verpoorte, R., Cannabis smoke condensate II: influence of tobacco on tetrahydrocannabinol levels. Inhal. Toxicol. 2009, 21 (2), 87-90.

(76) Bloor, R. N. W., T. S.; Spanel, P; Smith, D., Ammonia release from heated 'street' cannabis leaf and its potential toxic effects on cannabis users. Addiction 2008, 103, 1671-7.

(77) Chait, L. D.; Pierri, J., Some physical characteristics of NIDA marijuana cigarettes. Addict. Behav. 1989, 14, 61-7.

(78) Gieringer, D. H.; St. Laurent, J.; Goodrich, S., Cannabis Vaporizer Combines Efficient Delivery of THC with Effective Suppression of Pyrolytic Compounds. J. Cannabis Ther. 2004, 4 (1), 7-27.

(79) Hoffman, D.; Brunnemann, K. D.; Gori, G. B.; Wynder, E. L., On the carcinogenicity of marijuana smoke. In Recent Advances in Phytochemistry, Runeckles, V. C., Ed. Springer: Boston, MA, 1975.

(80) Lee, M. L.; Novotny, M.; Bartle, K. D., Gas chromatography/mass spectrometric and nuclear magnetic resonance spectrometric studies of carcinogenic polynuclear aromatic hydrocarbons in tobacco and marijuana smoke condensates. Anal. Chem. 1976, $48(2), 405-16$. 
(81) Maertens, R. M.; White, P. A.; Rickert, W.; Levasseur, G.; Douglas, G. R.; Bellier, P. V.; McNamee, J. P.; Thuppal, V.; Walker, M.; Desjardins, S., The genotoxicity of mainstream and sidestream marijuana and tobacco smoke condensates. Chem. Res. Toxicol. 2009, 22 (8), 1406-14.

(82) Moir, D.; Rickert, W. S.; Levasseur, G.; Larose, Y.; Maertens, R.; White, P.; Desjardins, S., A comparison of mainstream and sidestream marijuana and tobacco cigarette smoke produced under two machine smoking conditions. Chem. Res. Toxicol. 2008, 21 (2), 494-502.

(83) Kislov, V. V.; Sadovnikov, A. I.; Mebel, A. M., Formation mechanism of polycyclic aromatic hydrocarbons beyond the second aromatic ring. J. Phys. Chem. A 2013, $117(23), 4794-816$.

(84) Snook, M. E.; Severson, R. F.; Arrendale, R. F.; Higman, H. C.; Chortyk, O. T., The ldentification of High Molecular Weight Polynuclear Aromatic Hydrocarbons in a Biologically Active Fraction of Cigarette Smoke Condensate. Beiträge zur Tabakforschung / Contributions to Tobacco Research 1977, 9(2), 79-101.

(85) Meehan-Atrash, J.; Korzun, T.; Ziegler, A., Association of cannabis inhalation with voice disorders. JAMA Otolaryngol. Head Neck Surg. 2019, 145(10), 956-64.

(86) Lik, H. Electronic cigarette.US 8,511,318B2 August 20, 2013.

(87) Wollscheid, K. A.; Kremzner, M. E., Electronic cigarettes: safety concerns and regulatory issues. Am. J. Health Syst. Pharm. 2009, 66 (19), 1740-2.

(88) 2006 World Drug Report. United Nations Office on Drugs and Crime. United Nations Publications: 2006.

(89) Gieringer, D. H., Cannabis "Vaporization": A Promising Strategy for Smoke Harm Reduction. J. Cannabis Ther. 2001, 1 (3/4), 153-70. 
(90) Hazekamp, A.; Ruhaak, R.; Zuurman, L.; van Gerven, J.; Verpoorte, R., Evaluation of a vaporizing device (Volcano) for the pulmonary administration of tetrahydrocannabinol. J. Pharm. Sci. 2006, 95 (6), 1308-17.

(91) Pomahacova, B.; Van der Kooy, F.; Verpoorte, R., Cannabis smoke condensate III: the cannabinoid content of vaporised Cannabis sativa. Inhal. Toxicol. 2009, 21 (13), 1108-12.

(92) Lanz, C.; Mattsson, J.; Soydaner, U.; Brenneisen, R., Medicinal Cannabis: In Vitro Validation of Vaporizers for the Smoke-Free Inhalation of Cannabis. PLoS One 2016, 11 (1), e0147286.

(93) Abrams, D. I.; Vizoso, H. P.; Shade, S. B.; Jay, C.; Kelly, M. E.; Benowitz, N. L., Vaporization as a smokeless cannabis delivery system: a pilot study. Clin. Pharmacol. Ther. 2007, 82 (5), 572-8.

(94) Earleywine, M.; Barnwell, S. S., Decreased respiratory symptoms in cannabis users who vaporize. Harm Reduct. J. 2007, 4 (1), 11.

(95) Wilsey, B.; Marcotte, T.; Deutsch, R.; Gouaux, B.; Sakai, S.; Donaghe, H., Lowdose vaporized cannabis significantly improves neuropathic pain. J. Pain 2013, 14 (2), 136-48.

(96) Etter, J. F.; Bullen, C., Electronic cigarette: users profile, utilization, satisfaction and perceived efficacy. Addiction 2011, 106. (11), 2017-28.

(97) Etter, J. F., Electronic cigarettes and cannabis: an exploratory study. Eur. Addict. Res. 2015, 21 (3), 124-30.

(98) Giroud, C.; de Cesare, M.; Berthet, A.; Varlet, V.; Concha-Lozano, N.; Favrat, B., E-Cigarettes: A Review of New Trends in Cannabis Use. Int. J. Environ. Res. Public Health 2015, 12 (8), 9988-10008. 
(99) Jensen, R. P.; Strongin, R. M.; Peyton, D. H., Solvent Chemistry in the Electronic Cigarette Reaction Vessel. Sci. Rep. 2017, 7, 42549.

(100) Varlet, V.; Concha-Lozano, N.; Berthet, A.; Plateel, G.; Favrat, B.; De Cesare, M.; Lauer, E.; Augsburger, M.; Thomas, A.; Giroud, C., Drug vaping applied to cannabis: is "cannavaping" a therapeutic alternative to marijuana? Sci. Rep. 2016, 6, 25599 .

(101) CORESTA No. 74 - Determination of Selected Carbonyls in Mainstream Cigarette Smoke by High Performance Liquid Chromatography (HPLC). https://www. coresta.org/determination-selected-carbonyls-mainstream-cigarette-smoke-highperformance-liquid-chromatography.

(102) Tormohlen, K. N.; Brooks-Russell, A.; Ma, M.; Schneider, K. E.; Levinson, A. H.; Johnson, R. M., Modes of Marijuana Consumption Among Colorado High School Students Before and After the Initiation of Retail Marijuana Sales for Adults. J. of Stud. Alcohol Drugs 2019, 80 (1), 46-55.

(103) Vape. https://www.merriam-webster.com/dictionary/vape\#other-words (accessed March 13).

(104) Raber, J. C.; Elzinga, S.; Kaplan, C., Understanding dabs: contamination concerns of cannabis concentrates and cannabinoid transfer during the act of dabbing. J. Toxicol. Sci. 2015, 40 (6), 797-803.

(105) Loflin, M.; Earleywine, M., A new method of cannabis ingestion: the dangers of dabs? Addict. Behav. 2014, 39 (10), 1430-3.

(106) Hädener, M.; Vieten, S.; Weinmann, W.; Mahler, H., A preliminary investigation of lung availability of cannabinoids by smoking marijuana or dabbing BHO and decarboxylation rate of THC- and CBD-acids. Forensic Sci. Int. 2019, 295, 207-12. 
(107) Turner, C.; ElSohly, M. A., Constituents of Cannabis sativa L. XVI. A possible Decomposition Pathway of $\Delta^{9}$-Tetrahydrocannabinol to Cannabinol. J. Heterocyclic Chem. 1979, 16, 1667.

(108) Carbone, M.; Castelluccio, F.; Daniele, A.; Sutton, A.; Ligresti, A.; Di Marzo, V.; Gavagnin, M., Chemical characterisation of oxidative degradation products of $\Delta^{9}$-THC. Tetrahedron 2010, 66 (49), 9497-501.

(109) Perrotin-Brunel, H.; Buijs, W.; van Spronsen, J.; van Roosmalen, M. J. E.; Peters, C. J.; Verpoorte, R.; Witkamp, G. J., Decarboxylation of $\Delta^{9}$-tetrahydrocannabinol: Kinetics and molecular modeling. J. Mol. Struct. 2011, 987 (1), 67-73.

(110) Repka, M. A.; ElSohly, M. A.; Munjal, M.; Ross, S. A., Temperature stability and bioadhesive properties of $\Delta^{9}$-tetrahydrocannabinol incorporated hydroxypropylcellulose polymer matrix systems. Drug Dev. Ind. Pharm. 2006, 32 (1), 21-32.

(111) Fairbairn, J. W.; Liebmann, J. A.; Rowan, D. D., The stability of cannabis and its preparations on storage. J. Pharm. Pharmac. 1976, 28 (1), 1-7.

(112) Zamengo, L.; Bettin, C.; Badocco, D.; Di Marco, V.; Miolo, G.; Frison, G., The role of time and storage conditions on the composition of hashish and marijuana samples: A four-year study. Forensic Sci. Int. 2019, 298, 131-7.

(113) Tjeerdema, R. S., The pyrolysis of cannabinoids. Rev. Environ. Contam. Toxicol. 1987, 99, 61-81.

(114) Mikeš, F.; Waser, P. G., Effects of smoking on $\Delta^{9}$-tetrahydrocannabinol and cannabidiol. Science, New Series 1971, 172 (3988), 1158-9.

(115) Wachtel, S. R.; ElSohly, M. A.; Ross, S. A.; Ambre, J.; de Wit, H., Comparison of the subjective effects of $\Delta^{9}$-tetrahydrocannabinol and marijuana in humans. Psychopharmacology (Berl) 2002, 161 (4), 331-9. 
(116) Adams, R.; Cain, C. K.; McPhee, W. D.; Wearn, R. B., Structure of Cannabidiol. XII. Isomerization to Tetrahydrocannabinols. J. Am. Chem. Soc. 1941, 63 (8), 2209-13.

(117) Appendino, G., The early history of cannabinoid research. Rendiconti Lincei. Scienze Fisiche e Naturali 2020, 31 (4), 919-29.

(118) Quarles, W., Toxicology of marijuana: conditions for conversion of cannabidiol to THC upon smoking. Clin. Toxicol. 1973, 6 (2), 211-6.

(119) Kuppers, F. J. E. M.; Bercht, C. A. L.; Salemink, C. A.; Lousberg, R. J. J. C.; Terlouw, J. K.; Heerma, W., Cannabis - XV: Pyrolysis of cannabidiol. Structure elucidation of four pyrolytic products. Tetrahedron 1975, 31 (13-14), 1513-6.

(120) Kuppers, F. J. E. M.; Lousberg, R. J. J. C.; Bercht, C. A. L.; Salemink, C. A.; Terlouw, J. K.; Heerma, W.; Laven, A., Cannabis VIII - pyrolysis of Cannabidiol. Structure Elucidation of the Main Pyrolytic Product. Tetrahedron 1973, 29, 2797802.

(121) Spronck, H. J. W.; Salemink, C. A.; Alikaridis, F.; Papakadis, D., Pyrolysis of cannabinoids: a model experiment in the study of cannabis smoking. Bulletin on Narcotics 1978, 30 (3), 55-9.

(122) Stinchcomb, A. L.; Valiveti, S.; Hammell, D. C.; Ramsey, D. R., Human skin permeation of $\Delta^{8}$-tetrahydrocannabinol, cannabidiol and cannabinol. J. Pharm. Pharmacol. 2004, 56 (3), 291-7.

(123) Perrotin-Brunel, H.; Kroon, M. C.; van Roosmalen, M. J. E.; van Spronsen, J.; Peters, C. J.; Witkamp, G. J., Solubility of non-psychoactive cannabinoids in supercritical carbon dioxide and comparison with psychoactive cannabinoids. J. Supercrit. Fluids 2010, 55, 603-8. 
(124) Kuppers, F. J. E. M.; Bercht, C. A. L.; Salemink, C. A.; Lousberg, R. J. J. C.; Terlouw, J. K.; Heerma, W., Cannabis : XIV. Pyrolysis of cannabidiol-analysis of the volatile constituents. J. Chromatogr. 1975, 108 (2), 375-9.

(125) Luteyn, J. M.; Spronck, H. J. W.; Salemink, C. A., Cannabis XVIII: Isolation and synthesis of olivetol derivatives formed in the pyrolysis of cannabidiol Recl. Trav. Chim. Pays-Bas. 1978, 97 (7-8), 187-90.

(126) Spronck, H. J.; Lousberg, R. J., Pyrolysis of cannabidiol. Structure elucidation of a major pyrolytic conversion product. Experientia 1977, 33 (6), 705-6.

(127) Spronck, H. J. W.; Salemink, C. A., Cannabis XVII: Pyrolysis of cannabidiol. Structure elucidation of two pyrolytic conversion products. Recl. Trav. Chim. PaysBas. 1978, 97 (7-8), 185-6.

(128) Behr, A.; Johnen, L., Myrcene as a natural base chemical in sustainable chemistry: a critical review. ChemSusChem 2009, 2 (12), 1072-95.

(129) Ruzicka, L.; Stoll, M., Höhere. Terpenverbindungen XVIII. Über die Konstitution des Cadinens. Helv. Chim. Acta 1924, 7 (1), 84-94.

(130) Goldblatt, L. A.; Palkin, S. Process for converting nopinene to myrcene. US2420131A. 1947.

(131) Al Bakain, R. Z.; Al-Degs, Y. S.; Cizdziel, J. V.; Elsohly, M. A., Comprehensive chromatographic profiling of cannabis from 23 USA States marketed for medical purposes. Acta Chromatogr. 2020, 33 (1), 78-90.

(132) Leyva-Gutierrez, F. M. A.; Munafo, J. P., Jr.; Wang, T., Characterization of By-Products from Commercial Cannabidiol Production. J. Agric. Food Chem. 2020, 68 (29), 7648-59.

(133) Milay, L.; Berman, P.; Shapira, A.; Guberman, O.; Meiri, D., Metabolic Profil- 
ing of Cannabis Secondary Metabolites for Evaluation of Optimal Postharvest Storage Conditions. Front. Plant Sci. 2020, 11, 583605.

(134) Bueno, J.; Leuer, E.; Kearney, M., Jr.; Green, E. H.; Greenbaum, E. A., The preservation and augmentation of volatile terpenes in cannabis inflorescence. $J$. Cannabis Res. 2020, 2, 27.

(135) Krill, C.; Rochfort, S.; Spangenberg, G., A. High-Throughput Method for the Comprehensive Analysis of Terpenes and Terpenoids in Medicinal Cannabis Biomass. Metabolites 2020, 10 (7), 276.

(136) Mazian, B.; Cariou, S.; Chaignaud, M.; Fanlo, J. L.; Fauconnier, M. L.; Bergeret, A.; Malhautier, L., Evolution of temporal dynamic of volatile organic compounds (VOCs) and odors of hemp stem during field retting. Planta 2019, 250 (6), 1983-96. (137) Kwasnica, A.; Pachura, N.; Masztalerz, K.; Figiel, A.; Zimmer, A.; Kupczynski, R.; Wujcikowska, K.; Carbonell-Barrachina, A. A.; Szumny, A.; Rozanski, H., Volatile Composition and Sensory Properties as Quality Attributes of Fresh and Dried Hemp Flowers (Cannabis sativa L.). Foods 2020, 9 (8), 1118.

(138) Prodrom, I. Untersuchungen über Autoxydation und über Umwandlung verschiedener Terpene in Isopren. Swiss Federal Institute of Technology in Zürich, Zürich, 1913.

(139) Davis, B. L.; Goldblatt, L. A.; Palkin, S., Production of Isoprene from Turpentine Derivatives. Ind. Eng. Chem 1946, 38 (1), 53-7.

(140) Isoprene Market - Growth, Trends, and Forecast (2020 - 2025). https://www. researchandmarkets.com/reports/4774896/isoprene-market-growth-trends-andforecast?utm_source $=$ BW\&utm_medium $=$ PressRelease\&utm_code $=7 \mathrm{~d} 4 \mathrm{f} 62 \& u t m$ _ campaign $=1274971+-+$ Global + Isoprene + Market + Outlook $+2019-2024+$ with + Chevron 
+ Phillips + Chemical + Company $\% 2 \mathrm{c}+$ China + Petrochemical + Corporation $\% 2 \mathrm{c}+$ Dow DuPont $\% 2 \mathrm{c}+$ and + Kuraray + Co + Dominating\&utm_exec=joca220prd (accessed March 23).

(141) Kolicheski, M. B.; Cocco, L. C.; Mitchell, D. A.; Kaminske, M., Synthesis of myrcene by pyrolisis of $\beta$-pinene: Analysis of decomposition reactions. J. Anal. Appl. Pyrolisis 2007, 80, 92-100.

(142) Stolle, A.; Ondruschka, B., Comment to the paper "Synthesis of myrcene by pyrolysis of $\beta$-pinene: Analysis of decomposition reactions" by M.B. Kolicheski et al. [J. Anal. Appl. Pyrol. 80 (2007) 92-100]. J. Anal. Appl. Pyrol. 2008, 81 (1), 136-8. (143) Zheng, H.; Chen, J.; Li, C.; Chen, J.; Wang, Y.; Zhao, S.; Zeng, Y., Mechanism and kinetics of the pyrolysis of $\beta$-pinene to myrcene. J. Anal. Appl. Pyrol. 2017, 123, 99-106.

(144) Meehan-Atrash, J.; Strongin, R. M., Pine rosin identified as a toxic cannabis extract adulterant. Forensic Sci. Int. 2020, 312, 110301. 


\title{
2 Pine rosin identified as a toxic cannabis extract adulterant
}

\author{
Jiries Meehan-Atrash and Robert M. Strongin* \\ Department of Chemistry, Portland State University, Portland, OR, 97207-0751, \\ United States
}

This manuscript has been published and is adapted from:

Meehan-Atrash, J.; Strongin, R. M., Pine rosin identified as a toxic cannabis extract adulterant. Forensic Sci. Int. 2020, 312, 110301.

DOI: $10.1016 /$ j.forsciint. 2020.110301

Published by Elsevier B.V.

Article history:

Received: January 9, 2020

Received: in revised form: April 9, 2020

Accepted: April 17, 2020

Available online: April 22, 2020 


\subsection{Abstract}

Pine rosin (colophony) has been identified as a potentially new adulterant in cannabis oil. Its inhalation toxicity poses a significant health concern to users. For example, pine rosin fumes are released during soldering, and have been cited as a causative agent of occupational asthma. Symptoms also include desquamation of bronchial epithelium, which has also been observed in e-cigarette or vaping product used-associated lung injury (EVALI) patients. The sample analyzed herein was acquired from a cannabis industry source, also contains medium chain triglycerides and oleamide, the latter of which is a hypnotic that is commonly found in the synthetic marijuana product Spice, or K2. A combination of proton nuclear magnetic resonance $\left({ }^{1} \mathrm{H}\right.$ NMR $)$ and high pressure liquid chromatography-electrospray ionization mass spectrometry (HPLC-ESIMS) was used to unambiguously identify major pine rosin ingredients such as abietic and other resin acids. Comparison to commercial samples of pure pine rosin confirmed the assignment.

Keywords: Cannabis e-cigarette, BHO, Marijuana, EVALI, Rosin, Pine rosin, Adulterant, Cutting agent 


\subsection{Introduction}

Since the legalization of medical marijuana in California in 1996, and the legalization of recreational marijuana in Colorado in 2012, 33 states and the District of Colombia have medical cannabis programs, and 10 states and the District of Colombia have fully legalized recreational use as of 2020 [1]. Canada first enacted medical marijuana laws in 2001, and now has recreational cannabis as of 2018 [2]. With the passage of more lax laws, cannabis extracts (CEs) have surged in popularity as alternative products to cannabis flower, with expenditures on CEs in the legal Washington state cannabis market increasing $145 \%$ between 2014 and 2016 [3]. CEs are consumed by inhalation using modified e- cigarettes or via dabbing [4], and increased usage of these among teens and young adults [5] has led to concerns of safety, as up to $11 \%$ of high schooler students [6] report lifetime use of a cannabis vaporizer.

CEs may be consumed via inhalation by three main methods/ devices: cartridge vaporizers (CVs), top-loading vaporizers (TLVs), and dabbing [4]. In dabbing, a small amount of $\mathrm{CE}$ is placed on a hot surface (i.e. a "nail," which may be heated with a blow torch or electrically) that is connected to a water pipe [4,7]. A TLV is an electronic vaporizer device that consists of a battery-powered resistive heating coil in

an atomizer, upon which a user manually places small amounts of CE [4]. Disposable $\mathrm{CV}$ devices closely mimic nicotine e-cigarettes, and have surged in popularity given their ease of use and discretion, with sales of these increasing more than 10-fold to \$224 million in Colorado as of 2018 [8].

The cannabis concentrate hashish, commonly consumed in Europe from illicit manufacturers in North Africa, has an extensive history of containing adulterants [9]. 
A recent analysis of hashish in Madrid found that $18 \%$ suffers from contamination with glucose, sucrose, and/or abietic acid (a principal component of pine rosin) [10]. Pine rosin has also been identified as a hashish adulterant in Italy [11], Israel, and the Czeck Republic [12].

CEs available in North America are generally manufactured via solvent extraction (most commonly with butane, though propane or supercritical $\mathrm{CO}_{2}$ have widespread usage) followed by several refinement steps. Butane hash oil (BHO), propane hash oil (PHO) and $\mathrm{CO}_{2}$ oil may all adopt one of several names depending on consistency: shatter, wax, crumble, budder, or pull-n-snap [7]. Recently, applied heat and pressure has been used to press cannabis oils from flower to make a product known as rosin [13]. Despite the similarity in naming, cannabis rosin and pine rosin share few chemical similarities [13].

Cases of adulteration in North American cannabis products have only recently come into view. The synthetic cannabinoid 5-MDMB-PINACA and the antitussive dextromethorphan have been identified in certain commercially available cannabidiol e-liquids for CV devices [14]. Online reports on Reddit.com and cannabis websites have become grounds where users have aired complaints of $\mathrm{BHO}$ adulterated with pine rosin, and have cited specific brands and products as bad actors [15-17]. The timing of these forum posts about pine rosin being used as an adulterant for CEs, or as counterfeit $\mathrm{BHO}$, coincide with the EVALI outbreak. Additionally, several recent patents mention methyl ester of rosin, a pine rosin derivative, as a potential additive to cannabis vaporizers $[18-20]$.

CEs added to CV devices often require fluidizing agents to ensure better wicking efficiency in the atomizer of a vape pen, given the high viscosity of cannabis 
extracts [4]. Substances such as terpenes, medium chain triglyceride (MCT) oil, and phytol, among others are commonly used [21]. One CE additive to CV devices, vitamin E acetate (VEA), has been linked with the recent outbreak of e-cigarette, or vaping, product use associated lung injury (EVALI) [22]. It's use as a thickening agent has been suggested, however, the markedly lower viscosity of VEA relative to $\Delta^{9}$-tetrahydrocannabinol (THC), indicates that the former is used to dilute CEs, and that a different additive is the thickening agent, which is introduced to give the appearance of unadulterated CE. Herein is the first report of an adulterant containing pine rosin (a.k.a. rosin colophony or pine resin) for cannabis CV devices. The adulterant was acquired from a formulations consultant that works in the cannabis vaporizer formulations space, which itself acquired the adulterant from cannabis $\mathrm{CV}$ device manufacturer.

\subsection{Materials and methods}

Two adulterants were donated by Vialpando LLC. Initial analysis by nuclear magnetic resonance spectroscopy (NMR) identified one of them to be pure VEA, while the other (Fig. 2.1, dubbed cannabis extra adulterant [CEA]) required further analysis for identification. The CEA was initially assayed by GC-MS, which first suggested the presence of substituted abietanes and pimaranes. Analysis of the NMR spectrum showed peaks in the alkenyl region that are known to be characteristic of the resin acids in question [23], and the characteristic glycolic methylene peaks from a triglyceride (Fig. 7.1). 2D NMR techniques COSY and NOESY aided the confirmation of the identity of different isomeric resin acids, as well as the identification of communic acid, which was aided by semi-preparative HPLC. An HPLC-ESIMS chromatogram 
of CEA provided confirmation of the abietane and pimarane molecules and oleamide (Fig. 7.2). Oleamide is not directly visible in the NMR spectrum of CEA, but the amide $\mathrm{N}-\mathrm{H}$ protons are visible in the semi-preparative HPLC fraction that contains it when this is dissolved in DMSO- $d_{6}$ (Cambridge Isotope Laboratories), which was spiked with a pure standard of oleamide (TCI America) to confirmed its presence (Fig. 7.3). Commercially available medium chain triglyceride (MCT) oil (Nature's Way) was spiked in a CEA NMR sample (Fig. 7.4). An approximate \%mass of each identified component was determined by quantitative NMR (Q-NMR) [24]. See the supplementary appendix for further experimental details.

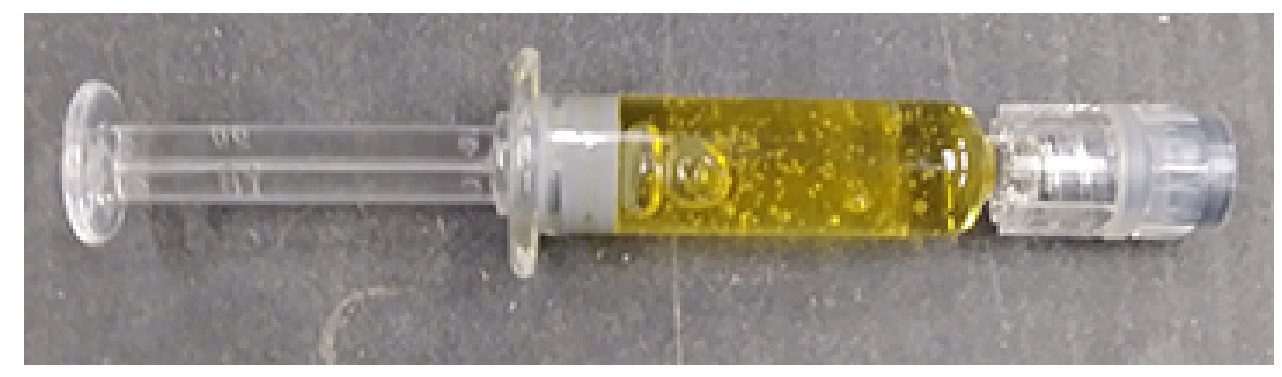

Figure 2.1: Cannabis extract thickener provided in a glass syringe.

\subsection{Results and discussion}

The analytical methods used discovered that the unknown CEA contains resin acids consistent with pine rosin (68\%), MCT oil (15\%), and small amounts of oleamide (Table 2.1). An overlay of a commercially available sample of gum rosin (Sigma Aldrich) and CEA demonstrates the similarity of these two substances (Fig. 2.2), with the major visible difference being the presence of the triglyceride peaks from MCT oil in the CEA. Rosin, a solid at room temperature, appears to have been amended with MCT oil to thin its consistency to allow extrusion from a syringe, making its 
final appearance very similar to pure THC or clarified cannabis extract. For the purposes of this study, only approximate quantification was necessary to determine the composition of the sample. Given that this adulterant is destined for use in cannabis e-cigarettes, it is unknown how the final matrix will affect identification and quantification of resin acids in a black market sample. The analytical methods presented herein may serve as a guide for identifying resin acids in a cannabis sample, but a more comprehensive quantitative method will need to be developed for cannabis extracts adulterated with pine rosin and/or oleamide. 


\begin{tabular}{|c|c|c|c|c|c|}
\hline Common name & CAS Number & $\begin{array}{l}\mathrm{RT} \text { in } \mathrm{LC} / \mathrm{MS} \\
(\mathrm{min})\end{array}$ & $\begin{array}{l}\text { NMR } \\
\text { Shift } \\
\text { (ppm) }\end{array}$ & $\begin{array}{l}\text { Mass } \\
\text { Accuracy } \\
\text { (ppm) }\end{array}$ & $\%$ in Sample \\
\hline Dehydroabietic acid & $1740-19-8$ & 16.5 & 6.88 & 0.03 & 3 \\
\hline Communic acid & $2761-77-5$ & 21.8 & 6.32 & 0.03 & 4 \\
\hline Pimarol & $1686-59-5$ & 23.9 & NA & 0.52 & NA \\
\hline Pimaric acid & $127-27-5$ & 23.9 & 5.71 & 1.25 & 3.2 \\
\hline Sandaracopimaric acid & $471-74-9$ & 23.9 & 5.22 & 1.25 & 1.5 \\
\hline Palustric acid & $1945-53-5$ & 23.9 & 5.39 & 1.25 & 14 \\
\hline Abietic acid & $514-10-3$ & 25.1 & 5.77 & 1.25 & 17 \\
\hline Oleamide & $301-02-0$ & 25.1 & $6.65-7.19$ & 0.64 & NA \\
\hline Neoabietic acid & $471-77-2$ & 25.1 & 6.2 & 1.25 & 12 \\
\hline Isopimaric acid & $5835-26-7$ & 25.1 & 5.81 & 1.25 & 13 \\
\hline Sandaracopimarinal & $3855-14-9$ & 30.3 & 5.22 & 0 & NA \\
\hline MCT oil & $438544-49-1$ & NA & 4.3 & NA & 15 \\
\hline
\end{tabular}

Table 2.1: Components identified in CEA by nuclear magnetic resonance (NMR) spectroscopy and HPLC-ESIMS, and approximate \% masses in the sample were determined by Q-NMR.

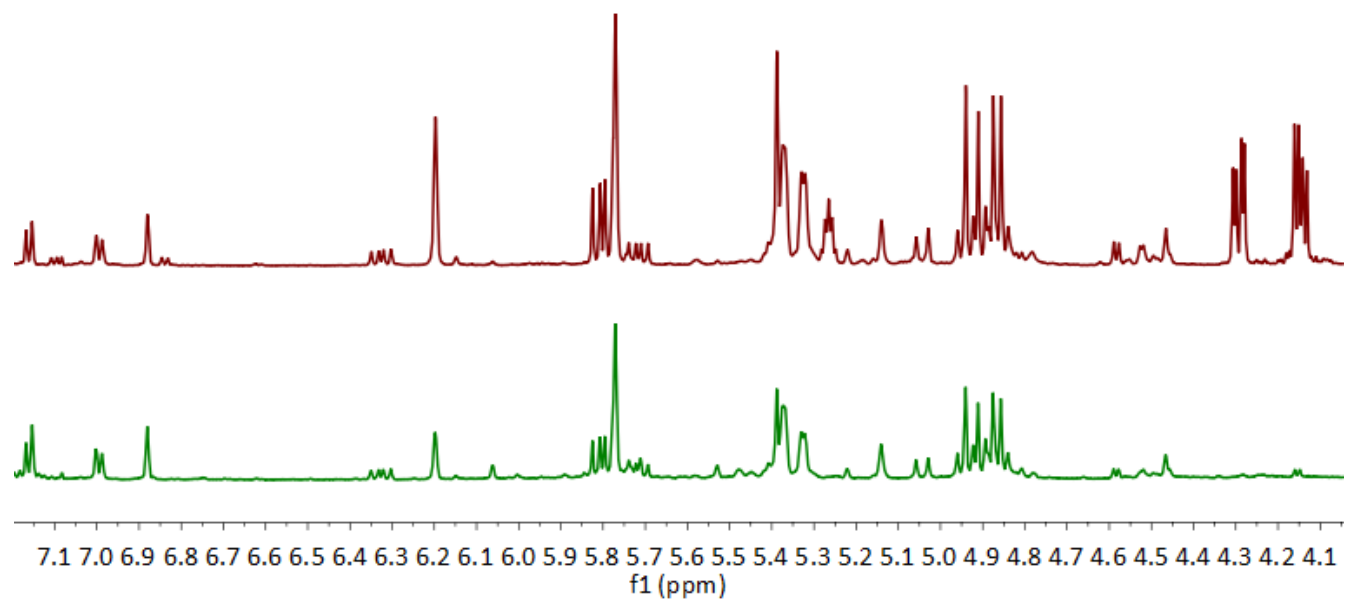

Figure 2.2: Overlaid ${ }^{1} \mathrm{H}$ NMR spectra of CEA (top, maroon) and commerciallyavailable gum rosin (bottom, green) from Sigma Aldrich (CAS no. 8050-09-7).

Rosin is a known respiratory tract irritant and a significant contributor to occupational asthma due to its use in soldering [25]. Occupational exposure to pine rosin vapor from solder flux at levels of $50 \mathrm{\mu g} / \mathrm{m}^{3}$, the 8-h Time Weighted Average (TWA) exposure limit, has not been known to produce sever acute lung injuries [25]. However, CEA added to CE at a level of just $1 \%$ will produce nearly $0.6 \mathrm{~g} / \mathrm{m}^{3}$ of pine rosin in the aerosol from a cannabis vaporizer pen with each puff, or 3500 times the 15-min TWA exposure limit [25]. In vivo exposure of abietic acid to rat lungs 
produced desquamation of bronchial epithelium [26], which has also been reported in EVALI cases [27]. We are unaware of efforts to date to test for pine rosin compounds in samples from patients with vaping-induced lung injuries. Oleamide appears to have been added to increase the psychoactivity of resulting adulterated $\mathrm{CE}$, as this compound is a cannabinoid receptor agonist and sleep-inducing agent [28]. Interestingly, oleamide is a common additive to synthetic cannabinoid "Spice" mixtures [29]. It is unknown what, if any, are the health effects of inhaling oleamide. Oleamide is also mentioned as a potential additive to vaping formulations in a patent registered to a cannabis vaporizer formulations company [30].

\subsection{Conclusion}

The use of pine rosin as an adulterant in cannabis oil has not been previously reported in the scientific literature. It is available through online vendors, typically used as an ingredient in industrial products such as varnishes, adhesives, soldering fluxes and sealing wax. It has significant inhalation toxicity. To date, there are no reports of testing for this substance in cannabis oil samples from patients with lung injury. Due to the significant toxicity and prevalence based on social media posts, regulators and laboratory personnel should be aware of its use in adulterated cannabis oil.

\subsection{CRediT authorship contribution statement}

Jiries Meehan-Atrash: Conceptualization, Methodology, Validation, Formal analysis, Investigation, Writing - original draft, Visualization, Project administration.

Robert M. Strongin: Conceptualization, Methodology, Validation, Resources, Writ- 
ing - review \& editing, Supervision, Funding acquisition.

\subsection{Acknowledgements}

We thank the NIH and the FDA for their support via award R01ES025257. Content is solely the responsibility of the authors and does not necessarily represent the views of the NIH or the FDA. We would like to acknowledge NSF grant \#0741993 for the HPLC-ESIMS data collection. We would like to thank the laboratory of Dr. James Pankow for assistance with acquiring GCMS data.

\subsection{References}

(1) State Info, (2020) https://norml.org/states (Accessed 8 January 2020).

(2) Cannabis Laws and Regulations, (2020) https://www.canada.ca/en/health- canada /services/drugs-medication/cannabis/laws-regulations.html (Accessed 8 January 2020). (3) R. Smart, J.P. Caulkins, B. Kilmer, S. Davenport, G. Midgette, Variation in cannabis potency and prices in a newly legal market: evidence from 30 million cannabis sales in Washington state, Addiction 112 (12) (2017) 2167-2177, doi:http:// dx.doi.org/10.1111/add.13886.

(4) J. Meehan-Atrash, W. Luo, K.J. McWhirter, R.M. Strongin, Aerosol gas-phase components from cannabis e-cigarettes and dabbing: mechanistic insight and quantitative risk analysis, ACS Omega 4 (14) (2019) 16111-16120, doi:http://dx.doi.org/ 10.1021/acsomega.9b02301.

(5) A.A. Knapp, D.C. Lee, J.T. Borodovsky, S.G. Auty, J. Gabrielli, A.J. Budney, Emerging trends in cannabis administration among adolescent cannabis users, J. Ado- 
lesc. Health 64 (2019) 487-493.

(6) M.E. Morean, G. Kong, D.R. Camenga, D.A. Cavallo, S. Krishnan-Sarin, High school students' use of electronic cigarettes to vaporize cannabis, Pediatrics 136 (4) (2015) 611-616, doi:http://dx.doi.org/10.1542/peds.2015-1727.

(7) J. Meehan-Atrash, W. Luo, R.M. Strongin, Toxicant formation in dabbing: the terpene story, ACS Omega 2 (2017) 6112-6117, doi:http://dx.doi.org/10.1021/ acsomega.7b01130.

(8) Cannabis Vaping: Opportunities in an Uncertain future, Executive Summary, Arcview Market Research in Partnership with BDS Analytics, (2019). bdsanalytics.com. (9) P.A. Chouvy, The Supply of Hashish to Europe, European Monitoring Center for Drugs and Drug Addiction, Lisbon, Portugal, 2015.

(10) M. Perez-Moreno, P. Perez-Lloret, J. Gonzalez-Soriano, I. Santos-Alvarez, Cannabis resin in the region of Madrid: adulteration and contamination, Forensic Sci. Int. 298 (2019) 34-38, doi:http://dx.doi.org/10.1016/j.for- sciint.2019.02.049.

(11) A. Caligiani, G. Palla, B. Bernardelli, GC-MS analysis of hashish samples: a case of adulteration with colophony, J. Forensic Sci. 51 (5) (2006) 1096-1100, doi:http://dx.doi.org/10.1111/j.1556-4029.2006.00202.x.

(12) L.O. Hanuš, D. De La Vega, M. Roman, P. Tomíček, False hashish without cannabis resin, Isr. J. Plant Sci. 62 (4) (2015) 277-282 doi:http://dx.doi.org/10.1080/ 07929978.2015 .1053202 .

(13) F.R. Lamy, R. Daniulaitye, M. Zathred, R.W. Nahhas, A. Sheth, S.S. Martins, E.W. Boyer, R.G. Carlson, "You got to love rosin: solventless dabs, pure, clean, natural medicine." Exploring Twitter data on emerging trends in Rosin Tech marijuana concentrates, Drug Alcohol Depend. 183 (2018) 248-252, doi:http://dx.doi.org/ 
10.1016/j.drugalcdep.2017.10.039.

(14) J.L. Poklis, H.A. Mulder, M.R. Peace, The unexpected identification of the cannabimimetic, 5F-ADB, and dextromethorphan in commercially available cannabidiol e-liquids, Forensic Sci. Int. 294 (2019) e25-e27, doi:http://dx.doi.org/10.1016/ j.forsciint.2018.10.019.

(15) Fake Shatter - Pine Resin Cut Hit Canada? (2019) https://future4200.com/t/ fake-shatter-pine-resin-cut-hit-canada/44648 (Accessed 29 November 2019). (16) The Dabs of Death Aka Pine Resin, (2019) https://www.reddit.com/r/Canadian MOMs/comments/dd9frt/the_dabs_of_death_aka_pine_resin_aka_that_shit/ (Accessed 29 November 2019).

(17) Pine Resin and Vitamin E Acetate Scare, (2019) https://www.reddit.com/r/ CanadianMOMs/comments/df3n2k/pine_resin_and_vitamin_e_acetate_scare/ (Accessed 29 November 2019).

(18) J.D. Cameron, Natural-Based Liquid Composition and Electronic Vaporizing Devices for Using Such Composition, LunaTech, LLC, USA, 2017.

(19) J.D. Cameron, Water-Based Vaporizable Liquids, Methods and Systems for Vaporizing Same, Lunatch, LLC, United States, 2017.

(20) J.D. Cameron, D. Becker, G. Fein, Liquid Composition Containing Nicotine From Non-Tobacco Source for Use With Electronic Vaporizing Devices, Lunatech, LLC, United States, 2017.

(21) B.E. Erickson, Cannabis industry gets crafty with terpenes, Chemical and Engineering News, American Chemical Society, 2019. cen.acs.org. (22) CDC, Outbreak of Lung Injury Associated With the Use of E-Cigarette, or Vaping, Products, (2019) https://www.cdc.gov/tobacco/basic_information/ 
e-cigarettes/severe-lung-disease.html (Accessed 27 November 2019).

(23) K. Ioannidis, E. Melliou, P. Magiatis, High-throughput (1)H-nuclear magnetic resonance-based screening for the identification and quantification of heartwood diterpenic acids in four black pine (Pinus nigra Arn.) marginal provenances in Greece, Molecules 24 (19) (2019), doi:http://dx.doi.org/ 10.3390/molecules24193603.

(24) S.K. Bharti, R. Roy, Quantitative 1H NMR spectroscopy, TrAC Trends Anal. Chem. 35 (2012) 5-26, doi:http://dx.doi.org/10.1016/j.trac.2012.02.007.

(25) P.E.J. Baldwin, J.R. Cain, R. Fletcher, K. Jones, N. Warren, Dehydroabietic acid as a biomarker for exposure to colophony, Occup. Med. 57 (2007) 362-366.

(26) G.H. Ayars, L.C. Altman, C.E. Frazier, E.Y. Chi, The toxicity of constituents of cedar and pine woods to pulmonary epithelium, J. Allergy Clin. Immunol. 83 (3) (1989) 610-618.

(27) Y.M. Butt, M.L. Smith, H.D. Tazelaar, T.V. Laslo, K.L. Swanson, M.J. Cecchini, J.M. Boland, M.C. Bois, J.H. Boyum, A.T. Froemming, A. Khoor, I. Mira-Avendano, A. Patel, B.T. Larsen, Pathology of vaping-associated lung injury, NEJM 381 (18) (2019), doi:http://dx.doi.org/10.1056/NEJMc1913069.

(28) J.D. Leggett, S. Aspley, S.R.G. Beckett, A.M. D'Antona, D.A. Kendall, D.A. Kendall, Oleamide is a selective endogenous agonist of rat and human CB1 cannabinoid receptors, Br. J. Pharmacol. 141 (2004) 253-262.

(29) L. Fattore, W. Fratta, Beyond THC: the new generation of cannabinoid designer drugs, Front. Behav. Neurosci. 5 (2011) 60, doi:http://dx.doi.org/10.3389/ fnbeh.2011.00060.

(30) S. Elzinga, J.C. Raber, Terpene-Based Compositions, Processes, Methodologies for Creation and Products Thereby, The Werc Shop LLC, 2015. 


\title{
3 Toxicant formation in dabbing: The terpene story
}

\author{
Jiries Meehan-Atrash, Wentai Luo, and Robert M. Strongin* \\ Department of Chemistry, Portland State University, Portland, OR, 97201
}

This manuscript has been published and is adapted from:

Meehan-Atrash, J.; Luo, W.; Strongin, R. M., Toxicant Formation in Dabbing: The Terpene Story. ACS Omega 2017, 2, 6112-6117.

DOI: 10.1021 /acsomega.7b01130

Published by The American Chemical Society

Article history:

Received: August 3, 2017

Accepted: September 12, 2017

Published: September 22, 2017 


\subsection{Abstract}

Inhalable, noncombustible cannabis products are playing a central role in the expansion of the medical and recreational use of cannabis. In particular, the practice of "dabbing" with butane hash oil has emerged with great popularity in states that have legalized cannabis. Despite their growing popularity, the degradation product profiles of these new products have not been extensively investigated. The study herein focuses on the chemistry of myrcene and other common terpenes found in cannabis extracts. Methacrolein, benzene, and several other products of concern to human health were formed under the conditions that simulated real-world dabbing. The terpene degradation products observed are consistent with those reported in the atmospheric chemistry literature. 


\subsection{Introduction}

Terpenes and terpenoids are present in such a wide diversity of environments (nature, food, cosmetics, pharmaceuticals, and drugs) that their consequences for inhalation toxicology cannot be ignored. Additionally, their inclusion in flavored electronic cigarettes $^{1}$ and ubiquitous presence in inhalable cannabis products are of particular concern. The medicinal and psychoactive effects of cannabis have been proposed to be enhanced by terpenes, a phenomenon known as the "entourage effect", ${ }^{2}$ and these relatively unsubstantiated assertions of benefits have led the cannabis industry to place a heavy emphasis on these aroma compounds.

Terpenoid degradation in the context of cannabis has not been extensively studied; ${ }^{3,4}$ however, it has attracted attention in the context of atmospheric chemistry. ${ }^{5,6}$ For instance, the reactions of terpenoids with $\mathrm{O}_{3}$ and $\mathrm{NOx}$ are well-known, but they are not directly applicable to e-cigarettes or inhalable cannabis products. However, these and other studies of pyrolysis and combustion of terpenoids should serve as a starting point toward understanding the reaction pathways in consumer vaporization devices. Despite the growing popularity of flavored e-cigarettes and terpene-enriched cannabis extracts, the chemical profiles of their terpene degradation products have not been evaluated in detail.

Of very recent concern is the practice of dabbing, which has emerged as a dangerous and rapidly growing trend in cannabis consumption. It consists of inhaling the vapors produced by placing a small amount of cannabis extract (a "dab") on a small heated surface (the "nail"), which is connected to a water pipe. ${ }^{7}$ Its delivery of harmfully large amounts cannabinoids ${ }^{8,9}$ represents a potential danger to consumers, 
but little is known about the toxicants the process may produce.

The principal extract used in dabbing is butane hash oil ( $\mathrm{BHO})$. $\mathrm{BHO}$ is a resinous, nonpolar extract of the cannabis made using butane as a solvent. ${ }^{10} \mathrm{BHO}$ has active ingredient (tetrahydrocannabinol (THC) or cannabidiol) contents ranging between 50 and $9 \%,{ }^{8,11}$ with terpene content ranging from 0.1 to $34 \%$ (unpublished). Myrcene is unequivocally the most abundant terpene in cannabis, followed by limonene, linalool, pinene, caryophyllene, and humulene; however, the plant can contain up to 68 additional terpenic compounds in trace amounts. ${ }^{12}$ Additionally, some consumers increase the terpenoid content by dipping BHO in a vial of terpenes prior to use ("terp dipping"). ${ }^{13}$

$\mathrm{BHO}$ is made by passing butane over cannabis buds and leaves, and subsequently "purging" the butane from the product under vacuum at room temperature or in an oven. Different nuances in its processing can lead to slightly different consistencies, which take on terms such as shatter, budder, crumble, pull-and-snap, wax, and so on. In all of its forms, the extract is a sticky, resinous substance similar to the oleo-resins of other plants. ${ }^{14}$ Because the process does not involve heating the extract to the point that delta-9-tetrahydrocannabinolic acid (THCA, the native form of this substance found in the plant) decarboxylates (unpublished) into the active THC, BHO is not orally active and must be vaporized for the users to achieve its effects. ${ }^{15}$

$\mathrm{BHO}$ production started out as a dangerous "backyard-chemist" style operation that is famous for causing numerous explosions and house fires. Through the course of legalization, the production has steadily gained sophistication. The most modern, legal extraction laboratories live up to the OSHA standards with full ventilation and butane recovery. Modern techniques also include steps to "de-wax" the product by 
dissolving the crude $\mathrm{BHO}$ in isopropyl alcohol and chilling in a freezer, and, finally, filtering off the precipitated waxes in a process known as winterization. Many subtleties in its production exist, but many remain secretive due to the highly competitive nature of the cannabis marketplace and the general inability of extract producers to file patents due to the drug's legal status at the federal level.

In addition to butane extraction, supercritical $\mathrm{CO}_{2}$ extraction has gained traction due to the fact that is does not leave any trace of hydrocarbon solvents in the end product. ${ }^{16}$ The cannabis extract made by this method, colloquially known as $\mathrm{CO}_{2}$ oil, has a lesser viscosity than $\mathrm{BHO}$, a property that allows it to be used in vaporizer pens on its own with no cutting agents. The lesser viscosity is due to the fact that the supercritical extraction process requires the product to be first decarboxylated (heating in an oven at $100+{ }^{\circ} \mathrm{C}$ ), ${ }^{17}$ leaving an extract consisting of all THC (an oil at room temperature) and no THCA (a solid at room temperature). $\mathrm{CO}_{2}$ oil is generally more expensive than $\mathrm{BHO}$ and mostly present on the market in prefilled vaporizer cartridges and not commonly as a standalone extract for dabbing. Because this extraction method does not leave residual hydrocarbons, it has been named, along with alcohol extracts, as the only allowable medical extracts to be sold under the medical cannabis regulations in New York, ${ }^{18}$ Minnesota, Ohio, and Pennsylvania.

According to a recent survey, ${ }^{11}$ the main reasons for using dabs are that less material is needed to get the desired effect and a "cleaner high." Consumers consider dabbing to be a form of vaporization, and, therefore, view it as easier on the lungs than smoking. ${ }^{19}$ However, little information exists on the prevalence of dabbing. From 213 BHO extraction laboratories in the 17 states raided in 2014, 2015 saw a steep increase in the number of laboratories raided to 337 in 26 states. $^{20}$ An analysis of the 
Twitter content related to dabs found a greater popularity in the states that have legalized recreational and/or medical cannabis. ${ }^{21}$

Different types of nails, the surface on which vaporization occurs, exist on the market. Use of an electrically controlled nail ("e-nail") allows temperature control; but, more commonly, users heat the nail (made of titanium, ceramic, or quartz) with a crème brulee torch ${ }^{22}$ and have no temperature control. A minority of dabbers use lower temperatures to preserve flavor, whereas a majority use higher temperatures to assure complete vaporization with no wasted material. E-nail users posting online cite a preferred temperature around $710^{\circ} \mathrm{F}\left(378^{\circ} \mathrm{C}\right)$, but cite a range from $340-482$ ${ }^{\circ} \mathrm{C} .{ }^{23-25}$ Raber et al. reported a dabbing temperature of $300{ }^{\circ} \mathrm{C}$, but this was only an (low) estimate. The boiling point of THC has recently been predicted to be ca. $417{ }^{\circ} \mathrm{C},{ }^{26}$ but vaporization can occur at temperatures lower than this by the use of a "carb cap" that reduces pressure on its surface during inhalation. ${ }^{27}$

This study is an initial effort toward assessing the safety of dabbing cannabis extracts. Due to the fact that these consist of a complex mixture, we have begun our focus on terpenoids, the component we predict to be the most thermally labile. To study dabbing, we carefully recreated the inhalation topography and temperatures employed by users. The study described herein is the first to investigate the degradation products from dabbing and is focused on the terpene fraction of the extracts used by consumers. 


\subsection{Results and discussion}

\subsubsection{Sample generation and product identification}

We investigated the dabbing temperature ranges (TRs, Figure 3.1) inclusive of and beyond the ranges of those reported by the users. The vapor collection and analysis methods were based on those by Jensen et al. ${ }^{28}$ using an impinger filled with NMR solvent for vapor collection. In the dabbing simulation experiments herein, the vapor generated from the heated ceramic nail connected to a water pipe passed through a cold trap followed by the impinger. The impinger was, in turn, connected to a smoking machine that generated the airflow. Degradation products from myrcene, limonene, linalool, and Fire OG cannabis terpenes, a commercially available mix specifically fabricated for terp dipping, were monitored. ${ }^{11}$ The presence of methacrolein (MC) and benzene in vapor NMR samples was confirmed by spiking with authentic samples (Supporting Information). Their levels were quantified by NMR using an internal standard. 


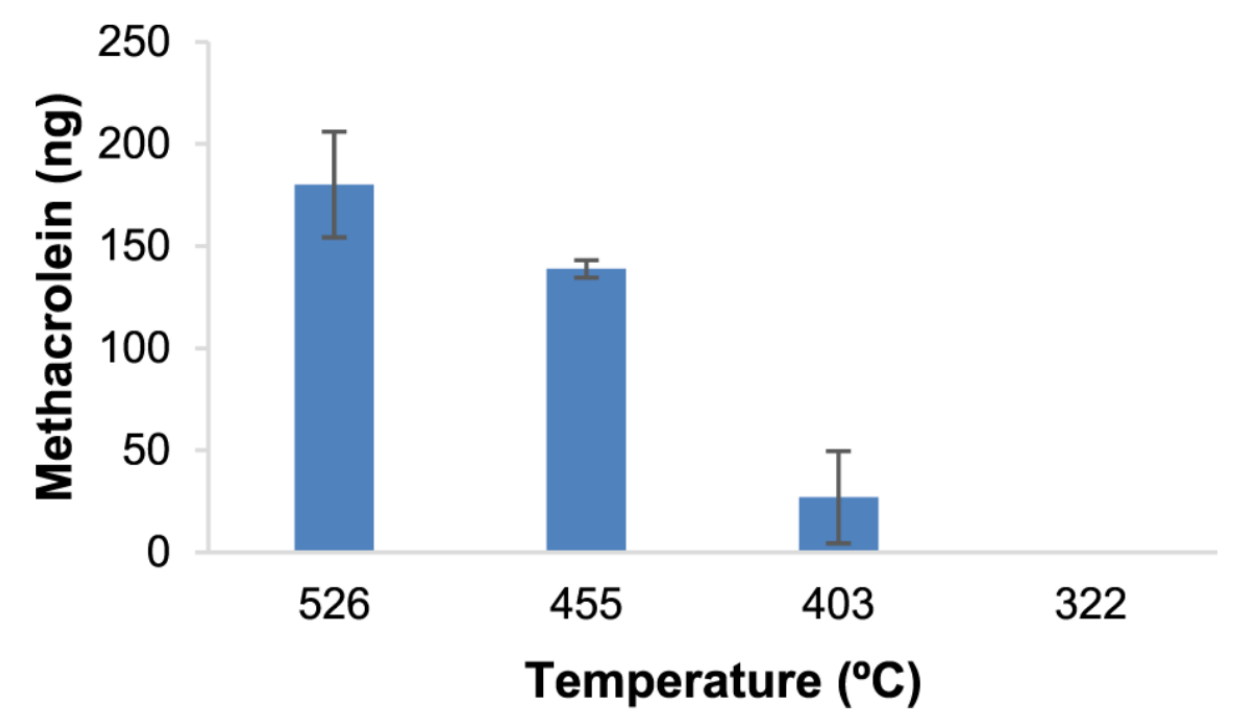

Figure 3.1: $\mathrm{MC}$ (ng) generated in a $40 \mathrm{mg}$ dab using myrcene as a model terpene assuming a $5.9 \%$ concentration of terpenes in BHO. Temperature values represent the $T_{\mathrm{m}}$ for each TR. Error bars are determined at the $95 \%$ confidence level using the standard deviation of the three replicates taken at each TR. At the lowest TR, MC was not detected by NMR.

In addition to the NMR method, the dabbing vapor was collected using an adsorption/thermal desorption (ATD) cartridge and analyzed using an automated adsorption/thermal desorption-gas chromatography-mass spectrometry (ATD- GC-MS) method similar to that in Pankow et al. ${ }^{29}$ Additional product structures (Scheme 3.1) were assigned by the GC-MS analysis. Other minor products that have been previously described in the literature ${ }^{30}$ were also tentatively identified in the chromatographs (Supporting Information). Air blanks were collected and analyzed using each of the NMR and the ATD-GC-MS methods.

Temperatures in dabbing experiments were carefully monitored for consistency using a thermographic camera. As the first drop in terpene touched the nail, an initial temperature $\left(T_{\mathrm{i}}\right)$ was recorded. Once a $10 \mathrm{~s}$ draw concluded, a final temper- 
ature $\left(T_{\mathrm{f}}\right)$ was recorded (the nail cooled between 50 and $30{ }^{\circ} \mathrm{C}$ during the draw due to convection). A median temperature $\left(T_{\mathrm{m}}\right)$ was calculated and averaged for each replicate to afford a representative $T_{\mathrm{m}}$ for each $\mathrm{TR}$.

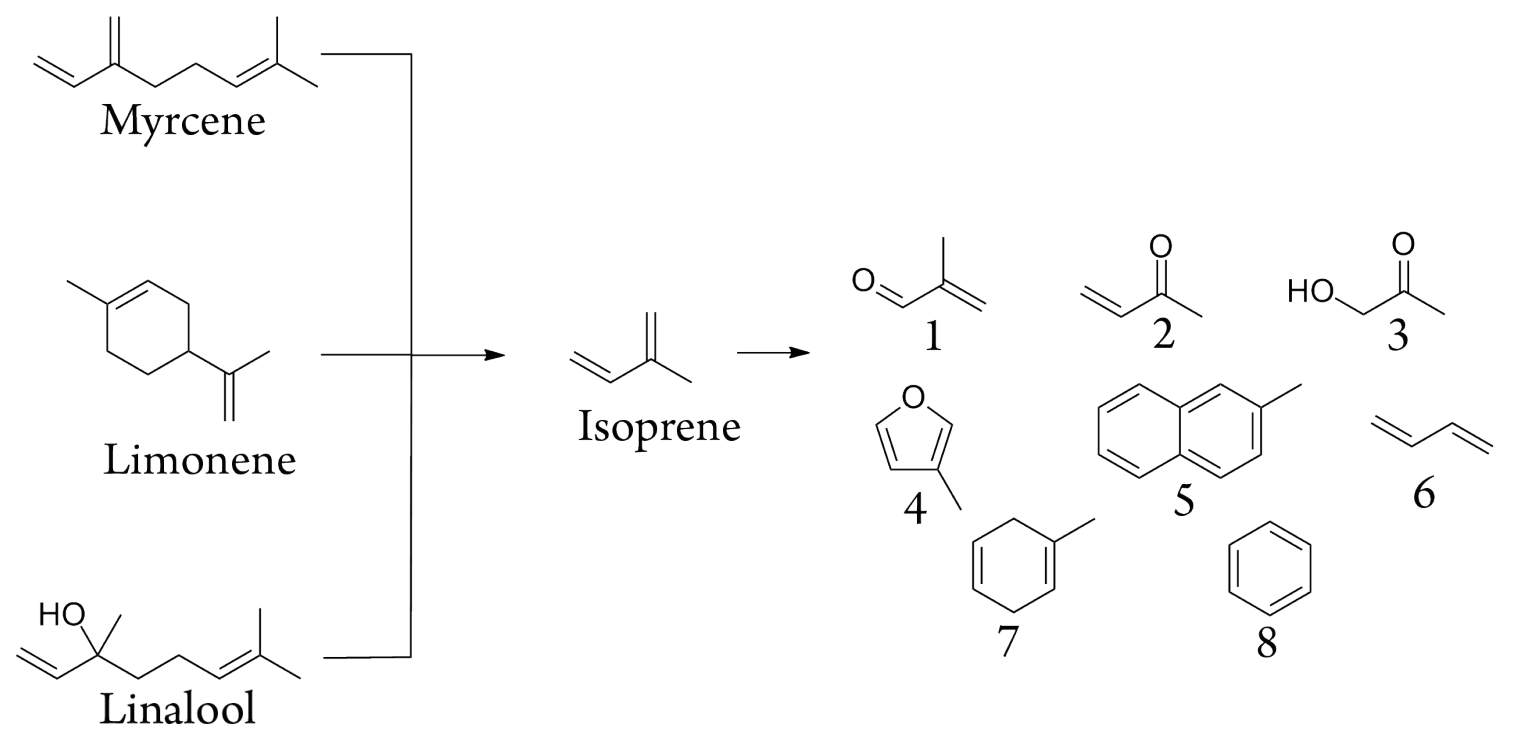

Scheme 3.1: Terpene degradation products identified via GC-MS analysis; 1, methacrolein; 2, methyl vinyl ketone; 3, hydroxyacetone; 4, 3-methylfuran; 5, 2methylnapthalene; 6, 1,3-butadiene; 7, 1-methylcyclohexa-1,4-diene; 8, benzene. These and other related products were produced from pure samples of each of limonene, linalool and myrcene.

\begin{tabular}{ccc} 
& $\mathrm{MC}(\mathrm{ng} / \mathrm{mg}$ terpene $)$ & Benzene $(\mathrm{ng} / \mathrm{mg}$ terpene $)$ \\
\hline "Fire OG" & 127 & 10 \\
Limonene & 261 & 63 \\
Linalool & 103 & $\mathrm{ND}$ \\
Myrcene & 81 & 60 \\
\hline
\end{tabular}

Table 3.1: Methacrolein (MC) and benzene levels produced per mg terpene starting material when vaporized at the highest temperature range investigated, ca. $550{ }^{\circ} \mathrm{C}$ $\left(T_{\mathrm{i}}\right)-500{ }^{\circ} \mathrm{C}\left(T_{\mathrm{f}}\right)$ using single replicate experiments

The ${ }^{1} \mathrm{H}$ NMR spectra from the dabbing samples displayed peaks characteristic of a range of organic acid, aldehyde, and aromatic products. The two products 
appearing in high abundance in the spectra were the toxins benzene and MC (Scheme 3.1, Table 3.1). MC is a well-known degradation product of isoprene, ${ }^{5,31,32}$ which is itself a known degradation product of myrcene ${ }^{33}$ and other terpenes. ${ }^{34}$ Benzene, alkyl benzenes, and polycyclic aromatic hydrocarbons are known to form during terpene thermolysis. For example, benzene has been observed as a degradation product in the synthesis of myrcene by the pyrolysis of $\beta$-pinene, ${ }^{35}$ and it is also a product of solanesol pyrolysis. ${ }^{34}$ Benzene has also been detected in cannabis smoke. ${ }^{36}$

\subsubsection{Product quantification}

Given the wide diversity of the terpenes present in $\mathrm{BHO}$, the relatively high abundance of myrcene and the similarity of the products from each of the terpenes studied (Table 3.1 and Scheme 3.1), we focused on myrcene as a model terpene in evaluating the effect of temperature on the yields of $\mathrm{MC}$ and benzene. Assuming $40 \mathrm{mg}$ as an average size dab, ${ }^{22}$ each dab contains $2.36 \mathrm{mg}$ of terpenes, which is based on an average concentration of terpenes of $5.9 \%$ in $\mathrm{BHO}$ (unpublished data). The amount of MC obtained per dab based on these calculations is displayed in Figure 3.1.

Because dabbing topography has not been previously investigated, we chose an inhalation volume of $338 \mathrm{~mL}$ and a $10 \mathrm{~s}$ duration to assure a more complete collection of vapor. The concentrations of $\mathrm{MC}$ in ppb per dab in this regime are $185 \pm 11 \mathrm{ppb}$ at $T_{\mathrm{m}}=526{ }^{\circ} \mathrm{C}, 157 \pm 2 \mathrm{ppb}$ at $T_{\mathrm{m}}=455{ }^{\circ} \mathrm{C}, 131 \pm 9 \mathrm{ppb}$ at $T_{\mathrm{m}}=403{ }^{\circ} \mathrm{C}$, and undetectable at $T_{\mathrm{m}}=322{ }^{\circ} \mathrm{C}$.

Benzene was not detected below the highest TR. Using the same rationale as above for MC emission, one dab of BHO delivers $17 \mathrm{ng}$ of benzene. Represented as a concentration in the draw volume, this value is $15 \pm 1.8 \mathrm{ppb}$. 


\subsubsection{Degradant toxicology}

MC's property as a noxious irritant is unsurprising due to its structural similarity to acrolein, a powerful pulmonary irritant ${ }^{37}$ and an air pollutant of great concern. Ambient concentrations of MC outside of Stockholm were determined to be 0.06 ppb, whereas those at different urban locations in Stockholm were 0.11, 0.13, 0.19, and $0.71 \mathrm{ppb}^{38} \mathrm{MC}$ 's effect on the respiratory tract in mice has shown it to be

a potent irritant, indicating its threshold limit value should not exceed $0.3 \mathrm{ppm} .{ }^{39}$ Nøjgaard et al. reported changes in the blink frequency during eye exposure to $\mathrm{MC}$ at a concentration of $100 \mathrm{ppb}$ and proposed a LOEL of $286 \mathrm{ppb} .{ }^{40}$ These conflicting reports indicate that the safe levels of $\mathrm{MC}$ are yet to be determined.

Unlike MC, the toxicology of benzene has been thoroughly evaluated. Although benzene is a ubiquitous pollutant, the concentrations of benzene found in the dabbing terpenes at the highest TR are far greater than those found in ambient air. The average concentration of benzene, a potent carcinogen, in U.S. air, measured over 137 different sites is $0.313 \mathrm{ppb}(313 \mathrm{ppt}),{ }^{3,41}$ and is correspondingly the "largest single known cancer-risk air toxic (sic)." 42

\subsubsection{Degradant formation mechanism}

We propose that the formation of $\mathrm{MC}$ and benzene occurs via isoprene as an intermediate (Scheme 3.1). The GC-MS spectra of limonene, linalool, and myrcene all displayed significant peaks tentatively assigned to isoprene, which suggests that these terpenes, the major terpenes in $\mathrm{BHO}$, break down to their isoprene monomers before further degradation. 
Studies of the atmospheric chemistry of isoprene have shown that it reacts with hydroxyl radicals and $\mathrm{O}_{2}$ to form not only $\mathrm{MC}$ and $\mathrm{HCHO}$ but also methyl vinyl ketone and 3-methylfuran. The GC-MS analysis of each pure terpene studied afforded a tentative identification with a high match quality of MC, methyl vinyl ketone, and 3methylfuran, as well as 1,3-butadiene and several cyclic and acyclic dienes, polyenes, and aromatics (Scheme 3.1 and Supporting Information).

\subsubsection{Limitations}

The main limitation of this study is the fact that the concentrations of MC and benzene determined are likely underestimated. One reason may be the relatively large draw volume used. In addition, the temperature-dependent concentration values were extrapolated from myrcene, which afforded the lowest yield of degradation products of all of the terpenes investigated. Another factor potentially contributing to the underestimation of yields is transfer inefficiency resulting in the potential losses of terpenes and their products. For example, the average myrcene recovery $(8.7 \pm 0.7$

$\mathrm{mg}$ ) was low compared to the amount delivered onto the nail $(59.6 \mathrm{mg})$. Although this low yield of terpenes in the NMR sample was initially attributed to their limited solubility in DMSO- $d_{6}$, dabbing experiments using $\mathrm{CDCl}_{3}$ also had low yield by NMR . This may not be due entirely to degradation. Transfer inefficiency in dabbing has been previously described. ${ }^{22}$

\subsection{Conclusions}

Given the widespread legalization of cannabis in the United States, it is imperative to study the full toxicology of its consumption to guide future policy. The results 
of these studies clearly indicate that dabbing, although considered a form of vaporization, may in fact deliver significant amounts of toxic degradation products. The difficulty users find in controlling the nail temperature put users at risk of exposing themselves to not only methacrolein but also benzene. Additionally, the heavy focus on terpenes as additives seen as of late in the cannabis industry is of great concern due to the oxidative lability of these compounds when heated. This research also has significant implications for flavored e-cigarette products due to the extensive use of terpenes as flavorings. Future research will also be directed toward assessing the contribution of terpenoids to the existing toxicant formation in e-cigarettes. Additionally, the methods discussed herein will also be used to further study the degradation of cannabis extracts used in dabbing and cannabis e-cigarettes.

\subsection{Methods}

\subsubsection{Materials}

Terpenes included myrcene $\geq 95 \%$, stabilized, FCC, FG (Sigma-Aldrich); (R)-(+)limonene analytical standard (Sigma-Aldrich); linalool $\geq 97 \%$, FCC, FG; and Fire OG terpene mix (Blue River Extracts).

\subsubsection{NMR experiments}

Air is drawn at a constant rate using and the Single Cigarette Smoking Machine (SCSM-STEP, CH Technologies) calibrated to pull $338 \mathrm{~mL}$ air during a $10 \mathrm{~s}$ dab. A HIVE Domeless Element $10 \mathrm{~mm}$ ceramic nail (HIVE Ceramics) was attached to a small dab water pipe (Zion Cannabis in Portland, OR). For each separate experiment, 
the water pipe was filled with $20 \mathrm{~mL}$ of fresh $200 \mathrm{ppm}$ solution of $\mathrm{NaCl}$ Biological, Certified Crystalline (Fisher Scientific) in HPLC grade water (Honeywell).

Terpene $(15 \mu \mathrm{L})$ was delivered per dab using a Hamilton $50 \mu \mathrm{L}$ analytical syringe. Five dabs were done per experiment. The vapor was collected through a cold trap chilled with isopropyl alcohol/dry ice at $-77^{\circ} \mathrm{C}$, proceeded by an impinger containing $750 \mu \mathrm{L}$ of DMSO- $d_{6}+0.05 \% \mathrm{v} / \mathrm{v}$ tetramethylsilane (99.9\%, Cambridge Isotope). After the experiment was concluded, the cold trap was washed with the NMR solvent in the impinger and collected quantitatively using an Eppendorf P1000 pipette in an NMR tube. The water pipe and the cold trap were connected by $5 \mathrm{~cm}$ of $1 / 2 \mathrm{in}$. outer diameter ACF0027-F Tygon S3 E-3603. The end connected to the water pipe was wrapped in Teflon tape to make it fit snugly. The cold trap and the impinger were connected by $3.5 \mathrm{~cm}$ of $1 / 2$ in. outer diameter ACF0027-F Tygon S3 E-3603. The impinger and the SCSM were connected by $5 \mathrm{~cm}$ of $3 / 8 \mathrm{in}$. outer diameter ACF0017F Tygon S3 E-3603. The tubing was discarded after every experiment, so sorptive losses were consistent with every experiment.

All of the NMR samples were spiked with $10 \mu \mathrm{L}$ of a $17.33 \mathrm{mM}$ solution of 2,3,5,6-tetrachloronitrobenzene (TCI Chemicals) in DMSO- $d_{6}$ using an Eppendorf P10 pipette. This standard solution was made by adding $11.23 \mathrm{mg}$ of 2,3,5,6-tetrachloronitrobenzene to $3 \mathrm{~mL}$ of DMSO- $d_{6}$.

Myrcene dab NMR experiments at each TR (Figure 3.1) were performed in triplicate. Terpene experiments shown in Table 3.1 were performed once each. The exact conditions used in recording the NMR spectra are presented in the SI. 


\subsubsection{ATD-GC-MS Experiments}

The same water pipe (containing $20 \mathrm{~mL} 200 \mathrm{ppm}$ solution of $\mathrm{NaCl}$ ) and the same ceramic nail were connected to an ATD cartridge with $5 \mathrm{~cm}$ of $1 / 2$ in. outer diameter ACF0027-F Tygon S3 E-3603 wrapped in the Teflon tape to make a seal and then attached to $5 \mathrm{~cm}$ of $3.5 \mathrm{~cm}$ of 3/8 in. outer diameter ACF0027-F Tygon S3 E-3603, also wrapped with Teflon tape on the end to assure an air-tight seal. The other end of the ATD cartridge was connected to the SCSM- STEP using $5 \mathrm{~cm}$ of $3.5 \mathrm{~cm}$ of $3 / 8 \mathrm{in}$. outer diameter ACF0027-F Tygon S3 E-3603. The ATD cartridges used contained 100 mg of 35/60 mesh Tenax TA and $200 \mathrm{mg}$ of 60/80 mesh Carbograph 1 TD (Camsco Inc., Houston, TX). The same dabbing topography used in the NMR experiments were used in the ATD cartridge sample collections. This high flow rate exceeds that normally used for these cartridges, but this was allowed due to the fact that these experiments were only used for product identification and not quantification. The conditions used in the ATD cartridge analysis are explained in the SI.

\subsection{Author information}

\subsubsection{Corresponding author}

*Email: strongin@pdx.edu

\subsubsection{ORCID}

Robert M. Strongin: 0000-0003-3777-8492 


\subsubsection{Author contributions}

J.M.-A. performed all of the experiments, collected sample, and wrote the manuscript. R.M.S. supervised the studies and edited the manuscript. W.L. ran the ATD-GC-MS samples, advised on sample collection by this method, and reviewed the manuscript. All of the authors have given approval to the final version of the manuscript.

\subsubsection{Funding}

We thank the NIH and FDA for support of this work via award R01ES025257. The content is solely the responsibility of the authors and does not necessarily represent the views of the NIH or the FDA.

\subsection{Acknowledgements}

Dr. Jorge Escobedo provided the guidance and useful discussion in the experiments and during manuscript drafting. Dr. David Peyton provided the guidance and useful discussion in the NMR methods used. Tim Frasca reviewed the manuscript for content and style.

\subsection{Abbreviations}

MC, methacrolein; THC, tetrahydrocannabinol; CBD, cannabidiol; BHO, butane hash oil; TR, temperature range; HCHO, formaldehyde; TLV, threshold limit value; LOEL, lowest observed effect level 


\subsection{References}

(1) Tierney, P. A.; Karpinski, C. D.; Brown, J. E.; Luo, W.; Pankow, J. F. Flavour chemicals in electronic cigarette fluids. Tob. Control 2016, 25, e10-e15.

(2) Russo, E. B. Taming THC: potential cannabis synergy and phytocannabinoidterpenoid entourage effects. Br. J. Pharmacol. 2011, 163, 1344-1364.

(3) do Monte, D.S.; Tenório, J.A.B.; Bastos,I.V.G.A.; Mendonça, F. d. S.; Neto, J.

E.; da Silva, T. G.; Ramos, C. S. Chemical and biological studies of beta-carotene after exposure to Cannabis sativa smoke. Toxicol. Rep. 2016, 3, 516-522.

(4) Iqbal, M. S.; Khan, M. U. A.; Akbar, J.; Shad, M. A.; Masih, R.; Chaudhary, M. T. Isoconversional thermal and pyrolytic GC-MS analysis of street samples of hashish. J. Anal. Appl. Pyrolysis 2016, 122, 175-182.

(5) Atkinson, R. Gas Phase Tropospheric Chemistry of Organic Compounds: A Review. Atmos. Environ., Part A 1989, 24, 1-41.

(6) Calogirou, A.; Larsen, B. R.; Kotzias, D. Gas-phase terpene oxidation products: a review. Atmos. Environ. 1999, 33, 1423-1439.

(7) Stogner, J. M.; Miller, B. L. The Dabbing Dilemma: A Call for Research on Butane Hash Oil and Other Alternate Forms of Cannabis Use. Subst. Abuse 2015, 36, 393-395.

(8) Pierre, J. M.; Gandal, M.; Son, M. Cannabis-induced psychosis associated with high potency "wax dabs". Schizophr. Res. 2016, 172, 211-212.

(9) Murray, R. M.; Quigley, H.; Quattrone, D.; Englund, A.; Di Forti, M. Traditional marijuana, high-potency cannabis and synthetic cannabinoids: increasing risk for psychosis. World Psychiatry 2016, 15, 195-204. 
(10) Stogner, J. M.; Miller, B. L. Assessing the Dangers of "Dabbing": Mere Marijuana or Harmful New Trend? Pediatrics 2015, 136, 1-3.

(11) Loflin, M.; Earleywine, M. A new method of cannabis ingestion: the dangers of dabs? Addict. Behav. 2014, 39, 1430-1433.

(12) Ross, S. A.; ElSohly, M. A. The volatile oil composition of fresh and air-dried buds of Cannabis sativa. J. Nat. Prod. 1996, 59, 49-51.

(13) danner1620 Terp Dippin' Kosher Kush Rosin with Blue River Extracts [video file]. https://www.youtube.com/watch?v=YOFkbcMo-so (accessed July 7, 2017).

(14) Stogner, J. M.; Miller, B. L. The Dabbing Dilemma: A Call for Research on Butane Hash Oil and Other Alternate Forms of Cannabis Use. Subst. Abuse 2015, 36, 393-395.

(15) ElSohly, M. A. Marijuana and the Cannabinoids, 1st ed.; Humana Press: NJ, 2007.

(16) Perrotin-Brunel, H.; Perez, P. C.; van Roosmalen, M. J. E.; van Spronsen, J.; Witkamp, G. J.; Peters, C. J. Solubility of Delta(9)- tetrahydrocannabinol in supercritical carbon dioxide: Experiments and modeling. J. Supercrit. Fluids 2010, 52, $6-10$.

(17) Perrotin-Brunel, H.; van Roosmalen, M. J. E.; van Spronsen, J.; Verpoorte, R.; Peters, C. J.; Witkamp, G. J. Supercritical fluid extraction of cannabis: experiments and modelling of the process design. ISASF-Graz 2010, 1-6.

(18) Manufacturing Requirements for Approved Medical Marihuana Products. Official Compilation of Codes, Rules and Regulations of the State of New York, Part 1004, Section 11(b), Title 10, 2017.

(19) Gieringer, D.; St. Laurent, J.; Goodrich, S. Cannabis Vaporizer Combines 
Efficient Delivery of THC with Effective Suppression of Pyrolytic Compounds. J. Cannabis Ther. 2004, 4, 7-27.

(20) 2015 National Drug Threat Assessment Summary; Report Number DEA-DCTDIR008-16; US Department of Justice, United States Drug Enforcement Agency; Homeland Security Digital Library, 2015.

(21) Daniulaityte, R.; Nahhas, R. W.; Wijeratne, S.; Carlson, R. G.; Lamy, F. R.; Martins, S. S.; Boyer, E. W.; Smith, G. A.; Sheth, A. "Time for dabs": Analyzing Twitter data on marijuana concentrates across the U.S. Drug Alcohol Depend. 2015, $155,307-311$.

(22) Raber, J. C.; Elzinga, S.; Kaplan, C. Understanding dabs: contamination concerns of cannabis concentrates and cannabinoid transfer during the act of dabbing. J. Toxicol. Sci. 2015, 40, 797-803.

(23) Burns, D. What's Your Preferred Enail Temp? https://www. reddit.com/r/ CannabisExtracts/comments/30mj24/whats_your_preferred_enail_temp/(accessed July 18, 2017).

(24) MFletcher, I. Is There a Consensus Temp for Low Temps Dabs on an Enail? https://www.reddit.com/r/enail/comments/4gjznx/is_there_a_consensus_temp_ for_low_temp_dabs_on_an/(accessed July 18, 2017).

(25) Propanekush What Temperature are you Dabbing at? What Type of Nail? https://www.reddit.com/r/CannabisExtracts/comments/3onqt8/what_temperature _are_you_dabbing_at_what_type_of/(accessed July 18, 2017).

(26) Tara, M.; Lovestead, T. J. B. Determination of Cannabinoid Vapor Pressures to Aid in Vapor Phase Detection of Intoxication. Forensic Chem. 2017, 5, 79-85. (27) Black, S. Why Carb Cap? Elevate Your Dabbing. http:// hightimes.com/culture/ 
why-carb-cap-elevate-your-dabbing/ (accessed July 18, 2016).

(28) Jensen, R. P.; Strongin, R. M.; Peyton, D. H. Solvent Chemistry in the Electronic Cigarette Reaction Vessel. Sci. Rep. 2017, 7, No. 42549.

(29) Pankow, J. F.; Kim, K.; McWhirter, K. J.; Luo, W.; Escobedo, J. O.; Strongin, R. M.; Duell, A. K.; Peyton, D. H. Benzene formation in electronic cigarettes. PLoS One 2017, 12, No. e0173055.

(30) McGraw, G. W.; Hemingway, R. W.; Ingram, L. L.; Canady, C. S.; McGraw, W. B. Thermal degradation of terpenes: Camphene, Delta(3)-carene, limonene, and alpha-terpinene. Environ. Sci. Technol. 1999, 33, 4029-4033.

(31) Carter, W. P. L. Condensed atmospheric photooxidation mechanisms for isoprene. Atmos. Environ. 1996, 30, 4275-4290.

(32) Palen, E. J.; Allen, D. T.; Pandis, S. N.; Paulson, S. E.; Seinfeld, J. H.; Flagan, R. C. Fourier Transform Infrared Analysis of Aerosol Formed in the Photo-Oxidation of Isoprene and [beta]-pinene. Atmos. Environ., Part A 1992, 26, 1239-1251.

(33) Egloff, G.; Herrman, M.; Levinson, B. L.; Dull, M. F. Thermal reactions of terpene hydrocarbons. Chem. Rev. 1934, 14, 287-383.

(34) Britt, P. F.; Buchanan, A. C., III; Owens, C. V., Jr. Mechanistic Investigation into the Formation of Polycyclic Aromatic Hydrocarbons from the Pyrolysis of Terpenes. Prepr. Pap.-Am. Chem. Soc., Div. Fuel Chem. 2004, 49, 868-871.

(35) Kolicheski, M. B.; Cocco, L. C.; Mitchell, D. A.; Kaminske, M. Synthesis of myrcene by pyrolysis of [beta]-pinene: Analysis of decomposition reactions. J. Anal. Appl. Pyrolysis 2007, 80, 92-100.

(36) Moir, D.; Rickert, W. S.; Levasseur, G.; Larose, Y.; Maertens, R.; White, P.; Desjardins, S. A comparison of mainstream and sidestream marijuana and tobacco 
cigarette smoke produced under two machine smoking conditions. Chem. Res. Toxicol. 2008, 21, 494-502.

(37) Wang, H. T.; Hu, Y.; Tong, D.; Huang, J.; Gu, L.; Wu, X. R.; Chung, F. L.; Li, G. M.; Tang, M. S. Effect of carcinogenic acrolein on DNA repair and mutagenic susceptibility. J. Biol. Chem. 2012, 287, 12379-12386.

(38) Jonsson, A.; Persson, K. A.; Grigoriadis, V. Measurements of Some Low MolecularWeight Oxygenated, Aromatic, and Chlorinated Hydrocarbons in Ambient Air and in Vehicle Emissions. Environ. Int. 1985, 11, 383-392.

(39) Larsen, S. T.; Nielsen, G. D. Effects of methacrolein on the respiratory tract in mice. Toxicol. Lett. 2000, 114, 197-202.

(40) Nøjgaard, J. K.; Christensen, K. B.; Wolkoff, P. The effect on human eye blink frequency of exposure to limonene oxidation products and methacrolein. Toxicol. Lett. 2005, 156, 241-251.

(41) EPA's Report on the Environment; Ambient Concentrations of Selected Air Toxics. Exhibit 3; US Environmental Protection Agency, 2014.

(42) George, B. J.; Schultz, B. D.; Palma, T.; Vette, A. F.; Whitaker, D. A.; Williams, R. W. An evaluation of EPA's National-Scale Air Toxics Assessment (NATA): Comparison with benzene measurements in Detroit, Michigan. Atmos. Environ. 2011, 45, 3301-3308. 


\title{
4 Aerosol gas-phase components from cannabis e-cigarettes and dabbing: mechanistic insight and quantitative risk analysis
}

\author{
Jiries Meehan-Atrash,${ }^{\dagger}$ Wentai Luo, ${ }^{\dagger, \ddagger}$ Kevin J. McWhirter ${ }^{\ddagger}$ and Robert M. Strongin ${ }^{* \dagger}$ \\ ${ }^{\dagger}$ Department of Chemistry and ${ }^{\ddagger}$ Department of Civil and Environmental Engineering, \\ Portland State University, Portland, OR, 97207-0751
}

This manuscript has been published and is adapted from:

Meehan-Atrash, J.; Luo, W.; McWhirter, J. K.; Strongin, R. M., Aerosol GasPhase Components from Cannabis E-Cigarettes and Dabbing: Mechanistic Insight and Quantitative Risk Analysis. ACS Omega 2019, 4 (14), 16111-16120.

DOI: $10.1021 /$ acsomega.9b02301

Published by The American Chemical Society

Article history:

Received: July 23, 2019

Accepted: August 30, 2019

Published: September 16, 2019 


\subsection{Abstract}

Consumption of cannabis by nontraditional methods has surged since the advent of legalization in North America and worldwide. Inhaling cannabis extracts using vaporizers and via dabbing has risen in popularity, while concerns over product safety have not hindered their proliferation. The work herein is the first step toward assessing the safety of vaporizing and dabbing concentrated cannabis extracts as a function of gas-phase reaction products. The gas-phase thermal degradants of $\Delta^{9}$ tetrahydrocannabinol (THC) have not been previously investigated. It was found that users may be exposed to concerning degradants such as methacrolein, benzene, and methyl vinyl ketone when using cartridge vaporizers and dabbing. It was shown that THC alone and mixed with terpenes generated similar degradation products and, most notably, elevated levels of isoprene. Importantly, it was shown that added terpenes led to higher levels of gas-phase products compared to THC alone. To estimate cancer and noncancer risks associated with exposure to these and other degradants, quantitative risk assessment was applied to experimentally determined values for dabbing and vaping and literature-sourced levels of hazardous components in cannabis smoke. Overall, gas-phase aerosol products had significantly lower values in dabbing and vaporizing compared to cannabis smoking, although these results should be interpreted in light of potential variations in degradant levels due to disparate usage patterns and the dangers of the higher aerosol concentration of THC. 


\subsection{Introduction}

Legalization and increasing social acceptance of cannabis in the United States and worldwide has led to a proliferation of novel cannabis administration methods. Advancement of cannabis extract $(\mathrm{CE})$ production and processing has placed these at the forefront of novel cannabis inhalation methods, and sales of CEs now make up more than $20 \%$ of the retail market share in the Washington state. ${ }^{1}$ Despite their popularity, little work has been done to assess the safety of these novel consumption methods.

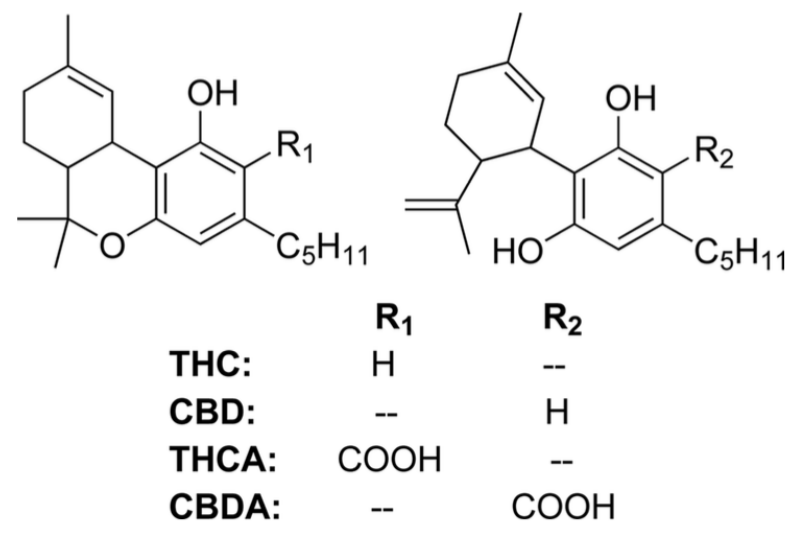

Figure 4.1: Relevant cannabinoids

Cannabinoids, the constituents responsible for cannabis' psychoactive and medicinal effects, are biosynthesized in trichomes of female cannabis inflorescences. ${ }^{2-4}$ Figure 4.1 displays the pharmacologically active cannabinoids THC (mp: $\left.<25{ }^{\circ} \mathrm{C}^{5}\right)$ and cannabidiol $\left(\mathrm{CBD}, \mathrm{mp}: 62-63{ }^{\circ} \mathrm{C}^{6}\right)$, which are biosynthesized as the acid cannabinoids $\Delta^{9}$-tetrahydrocannabinolic acid (THCA, mp: $75 \pm 3{ }^{\circ} \mathrm{C}^{7}$ ) and cannabidiolic acid (CBDA, mp: $68 \pm 3{ }^{\circ} \mathrm{C}^{8}$ ) that readily decarboxylate upon heating. ${ }^{9}$ Nonpolar solvents (e.g., butane ${ }^{10-12}$ and supercritical $\mathrm{CO}_{2}{ }^{13,14}$ ) are used to extract acid cannabi- 
noids in an oleoresin that includes terpenes, waxes, fatty acids, steroids, lignins, etc. ${ }^{15}$ While butane hash oil (BHO, an amber or gold solid ${ }^{10,16}$ ) contains primarily acid cannabinoids, ${ }^{10,11}$ superfluid cannabis extract (SFE) may contain acid or neutral cannabinoids depending on processing methods. Vacuum distillation affords purified neutral cannabinoids allowing manufacturers to tailor cannabinoid and terpene content in the final product commonly referred to as a distillate. ${ }^{17}$ Distillates are often amended with terpenes at $5-15 \%(\mathrm{~m} / \mathrm{m}){ }^{18}$

Three consumption methods/devices for CEs have predominated: dabbing, cartridge vaporizers $(\mathrm{CVs})$, and top-loading vaporizers $(\mathrm{TLVs})$. Dabbing involves flash vaporizing a small amount of $\mathrm{CE}$, a dab, on a hot surface, a nail, which is connected to a pipe or water pipe, an oil rig or rig. ${ }^{19}$ A user quickly and immediately inhales aerosol generated when the dab is placed onto the nail, which may require up to an entire vital capacity for complete capture. ${ }^{11} \mathrm{BHO}$, distillate, and SFE are amenable to dabbing, though $\mathrm{BHO}$ is most common. ${ }^{11,20} \mathrm{CVs}$ are small electronic cigarette-like devices that use battery-powered resistive heating to aerosolize CEs. A button-activated battery powers an atomizer located in a cartridge preloaded with CE to generate aerosol a user inhales through a mouthpiece; reliance on wicking necessitates extracts containing neutral THC with added terpenes to decrease viscosity. ${ }^{21}$ TLVs also use a battery to power a resistively heated coil but differ in that users manually place the $\mathrm{CE}$ directly onto exposed heating coils in the atomizer ad libitum. ${ }^{22}$ Any extract may be used in TLV. ${ }^{22}$ Both TLV and CV are colloquially referred to as vape pens, and no surveys to date distinguish between the two, categorizing them together as cannabis e-cigarettes or cannabis electronic vapor products (CEVPs). In all these CE consumption methods, carrier liquids such as glycerol, propylene glycol, 
and medium-chain triglycerides are not typically included as they are considered to be undesirable. ${ }^{23}$

Vaporizing (or vaping) cannabis by any method has gained popularity among recreational and medical users, particularly young adults and teens, ${ }^{24}$ as a less detectable method of using marijuana compared to smoking that is also perceived to be healthier. ${ }^{25-27}$ Vaporizers for cannabis inflorescences ${ }^{28,29}$ have existed long before popularization of CEs, ${ }^{30}$ and terminology used to refer to these (e.g., vaporizers and vapes) has been applied for TLV and CV, which has led to some confusion in the literature. Several studies have investigated prevalence of CEVPs specifically, though many others exist for inflorescence vaporizers. The 2016 National Youth Tobacco Survey ${ }^{31}$ reported that nearly 1 in 11 respondents reported lifetime use of a CEVP, and other state-level surveys report 3.4\% usage among middle-schoolers, ${ }^{32} 5.4-11.4 \%$ for high-schoolers, ${ }^{32,33}$ and $10.7 \%$ for college students. ${ }^{34}$ Sparse data exists on prevalence of dabbing, though it appears to be common among regular cannabis users. Twenty percent of daily/nearly daily cannabis users in the Washington state reported dabbing in the past week, ${ }^{35}$ and $36.5 \%$ of respondents from a Reddit survey of a similar cohort endorsed regular use of dabbing as well. ${ }^{36}$ An internet survey of Twitter posts found that dabbing- related posts are more prevalent in states with medical marijuana laws, ${ }^{37}$ suggesting that dabbing may grow in popularity as legalization of cannabis expands access to alternative cannabis products. 

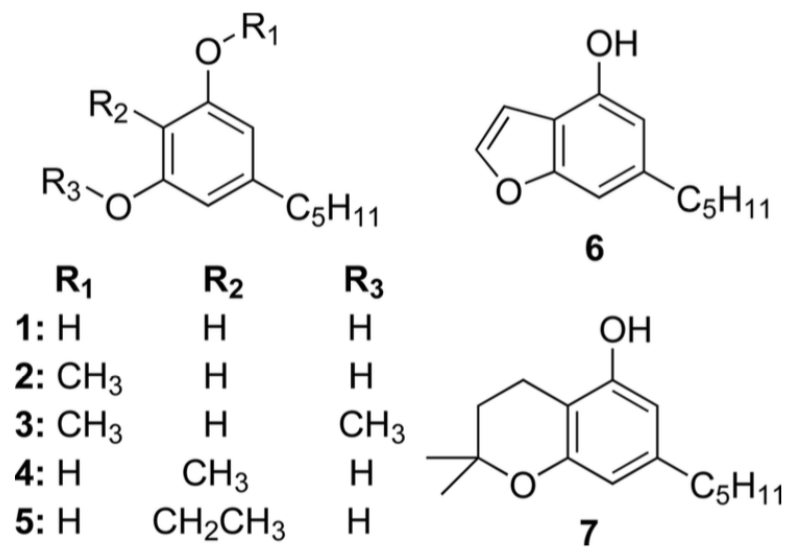

Figure 4.2: Cannabidiol degradation products

The thermal behavior of cannabinoids has been studied in the context of the conversion of CBD to THC or other potentially psychoactive compounds in smoked marijuana, smoked tobacco with $\mathrm{CBD},{ }^{38-41}$ and pyrolysis of CBD alone. ${ }^{42,43}$ While searching for potentially psychoactive CBD pyrolysis products, many olivetol derivatives with intact pentyl chains (Figure 4.2, compds $1-5)^{44,45}$ and other products were found to stem from rearrangement of CBD's terpene moiety (Figure 4.2, compds 6 and 7), ${ }^{46}$ indicating that this may be particularly labile. Exhaustive in its efforts to identify potential pharmacologically active products, work at the University of Utrecht did not prioritize identifying volatile organic compounds (VOCs). Harmful and potentially harmful constituents (HPHCs) of cannabis smoke have been previously studied, ${ }^{47,48}$ but no information is available concerning pyrolysis or oxidation products of cannabinoids relevant to dabbing or vaping conditions. Moreover, it is not clear if the HPHCs arise from the cannabinoids, terpenes, or any other plant constituents. A recent study described BHO diluted in glycerol and propylene glycol added to a CV-type device, which does not embody the manner in which cannabis concentrates are vaporized. ${ }^{49}$ Evidence-based data is needed to better understand 
toxicology and routes of administration of these emerging products. We currently do not know, for instance, the aerosol doses of cannabinoids, terpenes, and potentially toxic degradation products being delivered to vulnerable cohorts such as teens and pre-teens or to medical marijuana patients with compromised immune systems.

Quantitative risk assessment (QRA) is an analytically driven risk calculation that pools biological and chemical data to approximate the probability of the incidence of a defined outcome or symptom upon exposure to a given HPHC. QRA has been previously performed for tobacco products, ${ }^{50,52}$ for example, for comparison of "reduced exposure" cigarettes to regular cigarettes. ${ }^{51}$ Cancer risk may be approximated using the excess lifetime cancer risk (ELCR) and noncancer risks using the hazard index (HI). ELCR, the incremental probability of contracting cancer upon specified conditions of exposure to a carcinogen ${ }^{52}$ is derived from the inhalation unit risk (IUR), an estimate of the increased risk (i.e., above baseline) of developing cancer due to exposure to a $1 \mathrm{\mu g} / \mathrm{m}^{3}$ concentration of a given chemical. ${ }^{53}$ The reference exposure level (REL) is an estimate of an air concentration that is not likely to create an appreciable risk in humans after continuous inhalation and is calculated in reference to a given symptom that occurs after chronic exposure..$^{53}$ Both the IUR and REL may have uncertainties spanning an order of magnitude. A given exposure concentration divided by the REL yields a hazard quotient (HQ) wherein HQ $>1$ indicates that the threshold of toxic effects on the target system is surpassed. ELCR and HQ values for individual chemicals are summed to yield total ELCR $\left(\mathrm{ELCR}_{\mathrm{T}}\right)$ and $\mathrm{HI}$, respectively, which may be used to guide policy decisions regarding environmental cleanup projects and consumer products. ${ }^{52}$

Previously, our lab had investigated thermal degradation products of terpenes 
that are present in CEs when exposed to dabbing conditions. ${ }^{19}$ We hypothesize that cannabinoids will generate similar degradation products given their terpene backbone. Given the restricted availability of marijuana derivatives for research, it was possible only to synthetically recreate the CE product distillate by mixing analytical-grade THC with a terpene aromatherapy mix of cannabis cultivar Fire OG in a ratio of 9:1 THC:terpenes. Herein, we report an investigation of the chemical makeup of aerosol gas phases (GPs) obtained by dabbing pure THC and this synthetic distillate (SND) in addition to vaping SND in a CV device at three power levels commonly used. Adsorption/thermal desorption gas chromatography-mass spectrometry (ATD-GCMS) is used to quantify target VOC analytes, and other aerosol GP components are estimated using a nontarget analysis approach. Identified components provide mechanistic insight into the thermal degradation of cannabinoids. Quantitative risk assessment (QRA) calculations are applied to estimate cancer and noncancer risks from dabbing and CV usage, and the results of which are compared to risks from smoking cannabis using quantitated cannabis smoke components from the literature. ${ }^{55-58}$ To the best of our knowledge, this is the first time the safety of CEVP and dabbing has been studied, and the first time quantitative risk assessment has been used to evaluate the safety of cannabis smoking.

\subsection{Results}

GP aerosol components generated from dabbing THC and SND were quantified using internal standard (IS)-normalized multipoint calibration of methacrolein, benzene, xylenes, toluene, styrene, and ethylbenzene in duplicate samples, and response factors (RFs) calculated from ISs were used to estimate levels of these components seen 
from vaping SND in a $\mathrm{CV}$ at three voltages (Table 4.1). Isoprene levels were estimated using internal standard-calculated response factors (IS-RFs) in all cases. A large diversity of other hydrocarbon ( $\mathrm{HC})$ components with a majority of alkenes was observed in all GCMS chromatograms acquired, though the spread differed between SND dabbing (Table 9.1) and THC dabbing samples (Table 9.2). Levels of the major-occurring VOCs, identified by comparison of mass spectra against those in the National Institute for Standards and Technology (NIST) mass spectrometry database (match qualities of $>70 \%$ ), were estimated by a previously published nontarget analysis method (see Methods and Materials), ${ }^{58,59}$ and the results of which are displayed in Tables 9.1 and 9.2. GP components from dabs of $11 \pm 2.5 \mathrm{mg}$ of either THC or SND were measured and scaled up to $40 \mathrm{mg}$ (reported average dab ${ }^{60}$ ), assuming equivalent sidestream losses of the GP components across different dab sizes. For CV vaping, GP components are presented from single-puff measurements using standard puff topography for e-cigarettes. Many oxygenated compounds identified in the THC dabbing chromatograms (2,5-dimethylfuran, 2,3-dimethylacrolein, etc.) were not identifiable in SND dabbing and CV vaping chromatograms. Analysis of selected ion chromatograms of ions relevant to these oxygenated products in SND samples indicates the presence of these THC-specific degradation products, though they were not quantifiable by nontarget analysis due to overlap from vastly more abundant alkenic terpene degradation products. Sample chromatograms from dabbing THC and SND are presented in the Supporting Information (Figures 9.1 and 9.2). A sample chromatogram of CV vaping was not displayed given its similarity to that of SND dabbing.

To make the comparison between the risks associated with CV vaping, dabbing, 


\begin{tabular}{llllll} 
Component, unit & THC dab & SND dab & Vape 3.2 V & Vape 4.0 V & Vape 4.8 V \\
\hline Methacrolein, $\mu \mathrm{g}$ & $2.7 \pm 0.8$ & $12 \pm 0.82$ & $5.6 \mathrm{E}-3$ & $3.2 \mathrm{E}-2$ & $1.9 \mathrm{E}-1$ \\
Benzene, ng & $33 \pm 14$ & $360 \pm 120$ & $9.9 \mathrm{E}-1$ & $2.7 \mathrm{E}+0$ & $3.6 \mathrm{E}+1$ \\
Xylenes, $\mu \mathrm{g}$ & $0.33 \pm 0.20$ & $0.85 \pm 0.30$ & $1.0 \mathrm{E}-3$ & $1.5 \mathrm{E}-2$ & $1.8 \mathrm{E}-1$ \\
Toluene, $\mu \mathrm{g}$ & $0.44 \pm 0.22$ & $1.4 \pm 0.42$ & $7.0 \mathrm{E}-4$ & $1.0 \mathrm{E}-2$ & $1.6 \mathrm{E}-1$ \\
Styrene, ng & $0.88 \pm 0.72$ & $27 \pm 14$ & $9.3 \mathrm{E}-2$ & $2.7 \mathrm{E}-1$ & ND* \\
Ethylbenzene, $\mathrm{ng}$ & $1.5 \pm 0.99$ & $55 \pm 30$ & $3.7 \mathrm{E}-2$ & $2.5 \mathrm{E}-1$ & $2.7 \mathrm{E}+0$ \\
Isoprene, $\mu \mathrm{g}$ & $9.6 \pm 1.7$ & $44 \pm 3.5$ & $3.0 \mathrm{E}-2$ & $8.3 \mathrm{E}-1$ & $6.0 \mathrm{E}+0$ \\
Other HCs ${ }^{\dagger}{ }^{\ddagger} \mathrm{gg}$ & $5.3 \pm 0.7$ & $21 \pm 11$ & $4.2 \mathrm{E}-2$ & $7.2 \mathrm{E}-1$ & $7.9 \mathrm{E}+0$ \\
Total VOCs ${ }^{\ddagger} \mu \mathrm{g}$ & $2.0 \mathrm{E}+01$ & $7.7 \mathrm{E}+01$ & $9.4 \mathrm{E}-2$ & $1.5 \mathrm{E}+0$ & $1.2 \mathrm{E}+1$ \\
\hline
\end{tabular}

Table 4.1: Selected GP components identified in dabbing and CV vaping using ATD-GCMS

and smoking, the level of chronic consumption of each was matched so each would deliver an equivalent daily dose of THC. This was necessary given the lack of information about specific consumption habits for $\mathrm{CV}$ vaping and dabbing but is justified based on literature precedence. Van Dam et al. ${ }^{61}$ reported a significant decrease in daily grams of cannabis consumed in users that switched from smoking to vaporizing flower cannabis, which has a THC delivery efficiency higher than that of smoking, ${ }^{62}$ that users adjust the quantity consumed to obtain the same THC delivery based on personal preference. Analogous to the pack-year for cigarette smoking, the joint-year has been used as a measure of cannabis consumption widely used in epidemiological studies of cannabis use ${ }^{63-65}$ and is defined as smoking 1 joint/day over the course of a year. The joint-year was chosen as the reference point to which approximate THC deliveries for dabbing and CV vaping would be matched by the consumption rate (CR; see Methods and Materials). Assuming a THC content of $17.1 \%{ }^{66}$ in cannabis and a THC transfer efficiency of $43 \%{ }^{62,67}$ during smoking, a standard 0.75 g joint ${ }^{68,69}$ would yield $55 \mathrm{mg}$ of THC, two $40 \mathrm{mg}$ dabs would yield $55 \mathrm{mg}$ of THC assuming a THC content of $90 \%$ and a transfer efficiency of $76 \%,{ }^{70}$ and 20 puffs from a vape pen (at $4.8 \mathrm{~V}$ ) would yield $54 \mathrm{mg}$ of THC assuming an $85 \%$ yield on $4 \mathrm{mg}$ puffs of 
cannabis distillate containing $90 \%$ THC $(\mathrm{m} / \mathrm{m})$.

\begin{tabular}{lll} 
Consumption type & HI & ELCR \\
\hline Smoking (inflorescence) & $2 \mathrm{E}+2$ & $4 \mathrm{E}-4$ \\
Dabbing (distillate) & $2 \mathrm{E}-1$ & $2 \mathrm{E}-7$ \\
Vaping (distillate), 4.8 V & $4 \mathrm{E}-2$ & $2 \mathrm{E}-7$ \\
Vaping (distillate), 4.0 V & $6 \mathrm{E}-3$ & $2 \mathrm{E}-8$ \\
Vaping (distillate), 3.2 V & $8 \mathrm{E}-4$ & $2 \mathrm{E}-9$ \\
\hline
\end{tabular}

Table 4.2: Hazard index and excess lifetime cancer risk for smoking, dabbing, and vaping at 3 voltages.

\subsection{Discussion}

The identification of several carbonyls, aromatics, and isoprene was in line with a previous report from our lab. ${ }^{19}$ Given that all the terpenes tested in Meehan-Atrash et al. ${ }^{19}$ resulted in a comparable array of volatile products, it was hypothesized that isoprene is an intermediate in the degradation of these compounds. Cannabinoids such as THC contain a terpene backbone, and it is not surprising that similar volatile products are generated from dabbing THC, SND, and terpenes alone. ${ }^{19}$ A diversity of degradation mechanisms may occur upon thermal treatment of THC, but the significant levels of isoprene seen when dabbing THC alone indicate that the isoprene formed undergoes oxidation to release methacrolein and methyl vinyl ketone, a mechanism for which has been described in the context of atmospheric oxidation. ${ }^{71,72}$ Isoprene has been previously described as a neutral product formed during fragmentation of THC in electron impact mass spectrometry. ${ }^{73-75}$ The nearly fivefold increase in isoprene released from THC amended with $\sim 10 \%$ terpenes compared to THC alone (Table 4.1) suggests that terpenes release isoprene more readily than THC. Indeed, all identified VOCs form in higher amounts per milligram of product consumed when 
dabbing SND than from THC alone. Other minor components in CEs (hydrocarbons, fatty acids, flavonoids, phenols, etc. ${ }^{15}$ ) may add to or alter GP degradants of other extract formulations.

The work presented herein represents a preliminary investigation into the GP aerosol components a cannabis consumer may be exposed to when vaping distillate in a CV or via dabbing. Several identified components are International Agency for Research on Cancer-classified carcinogens, and exposure to these may place a burden on the health of people that use dabbing or vaping to consume cannabis. In an attempt to interpret results in the most relevant way possible to health professionals and consumers alike, components for which toxicological metrics had been previously calculated were applied to a QRA calculation. Despite the rise in alternative cannabis administration methods, cannabis smoking remains to be the more prevalent mode of cannabis consumption to date ${ }^{30,76,77}$ warranting a systematic comparison between methods of inhalation. Previously quantified components of cannabis smoke were aggregated from the literature ${ }^{54-57}$ and correspondingly applied to the same QRA analysis in a first attempt to compare the relative safety of smoking cannabis to two existing methods of vaporizing distillate.

Results indicate that vaping or dabbing distillates has lower HI and ELCR than those of cannabis smoking by several orders of magnitude (Table 4.2). These findings are not definitive and must be interpreted with caution as they are only a first step toward determining the overall safety of these cannabis inhalation methods. Only GP components were measured in this work and were applied to QRA calculations, which may underestimate risks due to exclusion of potentially toxic particulate phase components. Previous literature indicates that aldehydes/small organics contribute 
the largest percentage of the total cancer risk among constituents of cigarette smoke, ${ }^{50}$ which appears to hold true for cannabis smoke as well (Table 9.4). Furthermore, HI and ELCR are only measures of chronic effects and do not indicate relative safety in the context of acute effects, particularly in light of the recent rash of vaping related illnesses, the cause of which has not been fully identified.

Though widely used by regulatory bodies to make evidence-based decisions on environmental risks to human health, quantitative risk assessment has several unavoidable sources of uncertainty, which is currently magnified due to the lack of standardization in the study of cannabis consumption as compared to tobacco. Machine smoking attempts to imitate realistic use but is only an approximation. ${ }^{52}$ In this study, a puff profile set by the Cooperation Center for Scientific Research Relative to Tobacco (CORESTA) for e-cigarettes was chosen given the functional similarity of these devices to e-cigarettes; however, puffing topography for CEVPs has not been studied, which represents another source of systematic error of unknown magnitude in the work herein. When calculating ELCR and HI, it is assumed that $100 \%$ of each component is absorbed and that the total risk is the sum of the risk from each individual component, which may over- or underestimate the total risk. For cigarette smoking, it has been noted that ELCR values underestimate risks when these are compared to epidemiological data. ${ }^{50}$ However, the cancer risk for cannabis smoking calculated herein, which is comparable to that calculated for cigarette smoking, ${ }^{50}$ is in stark contrast to the negligible association between cannabis smoking and cancer. ${ }^{78}$

In regard to noncancer effects, the major contributor to the elevated HI for cannabis smoking, acrolein, could potentially be responsible for the association between cannabis smoking and respiratory symptoms. ${ }^{79,80}$ Given the uncertainty as- 
sociated with QRA, dabbing HI may exceed unity under altered conditions such as increased nail temperature, which has been shown to linearly increase degradant formation, ${ }^{19}$ or increased terpene content. Ninety-one percent of the HI from dabbing stems from methacrolein; the REL of which stems from chronic respiratory tract effects (Table 9.3) and has been specifically implicated as the cause of lung injury due to dabbing $\mathrm{BHO}$ in a medical case report. ${ }^{81}$ The elevated levels of conjugated dienes (Table 9.1 and 9.2) warrant mention as these have been implicated as prohaptens. ${ }^{82}$ The complete absence of detectable acrolein in dabbing and vaping GP warrants mention as it may imply that this cannabis smoke component stems from plant components other than cannabinoids and terpenes.

Despite the reduction in the toxicant yield for CE vaporizers compared to smoking and the corresponding low HI and ELCR values, the elevated concentration of THC in the total particulate matter (TPM) may have untold physicochemical ${ }^{83}$ and pharmacological effects ${ }^{84}$ on the respiratory system. For example, cannabis smoke with $\sim 1 \%$ THC content was shown to compromise the surface properties of a lung surfactant replacement product ${ }^{83}$ due to intercalation of the hydrophobic THC molecule. The effect of higher concentrations of THC and high-molecular weight terpenes in the aerosol particulate phase and any partitioning ${ }^{85}$ of GP dienes and other VOCs into the lung surfactant layer warrants further investigation.

\subsection{Conclusions}

ATD-GCMS identified and quantified gaseous degradants using calibrated standards for target analytes, and a nontarget analysis approach was used for other components identified in the chromatograms. Given the similarity of compounds identified in 
these experiments to those found when dabbing terpenes alone, ${ }^{19}$ GP degradants seen when dabbing THC alone were also assessed. The similarity in degradation products seen, particularly the elevated levels of isoprene seen across the board, suggests an analogous degradation mechanism for cannabinoids and terpenes. Higher levels of terpenes appear to promote increased production of VOCs.

Toxicants measured were applied to a QRA calculation to estimate cancer and noncancer risks for dabbing and vaping with a CV. In order to compare these results with cannabis smoking, cannabis smoke component levels were taken from the literature and applied to a QRA calculation. This represents the first time any degradation products have been identified from vaporizing CE components and is a first step toward understanding the degradation mechanism of $\mathrm{THC}$ via this route of administration. Additionally, the work herein is the first application of QRA to cannabis smoking to the best of our knowledge.

The development of novel cannabis inhalation products has outpaced both basic and applied biomedical research. This has hindered the ability of regulatory agencies from properly informing the public about the safety of these products and their routes of administration. Future work in our labs will focus on identifying other volatile organics that have not yet been detected in the GP, such as formaldehyde and carbon monoxide, and components of the particulate phase that are potentially toxicologically relevant. Further work must assess the biological impact these aerosols have on the respiratory system. 


\subsection{Methods and materials}

\subsubsection{Materials}

Analytical-grade THC was obtained from Cayman Chemical (Ann Arbor, MI). A terpene aromatherapy mix recreating the scent of cannabis cultivar Fire OG was obtained from Blue River (Oakland, CA) and is referred to hereafter as simply "terpenes." To make SND, terpenes were introduced into THC at $\sim 10 \%$. Verispec 200 ppm Aromatic Hydrocarbons Mixture 16 Components in Methanol EPA 503.1 was obtained from Ricca Chemical Company (Arlington, TX). An isoprene SPEXOrganics Certified Reference Material analytical standard $(1000 \mathrm{\mu g} / \mathrm{mL})$ was obtained from SPEX CertiPrep (Metuchen, NJ).
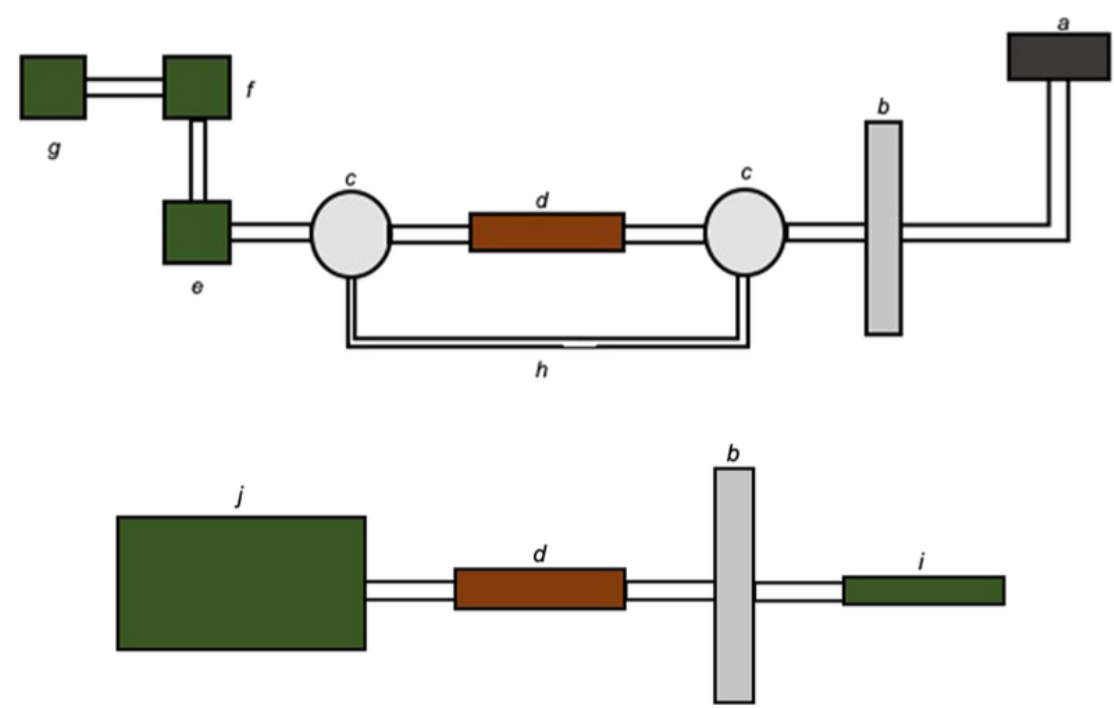

Figure 4.3: Experimental setups used for dabbing (top) and CV (bottom) vapor collection by ATD-GCMS. Components depicted are: $a$, e-nail; $b$, CFP holder; $c$, 3 -way stopcock; $d$, ATD cartridge; $e$, mass flow meter; $f$, flow control valve; $g$, vacuum source; $h$, by-pass line; $i$, CV; $j$, CSM. 


\subsubsection{Sample collection for dabbing}

An air flow was generated with a Welch 8907 rotary-vane vacuum pump (Mt. Prospect, IL), regulated with a Cole-Parmer PTFE multiturn needle valve (Vernon Hills, IL), and measured with an Aalborg GFM17 mass flow meter (Orangeburg, NY). A flow rate of $400-450 \mathrm{~mL} / \mathrm{min}$ was chosen to minimize breakthrough of volatile components from the adsorption/ thermal desorption (ATD) cartridge while maximizing vapor collection from the e-nail. The ATD cartridge was situated between two Pyrex T-Bore, three-way, glass key stopcocks (Corning, NY). Vapor was generated on a Jibtronix Corp. Errlectric Concentration Station (Gurnee, IL) e-nail heated to 370 ${ }^{\circ} \mathrm{C}$. The temperature used was chosen based on realistic use and was assessed thermographically using a FLIR System T450sc (Wilsonville, OR) as in Meehan-Atrash et al. ${ }^{19}$ A by-pass line circumventing the ATD cartridge facilitated sample collection by maintaining a constant backpressure between experiments. All connections were made using 3/8 in. outer diameter ACF0017-F Tygon S3 E-3603 (Saint-Gobain, Malvern, PA). All experiments were performed by collecting GPs generated from a single dab of $11 \pm 2.5 \mathrm{mg}$ of either THC or SND. Figure 4.3 (top) depicts the experimental setup used for collection of the aerosol GP generated from dabbing.

\subsubsection{Sample collection for CV vaping}

A CH Technologies cigarette smoking machine (CSM, Westwood, NJ) ran a puff program modified from CORESTA with $55 \mathrm{~mL}$ puff volume over a $3 \mathrm{~s}$ puff duration with an additional $1 \mathrm{~s}$ after the conclusion of each puff to clear the lines of aerosol (vaporizer button was only depressed during the $3 \mathrm{~s}$ puffs). Aerosol was generated using a CCell 
TH2 oil cartridge (Sneaky Pete vaporizers) loaded with SND and connected to an Innokin iTaste VV V3.0 variable voltage battery. The atomizer was rated at 1.4-1.5 $\Omega$ according to the digital display provided by the battery. All connections were made using 3/8 in. outer diameter ACF0017-F Tygon S3 E-3603. Vaping experiments were conducted using single puffs at three voltages chosen based on realistic use: 3.2, 4.0, and $4.8 \mathrm{~V}$, which consumed 1-4 mg of SND per puff. Figure 4.3 (bottom) depicts the experimental setup used for collection of the aerosol GP generated from vaping.

\subsubsection{Adsorption/thermal desorption gas chromatography- mass spectrometry}

GP samples were collected through a $47 \mathrm{~mm}$ Cambridge filter pad (CFP, GE Healthcare) onto an ATD cartridge, which contains $100 \mathrm{mg}$ of 35/60 mesh Tenax TA and 200 mg of 60/80 mesh Carbograph 1 TD (Camsco Inc., Houston, TX). ATD sample cartridges were thermally desorbed with a TurboMatrix 650 ATD unit (PerkinElmer, Waltham, MA). Twenty nanograms of fluorobenzene, $18.6 \mathrm{ng}$ of toluene- $d_{8}, 21.7 \mathrm{ng}$ of 4-bromofluorobenzene, and $20.3 \mathrm{ng}$ of 1,2-dichlorobenzene- $d_{4}$ were added automatically to all cartridges as ISs prior to desorption. The ATD unit thermally desorbed the ATD cartridges for $10 \mathrm{~min}$ at $285^{\circ} \mathrm{C}$ with a He desorption flow of $40 \mathrm{~mL} / \mathrm{min}$, a split flow of $10 \mathrm{~mL} / \mathrm{min}$, and the desorption stream was trapped at $-10{ }^{\circ} \mathrm{C}$ on an intermediate "Tenax trap." Thermal desorption of this intermediate trap occurred at $295{ }^{\circ} \mathrm{C}$ and 35 psi constant pressure of $\mathrm{He}$ on a split flow of $12 \mathrm{~mL} / \mathrm{min}$ for $4 \mathrm{~min}$. Through a $1 \mathrm{~m}$ long and $0.25 \mathrm{~mm}$ i.d. deactivated fused silica transfer line $\left(235{ }^{\circ} \mathrm{C}\right)$, the unsplit portion of the stream was passed on to a $60 \mathrm{~m}$ length, $0.25 \mathrm{~mm}$ i.d., and $1.4 \mu \mathrm{m}$ film thickness Agilent (Santa Clara, CA) DB-VRX capillary GC column 
mounted in an Agilent 7890A GC. The GC was interfaced to an Agilent 5975C MS in impact ionization at $70 \mathrm{eV}$ in the positive ion mode. $\mathrm{GC}$ oven temperature was held at $45{ }^{\circ} \mathrm{C}$ for $10 \mathrm{~min}$, programming to $190{ }^{\circ} \mathrm{C}$ at $12{ }^{\circ} \mathrm{C} / \mathrm{min}$, held at $190{ }^{\circ} \mathrm{C}$ for 2 min, then programming to $240{ }^{\circ} \mathrm{C}$ at $6{ }^{\circ} \mathrm{C} / \mathrm{min}$, held at $240{ }^{\circ} \mathrm{C}$ for $5 \mathrm{~min}$, and then programmed down to $210{ }^{\circ} \mathrm{C}$ at $10{ }^{\circ} \mathrm{C} / \mathrm{min}$. The MS scan range was 34 to $400 \mathrm{amu}$, and the electron multiplier voltage was $1725 \mathrm{~V}$.

\subsubsection{Quantification of components from CV vaping and dab- bing}

An ATD-GCMS IS-normalized multipoint calibration was generated for quantifying select analytes for dabbing experiments. A standardized solution of methacrolein and the components in the Verispec 200 ppm aromatic hydrocarbons mixture were made at concentrations of $6.25-200 \mathrm{ng} / \mathrm{\mu L}$ in serial dilution. An additional solution of 250 $\mathrm{ng} / \mathrm{\mu L}$ isoprene was made using the SPEXOrganics Certified Reference Material. Two microliters of each chosen standard solution was spiked through a 0.25 " Swagelok tee onto the inlet end of each ATD cartridge with a flow of $50 \mathrm{~mL} / \mathrm{min}$ of $\mathrm{N}_{2}$ gas. After spiking, the $\mathrm{N}_{2}$ flow was left on for $\sim 7$ min to purge the methanol solvent. Six ATD cartridges were amended with $0,3.125,12.5,25,50$, and 100 ng of each component from standard solutions containing methacrolein and the Verispec 200 ppm aromatic hydrocarbons mixture components. An additional cartridge was amended with 500 ng of isoprene only.

IS-RF factors for the 17 analytes used in the multipoint calibration and isoprene were calculated and used to estimate the concentration of these in the ATD-GCMS samples from three cannabis vaping experiments. Analytes in addition to those used 
in the multipoint calibration were tentatively identified by comparison of their mass spectra against those in the NIST mass spectrometry database. Quantification of some major-occurring alkenes, carbonyls, and aromatics was performed using a nontarget analysis approach based on one described in Fitch et al. ${ }^{58}$ and Allgood et al. ${ }^{59}$ Nontarget analytes were chosen based on abundance, integrated in the total ion chromatogram (TIC), and their molecular formula from the tentative match (all match qualities of $>70 \%$ ) was used to calculate their total ionization cross section $(Q)$ using the regression equation from Fitch et al. ${ }^{58}$ The $Q$ of an IS was used to determine the levels of the nontarget analyte using eq. 4.1 from Allgood et al.: ${ }^{59}$

$$
\frac{A_{a} / N_{a}}{A_{I S} / N_{I S}}=\frac{Q_{a}}{Q_{I S}}
$$

where $A$ is the integrated TIC area and $N$ is the number of moles of the analyte (a) and IS.

\subsubsection{Cannabis smoke component literature review}

Literature reports containing pertinent data were searched in multiple scientific databases including but not limited to SciFinder and Web of Science. Values for cannabis smoke HPHCs from all reports containing quantitative data were used. Smoke component identities and their measured values were pulled from the four references deemed suitable for this analysis. ${ }^{54-57}$ Other relevant information such as puff topography, cannabis consumed per experiment, and joint sizes were also noted. HPHC levels were presented as mass HPHC per joint, ${ }^{56}$ parts per million concentrations, ${ }^{54}$ mass HPHC per gram cannabis consumed, ${ }^{55}$ and mass HPHC per milligram TPM 
collected. ${ }^{57}$ All component levels identified were converted to microgram HPHC per gram of cannabis using the reported joint size. This was subsequently converted to microgram HPHC per $0.75 \mathrm{~g}$ joint, which was chosen as the standard joint mass. HPHCs were assigned CAS numbers, and levels of identical HPHCs were binned and averaged together.

\subsubsection{Quantitative risk assessment}

Toxicological metrics for cancer and chronic noncancer effects for HPCs identified in the GP of the aerosol from vaping, dabbing, and smoking were searched in relevant databases. The IUR was used for cancer risk assessment, and RELs were used for noncancer effects. IUR values were accessed from the Integrated Risk Information System (IRIS) online database provided by the United State Environmental Protection Agency ${ }^{86}$ and supplemented with values from the California Office of Environmental Health and Hazard Assessment (OEHHA) online chemical database. ${ }^{87}$ REL values were taken as an inhalation reference concentration (RfC) from IRIS ${ }^{86}$ or as a refer-

ence value (ReV) from the Texas Commission on Environmental Quality (TCEQ). ${ }^{88}$ Given the high levels of isoprene observed from vaping and dabbing, the IUR value for isoprene was found in the literature ${ }^{89}$ given its absence in IRIS, OEHHA, and TCEQ databases.

\subsubsection{Quantitative risk assessment for cancer effects}

ELCR as defined in Marano et al. ${ }^{52}$ for each HPHC $i$ for which an IUR value exists was calculated using eq. 4.2, adapted from Marano et al..52 


$$
E L C R_{i}=\frac{C Y_{i}\left(\frac{\mu g}{C U}\right) \times C R\left(\frac{C U}{d a y}\right) \times E D(\text { years }) \times I U R_{i}\left(\frac{\mu g}{m^{3}}\right)^{-1} \times E F\left(\frac{\text { days }}{\text { year }}\right)}{I R\left(\frac{m^{3}}{d a y}\right) \times A T_{C}(\text { days })}
$$

where $\mathrm{CY}_{i}$ is the yield for a given gaseous $\mathrm{HPHC}, \mathrm{CU}$ is the consumption unit, $\mathrm{CR}$ is the consumption rate, $\mathrm{ED}$ is the exposure duration, $\mathrm{EF}$ is the exposure frequency, IR is the inhalation rate, and ATC is the averaging time for cancer effects. CU is a consumption method-dependent unit (vaping: $\mathrm{CU}=$ puffs, dabbing: $\mathrm{CU}=$ dabs, and smoking: $\mathrm{CU}=$ joints $). \mathrm{CY}_{i}$ is the experimentally determined yield of a given $\mathrm{HPHC}$ given in micrograms per CU. As per United States Food and Drug Administration recommendations, ${ }^{52} \mathrm{ED}$ is taken as the difference of the default lifetime expectancy of 70 years $^{52}$ and the age of initiation, which for cannabis consumption is taken as 16 years based on literature precedence. ${ }^{90-96} \mathrm{EF}$ assumes daily consumption at 365.25 days/year. IR is taken as the human reference value of $20 \mathrm{~m}^{3} /$ day. ${ }^{52}$ ATC prorates the cumulative intake of the component over a lifetime of 70 years expressed in days (25567.5 days). ${ }^{52}$ Taking the assumption of dose additivity, the ELCR for $_{i}$ each component may be summed to obtain $\mathrm{ELCR}_{\mathrm{T}}:{ }^{50-52}$

$$
E L C R_{\mathrm{T}}=\sum_{i} E L C R_{\mathrm{T}}
$$




\subsubsection{Quantitative risk assessment for noncancer effects}

HQ, as previously defined, ${ }^{52}$ for a given component $i\left(\mathrm{HQ}_{i}\right)$ for which an REL exists was calculated using eq. 4.4, adapted from Marano et al.: ${ }^{52}$

$$
H Q_{i}=\frac{C Y_{i}\left(\frac{\mu g}{C U}\right) \times C R\left(\frac{C U}{d a y}\right) \times E D(\text { years }) \times E F\left(\frac{\text { days }}{\text { year }}\right)}{I R\left(\frac{m^{3}}{d a y}\right) \times A T_{\mathrm{NC}}(\text { days }) \times R E L_{i}\left(\frac{\mu g}{m^{3}}\right)}
$$

where $\mathrm{AT}_{\mathrm{NC}}$ is the averaging time for noncancer effects, which averages component intake over the ED, for a value of 19723.5 days assuming an ED of 54 years. HI, as previously defined, is the sum of HQ for all components for which an REL exists:

$$
H I=\sum_{i} H Q
$$

\subsection{Author information}

\subsubsection{Corresponding author}

*Email: strongin@pdx.edu

\subsubsection{ORCID}

Robert M. Strongin: 0000-0003-3777-8492 


\subsubsection{Author contributions}

Experimental design: all authors; sample collection: J.M.-A.; ATD-GCMS: W.L. and K.J.M.; data analysis: J.M.-A.; QRA: J.M.-A.; manuscript: J.M.-A. and R.M.S. All authors approved the final version of the manuscript.

\subsubsection{Funding}

We thank Portland State University for support. In addition, we thank the National Institute of Health and the Food and Drug Administration for partial support of this work via award no. R01ES025257. The content is solely the responsibility of the authors and does not necessarily represent the views of the National Institute of Health, the Food and Drug Administration, or Portland State University.

\subsubsection{Notes}

The authors declare the following competing financial interest(s): All authors except Jiries Meehan-Atrash report no competing financial interests. Jiries Meehan-Atrash reports receiving personal fees from Farm House Tomatoes, a company that has submitted a letter of intent to become a Florida medical marijuana treatment center, but has not yet submitted that application at the time of publishing.

\subsection{Acknowledgements}

We would like to acknowledge the United States Drug Enforcement Agency for their support and guidance with security and compliance. We would also like to acknowledge Alisha Ortiz for her help with experiments. 


\subsection{Abbreviations}

ATC, averaging time for cancer effects; ATD-GCMS, adsorption/thermal desorption gas chromatography-mass spectrometry; ATNC, averaging time for noncancer effects; $\mathrm{BHO}$, butane hash oil; CBD, cannabidiol; CBDA, cannabidiolic acid; CE, cannabis extract; CEVP, cannabis electronic vapor product; CFP, Cambridge filter pad; CORESTA, Cooperation Center for Scientific Research Relative to Tobacco; CR, consumption rate; $\mathrm{CU}$, consumption unit; $\mathrm{CV}$, cartridge vaporizer; $\mathrm{CY}_{i}$, component yield; ED, exposure duration; EF, exposure frequency; ELCR, excess lifetime cancer risk; GP, gas phase; HC, hydrocarbon; HI, hazard index; HPHC, harmful or potentially harmful constituent; HQ, hazard quotient; IR, inhalation rate; IRIS, Integrated Risk Information System; IS-RF, internal standard-calculated response factor; IS, internal standard; IUR, inhalation unit risk; NIST, National Institute of Standards and Technology; OEHHA, California Office of Environmental Health and Hazard Assessment; $Q$, total ionization cross section; QRA, quantitative risk assessment; REL, reference exposure level; $\mathrm{ReV}$, inhalation reference value; $\mathrm{RF}$, response factor; RfC, inhalation reference concentration; SFE, superfluid cannabis extract; SND, synthetic distillate; TCEQ, Texas Commission on Environmental Quality; THC, $\Delta^{9}$ tetrahydrocannabinol; THCA, $\Delta^{9}$-tetrahydrocannabinolic acid; TIC, total ion chromatogram; TLV, top-loading vaporizer; TPM, total particulate matter; VOC, volatile organic compound 


\subsection{References}

(1) Smart, R.; Caulkins, J. P.; Kilmer, B.; Davenport, S.; Midgette, G. Variation in cannabis potency and prices in a newly legal market: evidence from 30 million cannabis sales in Washington state. Addiction 2017, 112, 2167-2177.

(2) Kim, E.-S.; Mahlberg, P. G. Immunochemical localization of tetrahydrocannabinol (THC) in cryofixed glandular trichomes of Cannabis (Cannabaceae). Am J. Bot. $1997,84,336-342$.

(3) Sirikantaramas, S.; Taura, F.; Tanaka, Y.; Ishikawa, Y.; Morimoto, S.; Shoyama, Y. Tetrahydrocannabinolic acid synthase, the enzyme controlling marijuana psychoactivity, is secreted into the storage cavity of the glandular trichomes. Plant Cell Physiol. 2005, 46, 1578-1582.

(4) Rodziewicz, P.; Loroch, S.; Marczak, Ł.; Sickmann, A.; Kayser, O. Cannabinoid synthases and osmoprotective metabolites accumulate in the exudates of Cannabis sativa L. glandular trichomes. Plant Sci. 2019, 284, 108-116.

(5) Perrotin-Brunel, H.; Kroon, M. C.; van Roosmalen, M. J. E.; van Spronsen, J.; Peters, C. J.; Witkamp, G. J. Solubility of non- psychoactive cannabinoids in supercritical carbon dioxide and comparison with psychoactive cannabinoids. J. Supercrit. Fluids 2010, 55, 603-608.

(6) White, J.; Poovendran, D.; Kershaw, S. Cannabidiol (CBD) Pre- Review Report. Agenda Item 5.2. In. Expert Committee on Drug Dependence Thirty-ninth Meeting., World Health Organization: Geneva, 2017.

(7) Lipomed. THCA-A Specification sheet. https://www.lipomed.com/index.php? section $=$ mediadir\&cmd=specification\&eid=189 (accessed July 19, 2019). 
(8) Lipomed. Cannabidiolic acid specifications sheet. https://www.lipomed.com/ index.php?section $=$ mediadir\&cmd $=$ specification\&eid $=587($ accessed July 19, 2019) . (9) Perrotin-Brunel, H.; Buijs, W.; van Spronsen, J.; van Roosmalen, M. J. E.; Peters, C. J.; Verpoorte, R.; Witkamp, G.-J. Decarboxylation of $\Delta^{9}$-tetrahydrocannabinol: Kinetics and molecular modeling. J. Mol. Struct. 2011, 987, 67-73.

(10) Stogner, J. M.; Miller, B. L. Assessing the Dangers of "Dabbing": Mere Marijuana or Harmful New Trend? Pediatrics 2015, 136, 1-3.

(11) Stogner, J. M.; Miller, B. L. The Dabbing Dilemma: A Call for Research on Butane Hash Oil and Other Alternate Forms of Cannabis Use. Subst. Abus. 2015, $36,393-395$.

(12) Cervantes, J. The Cannabis Encyclopedia. Van Patten Publishing: Vancouver, WA, 2015, 546-547.

(13) Perrotin-Brunel, H.; Perez, P. C.; van Roosmalen, M. J. E.; van Spronsen, J.; Witkamp, G. J.; Peters, C. J. Solubility of $\Delta$ - tetrahydrocannabinol in supercritical carbon dioxide: Experiments and modeling. J. Supercrit. Fluids 2010, 52, 6-10. (14) Perrotin-Brunel, H.; van Roosmalen, M. J. E.; van Spronsen, J.; Verpoorte, R.; Peters, C. J.; Witkamp, G. J. Supercritical fluid extraction of cannabis: experiments and modelling of the process design. ISASF-Graz 2010, 1-6.

(15) Lewis, M. M.; Yang, Y.; Wasilewski, E.; Clarke, H. A.; Kotra, L. P. Chemical Profiling of Medical Cannabis Extracts. ACS Omega 2017, 2, 6091-6103.

(16) Sirius, J. High Times. What is 'Shatter' Marijuana. https:// hightimes.com/grow/ shatter-vs-wax-whats-the-difference/ (accessed July 9, 2019).

(17) Miller, M. High Times. Getting Near The Clear: A Guide To Cannabis Distillates. https://hightimes.com/culture/cannabis- distillates/ (accessed July 8, 2019). 
(18) Youtube. How to select your THC Vape Cartridge - The Terpene Institute. https://www.youtube.com/watch?v=p5ETFSljZkg (accessed July 9, 2019).

(19) Meehan-Atrash, J.; Luo, W.; Strongin, R. M. Toxicant formation in dabbing: the terpene story. ACS Omega 2017, 2, 6112-6117.

(20) Sirius, J. High Times. What is CO2 Oil? https://hightimes.com/ grow/whatis-co2-oil/ (accessed July 9, 2019).

(21) Leafly. Everything You Need to Know About Pre-Filled Oil Vape Cartridges. https://www.leafly.com/news/strains-products/what-are- pre-filled-cannabis-oil-vapecartridges (accessed July 9, 2019).

(22) Sirius, J. High Times. Vaping 101: The Proper Hash Oil for Your Pen. https:// hightimes.com/dabs/vaping-101-the-proper-hash-oil-for- your-pen/ (accessed July 9, 2019).

(23) Ward, A. Colorado Pot Guide. PG, PEG and Other Vape Cartridge Additives: Are They Safe? https://www.coloradopotguide. com/colorado-marijuanablog/article/pg-peg-and-other-vape- cartridge-additives-are-they-safe/ (accessed Aug 23, 2019).

(24) Knapp, A. A.; Lee, D. C.; Borodovsky, J. T.; Auty, S. G.; Gabrielli, J.; Budney, A. J. Emerging Trends in Cannabis Administration Among Adolescent Cannabis Users. J. Adolesc. Health 2019, 64, 487-493.

(25) Etter, J. F. Electronic cigarettes and cannabis: an exploratory study. Eur. Addict. Res. 2015, 21, 124-130.

(26) Jones, C. B.; Hill, M. L.; Pardini, D. A.; Meier, M. H. Prevalence and correlates of vaping cannabis in a sample of young adults. Psychol. Addict. Behav. 2016, 30, $915-921$. 
(27) Popova, L.; McDonald, E. A.; Sidhu, S.; Barry, R.; Maruyama Richers, T. A.; Sheon, N. M.; Ling, P. M. Perceived harms and benefits of tobacco, marijuana, and electronic vaporizers among young adults in Colorado: implications for health education and research. Addiction 2017, 112, 1821-1829.

(28) Hazekamp, A.; Ruhaak, R.; Zuurman, L.; van Gerven, J.; Verpoorte, R. Evaluation of a vaporizing device (Volcano) for the pulmonary administration of tetrahydrocannabinol. J. Pharm. Sci. 2006, 95, 1308-1317.

(29) Lanz, C.; Mattsson, J.; Soydaner, U.; Brenneisen, R. Medicinal Cannabis: In Vitro Validation of Vaporizers for the Smoke-Free Inhalation of Cannabis. PLoS One 2016, 11, No. e0147286.

(30) Hazekamp, A.; Ware, M. A.; Muller-Vahl, K. R.; Abrams, D.; Grotenhermen, F. The Medicinal Use of Cannabis and Cannabinoids- An International Cross-Sectional Survey on Administration Forms. J. Psychoactive Drugs 2013, 45, 199-210.

(31) Trivers, K. F.; Phillips, E.; Gentzke, A. S.; Tynan, M. A.; Neff, L. J. Prevalence of cannabis use in electronic cigarettes among US Youth. JAMA Pediatr. 2018, 172, 1097-1099.

(32) Eggers, M. E.; Lee, Y. O.; Jackson, J.; Wiley, J. L.; Porter, L.; Nonnemaker, J. M. Youth use of electronic vapor products and blunts for administering cannabis. Addict. Behav. 2017, 70, 79-82.

(33) Morean, M. E.; Kong, G.; Camenga, D. R.; Cavallo, D. A.; Krishnan-Sarin, S. High School Students' Use of Electronic Cigarettes to Vaporize Cannabis. Pediatrics 2015, 136, 611-616.

(34) Frohe, T.; Leeman, R. F.; Patock-Peckham, J.; Ecker, A.; Kraus, S.; Foster, D. W. Correlates of cannabis vape-pen use and knowledge among U.S. college students. 
Addict. Behav. Rep. 2018, 7, 32-39.

(35) Kilmer, B.; Caulkins, J. P.; Midgette, G.; Dahlkemper, L.; MacCoun, R. J.; Pac-

ula, R. L. Before the Grand Opening: Measuring Washington State's Marijuana Market in the Last Year Before Legalized Commercial Sales; Rand Corporation Research Reports, Drug Policy Research Center: 2013 https://www.rand.org/pubs/research_ reports/RR466.html.

(36) Sagar, K. A.; Lambros, A. M.; Dahlgren, K. M.; Smith, R. T.; Gruber, S. A. Made from concentrate? A national web survey assessing dab use in the United States. Drug Alcohol Depend. 2018, 190, 133- 142.

(37) Daniulaityte, R.; Nahhas, R. W.; Wijeratne, S.; Carlson, R. G.; Lamy, F. R.; Martins, S. S.; Boyer, E. W.; Smith, G. A.; Sheth, A. "Time for dabs": Analyzing Twitter data on marijuana concentrates across the U.S. Drug Alcohol Depend. 2015, $155,307-311$.

(38) Mikeš, F.; Waser, P. G. Marihuana Components: Effects of smoking on Dgr9Tetrahydrocannabinol and cannabidiol. Science 1971, 172, 1158-1159.

(39) Kuppers, F. J. E. M.; Lousberg, R. J. J. C.; Bercht, C. A. L.; Salemink, C. A.; Terlouw, J. K.; Heerma, W.; Laven, A. Cannabis VIII - pyrolysis of Cannabidiol. Structure Elucidation of the Main Pyrolytic Product. Tetrahedron 1973, 29, $2797-2802$.

(40) Quarles, W. Toxicology of marijuana: conditions for conversion of cannabidiol to THC upon smoking. Clin. Toxicol. 1973, 6, 211- 216.

(41) Spronck, H. J. W.; Salemink, C. A.; Alikaridis, F.; Papakadis, D. Pyrolysis of cannabinoids: a model experiment in the study of cannabis smoking. Bull. Narcotics $1978,30,55-59$. 
(42) Kuppers, F. J. E. M.; Bercht, C. A. L.; Salemink, C. A.; Lousberg, R. J. J. C.; Terlouw, J. K.; Heerma, W. Cannabis-XV: Pyrolysis of cannabidiol. Structure elucidation of four pyrolytic products. Tetrahedron 1975, 31, 1513-1516.

(43) Spronck, H. J. W.; Lousberg, R. J. J. C. Pyrolysis of cannabidiol. Structure elucidation of a major pyrolytic conversion product. Experientia 1977, 33, 705-706. (44) Kuppers, F. J. E. M.; Bercht, C. A. L.; Salemink, C. A.; Lousberg, R. J. J. C.; Terlouw, J. K.; Heerma, W. Cannabis : XIV. Pyrolysis of cannabidiol-analysis of the volatile constituents. J. Chromatogr. 1975, 108, 375-379.

(45) Luteyn, J. M.; Spronck, H. J. W.; Salemink, C. A. Cannabis XVIII: Isolation and synthesis of olivetol derivatives formed in the pyrolysis of cannabidiol. Recl. Trav. Chim. Pays-Bas 1978, 97, 187- 190.

(46) Spronck, H. J. W.; Salemink, C. A. Cannabis XVII: Pyrolysis of cannabidiol. Structure elucidation of two pyrolytic conversion products. Recl. Trav. Chim. PaysBas 1978, 97, 185-186.

(47) Tjeerdema, R. S. The pyrolysis of cannabinoids. Rev. Environ. Contam. Toxicol. 1987, 99, 61-81.

(48) ElSohly, H. N.; Elsohly, M. A. Marijuana smoke condensate: chemistry and pharmacology. In Marijuana and the cannabinoids, ElSohly, M. A., Ed. Humana Press: Totowa, New Jersey, 2007, 67-96.

(49) Varlet, V.; Concha-Lozano, N.; Berthet, A.; Plateel, G.; Favrat, B.; De Cesare, M.; Lauer, E.; Augsburger, M.; Thomas, A.; Giroud, C. Drug vaping applied to cannabis: is "cannavaping" a therapeutic alternative to marijuana? Sci. Rep. 2016, 6, 25599 .

(50) Fowles, J.; Dybing, E. Application of toxicological risk assessment principles to 
the chemical constituents of cigarette smoke. Tob. Control 2003, 12, 424-430.

(51) Pankow, J. F.; Watanabe, K. H.; Toccalino, P. L.; Luo, W. T.; Austin, D. F. Calculated cancer risks for conventional and "potentially reduced exposure product" cigarettes. Cancer Epidemiol. Biomarkers Prev. 2007, 16, 584-592.

(52) Marano, K. M.; Liu, C.; Fuller, W.; Gentry, P. R. Quantitative risk assessment of tobacco products: A potentially useful component of substantial equivalence evaluations. Regul. Toxicol. Pharmacol. 2018, 95, 371-384.

(53) United States Environmental Protection Agency, Basic Information about the Integrated Risk Information System. USEPA. https://www.epa.gov/iris/basic -information-about-integrated-risk- information-system (accessed June 6, 2019). (54) Bloor, R. N.; Wang, T. S.; Španěl, P.; Smith, D. Ammonia release from heated 'street' cannabis leaf and its potential toxic effects on cannabis users. Addiction 2008, 103, $1671-1677$.

(55) Gieringer, D.; Laurent, J. S.; Goodrich, S. Cannabis Vaporizer Combines Efficient Delivery of THC with Effective Suppression of Pyrolytic Compounds. J. Cannabis Ther. 2004, 4, 7-27.

(56) Moir, D.; Rickert, W. S.; Levasseur, G.; Larose, Y.; Maertens, R.; White, P.; Desjardins, S. A comparison of mainstream and sidestream marijuana and tobacco cigarette smoke produced under two machine smoking conditions. Chem. Res. Toxicol. 2008, 21, 494- 502.

(57) Maertens, R. M.; White, P. A.; Rickert, W.; Levasseur, G.; Douglas, G. R.; Bellier, P. V.; McNamee, J. P.; Thuppal, V.; Walker, M.; Desjardins, S. The genotoxicity of mainstream and sidestream marijuana and tobacco smoke condensates. Chem. Res. Toxicol. 2009, 22, 1406-1414. 
(58) Fitch, W. L.; Sauter, A. D. Calculation of Relative Electron Impact Total Ionization Cross Sections for Organic Molecules. Anal. Chem. 1983, 55, 832-835.

(59) Allgood, C.; Orlando, R.; Munson, B. Correlations of relative sensitivities in gas chromatography electron ionization mass spectrometry with molecular parameters. J. Am. Soc. Mass Spectrom. 1990, 1, 397-404.

(60) Raber, J. C.; Elzinga, S.; Kaplan, C. Understanding dabs: contamination concerns of cannabis concentrates and cannabinoid transfer during the act of dabbing. J. Toxicol. Sci. 2015, 40, 797-803.

(61) Van Dam, N. T.; Earleywine, M. Pulmonary function in cannabis users: Support for a clinical trial of the vaporizer. Int. J. Drug Policy 2010, 21, 511-513.

(62) Pomahacova, B.; Van der Kooy, F.; Verpoorte, R. Cannabis smoke condensate III: the cannabinoid content of vaporised Cannabis sativa. Inhalation Toxicol. 2009, 21, 1108-1112.

(63) Hashibe, M.; Morgenstern, H.; Cui, Y.; Tashkin, D. P.; Zhang, Z.-F.; Cozen, W.; Mack, T. M.; Greenland, S. Marijuana use and the risk of lung and upper aerodigestive tract cancers: Results of a population-based case-control study. Cancer Epidemiol. Biomarkers Prev. 2006, 15, 1829-1834.

(64) Hancox, R. J.; Poulton, R.; Ely, M.; Welch, D.; Taylor, D. R.; McLachlan, C. R.; Greene, J. M.; Moffitt, T. E.; Caspi, A.; Sears, M. R. Effects of cannabis on lung function: a population-based cohort study. Eur. Respir. J. 2009, 35, 42-47.

(65) Aldington, S.; Williams, M.; Nowitz, M.; Weatherall, M.; Pritchard, A.; McNaughton, A.; Robinson, G.; Beasley, R. Effects of cannabis on pulmonary structure, function and symptoms. Thorax 2007, 62, 1058-1063.

(66) Chandra, S.; Radwan, M. M.; Majumdar, C. G.; Church, J. C.; Freeman, T. P.; 
Elsohly, M. A. New trends in cannabis potency in USA and Europe during the last decade (2008-2017). Eur. Arch. Psychiatry Clin. Neurosci. 2019, 269, 5-15.

(67) Van der Kooy, F.; Pomahacova, B.; Verpoorte, R. Cannabis smoke condensate I: the effect of different preparation methods on tetrahydrocannabinol levels. Inhalation Toxicol. 2008, 20, 801-804.

(68) Zhang, L. R.; Morgenstern, H.; Greenland, S.; Chang, S.-C.; Lazarus, P.; Teare, M. D.; Woll, P. J.; Orlow, I.; Cox, B.; Brhane, Y.; Liu, G.; Hung, R. J. Cannabis smoking and lung cancer risk: Pooled analysis in the International Lung Cancer Consortium. Int. J. Cancer 2015, 136, 894-903.

(69) WHO. Cannabis a health perspective and research agenda; World Health Organization, 1997.

(70) Hädener, M.; Vieten, S.; Weinmann, W.; Mahler, H. A. preliminary investigation of lung availability of cannabinoids by smoking marijuana or dabbing BHO and decarboxylation rate of THC- and CBD-acids. Forensic Sci. Int. 2019, 295, 207-212. (71) Atkinson, R.; Arey, J. Atmospheric degradation of volatile organic compounds. Chem. Rev. 2003, 103, 4605-4638.

(72) Atkinson, R. Gas-phase Tropospheric Chemistry of Organic Compounds: A Review. Atmos. Environ. 1990, 24, 1-41.

(73) Harvey, D. J. Mass spectrometry of the cannabinoids and their metabolites. Mass Spectrom. Rev. 1987, 6, 135-229.

(74) Holler, J. M.; Smith, M. L.; Paul, S. N.; Past, M. R.; Paul, B. D. Isomerization of delta-9-THC to delta-8-THC when tested as trifluoroacetyl-, pentafluoropropionyl-, or heptafluorobutyryl- deriva- tives. J. Mass Spectrom. 2008, 43, 674-679.

(75) Terlouw, J. K.; Heerma, W.; Burgers, P. C.; Dijkstra, G.; Boon, A.; Kramer, H. 
F.; Salemink, C. A. The use of metastable ion characteristics for the determination of ion structures of some isomeric cannabinoids. Tetrahedron 1974, 30, 4243-4248. (76) Lintzeris, N.; Driels, J.; Elias, N.; Arnold, J. C.; McGregor, I. S.; Allsop, D. J. Medicinal cannabis in Australia, 2016: the Cannabis as Medicine Survey (CAMS-16). Med. J. Australia 2018, 209, 211-216.

(77) Cranford, J. A.; Bohnert, K. M.; Perron, B. E.; Bourque, C.; Ilgen, N. Prevalence and correlates of "Vaping" as a route of cannabis administration in medical cannabis patients. Drug Alcohol Depend. 2016, 169, 41-47.

(78) Huang, Y.-H. J.; Zhang, Z.-F.; Tashkin, D. P.; Feng, B.; Straif, K.; Hashibe, M. An epidemiologic review of marijuana and cancer: an update. Cancer Epidemiol. Biomarkers Prev. 2015, 24, 15-31.

(79) Ghasemiesfe, M.; Ravi, D.; Vali, M.; Korenstein, D.; Arjomandi, M.; Frank, J.; Austin, P. C.; Keyhani, S. Marijuana use, respiratory symptoms, and pulmonary function. Ann. Intern. Med. 2018, 169, 106-116.

(80) Meehan-Atrash, J.; Korzun, T.; Ziegler, A. Cannabis inhalation and voice disorders. JAMA Otolaryngol, Head Neck Surg. 2019, DOI: 10.1001/jamaoto.2019.1986. (81) Anderson, R. P.; Zechar, K. Lung injury from inhaling butane hash oil mimics pneumonia. Respir. Med. Case Rep. 2019, 26, 171- 173.

(82) Nilsson, A. M.; Bergstrom, M. A.; Luthman, K.; Nilsson, J. L. G.; Karlberg, A. T. A conjugated diene identified as a prohapten: Contact allergenic activity and chemical reactivity of proposed epoxide metabolites. Chem. Res. Toxicol. 2005, 18, $308-316$.

(83) Davies, M. J.; Birkett, J. W.; Court, O.; Mottram, A.; Zoroaster, F. The impact of cannabis smoke on the performance of pulmonary surfactant under physiologically 
relevant conditions. Surf. Interface Anal. 2018, 50, 188-197.

(84) Turcotte, C.; Blanchet, M. R.; Laviolette, M.; Flamand, N. Impact of cannabis, cannabinoids, and endocannabinoids in the lungs. Front. Pharmacol. 2016, 7, 317. (85) Pankow, J. F. A consideration of the role of gas/particle partitioning in the deposition of nicotine and other tobacco smoke compounds in the respiratory tract. Chem. Res. Toxicol. 2001, 14, 1465-1481.

(86) USEPA. Integrated Risk Information System (Online Database of Toxicity Values). United States Environmental Protection Agency: 2018, https://www.epa.gov/iris (accessed June 6, 2019)

(87) CALEPA. Online OEHHA Chemical Database. California Office of Environmental Health and Hazard Assessment, California Environmental Protection Agency: 2019, https://oehha.ca.gov/chemicals (accessed June 6, 2019).

(88) TCEQ. Development Support Documents. Texas Commission on Environmental Quality. https://www.tceq.texas.gov/toxicology/dsd (accessed June 6, 2019).

(89) Haney, J. T., Jr.; Phillips, T.; Sielken, R. L., Jr.; Valdez-Flores, C. Development of an inhalation unit risk factor for isoprene. Regul. Toxicol. Pharmacol. 2015, 73, $712-725$.

(90) Clark, T. T.; Doyle, O.; Clincy, A. Age of First Cigarette, Alcohol, and Marijuana Use Among U.S. Biracial/Ethnic Youth: A Population-Based Study. Addict. Behav. 2013, 38, 2450-2454.

(91) Hayatbakhsh, R.; Williams, G. M.; Bor, W.; Najman, J. M. Early childhood predictors of age of initiation to use of cannabis: A birth prospective study. Drug Alcohol Rev. 2013, 32, 232-240.

(92) Henchoz, Y.; N'Goran, A. A.; Baggio, S.; Deline, S.; Studer, J.; Gmel, G. As- 
sociations of age at cannabis first use and later substance abuse with mental health and depression in young men. J. Subst. Use 2015, 21, 85-91.

(93) Melchior, M.; Bolze, C.; Fombonne, E.; Surkan, P. J.; Pryor, L.; JauffretRoustide, M. Early cannabis initiation and educational attainment: is the association causal? Data from the French TEMPO study. Int. J. Epidemiol. 2017, 46, $1641-1650$.

(94) Sokol, N. A.; Okechukwu, C. A.; Chen, J. T.; Subramanian, S. V.; Rees, V. W. Maternal Cannabis Use During a Child's Lifetime Associated With Earlier Initiation. Am. J. Prev. Med. 2018, 55, 592-602.

(95) O'Connell, T. J.; Bou-Matar, C. B. Long term marijuana users seeking medical cannabis in California (2001-2007): demographics, social characteristics, patterns of cannabis and other drug use of 4117 applicants. Harm Reduct. J. 2007, 4, 16.

(96) Borodovsky, J. T.; Crosier, B. S.; Lee, D. C.; Sargent, J. D.; Budney, A. J. Smoking, vaping, eating: Is legalization impacting the way people use cannabis? Int. J. Drug Policy 2016, 36, 141-147. 


\section{The influence of terpenes on the release of volatile organic compounds and active ingredients to cannabis vaping aerosols}

Jiries Meehan-Atrash, ${ }^{\dagger}$ Wentai Luo,${ }^{\dagger} \ddagger$ Kevin J. McWhirter, ${ }^{\ddagger}$ David G. Dennis, ${ }^{\S}$ David

Sarlah, ${ }^{\S}$ Robert P. Jensen," Isaac Afreh, ${ }^{\#}$ Kelley C. Barsanti, ${ }^{\#}$ Alisha Ortiz, ${ }^{\dagger}$ and Robert M. Strongin ${ }^{* \dagger}$

†Department of Chemistry, Portland State University, Portland, OR 97207

${ }^{\ddagger}$ Department of Civil and Environmental Engineering, Portland State University, Portland, OR 97207-0751

$\S$ Roger Adams Laboratory, Department of Chemistry, University of Illinois, Urbana, IL 61801

"Florascience Inc., Milwaukie, OR 97222

\#Chemical and Environmental Engineering, Center for Environmental Research and Technology, University of California-Riverside, Riverside, CA, 92521

This manuscript has been published and is adapted from:

Meehan-Atrash, J.; Luo, W.; McWhirter, J. K.; Dennis, D. G.; Sarlah, D.; Jensen, R. P.; Afreh, I.; Barsanti, K. C.; Ortiz, A.; Strongin, R. M., The influence of terpenes on the release of volatile organic compounds and active ingredients to cannabis vaping aerosols. $R S C A d v$. 2021, 11, 11714.

DOI: $10.1039 /$ d1ra00934f

Published by the Royal Society of Chemistry

Article history:

Received: February 3, 2021

Accepted: March 4, 2021

Published: March 23, 2021 


\subsection{Abstract}

Dabbing and vaping cannabis extracts have gained large popularity in the United States as alternatives to cannabis smoking, but diversity in both available products and consumption habits make it difficult to assess consumer exposure to psychoactive ingredients and potentially harmful components. This work studies the how relative ratios of the two primary components of cannabis extracts, $\Delta^{9}$-tetrahydrocannabinol (THC) and terpenes, affect dosage of these and exposure to harmful or potentially harmful components (HPHCs). THC contains a monoterpene moiety and has been previously shown to emit similar volatile degradation products to terpenes when vaporized. Herein, the major thermal degradation mechanisms for THC and $\beta$-myrcene are elucidated via analysis of their aerosol gas phase products using automated thermal desorption-gas chromatography-mass spectrometry with the aid of isotopic labelling and chemical mechanism modelling. Four abundant products - isoprene, 2-methyl-2-butene, 3-methylcrotonaldehyde, and 3-methyl-1-butene - are shown to derive from a common radical intermediate for both THC and $\beta$-myrcene and these products comprise $18-30 \%$ of the aerosol gas phase. The relative levels of these four products are highly correlated with applied power to the e- cigarette, which indicates formation of these products is temperature dependent. Vaping THC- $\beta$-myrcene mixtures with increasing $\%$ mass of $\beta$-myrcene is correlated with less degradation of the starting material and a product distribution suggestive of a lower aerosolization temperature. By contrast, dabbing THC- $\beta$-myrcene mixtures with increasing $\%$ mass of $\beta$-myrcene is associated with higher levels of HPHCs, and isotopic labelling showed this is due to increased reactivity of $\beta$-myrcene relative to THC. 


\subsection{Introduction}

Humans have consumed cannabis for its psychoactive effect for as long as 2500 years $^{1}$ and is the most consumed illicit substance worldwide. ${ }^{2}$ Smoking dried inflorescences in a pipe or cannabis cigarette remains the most popular mode of consumption, ${ }^{3}$ but novel inhalation methods have been recently developed ${ }^{4}$ with the purpose of avoiding toxic combustion byproducts, and for more intense delivery of active ingredients and flavorings. ${ }^{5}$ Vaporizing or vaping cannabis has surged in popularity in the United States in all age groups ${ }^{6}$ particularly among adolescents. ${ }^{7}$

The two primary methods for inhaling cannabis extracts are dabbing and vaping with cannabis e-cigarettes (CECs). ${ }^{5,8}$ Dabbing is performed by placing a small amount of cannabis extract onto a heated surface while the user takes a large inhalation of up to an entire inspiratory capacity $(<3 \mathrm{~L}){ }^{5,8} \mathrm{CECs}$, commonly known as vape pens or oil pens, are compact e-cigarettes comprised of a single-use or refillable atomizer cartridge attached to variable or fixed-voltage batteries. The cartridge contains $0.3-1.0$ g cannabis oil, a viscous substance that may contain up to $90 \%$ of the psychoactive $\Delta^{9}$-tetrahydrocannabinol (THC, $\mathrm{mp}=\mathrm{rt},{ }^{9} \mathrm{bp}=416{ }^{\circ} \mathrm{C}$ (ref. 10)). ${ }^{5}$ Dabbing and CEC use have quickly surged in popularity, and one recent study showed $19.5 \%$ of past-month cannabis users reported CEC vaping, and 14.6\% reported dabbing. ${ }^{11}$

Cannabinoids are expressed in Cannabis sativa as cannabinoid acids, ${ }^{12}$ with an aryl carboxy group at the 2-position of the phenol ring (Fig. 5.1). ${ }^{13} \Delta^{9}$-Tetrahydrocannabinolic acid (THCA, mp $=70{ }^{\circ} \mathrm{C}$ (ref. 14)) decarboxylates readily to THC at temperatures seen in smoking ${ }^{15,16}$ and vaping. ${ }^{17,18}$ Butane extracts (butane hash oil, $\mathrm{BHO})$ do not experience high temperatures during production, ${ }^{19}$ primarily contain 
cannabinoid acids ${ }^{20}$ and are solid. $\mathrm{BHO}$ is typically consumed by dabbing. ${ }^{19} \mathrm{Pu}-$ rification and decarboxylation using advanced techniques isolates neutral cannabinoids and cannabis terpenes which may be reconstituted and used in a CEC. ${ }^{21}$ In addition to adding flavor, terpene blends of cannabis-derived and synthetic or botanical terpenes ${ }^{21}$ also reduce the viscosity of THC which facilitates handling and administration. ${ }^{22}$ Other ingredients added as cutting agents ${ }^{22-24}$ are extremely controversial given the recent outbreak of e-cigarette or vaping product use-associated lung injury (EVALI), in which the viscosity modifier vitamin E acetate was implicated as a potential causative agent. ${ }^{23,25,26}$
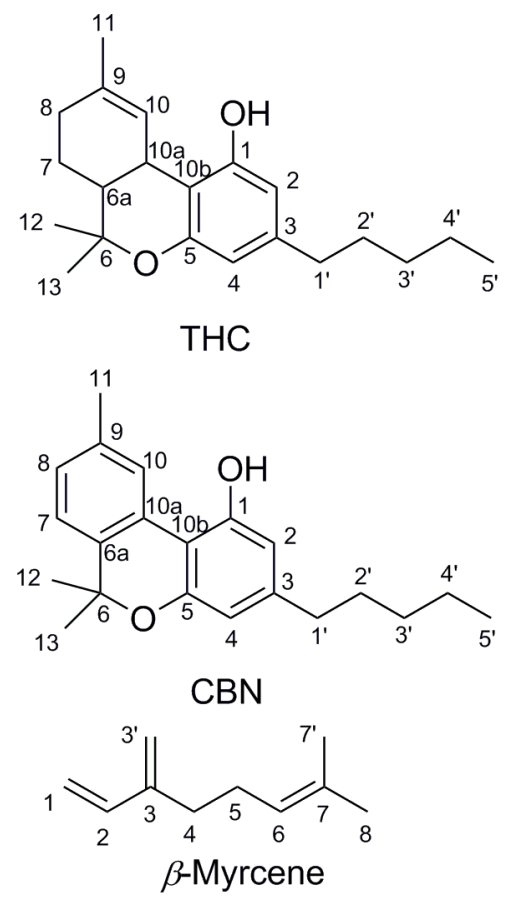

Figure 5.1: Chemical structures of $\Delta^{9}$-tetrahydrocannabinol (THC), cannabinol $(\mathrm{CBN})$, and $\beta$-myrcene shown with carbons numbered.

Volatile Organic Compounds (VOCs) in cigarette smoke $^{27}$ contribute $62 \%$ of the excess lifetime cancer risk associated with cigarette smoking. ${ }^{28}$ VOCs present 
in cannabis vaporizer aerosols are significantly different from those in tobacco and cannabis smoke. They consist largely of terpenes and terpene pyrolysis and oxidation products such as isoprene, methacrolein (MACR), methyl vinyl ketone (MVK), and 3-methyl-furan, among others. ${ }^{5,8}$ Exposure to terpene oxidation products causes sensory irritation and airflow limitation in exposed mice, ${ }^{29}$ and gaseous products are indicated to be responsible for the majority of these symptoms. ${ }^{30}$ In humans, exposure to terpenes and terpene/isoprene oxidation products at concentrations typical of indoor air do not significantly cause airway inflammation or sensory irritation, ${ }^{31}$ but the impact of inhaling these products at concentrations orders of magnitude greater than in indoor air has not been thoroughly investigated.

Automated thermal desorption-gas chromatography-mass spectrometry (ATD-GC$\mathrm{MS}$ ) is a powerful analytical technique that allows the identification and quantification of gases at trace levels for applications such as the atmospheric analysis of anthropogenic VOCs, ${ }^{32,33}$ metabolomics, ${ }^{34}{ }^{\varsigma} 36$ and materials analysis. ${ }^{37,38}$ In the e-cigarette aerosol analysis field, ATD-GC-MS has allowed the determination of gas/particle partitioning constants of e-cigarette ingredients ${ }^{39}$ including nicotine in heat-not-burn tobacco vaporizers ${ }^{40}$ as well as the identification of myriad degradation products emitted by both nicotine and cannabis vaporizers. ${ }^{5,8,41}$

It was previously shown that the addition of $10 \%$ cannabis terpenes to THC was associated with an increase in the levels of all VOCs as compared to pure THC when these were subjected to dabbing. ${ }^{5}$ Herein, the degradation of a model cannabis terpene, $\beta$-myrcene, and THC are studied mechanistically, and a site-specifically isotopically-labelled $\beta$-myrcene is used to track this terpene's degradation during dabbing THC- $\beta$-myrcene mixtures. Given the popularity of CEC vaping, VOCs re- 
leased by a popular CEC containing THC with variable terpene content are studied to investigate how added terpenes and applied power impact the nature and quantity of gas phase VOCs. Additionally, the impact of applied power on the release of HPHCs, terpenes, and THC per puff is investigated, providing insight into aerosolization efficiency and dosing of a popular type of cannabis vaporizer.

\subsection{Materials and methods}

\subsubsection{Synthetic cannabis oil (SCO)}

THC (Cayman Chemical, Ann Arbor, MI) was acquired as a $50 \mathrm{mg} \mathrm{mL} \mathrm{m}^{-1}$ solution in acetonitrile, which was concentrated in vacuo. Pure THC was assessed for purity by high performance liquid chromatography with UV-vis detection (HPLC-UV) and nuclear magnetic resonance spectroscopy (NMR). THC was used alone in vaping or dabbing experiments, or mixed with $\beta$-myrcene (Sigma Aldrich) or $\beta$-myrcene- $d_{6}$ for studies using SCO. THC and $\beta$-myrcene mixtures were homogenized in scintillation vials using a rotary evaporator slowly spinning at atmospheric pressure with the vial partially submerged in a $50{ }^{\circ} \mathrm{C}$ water bath for $1-2$ hours. THC content was assessed by HPLC-UV. See SI for $\beta$-myrcene- $d_{6}$ synthetic methodology and spectral characterization.

\subsubsection{Dabbing and vaping}

SCO containing $\beta$-myrcene- $d_{6}$ and THC, pure $\beta$-myrcene- $d_{6}$, and pure THC were subjected to dabbing as per a previously established dabbing protocol..$^{5}$ A novel CEC vaping protocol is described herein for chemical analysis of the aerosol gas phase 
(GP) and quantification of THC in the particle phase. Aerosols were generated using a TH2 CCELL connected to an iStick PICO battery. Cambridge filter pads (CFPs) were used to collect and remove particulate matter (PM), and GP products were collected on sorbent tubes containing a mixture of Tenax TA and Carbograph 1 sorbent materials. Airflow was generated using a Cigarette Smoking Machine used to generate puffs replicating the e-cigarette puff profile defined by the Cooperation Center for Scientific Research Relative to Tobacco (CORESTA) (50 mL puff volume, 3 s puff duration). ${ }^{42}$ A mass flowmeter was used to monitor puff volume, and an average of $44 \pm 3 \mathrm{~mL}$ volume and $0.87 \pm 0.05 \mathrm{~L} \mathrm{~min}^{-1}$ flowrate were observed. The battery was manually activated which caused small variations in puff duration, but puff durations were not recorded. Variation in flowrate through the sorbent material caused differences in puff volume between samples, but no significant differences ( $p$ $<0.05)$ in flowrate or puff volume exist between any two sample sets. A single puff was collected per replicate to limit over- loading the GC-MS. The vaporizer atomizer was weighed before and after each puff to obtain the mass consumed per puff $\left(m_{C}\right)$. See Supporting Information (SI) for further details.

\subsubsection{Aerosols gas phase analysis}

Sorbent tubes were stored at $-20{ }^{\circ} \mathrm{C}$ for not more than seven days before analysis. Sample tubes were desorbed using a TurboMatrix 650 automated thermal desorption unit, and were amended with internal standards prior to desorption. Following desorption, samples were trapped, desorbed and transferred to an Agilent 7890A gas chromatograph for separation, interfaced with an Agilent 5975C mass spectrometer (MS) for detection. See SI for further ATD-GC-MS details. 


\subsubsection{THC transfer analysis}

THC transfer per puff $\left(\mathrm{THC}_{\mathrm{T}}\right)$ was determined for CEC vaping experiments only. Aerosol PM analysis is sufficient for assessing $\mathrm{THC}_{\mathrm{T}}$, as its low vapor pressure (2.6 $\left.\times 10^{-5} \mathrm{~Pa}\right)^{10}$ affords it a high theoretically-calculated gas/particle partitioning constant $\left(K_{\mathrm{p}}=0.31\right.$, calculated using Pankow $\left.[2001]^{43}\right)$, with $100.00 \%$ partitioned to the aerosol PM. CFPs were extracted in 1:1 methanol:acetonitrile, added with an internal standard (olivetol), and analyzed for THC content by HPLC-UV on a six-point internal standard calibration curve. See SI for further details.

\subsubsection{Data analysis and statistics}

Semi-quantitative cannabinoid and terpene dabbing experiments were performed in duplicate, and quantitative CEC vaping experiments were carried out using 3-6 replicates. For semi-quantitative ATD-GC-MS studies, single air blanks were collected and compounds present in the air were manually removed from sample data sets. For CEC vaping experiments, air blanks were collected in triplicate, and VOCs present in the air were quantified per volume unit of air, and the air-contribution of VOCs was accounted for. Quantification of GP analytes by ATD-GC-MS was performed by comparing their total ion chromatogram integrations to that of an internal standard (fluorobenzene or 1,2-dichlorobenzene- $d_{4}$ ), assuming a 1:1 response factor. To provide higher accuracy for HPHCs with toxicological significance, their response factors relative to internal standard were determined by estimating their ionization cross section. Outliers were removed when appropriate using a Grubb's test performed at the $95 \%$ confidence level. All values are presented as $\bar{x} \pm 95 \%$ confidence interval, unless 
otherwise noted, and all significance tests were performed considering $p<0.05$. See SI for further details.

\subsection{Results and discussion}

\subsubsection{The thermal degradation of $\beta$-myrcene}

Humans The thermal degradation of $\beta$-myrcene, a ubiquitous and often dominant terpene present in many inhalable cannabis products, was characterized extensively herein to help reveal the influence of terpenes on dabbing and vaping using a CEC. A site-specifically isotopically-labelled $\beta$-myrcene, $\beta$-myrcene- $d_{6}$ (Fig. 5.2) was subjected to dabbing, and isotopologues of known degradants were identified by examination of their mass spectra. A sample chromatogram is displayed in the SI (Fig. 10.10). The diversity of degradation products seen for $\beta$-myrcene dabbing suggest that many degradation pathways exist, but a mechanism can be ascribed to account for $30 \%$ of the formed VOCs, including the most abundant product, isoprene (Fig. 5.2). After homolytic cleavage between carbons 4 and $5,{ }^{44}$ radicals $\mathbf{1}$ and $\mathbf{2}$ are formed. Resonance structure 1a undergoes oxidation to form 3-methylcrotonaldehyde- $d_{6}\left(3 \mathrm{MCA}-d_{6}\right)$, or is reduced by an alkyl $\mathrm{R}-\mathrm{H}$ to form 2 -methyl-2-butene- $d_{6}\left(2 \mathrm{M} 2 \mathrm{~B}-d_{6}\right)$. The tertiary radical $\mathbf{1 b}$ oxidizes to the isoprene deuterium isotopologue isoprene- $d_{5}$, or undergoes reduction to 3 -methyl-1-butene- $d_{6}\left(3 \mathrm{M} 1 \mathrm{~B}-d_{6}\right)$. Radical 2 undergoes reduction to isoprene, but no oxidation products of this radical are observed.

MACR and MVK, two abundant and toxicologically-concerning VOCs observed in all terpene and cannabinoid vaping experiments, are known isoprene oxidation

products. ${ }^{45,46}$ During atmospheric oxidation of isoprene, the formation of MVK is 


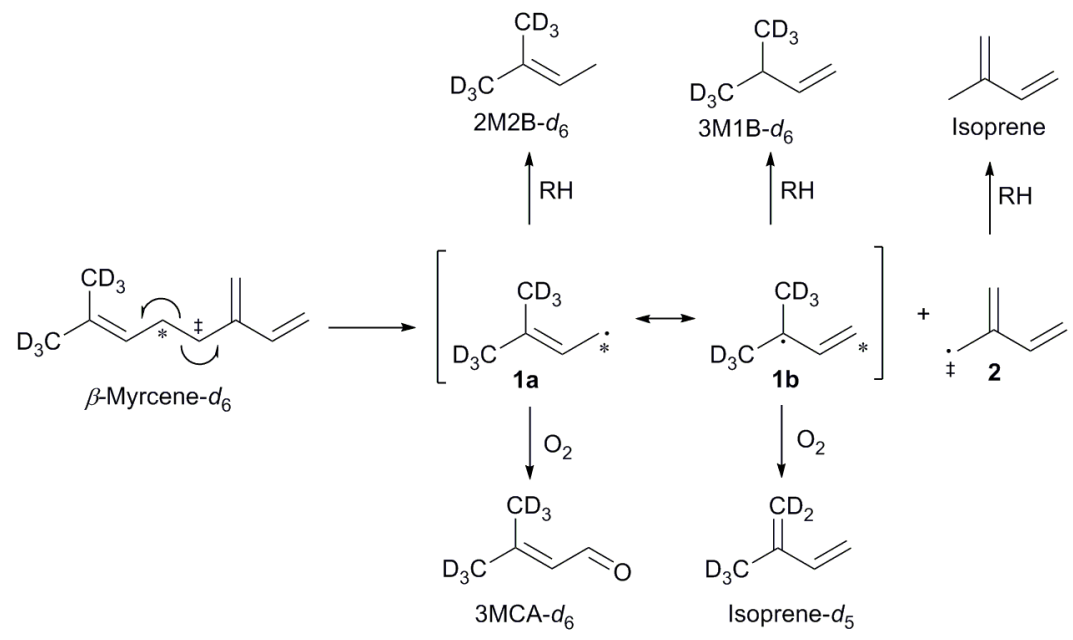

Figure 5.2: Proposed mechanism for the thermal degradation of $\beta$-myrcene- $d_{6}$. The natural isotopologues of these reactions products compose $30 \%$ of the $\mathrm{VOC}_{N T}$ observed for $\beta$-myrcene.

more favorable than MACR due to its more stable reactive intermediates. ${ }^{45,46}$ For terpene and cannabinoid vaping experiments, a MACR:MVK ratio of 10 is typically observed, ${ }^{5,8}$ contrary to what would be expected. ${ }^{45,46}$ Two gas phase chemical mechanism generators and box models, SAPRC and GECKO-A, were used to derive chemical mechanisms for $\beta$-myrcene oxidation under vaping conditions; SAPRC was also used to predict levels of product formation in the vapor stream immediately following the heat source (simulation conditions: $300 \mathrm{ppm}$ gaseous $\beta$-myrcene, $643 \mathrm{~K})$. The chemical mechanism derived using GECKO-A was consistent with the experimentally derived mechanism supported by the deuterium incorporation in the isotopologues of MACR and MVK that were observed (MACR- $d_{3}$ and MVK- $d_{3}$, Fig. 10.8 and 10.9). Importantly, SAPRC predicted an elevated MACR:MVK ratio that generally increased as a function of temperature and was 10 at $643 \mathrm{~K}$. See SI for details regarding chemical mechanism modelling. 


\subsubsection{Thermal degradation of $\Delta^{9}$-tetrahydrocannabinol}

The thermal degradation of cannabinoids has been previously investigated from a chemical perspective with the focus on identifying novel, high molecular weight products that may have mutagenic or carcinogenic potential. ${ }^{47}$ Many of the chemical transformations observed involve the $p$-menthyl ring on THC and cannabidiol (CBD), and CBD pyrolysis products such as 2-methyl-5-pentylresorcinol and 5-pentylresorcinol indicate this terpenoid moiety may be lost entirely. ${ }^{47-50}$ GP degradants emitted by pure THC subjected to dabbing were previously reported by us, and as with the case for $\mathrm{CBD}$, the $p$-menthyl moiety was hypothesized to be particularly labile given the high levels of isoprene, MACR, and other known terpene- and isoprene-derived degradants. ${ }^{5}$

Given the known topography associated with CEC vaping, THC degradation was investigated using this type of device to provide a per-puff-based quantitation of the VOCs released to the aerosol GP. Pure THC was introduced in a CCELL TH2 atomizer and the aerosol GPs from single puffs at $10 \mathrm{~W}$ using the CORESTA puffing topography for e-cigarettes were collected (in triplicate) and characterized by ATDGC-MS. The resultant chromatograms display particularly elevated levels of isoprene, substituted C6-C10 dienes, and aromatics such as toluene and xylenes, with a total of $6.3 \pm 0.4 \mathrm{\mu g}$ of total VOCs $\left(\mathrm{VOC}_{\mathrm{T}}\right)$ in the aerosol GP quantified by non-target analysis. THC was also subjected to dabbing for qualitative analysis of its product

distribution. See SI for a sample chromatogram, a full list of products tentatively identified.

In order to determine the origin of these degradation products, cannabinol (CBN, Fig. 5.1), was subjected to identical vaping conditions as THC. CBN is a THC 
oxidation product that forms during storage and processing. ${ }^{51} \mathrm{CBN}$ shares identical structural features with THC except for the aromatic thymyl ring, and CBN has only limited psychoactivity when compared with THC. ${ }^{52} \mathrm{CBN}$ vaporized in a CEC shows a starkly different aerosol GP that consists almost entirely of 1-butene, 1propene, 1-pentene, butanal, propanal, and pentanal. $\mathrm{C}-\mathrm{C}$ bond scission on the alkyl chain releases $1^{\circ}$ alkyl radicals that form peroxy radicals after $\mathrm{O}_{2}$ addition, which subsequently undergo intra-molecular rearrangement to hydroperoxy radicals that decompose to an alkene, or may undergo direct beta scission to an aldehyde. The quantity of VOCs released by CBN $(0.6 \pm 0.3 \mu \mathrm{g})$ is 10 -fold lower than those released by THC vaporized under identical conditions.

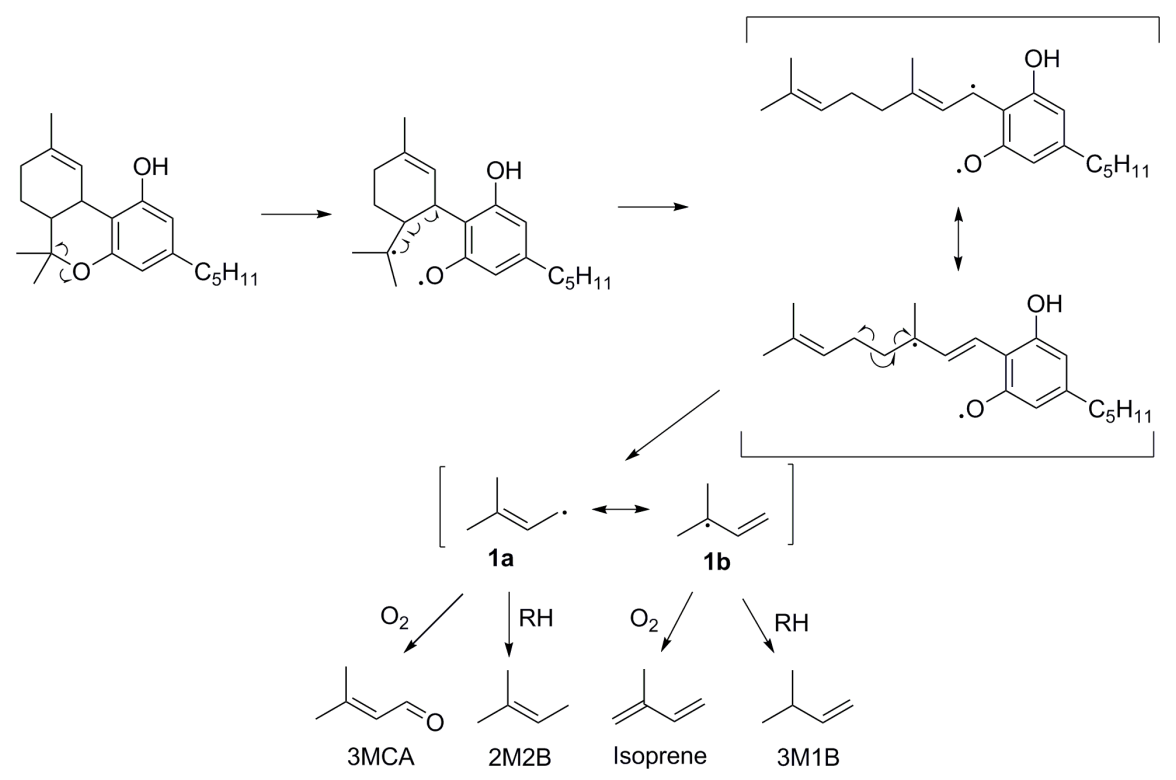

Figure 5.3: The proposed reaction scheme for a major thermal degradation pathway of $\mathrm{THC}$ which accounts for $22 \pm 6 \%$ of $\mathrm{VOC}_{\mathrm{T}}$ when $\mathrm{THC}$ is vaporized alone in a $\mathrm{CEC}$ at $10 \mathrm{~W}$, and $18 \pm 4 \%$ of $\mathrm{VOC}_{\mathrm{T}}$ when $\mathrm{THC}$ is vaporized alone by dabbing at $370{ }^{\circ} \mathrm{C}$.

The lack of isoprene and terpene-related degradation products in CBN's VOC profile is strong evidence that THC's $p$-menthyl ring accounts for the majority of 
THC's thermal degradation products. Moreover, the starkly increased quantity of VOCs (significant at $p<0.05$ ) suggest this is a particularly labile structure. Fig. 5.3 is proposed pathway of THC decomposition accounting for $23 \pm 6 \%$ of its $\mathrm{VOC}_{\mathrm{T}}$ for vaping THC in a CEC. The initial bond scission between carbon 6 and $\mathrm{O}$ is likely the most thermodynamically favorable to occur in THC given the stability of the two resultant radicals $\left(3^{\circ}\right.$ and phenoxyl). Subsequent beta scission opens the $p$-menthyl ring resulting in a cannabigerol-like diradical with a linear terpene moiety that readily decomposes to release the same radical formed during $\beta$-myrcene thermal degradation (1), and consequently, four of the same products are released: 3MCA, 2M2B, isoprene, and 3M1B. THC subjected to dabbing releases elevated levels of oxidation products, with $30 \pm 10 \%(\mathrm{n}=2)$ carbonyls relative to all other GP products tentatively identified, which is significantly higher than THC vaporized in a CEC with $2.1 \pm 0.9 \%(\mathrm{n}=4)$ carbonyls.

\subsubsection{Increased terpene content leads to elevated release of degradation products for dabbing}

Many different types of dabbing apparatuses exist, but even for two consumers using the same device, the process by which they heat the nail, administer the dab, and take the inhalation may vary greatly. The two primary generalities that can be extrapolated are: the use of a nail, and a high inhalation volume. The experiments herein use an electrically heated titanium nail that is directly connected to CFP holder via a small glass adapter. Air flow generated by a laboratory vacuum pump is adjusted with a needle valve and monitored with a mass flow meter to generate enough flow $\left(1-2 \mathrm{~L} \mathrm{~min}^{-1}\right)$ so that the aerosol stream is pulled through the nail. 
We previously reported levels of HPHCs and all VOCs for dabbing a synthetic cannabis extract containing $10 \%$ of a cannabis terpenes mixture in THC, and showed that this mixture releases higher levels of all VOCs as compared to pure THC, and higher levels of selected toxicants compared to vaping a THC-terpene mix. ${ }^{5}$ It was hypothesized that terpenes may be more thermally labile than THC, and thus responsible for the increased quantity of degradation products. In order to test this, THC- $\beta$-myrcene mixtures were subjected to dabbing at $370{ }^{\circ} \mathrm{C}$ (a typical dabbing temperature ${ }^{5}$ ) using a previously reported dabbing method, ${ }^{5}$ and the levels of known degradants and their D-isotopologues were compared. Fig. 5.4 displays the levels of select degradants and their D-isotopologues as $\mu \mathrm{mg}^{-1}$ of PM collected on CFPs for pure THC, THC with $5 \% \beta$-myrcene- $d_{6}$, and THC with $9 \% \beta$-myrcene- $d_{6}$.

Aerosol levels of major HPHCs known to exist when vaping cannabis oil components $^{5,8}$ (isoprene, MACR, and MVK) increased with increasing \% mass of $\beta$-myrcene- $d_{6}$, and the elevated levels of their isotopologues that are known to derive from $\beta$-myrcene- $d_{6}$ suggest this terpene was responsible for disproportionately more HPHCs compared to THC. Accounting for the isoprene-isoprene- $d_{5}$ ratio of $0.45 \pm 0.02$ observed when pure $\beta$-myrcene- $d_{6}$ is subjected to dabbing, in the THC- $\beta$ myrcene mixture containing $5 \% \beta$-myrcene- $d_{6}$, the terpene affords a $0.75 \%$ yield of isoprene, while THC produces only $0.15 \%$. For the THC- $\beta$-myrcene mix containing $9 \% \beta$-myrcene- $d_{6}$, the terpene results in a $1.9 \%$ yield of isoprene, and THC a yield of $0.3 \%$.

The higher yield of isoprene from $\beta$-myrcene may be explained via a combination of several factors. Isoprene has a more direct route to formation from $\beta$-myrcene than from THC, requiring less energy to generate this product. Additionally, $\beta$ - 


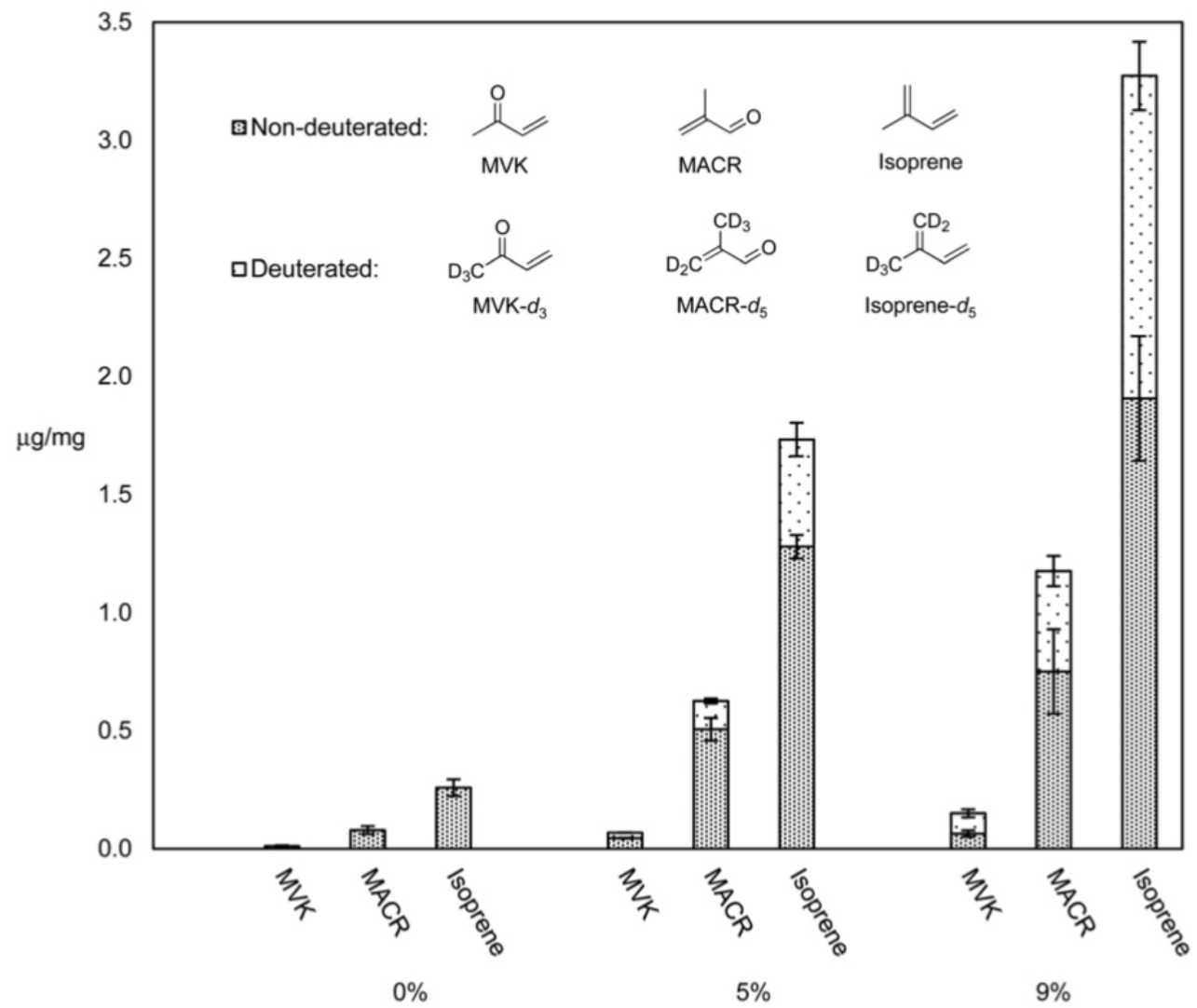

Figure 5.4: Comparative levels of major degradation products and their deuterated isotopologues encountered in the aerosol GP from dabbing pure THC $(0 \% \beta$-myrcene$d_{6}$ ), THC with $5 \% \beta$-myrcene- $d_{6}$, and THC with $9 \% \beta$-myrcene- $d_{6}$. Error bars are SEM.

myrcene partitions mostly to the aerosol GP, facilitating these reactions that are known to occur in this state. ${ }^{45,46,53,54} \mathrm{THC}$ only has an appreciable distribution to GP at elevated temperatures directly surrounding the nail, but quickly condenses to $\mathrm{PM}$, allowing less time for GP reactions to occur. $\beta$-Myrcene's smaller size and many fewer degrees of freedom than THC affords it a smaller molar heat capacity than THC, increasing the likelihood of bond homolysis with applied heat. 


\subsubsection{Increased terpene content in cannabis oil decreases degra- dation and increases transfer of starting materials for cannabis e-cigarette vaping}

VOCs released from vaping SCO in a CEC using THC and a commercially-available terpene mixture have been previously reported by us. ${ }^{5}$ Unlike the case with dabbing, this method's similarity to traditional nicotine e-cigarettes permits the usage of a standardized vaping topography (CORESTA ${ }^{42}$ ) in the experiments, and it is possible to extract quantitative data related to starting material transfer (THC and $\beta$-myrcene), the quantity of SCO consumed, and VOC emissions on a per-puff basis. As with the case with the above dabbing experiments, these experiments used $\beta$-myrcene as a model terpene to test how this cannabis oil component impacts aerosolization during vaping.

Pure THC, THC with $7.2 \% \beta$-myrcene, and $14 \% \beta$-myrcene were added to CCELL TH2 atomizers and vaporized at $10 \mathrm{~W}$. Mass of SCO consumed $\left(m_{C}\right.$, Table 5.1) did not significantly change as $\beta$-myrcene $\%$ mass increased from $0 \%$ (pure THC) to $7.2 \%$, and decreased non-significantly as $\%$ mass increased to $14 \%$. $\mathrm{THC}_{\mathrm{T}}$ increased significantly in a linear fashion $\left(R^{2}=0.99\right)$ with increasing $\beta$-myrcene $\%$ mass. THC yield $\left(\mathrm{THC}_{\mathrm{Y}}\right)$ increased significantly in a linear fashion $\left(R^{2}=0.98\right)$ upon increasing the $\beta$-myrcene $\%$ mass. $\beta$-Myrcene transfer $\left(\beta\right.$-myrcene $\left._{\mathrm{T}}\right)$ expectedly doubled as the $\%$ mass $\beta$-myrcene doubled from $7.2 \%$ to $14 \%$, but the yield of $\beta$-myrcene ( $\beta$ myrcene $_{Y}$ ) did not significantly change.

Some HPHCs previously identified in the cannabis vaporizer aerosol GP that have a calculated inhalation unit risk or reference exposure level values with regard to 


\begin{tabular}{|c|c|c|c|c|c|c|}
\hline & \multicolumn{3}{|c|}{$\% \beta$-myrcene in THC } & \multicolumn{3}{|c|}{ Power } \\
\hline & $0 \%$ & $7 \%$ & $14 \%$ & $8 \mathrm{~W}$ & $10 \mathrm{~W}$ & $12 \mathrm{~W}$ \\
\hline$n$ & 4 & 6 & 5 & 3 & 5 & 3 \\
\hline$m_{C}(\mathrm{mg})$ & $5 \pm 3$ & $5 \pm 4$ & $7 \pm 3$ & $4 \pm 1$ & $7 \pm 3$ & $7 \pm 2$ \\
\hline $\mathrm{THC}_{\mathrm{T}}(\mathrm{mg})$ & $1.6 \pm 0.6$ & $3 \pm 2$ & $4 \pm 1$ & $2.9 \pm 0.2$ & $5 \pm 1$ & $5 \pm 1$ \\
\hline $\mathrm{THC}_{\mathrm{T}}(\%)$ & $4 \times 10^{1} \pm 2 \times 10^{1}$ & $5 \times 10^{1} \pm 2 \times 10^{1}$ & $8 \times 10^{1} \pm 1 \times 10^{1}$ & $9 \times 10^{1} \pm 3 \times 10^{1}$ & $8 \times 10^{1} \pm 1 \times 10^{1}$ & $8 \times 10^{1} \pm 1 \times 10^{1}$ \\
\hline$\beta$-Myrcene $_{\mathrm{T}}(\mu \mathrm{g})$ & $0 \pm 0$ & $8 \pm 5$ & $17 \pm 6$ & $18 \pm 4$ & $17 \pm 8$ & $12 \pm 3$ \\
\hline$\beta$-Myrceney $(\%)$ & NA & $2.2 \pm 0.6$ & $1.8 \pm 0.9$ & $3.3 \pm 0.4$ & $1.8 \pm 0.9$ & $1.4 \pm 0.4$ \\
\hline psi-Limonene $_{\mathrm{T}}(\mu \mathrm{g})$ & $0 \pm 0$ & $3 \pm 3$ & $9 \pm 3$ & $9 \pm 2$ & $9 \pm 4$ & $6 \pm 2$ \\
\hline $\operatorname{VOC}_{\mathrm{NT}}(\mu \mathrm{g})$ & $6.3 \pm 0.4$ & $9 \pm 4$ & $5 \pm 1$ & $3 \pm 1$ & $5 \pm 1$ & $9 \pm 2$ \\
\hline Isoprene ( $\mathrm{kg})$ & $1.35 \pm 0.04$ & $1.5 \pm 0.5$ & $0.5 \pm 0.2$ & $0.07 \pm 0.02$ & $0.5 \pm 0.2$ & $1.5 \pm 0.1$ \\
\hline Isoprene epoxide (ng) & $7 \pm 4$ & $5 \pm 3$ & $3 \pm 1$ & $0.59 \pm 0.01$ & $3 \pm 1$ & $4 \pm 3$ \\
\hline $1,3-\mathrm{BD}$ (ng) & $12 \pm 8$ & $13 \pm 9$ & $3 \pm 1$ & $3 \pm 1$ & $3 \pm 2$ & $6 \pm 8$ \\
\hline MACR (ng) & $41 \pm 3$ & $4 \times 10^{1} \pm 2 \times 10^{1}$ & $16 \pm 5$ & $5 \pm 2$ & $16 \pm 8$ & $31 \pm 9$ \\
\hline MVK (ng) & $39 \pm 3$ & $5 \times 10^{1} \pm 2 \times 10^{1}$ & $22 \pm 4$ & $5 \pm 7$ & $22 \pm 6$ & $4 \times 10^{1} \pm 2 \times 10^{1}$ \\
\hline Butanal (ng) & $11 \pm 3$ & $7 \pm 2$ & $5.8 \pm 0.8$ & $0.8 \pm 0.2$ & $6 \pm 1$ & $4 \pm 2$ \\
\hline Benzene (ng) & $10 \pm 4$ & $3 \times 10^{1} \pm 4 \times 10^{1}$ & $2 \pm 2$ & $0 \pm 0$ & $2 \pm 3$ & $4 \pm 3$ \\
\hline Toluene (ng) & $1 \times 10^{2} \pm 2 \times 10^{1}$ & $2 \times 10^{2} \pm 2 \times 10^{2}$ & $2 \times 10^{1} \pm 1 \times 10^{1}$ & $10 \pm 7$ & $3 \times 10^{1} \pm 1 \times 10^{1}$ & $8 \times 10^{1} \pm 5 \times 10^{1}$ \\
\hline Xylenes (ng) & $2.4 \times 10^{2} \pm 3 \times 10^{1}$ & $4 \times 10^{2} \pm 4 \times 10^{2}$ & $2 \times 10^{1} \pm 2 \times 10^{1}$ & $2 \times 10^{1} \pm 2 \times 10^{1}$ & $2 \times 10^{1} \pm 3 \times 10^{1}$ & $1 \times 10^{2} \pm 1 \times 10^{2}$ \\
\hline
\end{tabular}

Table 5.1: CEC vaping experiments in which both terpene content and power level were studied to probe their effect on yields of active ingredients and degradation products. For the experiments wherein $\%$ mass $\beta$-myrcene was the variable, power level was kept at a constant $10 \mathrm{~W}$. For the experiments wherein power level was varied, \% mass $\beta$-myrcene in CVL was $14 \%$

their cancer or non-cancer chronic exposure risk were measured and are displayed in Table 5.1. ${ }^{5}$ Isoprene epoxide was identified in all ATD-GC-MS chromatograms, and quantitative data for this compound was also included in Table 5.1 as this molecule is known to mediate the mutagenic effect of isoprene. ${ }^{55}$ Overall, the highest $\beta$-myrcene $\%$ mass tested, 14\%, resulted in the lowest overall delivery of HPHCs. Pure THC and the SCO with $7.2 \% \beta$-myrcene release similar levels of all HPHCs.

These results suggest THC and terpene transfer occur with less degradation as terpene $\%$ mass increases, and that the vaporizer operates with higher overall efficiency at the highest terpene $\%$ mass tested, $14 \%$. The lower boiling point of $\beta$-myrcene $\left(167{ }^{\circ} \mathrm{C}\right.$ (ref. 56)) compared to $\mathrm{THC}\left(417^{\circ} \mathrm{C}\right.$ (ref. 10)) may translate to a reduced boiling point of the mixture, depressing the aerosolization temperature. $\beta$-Myrcene's enthalpy of vaporization may further depress reaction temperature. In addition to these effects, the observably lower viscosity of $14 \% \beta$-myrcene likely facilitates wicking and improves atomizer efficiency. 


\subsubsection{Applied electrical power increases degradation products and decreases transfer of starting materials for cannabis e-cigarette vaping}

Herein we report the influence of power level applied to the CEC atomizer on the release of active ingredients and VOCs from an idealized cannabis e-cigarette that contains THC with $14 \%$ mass $\beta$-myrcene, a composition seen in many available products. ${ }^{21}$ Two power levels above and below an acceptable and recommended power level for CCELL atomizers (10 W (ref. 57 and 58)) were used in this investigation: 8,10 , and $12 \mathrm{~W}$. The relationship between power level at the atomizer and active ingredient transfer for vaporized THC with $14 \%$ mass $\beta$-myrcene in a CEC displayed both linear and non-linear correlations (Table 5.1). $\mathrm{THC}_{\mathrm{T}}$ and $m_{C}$ both increased significantly from 8-10 W, but did not significantly change from 10-12 W. Correspondingly, $\mathrm{THC}_{\mathrm{Y}}$ decreased significantly from 8-10 W, but did not significantly change from $10-12 \mathrm{~W}$.

The observation of pseudolimonene (psi-limonene, Fig. 10.12) in the ATD-GC-MS chromatogram of the aerosol was unexpected, but this product has been reported as a byproduct of $\beta$-myrcene synthesis via pyrolysis of $\beta$-pinene. ${ }^{59}$ psi-Limonene occurred at a near-uniform 1:2 ratio $(\beta$-myrcene:psi-limonene $=2.04 \pm 0.04)$ when vaping the $14 \% \beta$-myrcene in THC. Levels of $\beta$-myrcene ${ }_{\mathrm{T}}$ and psi-limonene ${ }_{\mathrm{T}}$ did not significantly change from 8-10 W but decreased significantly as power increased from 10-12 W.

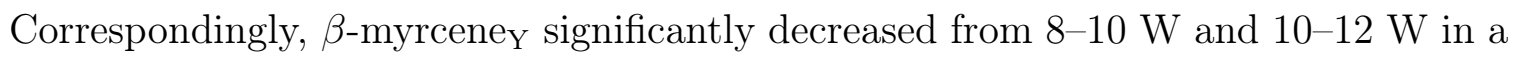
linear fashion $\left(R^{2}=0.92\right)$. $\mathrm{VOC}_{\mathrm{NT}}$ increased significantly from $8-10 \mathrm{~W}$ and $10-12$ $\mathrm{W}$ in a linear fashion $\left(R^{2}=0.95\right)$. 
With regards to the release of HPHCs to the aerosol GP from vaping synthetic SCO, power level increased the amount of HPHC delivered per puff (Table 5.1). Linear correlations (all $R^{2}>0.9$ ) are observed for isoprene, MACR, MVK, benzene, toluene, and isoprene epoxide. Butanal, xylenes, and butadiene displayed non-linearities that likely stemmed from integration error, which may be remedied by external calibration for more accurate data if necessary. Together these results indicate that this type of vaporizer should ideally be operated at the lowest power setting possible to avoid degradation of the starting material and production of HPHCs.

\subsubsection{Terpene and power levels influence the major degrada- tion pathway of THC and $\beta$-myrcene during cannabis e-cigarette vaping}

Reaction products that derive from the major degradation pathways of $\beta$-myrcene and THC show a dependence on both $\%$ mass $\beta$-myrcene and applied power suggesting

that the $1 \mathrm{a} \longleftrightarrow 1 \mathrm{~b}$ equilibrium may be impacted by these factors. To assess relative levels of the oxidation and reduction products of this radical, integrations of the molecular ion for each species on the ATD-GC-MS chromatogram were obtained, and the relative levels of $\mathbf{1 a}$ to $\mathbf{1} \mathbf{b}$ products were calculated by summing the molecular ion or base peak integrations of 3MCA $(m / z=84 \mathrm{amu})$ and 2M2B $(m / z=70 \mathrm{amu})$ for $\mathbf{1 a}$, and those of isoprene $(\mathrm{m} / z=67 \mathrm{amu})$ and 3M1B $(\mathrm{m} / z=70 \mathrm{amu})$ for $\mathbf{1 b}$. 

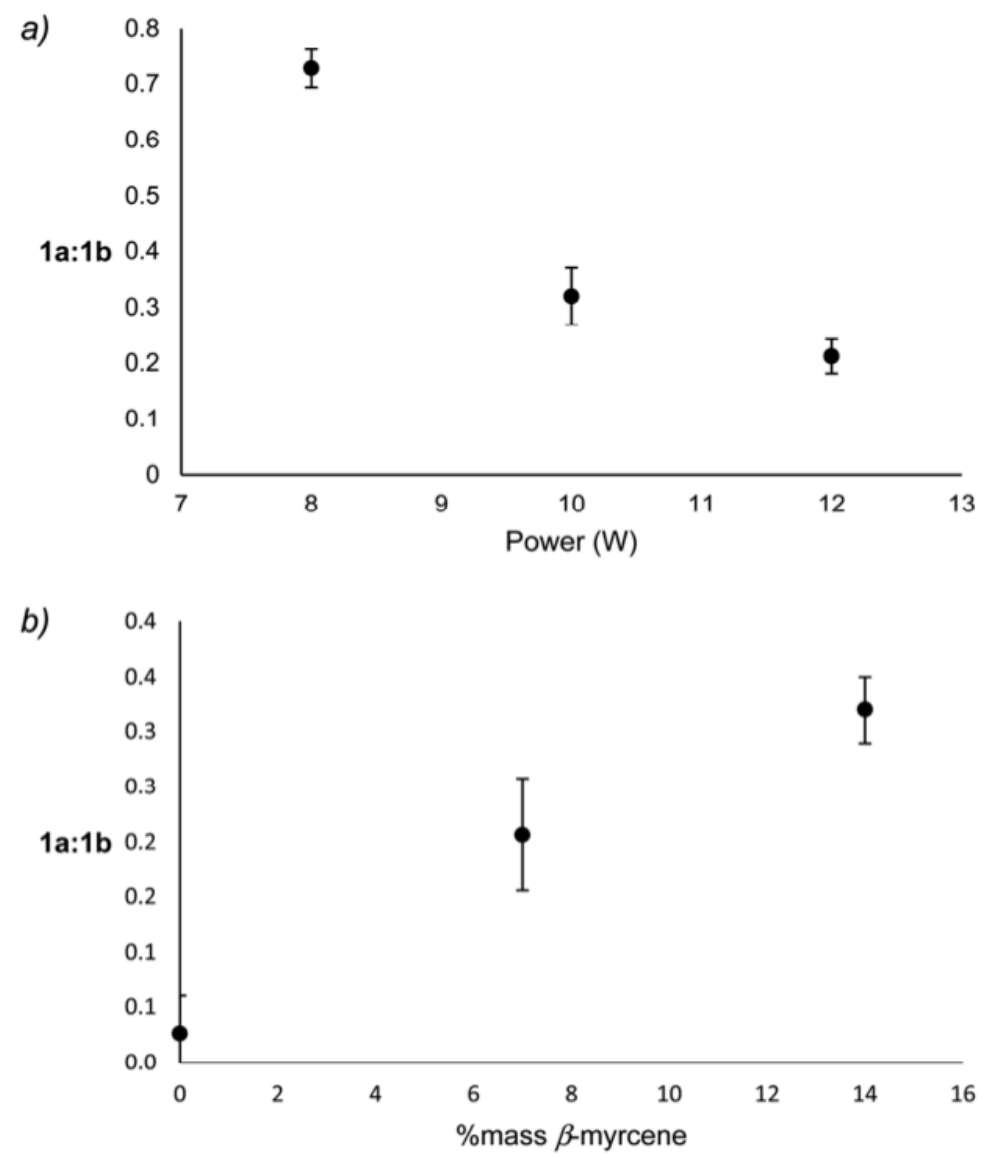

Figure 5.5: The relationship between applied power to 1a:1b (a) and \% mass $\beta$ myrcene to $1 \mathbf{a}: \mathbf{1 b}(\mathrm{b})$. $\mathbf{1 a}: \mathbf{1 b}$ is calculated as the quotient of the selected ion chromatogram integrations of the moleculear ions for 1a products, 3MCA $(\mathrm{m} / z=84$ $\mathrm{amu})$ and $2 \mathrm{M} 2 \mathrm{~B}(\mathrm{~m} / z=70 \mathrm{amu})$, with $\mathbf{1 b}$ products, isoprene $(\mathrm{m} / z=67 \mathrm{amu})$ and $3 \mathrm{M} 1 \mathrm{~B}(\mathrm{~m} / z=70 \mathrm{amu})$.

Though it is not possible to measure the exact temperature experienced at the atomizer, it may be assumed that power level is directly related to aerosolization temperature. With increasing power, $\mathbf{1 a}$-derived products decrease relative to $\mathbf{1} \mathbf{b}$ derived products, a correlation that is largely governed by an increase of isoprene relative to $3 \mathrm{MCA}$ (see SI). The formation of 3MCA begins with $\mathrm{O}_{2}$ addition to $\mathrm{C} \bullet$ on 1a to form a $\mathrm{COO} \bullet$ species, which decomposes via $\mathrm{C}-\mathrm{H}$ beta scission to yield 3MCA 
and a hydroxyl radical. ${ }^{60}$ Isoprene similarly begins with $\mathrm{O}_{2}$ addition at $\mathrm{C} \bullet$ on $\mathbf{1 b}$ to form an $\mathrm{RO}_{2}$ radical which can directly release a hydroperoxyl radical and isoprene. ${ }^{61}$ At lower temperatures, the reversible addition of $\mathrm{O}_{2}$ onto $\mathrm{C} \bullet$ faces a high barrier in the back reaction for $\mathbf{1 a}$ as this releases a primary radical, leading to an abundance of $3 \mathrm{MCA}$ as an end product. It is known that at higher temperatures, the barrier for $\mathrm{O}_{2}$ addition on any $\mathrm{C} \bullet$ becomes nearly nonexistent. ${ }^{61}$ This favors oxidation via the more stable resonance contributor, $\mathbf{1 b}$, at higher temperatures. 3MCA may be considered a kinetic product favored at low temperatures, and isoprene a thermodynamic product favored at higher temperatures. Significant decreases of the ratio of $\mathbf{1 a} \mathbf{1} \mathbf{1}$ p products with increasing power support this hypothesis (Fig. 5.5a). Significant increases in 1a:1b products with increasing $\%$ mass $\beta$-myrcene (Fig. 5.5b) suggest that vaping conditions with higher $\%$ mass $\beta$-myrcene occur at lower temperatures, which is supported by the observation of lower levels of degradation products and higher yield of starting materials under these conditions.

\subsubsection{Conclusions}

Terpenes are shown to have a significant impact on aerosolization in both dabbing and CEC vaping. Curiously, opposite effects are observed for these two cannabis inhalation methods: higher levels of $\beta$-myrcene produces elevated levels of HPHCs during dabbing, but higher $\beta$-myrcene levels in SCO leads to lesser degradation and lower HPHC release for CEC vaping. For dabbing, this result is described using isotopic labelling, and it is shown that $\beta$-myrcene is more thermally labile than THC. The surface upon which aerosolization occurs is pre-heated to a desired temperature prior to administration of the material, and therefore all its components are subjected 
to the same temperature. Isotope labelling experiments indicate that $\beta$-myrcene has a 5-6 fold higher $\%$ yield of isoprene than THC. More facile routes to gaseous degradants, higher partitioning to the GP, and lower molar heat capacity are all factors that may explain the more extensive $\beta$-myrcene degradation compared to THC. Analogous findings consistent with this trend are likely for other terpenes with similar vapor pressures and molecular masses. Cannabis extracts used for dabbing typically contain cannabinoid acids, but these were not studied in this work given their lack of commercial availability for federally-funded academic research institutions in the United States of America as of this writing.

Conversely, higher $\beta$-myrcene $\%$ mass is associated with a decrease in the levels of all HPHCs and lesser overall degradation for CEC vaping. Less degradation and higher overall operating efficiency was observed when vaping $\mathrm{SCO}$ with higher $\%$ mass $\beta$-myrcene, likely a consequence of decreases in boiling point and viscosity. Depression of the boiling point would correspondingly depress aerosolization temperature in the atomizer and lead to lesser chemical degradation. Using the $\beta$-myrcene $\%$ mass that displays optimum performance, $14 \%$, the influence of power level on VOC profile and $\mathrm{THC}$ content in the PM was examined. The increase in $\mathrm{THC}_{\mathrm{T}}$ and decrease in $\mathrm{THC}_{\mathrm{Y}}$ from 8-10 W, which plateaus from $10-12 \mathrm{~W}$ suggests that even at $10 \mathrm{~W}$ degradation of the starting material becomes significant.

In the United States state-level legal recreational cannabis market, reconstituted cannabis oils containing cannabinoids and terpenes are the norm for $\mathrm{CECs},{ }^{21}$ but vaporizers of black market origin are known to contain non-cannabis additives such as medium chain triglyceride oil, triethyl citrate, or phytol. ${ }^{23}$ The findings herein may not translate to cannabis vaporizer liquids containing these and other additives, 
though future work may investigate the impact of these on the release of VOCs and the delivery of THC and other aerosol components.

\subsection{Author contributions}

JMA and RMS designed the experiments and wrote manuscript draft. JMA and AO performed vaping experiments, HPLC experiments, characterization, and analysis. WL and KJM designed and performed ATD-GC-MS experiments. DGD and DS

designed and synthesized the $\beta$-myrcene- $d_{6}$. RPJ synthesized CBN and aided in experimental design. IA, JJ, and KCB designed and performed the computational experiments. All authors approved the final version of the manuscript.

\subsection{Conflicts of interest}

RPJ is a founder and Vice President of Florascience Inc., an Oregon hemp company. All other authors have no conflicts to declare.

\subsection{Acknowledgements}

We thank the NIH and the FDA for their partial support via award R01ES025257. The content is solely the responsibility of the authors and does not necessarily represent the views of the NIH or the FDA.

\subsection{References}

(1) M. Ren, Z. Tang, X. Wu, R. Spengler, H. Jiang, Y. Yang and N. Boivin, Sci. Adv., 2019, 5, eeaw1391. 
(2) World Drug Report 2020, United Nations publications, Sales No. E.20.XI.26.

(3) A. Hazekamp, M. A. Ware, K. R. Muller-Vahl, D. Abrams and F. Grotenhermen, J. Psychoact. Drugs, 2013, 45, 199-210.

(4) C. A. Struble, J. D. Ellis and L. H. Lundahl, Pediatr. Clin. North Am., 2019, 66, 1087-1097.

(5) J. Meehan-Atrash, W. Luo, K. J. McWhirter and R. M. Strongin, ACS Omega, 2019, 4, 16111-16120.

(6) J. E. Schulenberg, L. D. Johnston, P. M. O’Malley, J. G. Bachman, R. A. Miech and M. E. Patrick, Monitoring the Future national survey results on drug use, 19752018: Volume II, college students and adults ages 19-60, Institute for Social Research, The University of Michigan, Ann Arbor, 2019.

(7) R. A. Miech, M. E. Patrick, P. M. O’Malley, L. D. Johnston and J. G. Bachman, JAMA, 2020, 323, 475-476.

(8) J. Meehan-Atrash, W. Luo and R. M. Strongin, ACS Omega, 2017, 2, 6112-6117.

(9) H. Perrotin-Brunel, M. C. Kroon, M. J. E. van Roosmalen, J. van Spronsen, C. J. Peters and G. J. Witkamp, J. Supercrit. Fluids, 2010, 55, 603-608.

(10) T. M. Lovestead and T. J. Bruno, Forensic Chem., 2017, 5, 79-85.

(11) G. L. Schauer, R. Njai and A. M. Grant-Lenzy, Drug Alcohol Depend., 2020, 209, 107900 .

(12) F. Taura, S. Morimoto, Y. Shoyama and R. Mechoulam, J. Am. Chem. Soc., 1995, 117, 9766-9767.

(13) A. Hazekamp, A. Peltenburg, R. Verpoorte and C. Giroud, J. Liq. Chromatogr. Relat. Technol., 2007, 28, 2361-2382.

(14) World Pat., WO 2004/026857 A2, 2004. 
(15) F. Van der Kooy, B. Pomahacova and R. Verpoorte, Inhalation Toxicol., 2008, 20, 801-804.

(16) G. W. Kinzer, R. L. Foltz and R. I. Mitchell, Bull. Narc., 1974, 26, 41-54.

(17) B. Pomahacova, F. Van der Kooy and R. Verpoorte, Inhalation Toxicol., 2009, 21, 1108-1112.

(18) H. Perrotin-Brunel, W. Buijs, J. van Spronsen, M. J. E. van Roosmalen, C. J. Peters, R. Verpoorte and G. J. Witkamp, J. Mol. Struct., 2011, 987, 67-73. (19) J. Cervantes, The Cannabis Encyclopedia, Van Patten Publishing, 2015. (20) M. M. Lewis, Y. Yang, E. Wasilewski, H. A. Clarke and L. P. Kotra, ACS Omega, 2017, 2, 6091-6103.

(21) B. E. Erickson, Cannabis industry gets crafty with terpenes Chemical and Engineering News [Online], 2019. https:// cen.acs.org/biological-chemistry/naturalproducts/ Cannabis-industry-crafty-terpenes/97/i29.

(22) J. Meehan-Atrash and R. M. Strongin, Forensic Sci. Int., 2020, 312, 110301.

(23) B. Duffy, L. Li, S. Lu, L. Durocher, M. Dittmar, E. Delaney- Baldwin, D. Panawennage, D. LeMaster, K. Navarette and D. Spink, Toxics, 2020, 8, DOI: 10.3390/toxics8010008.

(24) D. Schwotzer, A. Gigliotti, H. Irshad, W. Dye and J. McDonald, Inhalation Toxicol., 2021, 1-8, DOI: 10.1080/ 08958378.2020.1867260.

(25) A. Lanzarotta, T. M. Falconer, R. Flurer and R. A. Wilson, Anal. Chem., 2020, 92, 2374-2378.

(26) N. Lewis, K. McCaffrey, K. Sage, C.-J. Cheng, J. Green, L. Goldstein, H. Campbell, D. Ferrell, N. Malan, N. LaCross, A. Maldonado, A. Board, A. Hanchey, D. Harris, S. Callahan, S. Aberegg, I. Risk, S. Willardson, A. Carter, A. Nakashima, J. 
Duncan, C. Burnett, R. Atkinson-Dunn and A. Dunn, Morb. Mortal. Wkly. Rep., 2019, 68, 953-956.

(27) D. Y. Pazo, F. Moliere, M. M. Sampson, C. M. Reese, K. A. Agnew-Heard, M. J. Walters, M. R. Holman, B. C. Blount, C. H. Watson and D. M. Chambers, Nicotine Tob. Res., 2016, 18, 1886-1894.

(28) J. Fowles and E. Dybing, Tob. Control, 2003, 12, 424-430.

(29) A. C. Rohr, Environ. Int., 2013, 60, 145-162.

(30) P. Wolkoff, P. A. Clausen, K. Larsen, M. Hammer, S. T. Larsen and G. D. Nielsen, Toxicol. Lett., 2008, 181, 171-176.

(31) P. Wolkoff, Int. J. Hyg. Environ. Health, 2020, 225, 113439. 32 P. S. Scott, J. P. Andrew, B. A. Bundy, B. K. Grimm, M. A. Hamann, D. T. Ketcherside, J. Li, M. Y. Manangquil, L. A. Nunez, D. L. Pittman, A. Rivero-Zevallos, R. Uhlorn and N. A. C. Johnston, Atmos. Pollut. Res., 2020, 11, 1870- 1881.

(33) T. J. Ward, H. Underberg, D. Jones, R. F. Hamilton Jr and E. Adams, Environ. Monit. Assess., 2009, 153, 119-126.

(34) X. Chen, F. Wang, L. Lin, H. Dong, F. Huang, K. Ghulam Muhammad, L. Chen and O. Y. Gorlova, Int. J. Mol. Sci., 2017, 18, 2235.

(35) R. Selyanchyn, T. Nozoe, H. Matsui, T. Kadosawa and S. W. Lee, Diagnostics, 2013, 3, 68-83.

(36) C. Lourenco, D. Kelly, J. Cantillon, M. Cauchi, M. A. Yon, L. Bentley, R. D. Cox and C. Turner, Sci. Rep., 2019, 9, 18779.

(37) J. H. Lee, C. Jia, Y. D. Kim, H. H. Kim, T. T. Pham, Y. S. Choi, Y. U. Seo and I. W. Lee, Int. J. Anal. Chem., 2012, 2012, 690356.

(38) C. Lourenco, D. Francis, D. P. Fowler, S. E. Staines, J. Hodgkinson, C. Walton, 
S. Bergin and R. P. Tatam, Sci. Rep., 2020, 10, 8702.

(39) J. F. Pankow, K. Kim, W. Luo and K. J. McWhirter, Chem. Res. Toxicol., 2018, 31, 985-990.

(40) J. Meehan-Atrash, A. K. Duell, K. J. McWhirter, W. Luo, D. H. Peyton and R. M. Strongin, Chem. Res. Toxicol., 2019, 32, 974-976.

(41) J. F. Pankow, K. Kim, K. J. McWhirter, W. Luo, J. O. Escobedo, R. M. Strongin, A. K. Duell and D. H. Peyton, PLoS One, 2017, 12, DOI: 10.1371/ journal.pone. 0173055 .

(42) Cooperation Centre for Scientific Research Relative to Tobacco, Routine Analytical Machine for E-Cigarette Aerosol Generation and Collection - Definitions and Standard Conditions. CORESTA Recommended Method No.81, CORESTA, Paris, France, 2015.

(43) J. F. Pankow, Chem. Res. Toxicol., 2001, 14, 1465-1481.

(44) A. Stolle and B. Ondruschka, J. Anal. Appl. Pyrolysis, 2008, 81, 136-138. (45) R. Atkinson, Atmos. Environ., Part A, 1989, 24, 1-41.

(46) A. P. Teng, J. D. Crounse and P. O. Wennberg, J. Am. Chem. Soc., 2017, 139, $5367-5377$.

(47) R. S. Tjeerdema, Rev. Environ. Contam. Toxicol., 1987, 99, 61-81.

(48) F. J. E. M. Kuppers, C. A. L. Bercht, C. A. Salemink, R. J. J. C. Lousberg, J. K. Terlouw and W. Heerma, Tetrahedron, 1975, 31, 1513-1516.

(49) F. J. E. M. Kuppers, C. A. L. Bercht, C. A. Salemink, R. J. J. C. Lousberg, J. K. Terlouw and W. Heerma, J. Chromatogr., 1975, 108, 375-379.

(50) F. J. E. M. Kuppers, R. J. J. C. Lousberg, C. A. L. Bercht, C. A. Salemink, J. K. Terlouw, W. Heerma and A. Laven, Tetrahedron, 1973, 29, 2797-2802. 
(51) C. E. Turner and M. A. ElSohly, J. Heterocycl. Chem., 1979, 16, 1667.

(52) Structure-Activity Relationships of the Cannabinoids, ed. R. S. Rapaka and A. Makriyannis, NIDA Office of Science and Policy Communications, 1987. (53) R. Atkinson and J. Arey, Chem. Rev., 2003, 103, 4605-4638.

(54) A. Reissell, C. Harry, S. M. Aschmann, R. Atkinson and J. Arey, J. Geophys. Res.: Atmos., 1999, 104, 13869-13879.

(55) R. Fabiani, P. Rosignoli, A. De Bartolomeo, R. Fuccelli and G. Morozzi, Mutat. Res., 2007, 629, 7-13.

(56) CRC Handbook of Chemistry and Physics, ed. W. M. Haynes, CRC Press Inc., 2010-2011.

(57) CCell or similar THC/distillate tank - recommended wattage, https://forum.

vapelife.com/discussion/2959/ccell-or-similar- thcdistillate-tank-recommended-wattage, (accessed January 13, 2020).

(58) B. Joyner, Trouble Using Your CCELL Coil or Cartridge? Here's the Solution, https://marijuanapackaging.com/ blogs/resources/trouble-using-your-ccell-coilor-cartridge-heres-the-solution, (accessed January 13, 2020).

(59) M. B. Kolicheski, L. C. Cocco, D. A. Mitchell and M. Kaminski, J. Anal. Appl. Pyrolysis, 2007, 80, 92-100.

(60) F. H. Vermeire, R. De Bruycker, O. Herbinet, H.-H. Carstensen, F. BattinLeclerc, G. B. Marin and K. M. Van Geem, Fuel, 2017, 208, 779-790.

(61) C. A. Taatjes, J. Phys. Chem. A, 2006, 110, 4299-4312. 


\section{Overall conclusions}

The historical context of cannabis' use as a psychoactive drug or entheogen and the evolution of its associated consumption modalities, particularly for inhalation, have been described. The known chemistry of novel cannabis inhalation methods has been presented, and it is clear that significant work is required to understand these methods and how they impact consumer health. While these novel vaporizing or vaping methods do not involve heating cannabis concentrates to the point of combustion, the propensity of the major active ingredients to decompose below their point of combustion, or even below their boiling point, must be addressed. A chemical understanding of the reactions that occur in this context is an essential first step in assessing the safety of any inhalable cannabis product.

Thermal decomposition reactions of the primary cannabis concentrate ingredients, THC and terpenoids including $\beta$-myrcene, were not thoroughly studied before publication of the manuscripts presented in this document. Studies of $\beta$-myrcene pyrolysis date back to $1913,{ }^{1}$ but it was not until 2008 that a first step in the mechanism for pyrolytic $\beta$-myrcene decomposition was proposed. ${ }^{2}$ Herein, qualitative and quantitative product analysis aided by isotopic labelling provided enough evidence to propose a reaction mechanism that accounts for $30 \%$ of the total volatile products emitted when this terpene is subjected to heating in the context of cannabis vaporization. ${ }^{3}$ 
Volatile reaction products of THC thermal decomposition had not been studied at all prior to the writing of the manuscripts presented herein. It is shown that the $p$-menthyl terpenoid backbone is especially labile when heated, a result that is suggested by comparing its volatile emissions to those of CBN, which presents an aromatized thymyl moiety that does not so easily degrade. ${ }^{3}$ Qualitative and quantitative product analysis allowed the proposal of a reaction mechanism that, curiously, shares a reactive intermediate with $\beta$-myrcene, ${ }^{3}$ and consequently displays a similar volatile degradation profile to this and other terpenoids.

In addition to the fundamental chemistry of these molecules, the work presented herein has important implications for the understanding of the health effects of vaporizing cannabis concentrates. A novel quantitative risk analysis method for inhalable cannabis products was reported, and the data presented provides insight into the risk inherent to inhaling substances found in cannabis smoke and vapor product aerosols that have known chronic exposure data. ${ }^{4}$ Structural characterization of the hundreds of other gaseous degradants of $\mathrm{THC}^{3-4}$ and cannabis terpenes ${ }^{3-5}$ for which toxicological data has not been ascertained due to the prior inexistence of other exposure avenues may help guide future work to assess the impacts of these substances. Methodology used in the execution of these experiments also represents important progress to the scarce existing literature, especially with regard to the collection of aerosols released by dabbing, which presents unique experimental challenges given the variables inherent to this cannabis consumption technique. ${ }^{4-5}$

This document also details efforts to identify a known airway toxic that was used as a cannabis extract adulterant during the EVALI crisis. ${ }^{6}$ This substance, pine rosin or colophony, has been previously reported as a hashish adulterant in Europe, and 
there is evidence to suggest it may have been used to adulterate cannabis concentrates in the United States and Canada. ${ }^{6}$

\subsection{References}

(1) Prodrom, I. Untersuchungen über Autoxydation und über Umwandlung verschiedener Terpene in Isopren. Swiss Federal Institute of Technology in Zürich, Zürich, 1913.

(2) Stolle, A.; Ondruschka, B., Comment to the paper "Synthesis of myrcene by pyrolysis of $\beta$-pinene: Analysis of decomposition reactions" by M.B. Kolicheski et al. [J. Anal. Appl. Pyrol. 80 (2007) 92-100]. J. Anal. Appl. Pyrol. 2008, 81 (1), 136-138. (3) Meehan-Atrash, J.; Luo, W.; McWhirter, K. J.; Dennis, D. G.; Sarlah, D.; Jensen, R. P.; Afreh, I.; Jiang, J.; Barsanti, K. C.; Ortiz, A.; Strongin, R. M., The influence of terpenes on the release of volatile organic compounds and active ingredients to cannabis vaping aerosols. $R S C A d v$. 2021, 11 (19), 11714-11723.

(4) Meehan-Atrash, J.; Luo, W.; McWhirter, K. J.; Strongin, R. M., Aerosol GasPhase Components from Cannabis E-Cigarettes and Dabbing: Mechanistic Insight and Quantitative Risk Analysis. ACS Omega 2019, 4 (14), 16111-16120.

(5) Meehan-Atrash, J.; Luo, W.; Strongin, R. M., Toxicant Formation in Dabbing: The Terpene Story. ACS Omega 2017, 2 (9), 6112-6117.

(6) Meehan-Atrash, J.; Strongin, R. M., Pine rosin identified as a toxic cannabis extract adulterant. Forensic. Sci. Int. 2020, 312, 110301. 


\section{Appendix A: Supporting Information to Pine rosin identified as a toxic cannabis extract adulterant}

\subsection{Quantitative NMR}

The cannabis extract adulterant (CEA) sample was dissolved in $\mathrm{CDCL}_{3}$ (Cambridge Isotope Laboratories) and acquired at 512 scans, a 6.7 second repetition rate, with a $30^{\circ}$ flip angle, and with $64 \mathrm{k}$ data points on a Bruker Avance III $600 \mathrm{MHz}$ NMR spectrometer. Spectra were processed with $0.3 \mathrm{~Hz}$ of line broadening with a final data size of $64 \mathrm{k}$ real data points. Quantification was performed using Global Spectral Deconvolution from MestreLab software by comparing analyte peaks to that of a pure standard of caffeine (Sigma Aldrich) as a $\mathrm{CDCl}_{3}$-soluble internal standard. The masses of internal standard and CEA sample added to the NMR tube were then used to calculate an approximate \%mass of identified components in the sample.[1]

\subsection{Semi-preparative HPLC}

Fractions from the HPLC chromatogram were collected manually using the method in Nilsson et al.[2] using an $25 \mathrm{~cm} \times 10 \mathrm{~mm}, 5$ pm Discovery C18 semi-preparative column on a Waters 1525 Binary HPLC Pump and a Waters 2996 Photodiode Array Detector. Product peaks were eluted using an isocratic method consisting of $80 \%$ 
95:5 MeOH:H2O and $20 \%$ 5:95 MeOH:H2O with $0.05 \%$ formic acid in each with a total flow of $3.5 \mathrm{~mL} / \mathrm{min}$. Methanol was removed via rotary evaporation, and product was extracted in dichloromethane.

\subsection{HPLC-ESIMS}

The chromatogram was collected on a Vanquish UHPLC system. $20 \mu \mathrm{L}$ of CEA in methanol at $930 \mathrm{ng} / \mathrm{\mu L}$ were injected over an Acclaim RSLC Polar Advantage II $3 \mu \mathrm{m}$, $120 \AA$, 3.0 x $75 \mathrm{~mm}$ column using the following elution program: hold $30 \%$ A for 5 min., ramp to $27 \%$ A until 18 min., hold until $40 \mathrm{~min}$. with a total flow of $0.5 \mathrm{~mL} / \mathrm{min}$. Solvent A: $0.05 \%$ formic acid in $\mathrm{H} 2 \mathrm{O}$, solvent B: $0.05 \%$ formic acid in methanol. MS data was acquired using a high-resolution $(35,000)$ Thermo Scientific Q Exactive Mass Spectrometer with an electrospray ionization source operating in the positive mode. The Orbitrap was externally calibrated prior to data acquisition allowing accurate mass measurements for $[\mathrm{M}+\mathrm{H}]^{+}$to be obtained within $4 \mathrm{ppm}$. The ionization interface was operated using the following settings: source voltage, $4 \mathrm{kV}$; sheath and auxiliary gas at 75 and 20 units respectively; capillary temperature, $400{ }^{\circ} \mathrm{C}$. Ionization in the positive mode allowed identification of the fatty acid amide oleamide, but the negative mode would provide higher ionization efficiency for identifying pine rosin components (which are organic acids) at small concentrations. 


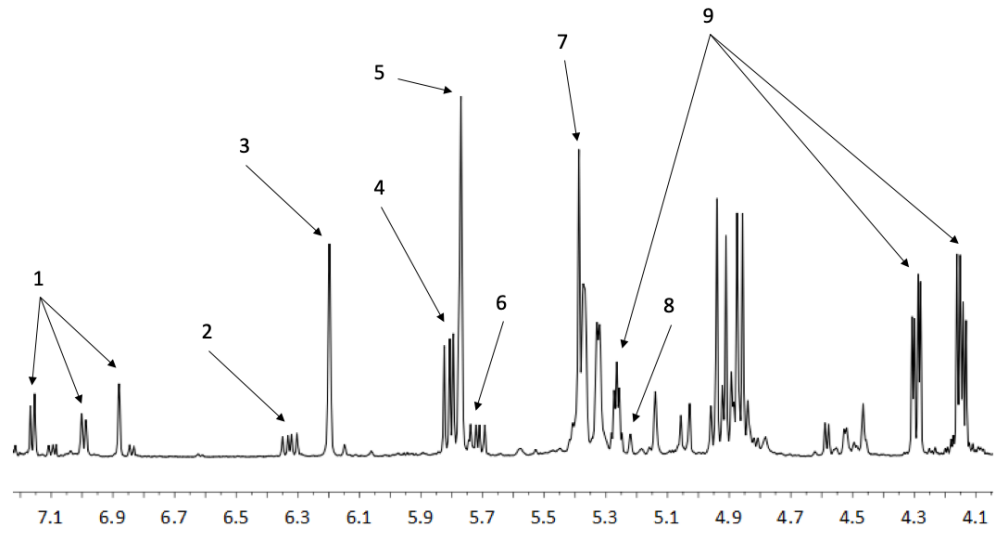

Figure 7.1: ${ }^{1} \mathrm{H}$ NMR spectrum of CEA showing relevant peaks for (1) dehydroabietic acid, (2) communic acid, (3) neoabietic acid, (4) isopimaric acid, (5) abietic acid, (6) pimaric acid, (7) palustric acid, (9) sandaracopimaric acid, (9) MCT oil.

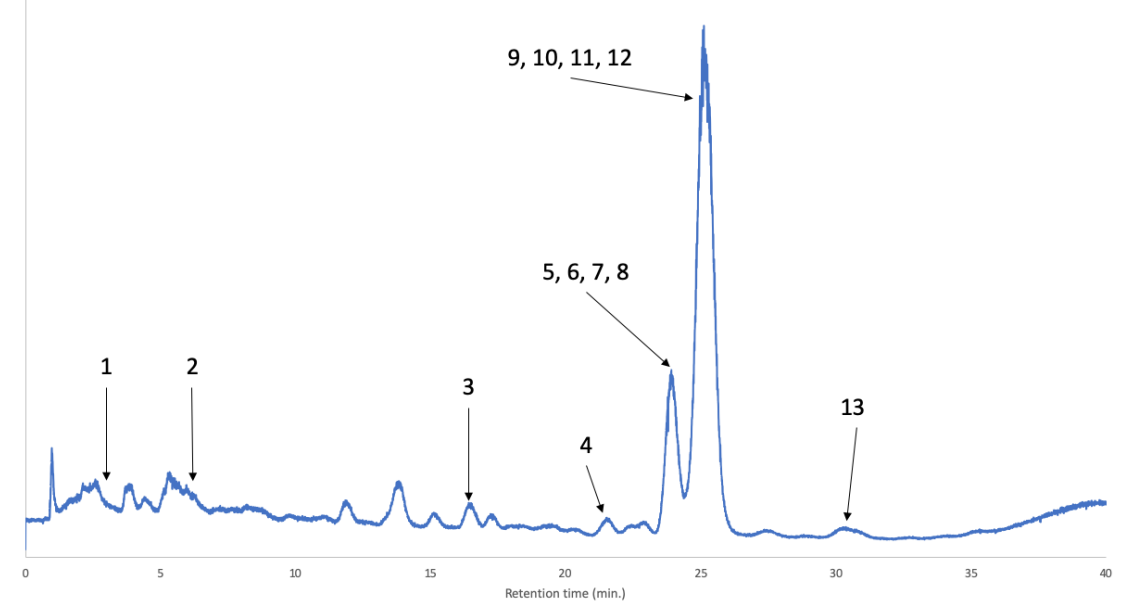

Figure 7.2: HPLC-ESIMS total ion chromatogram with several peaks of interest highlighted: (1) 15-hydroxyperoxyabietic acid, (2) 12-oxopimaric acid, (3) dehydroabietic acid, (4) communic acid, (5) pimarol, (6) pimaric acid, (7) sandaracopimaric acid, (8) palustric acid, (9) abietic acid, (10) oleamide, (11) neoabietic acid, (12) isopimaric acid, (13) sandaracopimarol. 


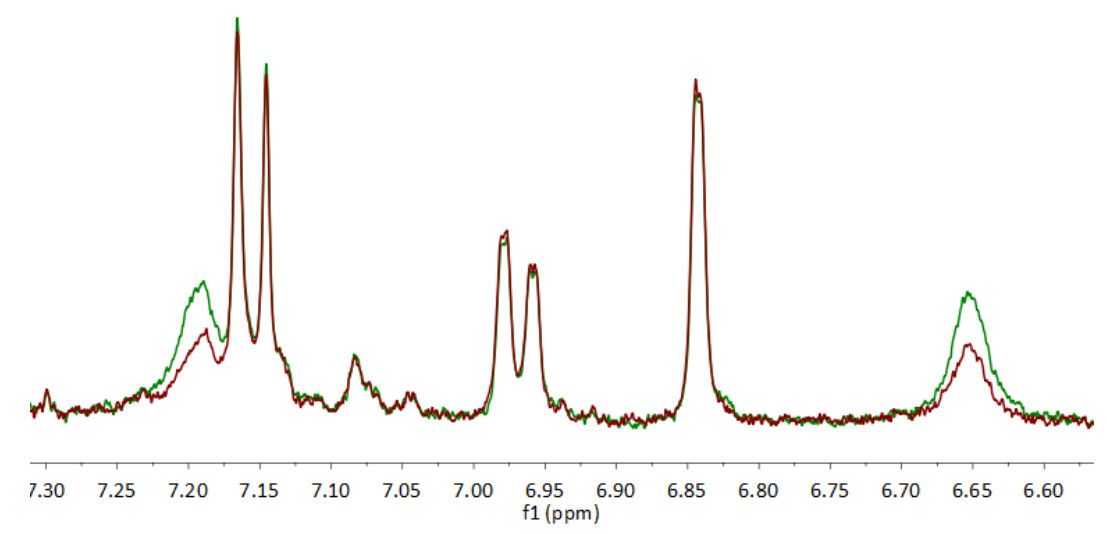

Figure 7.3: Overlaid ${ }^{1} \mathrm{H}$ NMR spectra of the semi-preparative HPLC band containing oleamide in DMSO- $d_{6}$ (maroon), and the same sample spiked with $100 \mu \mathrm{g}$ oleamide (green). An increase in the amide $\mathrm{N}-\mathrm{H}$ proton peaks in the sample without the introduction of new peaks confirms the presence of this compound in CEA.

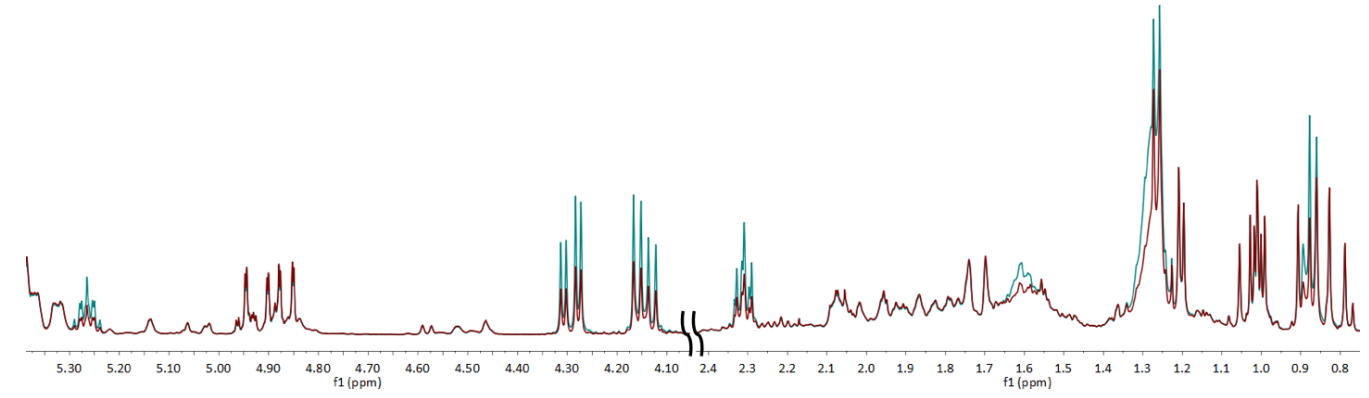

Figure 7.4: Overlaid ${ }^{1} \mathrm{H}$ NMR spectra of the semi-preparative HPLC band containing oleamide in DMSO- $d_{6}$ (maroon), and the same sample spiked with $100 \mathrm{\mu g}$ oleamide (green). An increase in the amide $\mathrm{N}-\mathrm{H}$ proton peaks in the sample without the introduction of new peaks confirms the presence of this compound in CEA.

\subsection{References}

(1) S.K. Bharti, R. Roy, Quantitative 1H NMR spectroscopy, TrAC Trends in Analytical Chemistry 35 (2012) 5-26. https://doi.org/10.1016/j.trac.2012.02.007

(2) U. Nilsson, N. Berglund, F. Lindahl, S. Axelsson, T. Redeby, P. Lassen, A.T. 
Karlberg, SPE and HPLC/UV of resin acids in colophonium-containing products, J Sep Sci 31(15) (2008) 2784-90. https://doi.org/10.1002/jssc.200800210 


\section{Appendix B: Supporting Information to Toxicant formation in dabbing: The terpene story}

\subsection{Experimental setups}

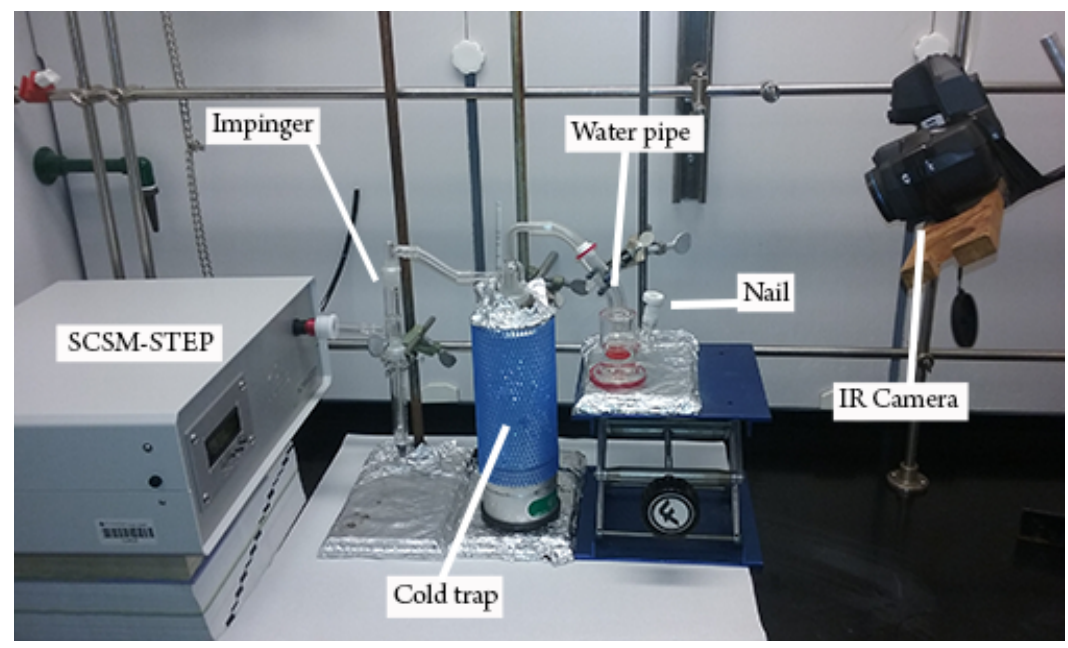

Figure 8.1: The experimental setup used in all NMR experiments. Conditions were exactly replicated in all experiments, using the same height in the lab jack, camera and SCSM. Tubing between the water pipe, cold trap, impinger and SCSM was the same length every experiment. Photograph courtesy of J.M.A. Copyright 2017. 


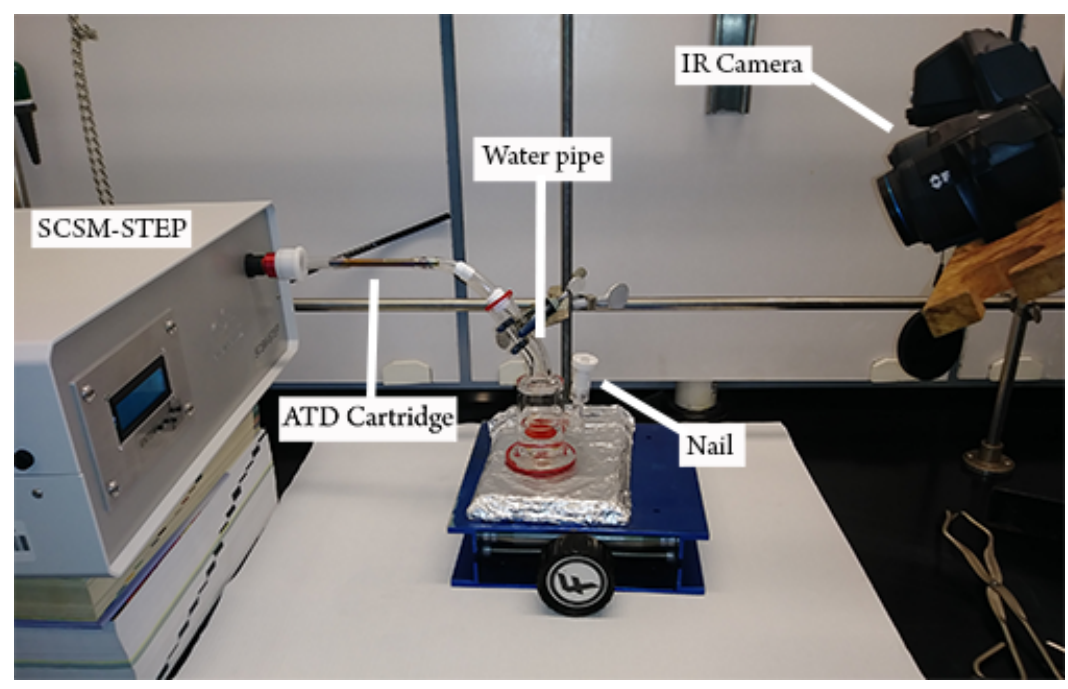

Figure 8.2: Experimental setup used in ATD cartridge sample collection. Photograph courtesy of J.M.A. Copyright 2017.

\subsection{ATD-GC-MS Conditions}

A sample of one $338 \mathrm{~mL}$ in 10s draw was collected onto an adsorption/thermal desorption (ATD) cartridge as showing in Figure 8.2. The ATD cartridge contains 100 mg of 35/60 mesh Tenax TA and 200 mg of 60/80 mesh Carbograph 1 TD (Camsco Inc., Houston, TX). Each ATD sample cartridge was thermally desorbed using a TurboMatrix 650 ATD unit (PerkinElmer, Waltham, MA). Each cartridge was automatically added with $20 \mathrm{ng}$ of fluorobenzene, $18.6 \mathrm{ng}$ of toluene- $d_{8}, 21.7 \mathrm{ng}$ of 4bromofluorobenzene, and $20.3 \mathrm{ng}$ of 1,2-dichlorobenzene- $d_{4}$ as the internal standards. The ATD unit thermally desorbed each ATD cartridge for 10 min at $285{ }^{\circ} \mathrm{C}$ with a He desorption flow of $40 \mathrm{~mL} / \mathrm{min}$ and split flow of $10 \mathrm{~mL} / \mathrm{min}$, the desorption stream was trapped at $-10{ }^{\circ} \mathrm{C}$ on an intermediate "Tenax $\mathrm{R}$ trap". Thermal desorption of the intermediate trap occurred at $295^{\circ} \mathrm{C}$ and 25 psi constant pressure He, on a split flow of $12 \mathrm{~mL} / \mathrm{min}$ for $4 \mathrm{~min}$. Through a $1 \mathrm{~m}$ long and $0.25 \mathrm{~mm}$ i.d. deactivated fused 
silica transfer line $\left(235^{\circ} \mathrm{C}\right)$, the un-split portion of the stream was passed on to a 30 m length, $0.25 \mathrm{~mm}$ i.d., and $1.4 \mu \mathrm{m}$ film thickness Rxi-624Sil MS (Restek Inc., Bellefonte, PA) capillary GC column mounted in an Agilent (Santa Clara, CA) 7890A GC. This was interfaced to an Agilent 5975C MS operated in electron impact ionization mode. The GC oven temperature was hold at $40{ }^{\circ} \mathrm{C}$ for $2 \mathrm{~min}$, programming to 100 ${ }^{\circ} \mathrm{C}$ at $10{ }^{\circ} \mathrm{C} / \mathrm{min}$, then programming to $280{ }^{\circ} \mathrm{C}$ at $12{ }^{\circ} \mathrm{C} / \mathrm{min}$, and then at $15{ }^{\circ} \mathrm{C} / \mathrm{min}$ to $220{ }^{\circ} \mathrm{C}$. The MS scan range was 34 to $300 \mathrm{amu}$. The electron multiplier voltage was $1525 \mathrm{~V}$.

\subsection{Temperature measurements}

Limonene, linalool and Fire OG terpenes were only tested once each at the highest TR chosen for the NMR experiments. Temperatures used in each of these experiments are shown in Table 8.1.

Myrcene experiments for each TR were done in triplicate. The five $T_{\mathrm{i}}$ and $T_{\mathrm{f}}$ for each dab taken in each experiment were averaged. Data for all temperatures used are shown in Tables 8.2 though 8.6. The average of the standard deviations of each $T_{\mathrm{i}}$ and $T_{\mathrm{f}}$ for all 12 experiments is $2.4{ }^{\circ} \mathrm{C}$, indicating the experiments were done consistently. The average of the $T_{\mathrm{i}}$ and $T_{\mathrm{f}}$ of the four TR replicates was taken and a median temperature $\left(T_{\mathrm{m}}\right)$ was calculated. Table 8.2 shows the total average $T_{\mathrm{i}}$ and $T_{\mathrm{f}}$ for each TR. M1-M12 are the abbreviations used for each individual myrcene experiment (four TRs $\times$ three replicates). 


\begin{tabular}{lcc|cc|cc} 
& \multicolumn{2}{c}{ Limonene } & \multicolumn{2}{c}{ Linalool } & \multicolumn{2}{c}{ Fire OG } \\
\cline { 2 - 7 } & $T_{\mathrm{i}}$ & $T_{\mathrm{f}}$ & $T_{\mathrm{i}}$ & $T_{\mathrm{f}}$ & $T_{\mathrm{i}}$ & $T_{\mathrm{f}}$ \\
\hline Hit 1 & 549 & 498 & 558 & 503 & 565 & 510 \\
Hit 2 & 550 & 503 & 557 & 500 & 556 & 500 \\
Hit 3 & 550 & 500 & 552 & 502 & 552 & 501 \\
Hit 4 & 547 & 502 & 556 & 501 & 559 & 500 \\
Hit 5 & 549 & 500 & 556 & 506 & 555 & 502 \\
\hline Average & 549 & 501 & 556 & 502 & 557 & 503 \\
\hline St. Dev. & 1.22 & 1.95 & 2.28 & 2.30 & 4.93 & 4.21 \\
\hline
\end{tabular}

Table 8.1: Temperatures in ${ }^{\circ} \mathrm{C}$ used for each individual hit, shown with their averages and standard deviations.

\begin{tabular}{c|c|c}
$T_{\mathrm{m}}$ & $T_{\mathrm{i}}$ & $T_{\mathrm{f}}$ \\
\hline 526 & $551 \pm 0.8$ & $500 \pm 2.4$ \\
455 & $477 \pm 0.1$ & $434 \pm 0.8$ \\
403 & $421 \pm 0.2$ & $386 \pm 0.8$ \\
322 & $336 \pm 1.4$ & $309 \pm 2.7$ \\
\hline
\end{tabular}

Table 8.2: $T_{\mathrm{m}}, T_{\mathrm{i}}$, and $T_{\mathrm{f}}$ values for each $\mathrm{TR}$ in ${ }^{\circ} \mathrm{C}$

\subsection{NMR conditions}

All myrcene samples were run at 1024 scans, 6.7 second repetition rate, 30-degree flip angle with $64 \mathrm{k}$ data point acquisition on a Bruker Avance III $600 \mathrm{MHz}$ NMR spectrometer. Spectra were processed with $0.3 \mathrm{~Hz}$ of line broadening with a final data size of $64 \mathrm{k}$ real data points. Fire OG terpenes, limonene and linalool were run under the same conditions but with 256 scans. Analyte assignments of benzene and methacrolein were performed by spiking of authentic standards. Integral measurements for quantitative-NMR were done using Global Spectral Deconvolution (GSD) from MestreLab software. 


\begin{tabular}{lll|ll|ll} 
& \multicolumn{6}{c}{$T_{\mathrm{m}}=526{ }^{\circ} \mathrm{C}$} \\
\cline { 2 - 7 } & $\mathrm{M} 1$ & \multicolumn{3}{c}{$\mathrm{M} 2$} & \multicolumn{3}{c}{$\mathrm{M} 3$} \\
\cline { 2 - 7 } & $T_{\mathrm{i}}$ & $T_{\mathrm{f}}$ & $T_{\mathrm{i}}$ & $T_{\mathrm{f}}$ & $T_{\mathrm{i}}$ & $T_{\mathrm{f}}$ \\
\hline Hit 1 & 552 & 500 & 550 & 501 & 555 & 496 \\
Hit 2 & 549 & 500 & 555 & 502 & 550 & 498 \\
Hit 3 & 550 & 507 & 550 & 495 & 554 & 500 \\
Hit 4 & 551 & 504 & 552 & 499 & 552 & 501 \\
Hit 5 & 552 & 503 & 550 & 494 & 551 & 499 \\
\hline Average & 551 & 503 & 551 & 498 & 552 & 499 \\
\hline St. Dev. & 1.30 & 2.95 & 2.19 & 3.85 & 2.07 & 1.92 \\
\hline
\end{tabular}

Table 8.3: Temperatures in ${ }^{\circ} \mathrm{C}$ used for each individual hit, shown with their averages and standard deviations.

\begin{tabular}{lll|ll|ll} 
& \multicolumn{6}{c}{$T_{\mathrm{m}}=455^{\circ} \mathrm{C}$} \\
\cline { 2 - 7 } & $\mathrm{M} 4$ & \multicolumn{3}{c}{$\mathrm{M} 5$} & \multicolumn{3}{c}{$\mathrm{M} 6$} \\
\cline { 2 - 7 } & $T_{\mathrm{i}}$ & $T_{\mathrm{f}}$ & $T_{\mathrm{i}}$ & $T_{\mathrm{f}}$ & $T_{\mathrm{i}}$ & $T_{\mathrm{f}}$ \\
\hline Hit 1 & 477 & 436 & 477 & 434 & 476 & 430 \\
Hit 2 & 476 & 432 & 476 & 432 & 476 & 432 \\
Hit 3 & 475 & 433 & 477 & 436 & 478 & 434 \\
Hit 4 & 478 & 437 & 476 & 434 & 475 & 434 \\
Hit 5 & 477 & 434 & 478 & 439 & 478 & 437 \\
\hline Average & 477 & 434 & 477 & 435 & 477 & 433 \\
\hline St. Dev. & 1.14 & 2.07 & 0.84 & 2.65 & 1.34 & 2.61 \\
\hline
\end{tabular}

Table 8.4: Temperatures values used for each myrcene hit at $T_{\mathrm{m}}=455{ }^{\circ} \mathrm{C}$. The average $T_{\mathrm{i}}$ and $T_{\mathrm{f}}$ values for M4, M5, and M6 were themselves average to get the total average $T_{\mathrm{i}}$ and $T_{\mathrm{f}}$ for the $T_{\mathrm{m}}=455^{\circ} \mathrm{C} \mathrm{TR}$, shown in Table 8.2

\subsection{Toxicant levels generated in myrcene NMR experiments}

Table 8.7 shows the initial data used for calculations. Averages of each triplicate value were taken, standard deviation calculated, and confidence interval found at 95 $\%$ confidence level. The amount of toxicant generated per mg of myrcene administered in the dab $(75 \mu \mathrm{L})$ was calculated from the values in Table S8, using the density of myrcene. The amount of toxicant generated per mg of limonene, linalool and Fire 


\begin{tabular}{lll|ll|ll} 
& \multicolumn{6}{c}{$T_{\mathrm{m}}=405{ }^{\circ} \mathrm{C}$} \\
\cline { 2 - 7 } & $\mathrm{M} 7$ & \multicolumn{3}{c}{$\mathrm{M} 8$} & \multicolumn{3}{c}{$\mathrm{M} 9$} \\
\cline { 2 - 7 } & $T_{\mathrm{i}}$ & $T_{\mathrm{f}}$ & $T_{\mathrm{i}}$ & $T_{\mathrm{f}}$ & $T_{\mathrm{i}}$ & $T_{\mathrm{f}}$ \\
\hline Hit 1 & 420 & 385 & 421 & 384 & 420 & 383 \\
Hit 2 & 421 & 388 & 420 & 387 & 422 & 386 \\
Hit 3 & 422 & 388 & 420 & 385 & 420 & 383 \\
Hit 4 & 419 & 386 & 420 & 384 & 421 & 387 \\
Hit 5 & 423 & 386 & 422 & 387 & 421 & 386 \\
\hline Average & 421 & 387 & 421 & 385 & 421 & 385 \\
\hline St. Dev. & 1.85 & 1.34 & 0.89 & 1.52 & 0.84 & 1.87 \\
\hline
\end{tabular}

Table 8.5: Temperatures values used for each myrcene hit at $T_{\mathrm{m}}=405^{\circ} \mathrm{C}$. The average $T_{\mathrm{i}}$ and $T_{\mathrm{f}}$ values for M7, M8, and M9 were themselves average to get the total average $T_{\mathrm{i}}$ and $T_{\mathrm{f}}$ for the $T_{\mathrm{m}}=405^{\circ} \mathrm{C} \mathrm{TR}$, shown in Table 8.2

OG were calculated analogously using their density, results of which are shown in Table 1 in the main body of the report. Knowing that an average mass of a dab is $40 \mathrm{mg}$, and assuming that all terpenes will degrade to form similar levels of toxicants as myrcene, the amount of toxicant per mg of myrcene formed is multiplied by the mass of terpenes in a $40 \mathrm{mg}$ dab of $\mathrm{BHO}, 2.36 \mathrm{mg}$. This mass of toxicant formed per dab is then divided by the volume of the draw $(338 \mathrm{~mL})$ to give a concentration of toxicant in the air that would be inhaled. 


\begin{tabular}{lll|ll|ll} 
& \multicolumn{6}{c}{$T_{\mathrm{m}}=322{ }^{\circ} \mathrm{C}$} \\
\cline { 2 - 7 } & $\mathrm{M} 10$ & \multicolumn{3}{c}{$\mathrm{M} 11$} & \multicolumn{3}{c}{$\mathrm{M} 12$} \\
\cline { 2 - 7 } & $T_{\mathrm{i}}$ & $T_{\mathrm{f}}$ & $T_{\mathrm{i}}$ & $T_{\mathrm{f}}$ & $T_{\mathrm{i}}$ & $T_{\mathrm{f}}$ \\
\hline Hit 1 & 337 & 311 & 335 & 307 & 335 & 308 \\
Hit 2 & 336 & 309 & 336 & 309 & 224 & 306 \\
Hit 3 & 326 & 291 & 344 & 319 & 337 & 311 \\
Hit 4 & 337 & 310 & 336 & 311 & 377 & 308 \\
Hit 5 & 377 & 309 & 336 & 311 & 338 & 309 \\
\hline Average & 335 & 306 & 337 & 311 & 336 & 308 \\
\hline St. Dev. & 4.83 & 8.43 & 3.71 & 4.56 & 1.64 & 1.82 \\
\hline
\end{tabular}

Table 8.6: Temperatures values used for each myrcene hit at $T_{\mathrm{m}}=322{ }^{\circ} \mathrm{C}$. The average $T_{\mathrm{i}}$ and $T_{\mathrm{f}}$ values for M10, M11, and M12 were themselves average to get the total average $T_{\mathrm{i}}$ and $T_{\mathrm{f}}$ for the $T_{\mathrm{m}}=322{ }^{\circ} \mathrm{C}$ TR, shown in Table 8.2

Levels by Experiment

\begin{tabular}{|c|c|c|c|}
\hline $\operatorname{Tm}\left({ }^{\circ} \mathrm{C}\right)$ & Experiment & Benzene (ng) & Methacrolein (ng) \\
\hline \multirow{3}{*}{526} & M1 & 432 & 4569 \\
\hline & M2 & 362 & 4279 \\
\hline & M3 & 457 & 4804 \\
\hline \multirow{3}{*}{455} & M4 & $N D$ & 2470 \\
\hline & M5 & $N D$ & 2392 \\
\hline & M6 & $N D$ & 2397 \\
\hline \multirow{3}{*}{403} & M7 & $N D$ & 1405 \\
\hline & M8 & $N D$ & 1405 \\
\hline & M9 & $N D$ & 1340 \\
\hline \multirow{3}{*}{302} & M10 & $N D$ & $N D$ \\
\hline & M11 & $N D$ & $N D$ \\
\hline & M12 & $N D$ & $N D$ \\
\hline
\end{tabular}

Table 8.7: Benzene and methacrolein levels determined in the NMR tube for each experiment 


\begin{tabular}{|c|c|c|c|}
\hline Retention time (min) & Product & Match Quality & CAS Number \\
\hline 1.242 & 2-methylpropene & 90 & $115-11-7$ \\
\hline 1.297 & 1,3-butadiene & 91 & $106-99-0$ \\
\hline 1.348 & acetaldehyde & 72 & $75-07-0$ \\
\hline 1.929 & isoprene & 95 & $78-79-5$ \\
\hline 2.1 & acetone & 80 & $67-64-1$ \\
\hline 2.3 & cyclopentadiene & 97 & $542-92-7$ \\
\hline 2.868 & 2-methyl propanal & 83 & $78-84-2$ \\
\hline 3.019 & methacrolein & 94 & $78-85-3$ \\
\hline 3.148 & 2,3-dimethyl-2-butene & 90 & $563-79-1$ \\
\hline 3.287 & 1,3-hexadiene & 93 & $592-48-3$ \\
\hline 3.439 & methyl vinyl ketone & 80 & $78-94-4$ \\
\hline 3.51 & 3-methyl furan & 91 & $930-27-8$ \\
\hline 3.881 & 2-methyl-1,3-pentadiene & 94 & $1118-58-7$ \\
\hline 3.993 & 2-methyl-1,3-cyclopentadiene & 92 & $3727-31-9$ \\
\hline 4.481 & 1,3-cyclohexadiene & 93 & $592-57-4$ \\
\hline 4.893 & 2-ethylacrolein & 94 & $922-63-4$ \\
\hline 6.406 & 1-methyl-1,4-cyclohexadiene & 94 & $4313-57-9$ \\
\hline 6.732 & 1,3,5-cycloheptatriene & 95 & $544-25-2$ \\
\hline 14.797 & naphthalene & 95 & $91-20-3$ \\
\hline 15.691 & 4-isopropyl benzaldehyde & 93 & $122-03-2$ \\
\hline 15.884 & 3,7-dimethyl-2,6-octadienal & 97 & $5392-40-5$ \\
\hline 16.123 & 4-isopropenyl-1-cyclohexene-1-carbaldehyde & 98 & $2111-75-3$ \\
\hline 16.307 & 1-methyl naphthalene & 95 & $90-12-0$ \\
\hline 16.549 & 2-methyl naphthalene & 96 & $91-57-6$ \\
\hline 22.281 & $\begin{array}{l}(\mathrm{E}, \mathrm{E})-7,11,15 \text {-trimethyl-3-methylene-hexadeca- } \\
1,6,10,14 \text {-tetraene }\end{array}$ & 70 & $70901-63-2$ \\
\hline 22.511 & $\begin{array}{l}(\mathrm{E}, \mathrm{E}, \mathrm{E})-3,7,11,15 \text {-tetramethylhexadeca-1,3,6,10,14- } \\
\text { pentaene }\end{array}$ & 83 & $77898-97-6$ \\
\hline
\end{tabular}

Table 8.8: Products identified in a myrcene dab sample taken at the second highest TR of $T_{\mathrm{m}}=$ ca. $450{ }^{\circ} \mathrm{C}\left(T_{\mathrm{i}}=470{ }^{\circ} \mathrm{C}\right.$ and $\left.T_{\mathrm{f}}=430{ }^{\circ} \mathrm{C}\right)$ using ATD-GC-MS. Products highlighted in red were also identified in the air blank.

\subsection{Product identification by spiking}

A sample from the highest TR, M1, was spiked with low concentration methacrolein and benzene standards to verify the presence of these in the spectra. All methacrolein peaks were identified (Figures 8.3-8.6), as well as the singular benzene peak (Figure 8.7). The methacrolein standard was spiked twice to fully verify its existence amongst overlapping peaks. 


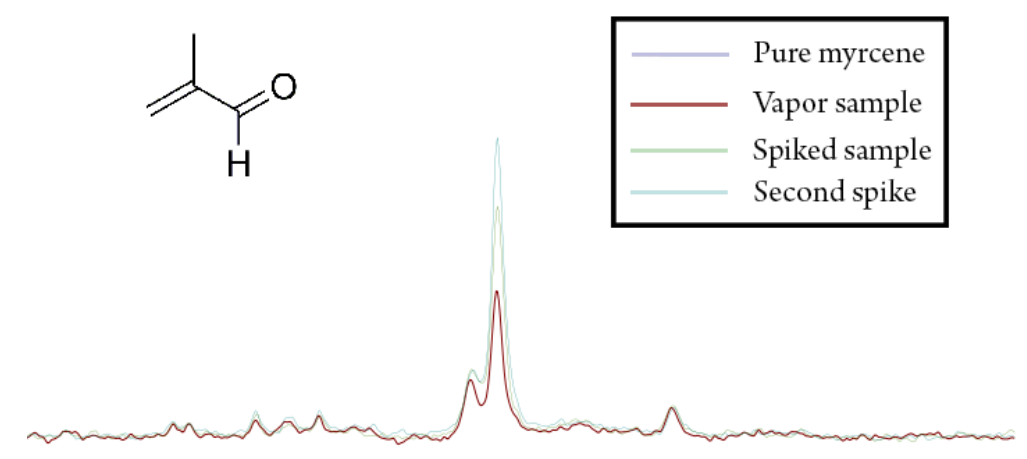

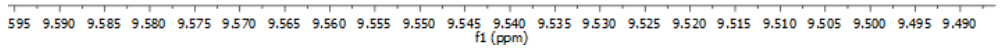

Figure 8.3: Overlay in the aldehyde proton region of methacrolein (9.54 ppm) displaying a pure myrcene sample, a vapor sample, the same vapor sample spiked with pure methacrolein, and a second spike with pure methacrolein showing a rise in intensity of this aldehyde signal. 


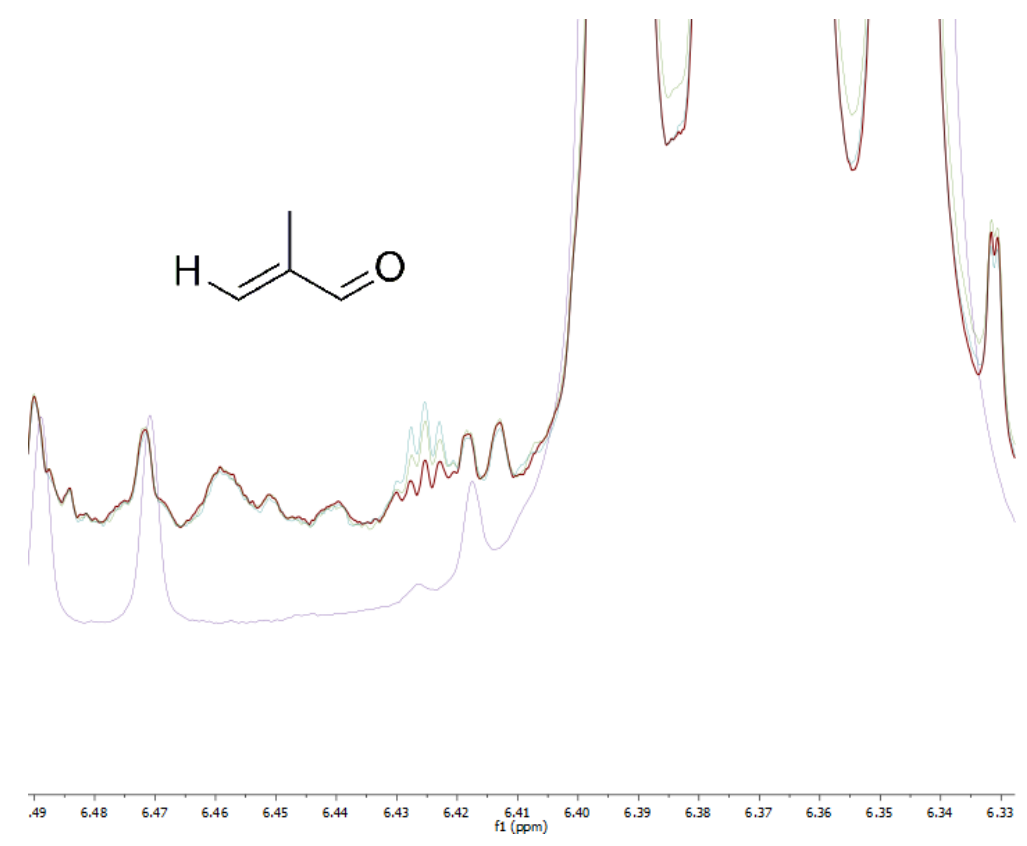

Figure 8.4: Overlay in the alkene proton region of methacrolein $(6.43 \mathrm{ppm})$ displaying a pure myrcene sample, a vapor sample, the same vapor sample spiked with pure methacrolein, and a second spike with pure methacrolein showing a rise in intensity of this alkene signal. 

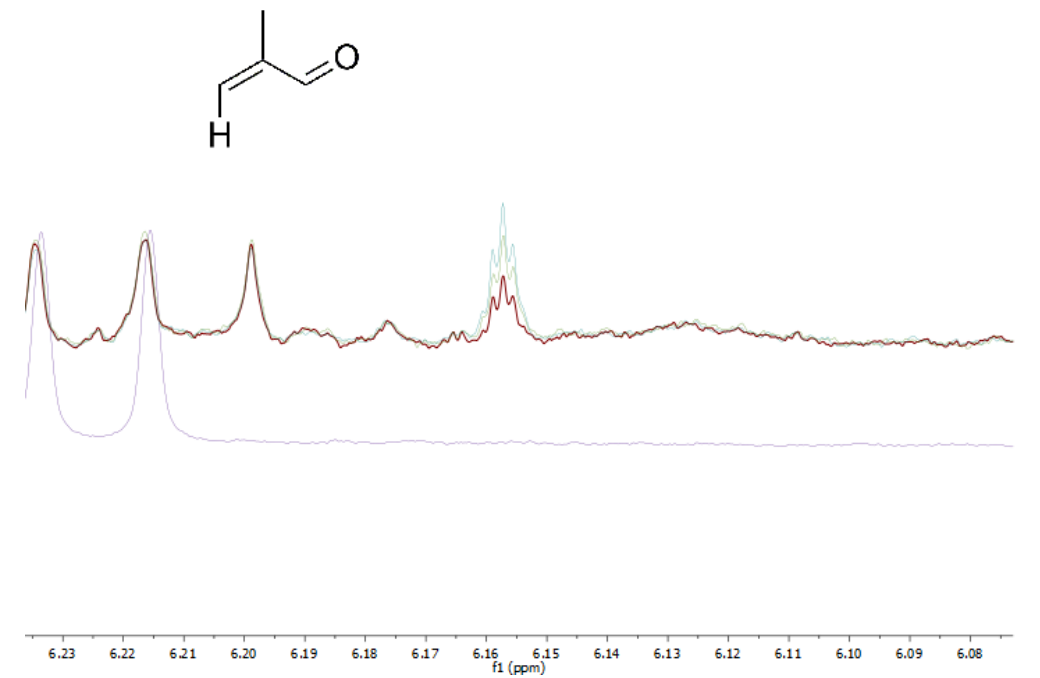

Figure 8.5: Overlay in the alkene proton region of methacrolein $(6.16 \mathrm{ppm})$ displaying a pure myrcene sample, a vapor sample, the same vapor sample spiked with pure methacrolein, and a second spike with pure methacrolein showing a rise in intensity of this alkene signal. 


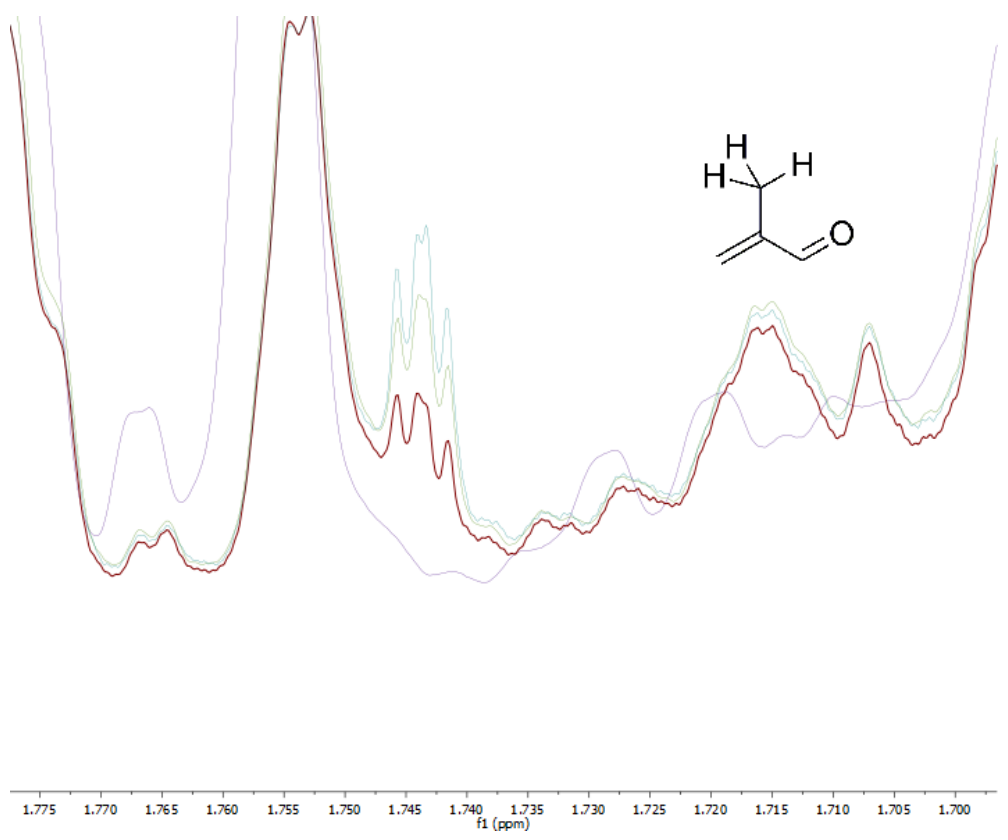

Figure 8.6: Overlay in the methyl proton region of methacrolein (1.74 ppm) displaying a pure myrcene sample, a vapor sample, the same vapor sample spiked with pure methacrolein, and a second spike with pure methacrolein showing a rise in intensity of this methyl signal. 

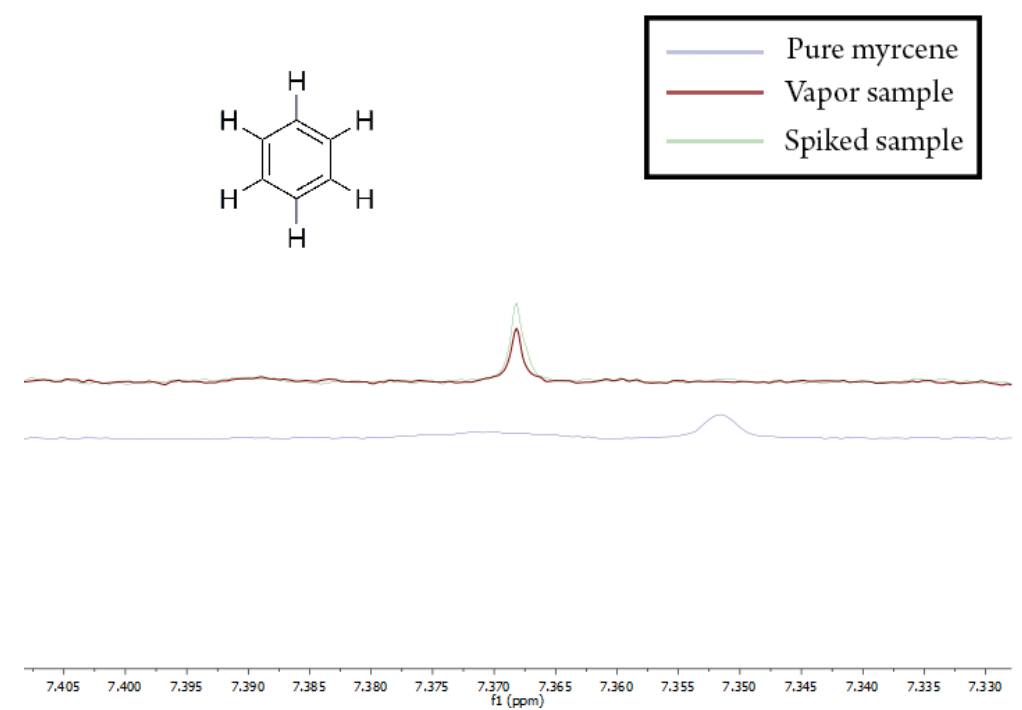

Figure 8.7: Overlay in the benzene proton region $(7.37 \mathrm{ppm})$ displaying a pure myrcene sample, a vapor sample, the same vapor sample spiked with pure benzene showing a rise in intensity of the benzene proton signal.

\subsection{Sample chromatograms and mass spectra of select degradants}




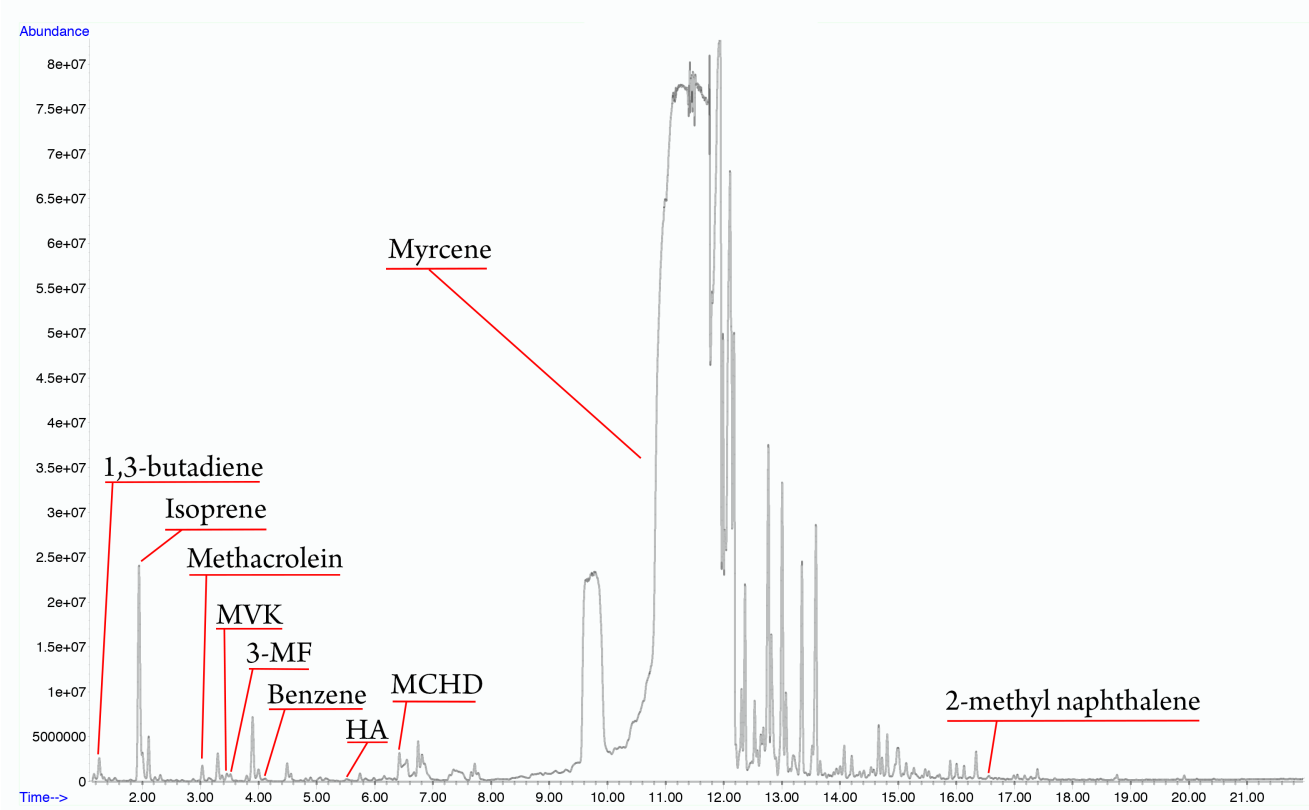

Figure 8.8: A sample chromatogram from a high-temperature myrcene dabbing sample collected using ATD-GC-MS. Highlighted peaks include: 1,3-butadiene, isoprene, methacrolein, methyl vinyl ketone (MVK), 3-methylfuran (3-MF), benzene, hydroxyacetone (HA), 1-methyl-1,4-cyclohexadiene (MCHD), myrcene, and 2methylnaphthalene. 


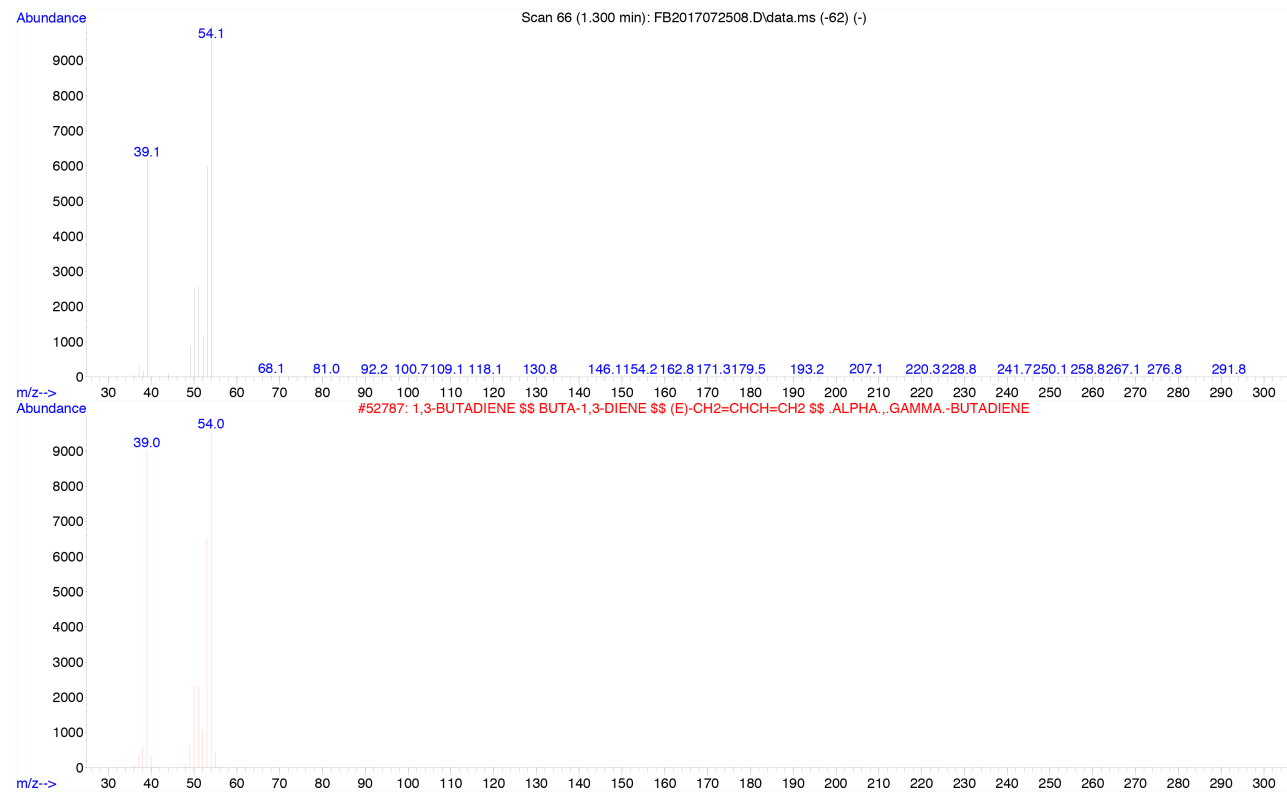

Figure 8.9: Mass spectrum of 1,3-butadiene (top, grey) compared to NIST library mass spectrum (bottom, red).

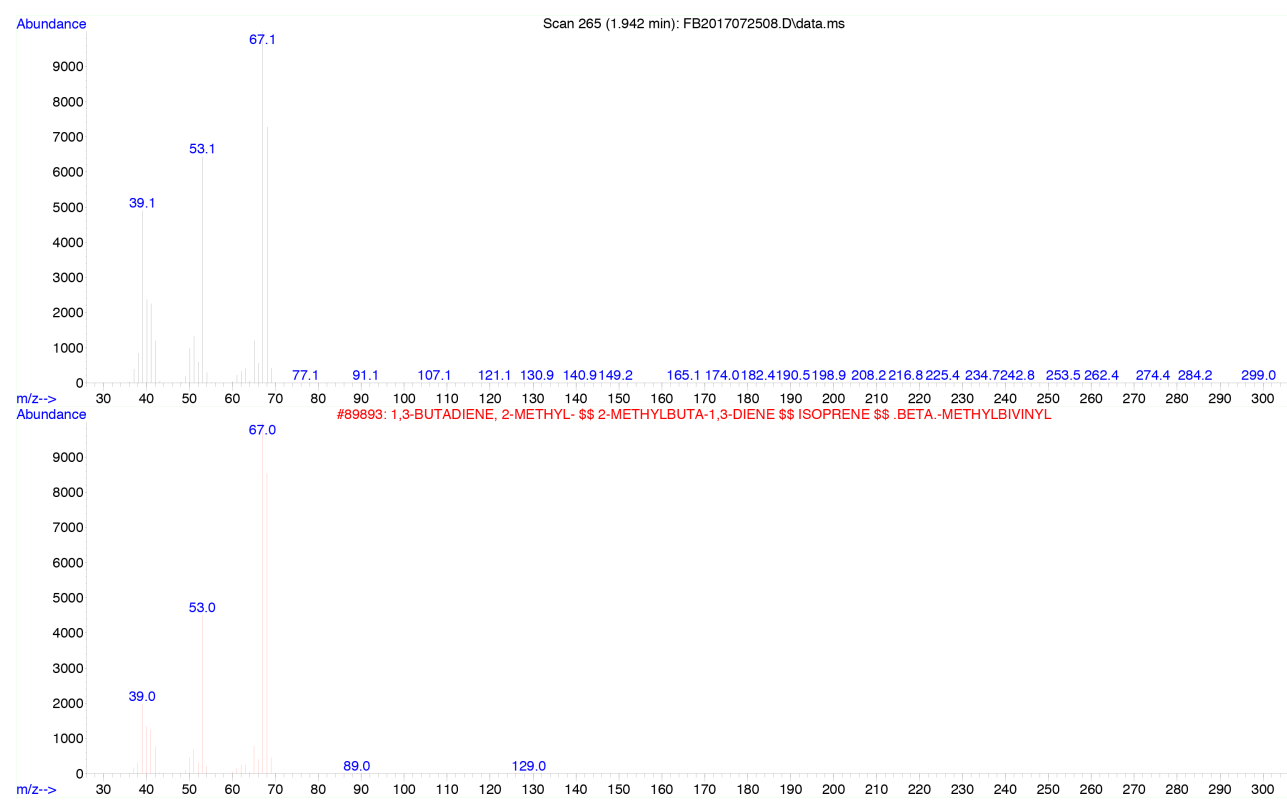

Figure 8.10: Mass spectrum of isoprene (top, grey) compared to NIST library mass spectrum (bottom, red). 


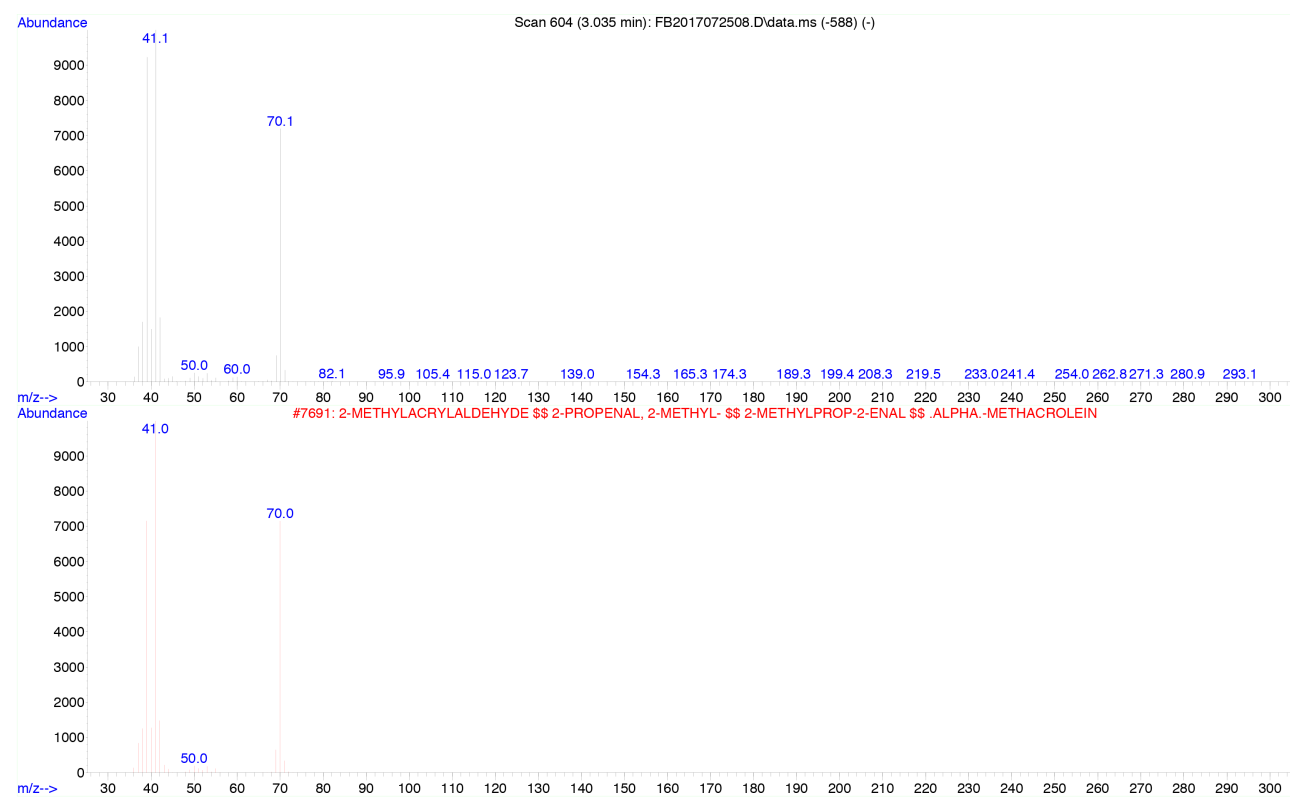

Figure 8.11: Mass spectrum of methacrolein (top, grey) compared to NIST library mass spectrum (bottom, red).

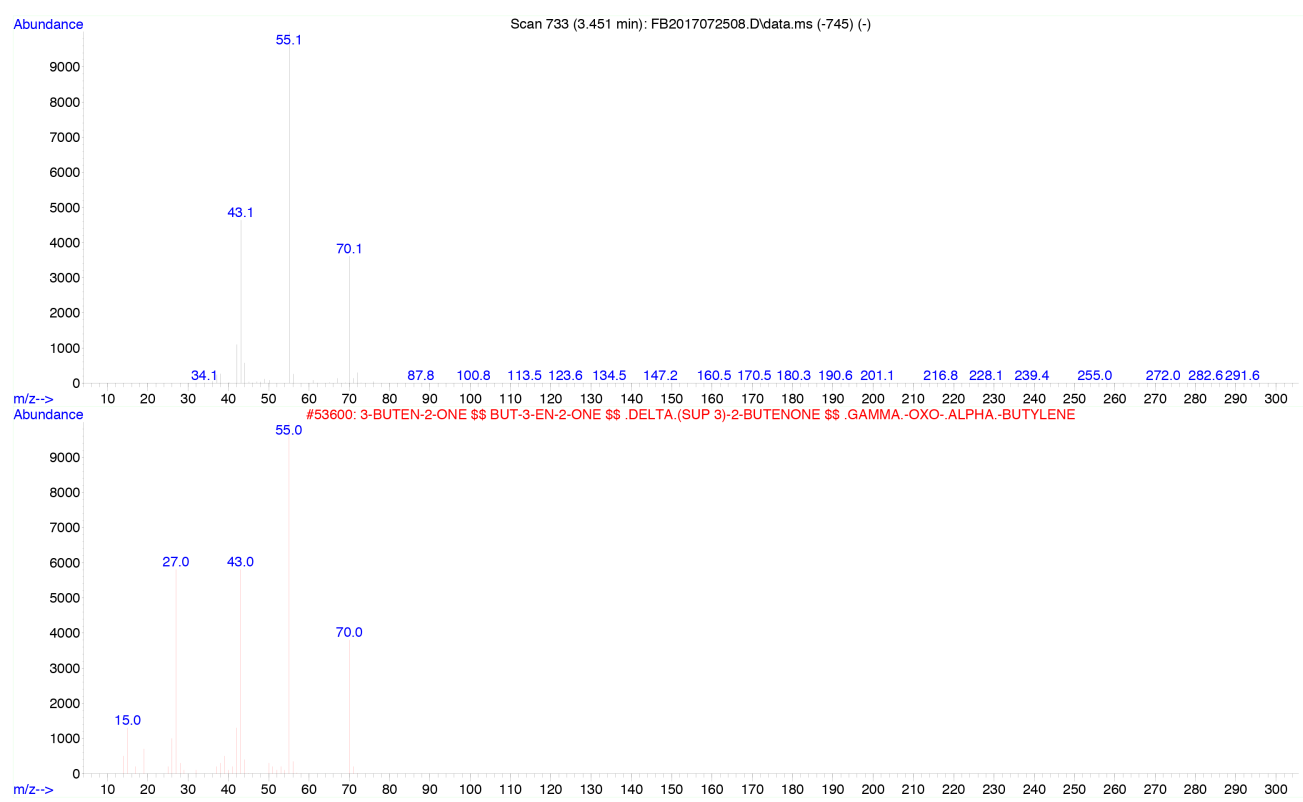

Figure 8.12: Mass spectrum of methyl vinyl ketone (top, grey) compared to NIST library mass spectrum (bottom, red). 


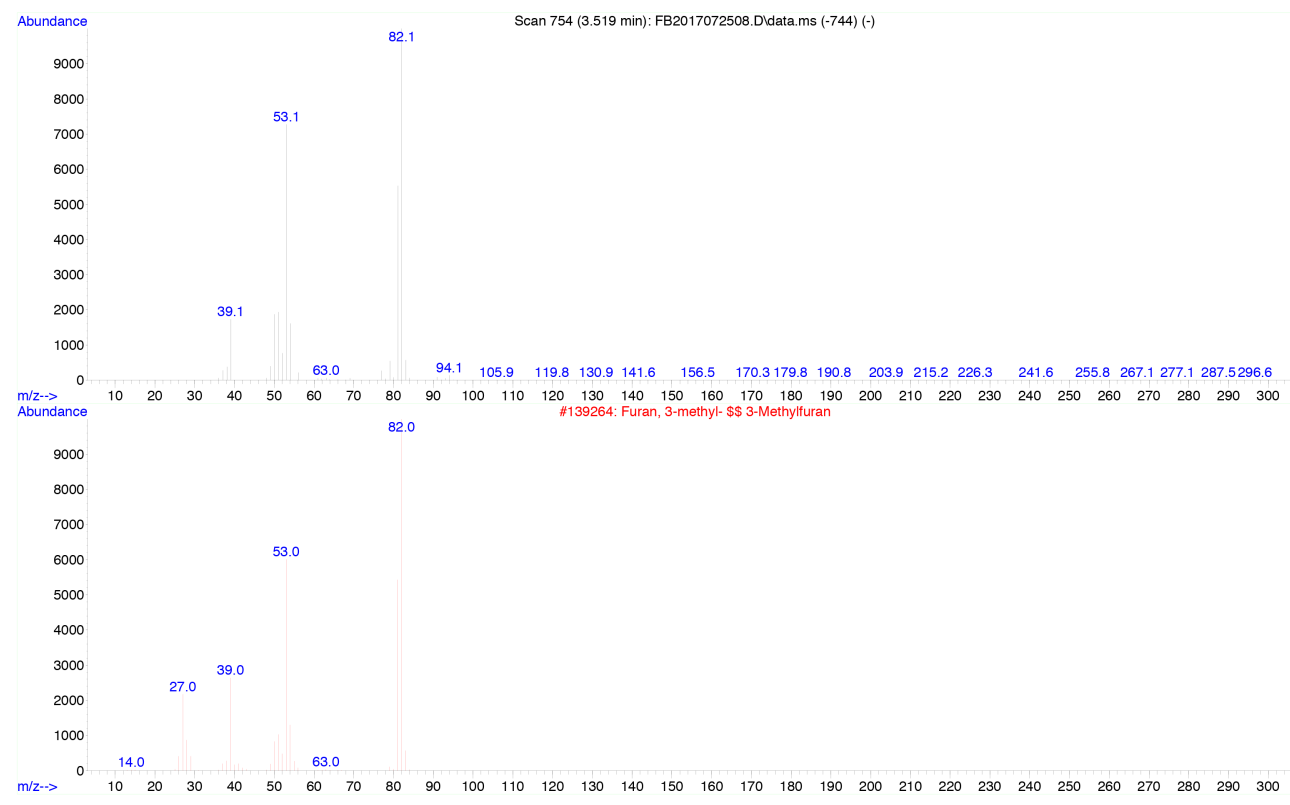

Figure 8.13: Mass spectrum of 3-methyl furan (top, grey) compared to NIST library mass spectrum (bottom, red).

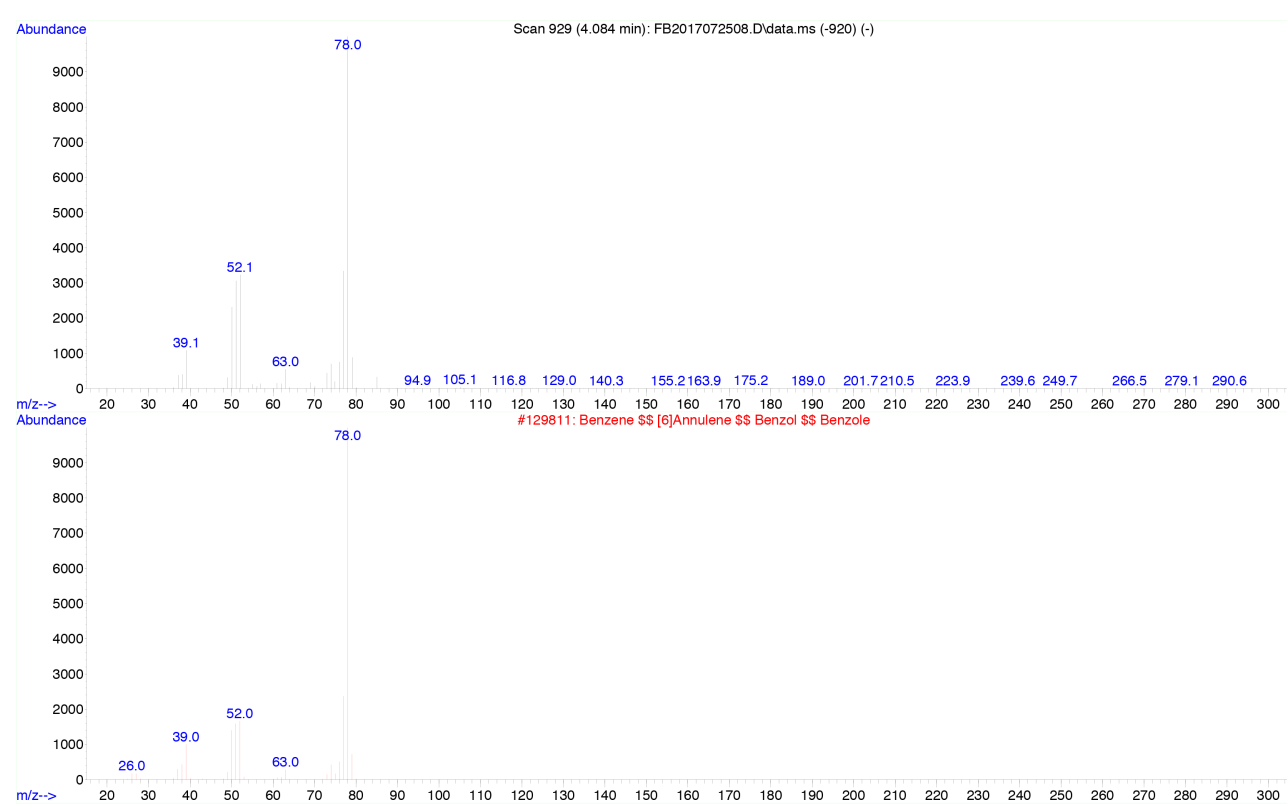

Figure 8.14: Mass spectrum of benzene (top, grey) compared to NIST library mass spectrum (bottom, red). 


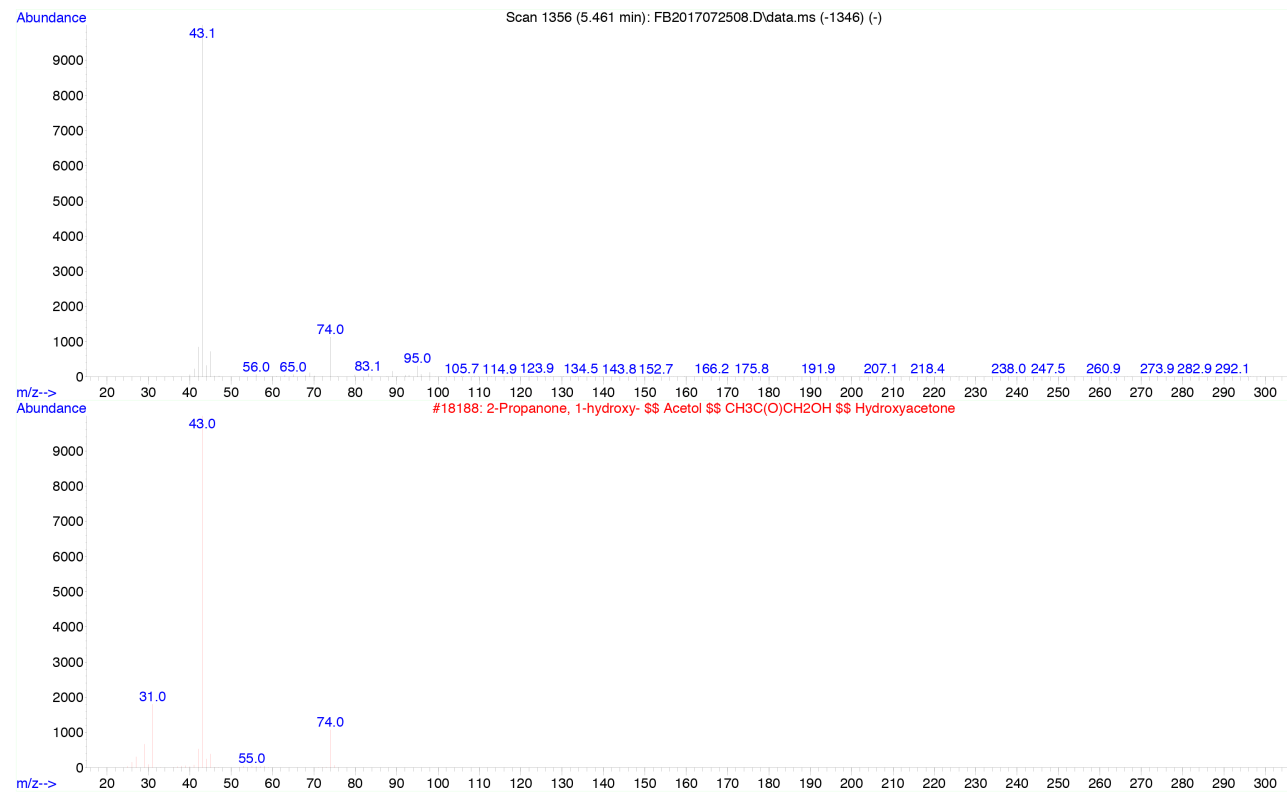

Figure 8.15: Mass spectrum of hydroxyacetone (top, grey) compared to NIST library mass spectrum (bottom, red).

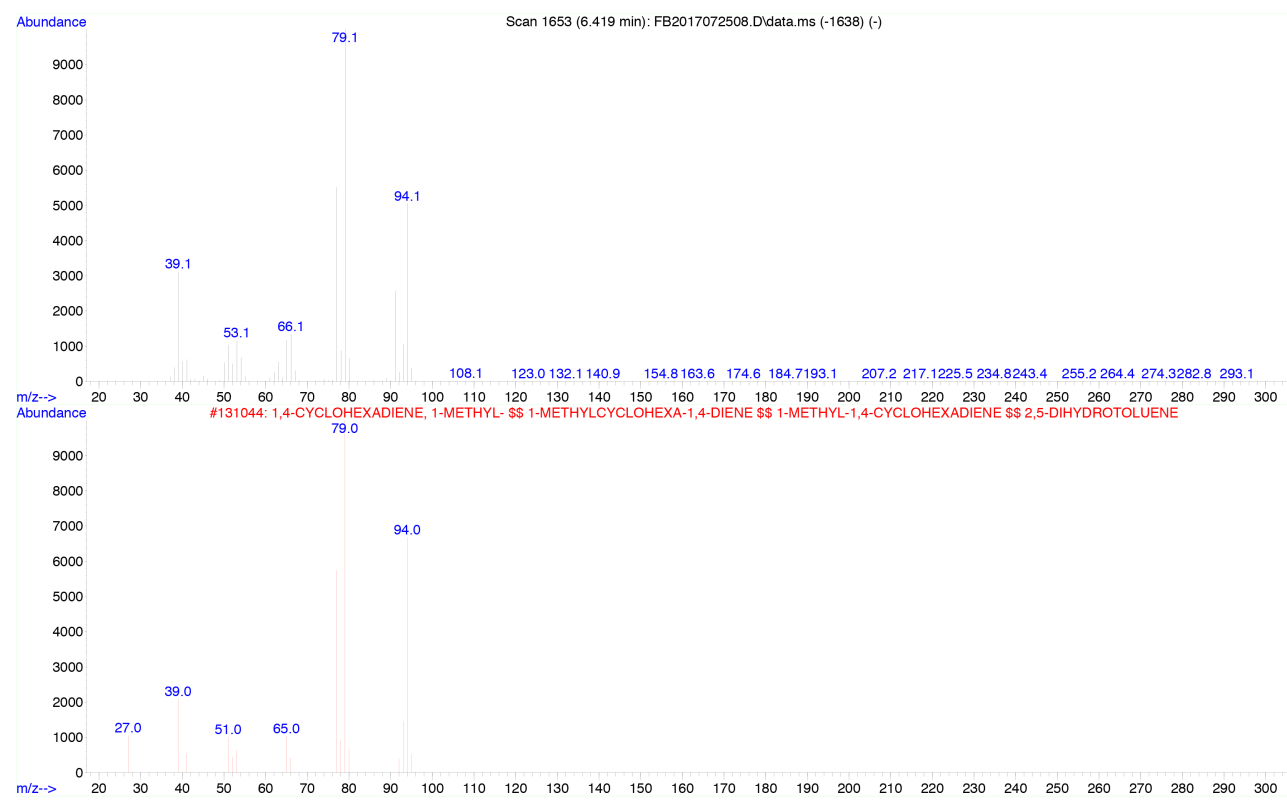

Figure 8.16: Mass spectrum of 1-methyl-1,4-cyclohexadiene (top, grey) compared to NIST library mass spectrum (bottom, red). 


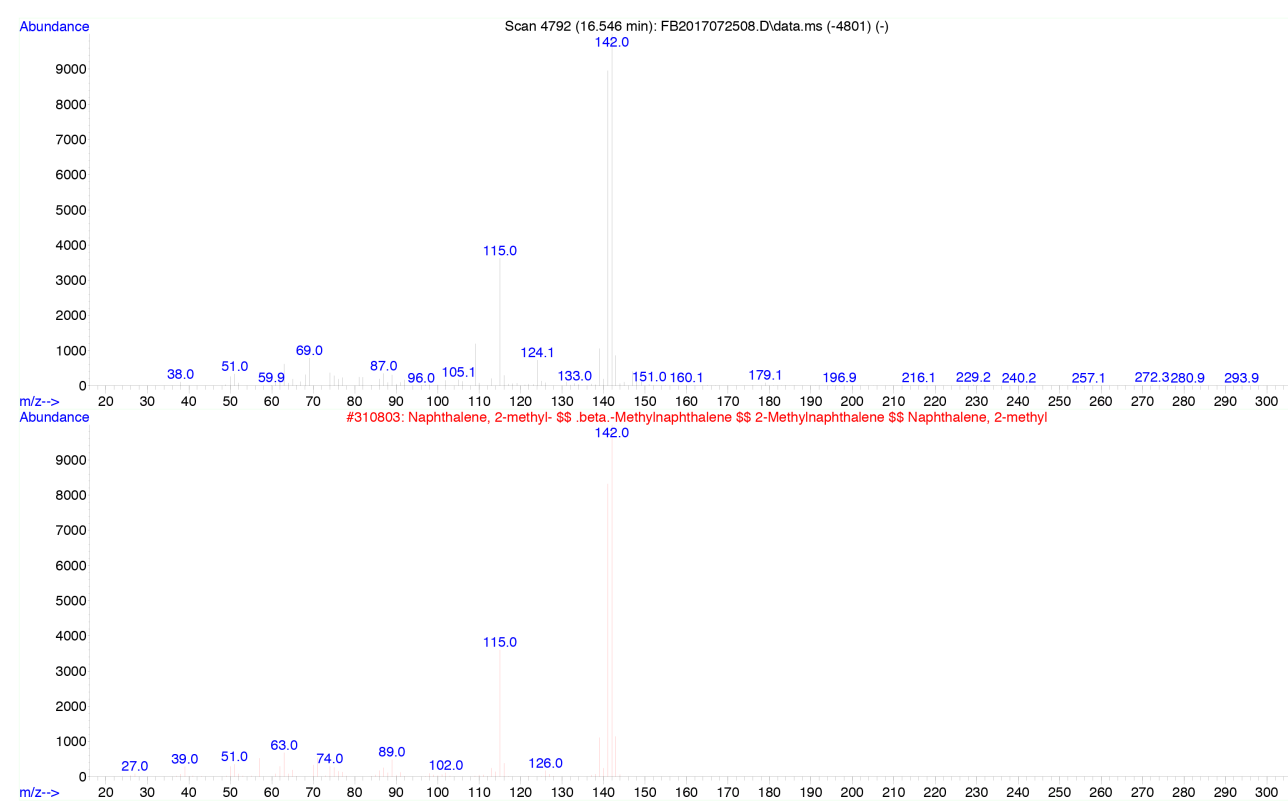

Figure 8.17: Mass spectrum of 2-methylnaphthalene (top, grey) compared to NIST library mass spectrum (bottom, red). 


\section{Appendix C: Supporting Information to Aerosol gas-phase components from cannabis e-cigarettes and dabbing: mecha- nistic insight and quantitative risk analysis}

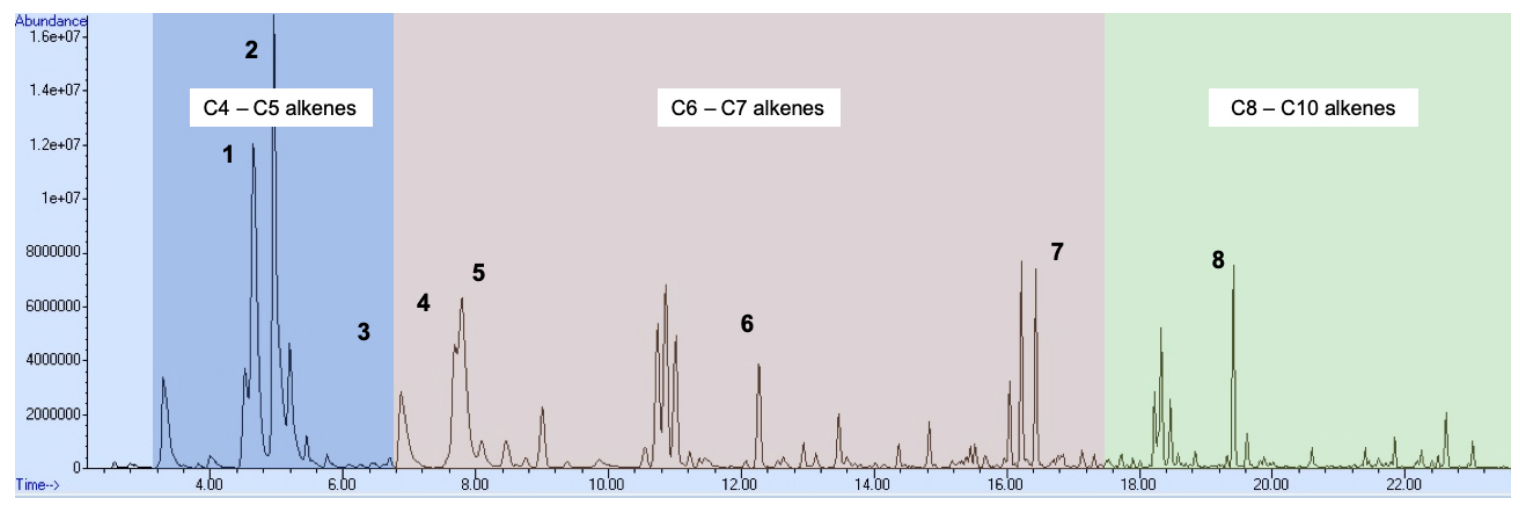

Figure 9.1: Sample chromatogram of collected for ATD-GCMS experiment of THC dabbing. Some compounds have been highlighted: 1, acetone; 2, isoprene; 3, methacrolein; 4, methyl vinyl ketone; 5, butyraldehyde; 6, 2-methyltetrahydrofuran; 7 , toluene; $o$ - and $p$-xylenes. Three regions have been highlighted based on carbon number of the hydrocarbons eluting in each. 


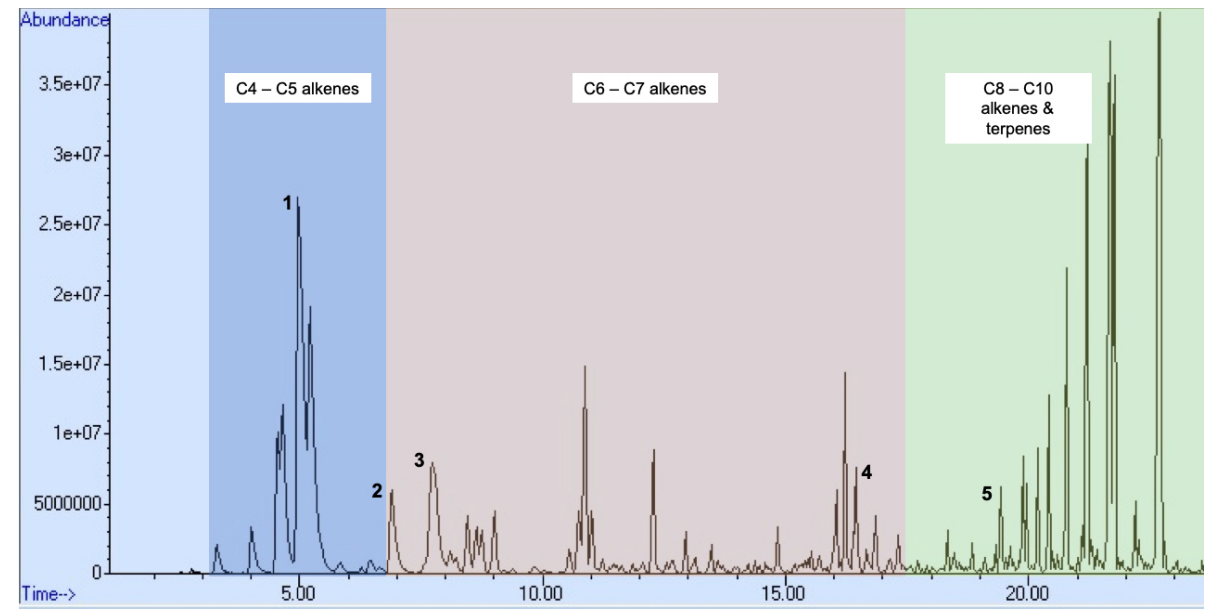

Figure 9.2: Sample chromatogram of collected for ATD-GCMS experiment of THC + terpenes dabbing. Some compounds have been highlighted: 1, isoprene; 2, methacrolein; 3, methyl vinyl ketone; 4, toluene; 5, $o$ - and $p$-xylenes. Three regions have been highlighted based on carbon number of the hydrocarbons eluting in each. 


\begin{tabular}{|c|c|c|c|c|c|c|}
\hline $\begin{array}{l}\text { RT } \\
\text { (min) }\end{array}$ & $\begin{array}{l}\text { CAS } \\
\text { Number }\end{array}$ & Name & $3.2 \mathrm{~V}$ & $4.0 \mathrm{~V}$ & $4.8 \mathrm{~V}$ & $\begin{array}{l}\text { THC+terp } \\
\text { dabbing }\end{array}$ \\
\hline 3.29 & $115-11-7$ & Isobutylene & $4.8 \mathrm{E}-01$ & $3.6 \mathrm{E}+01$ & $9.5 \mathrm{E}+01$ & $1.9 \mathrm{E}+02$ \\
\hline 3.98 & $563-46-2$ & 2-Methylbutene & $1.3 \mathrm{E}+00$ & $1.8 \mathrm{E}+01$ & $1.7 \mathrm{E}+02$ & $5.8 \mathrm{E}+02$ \\
\hline 4.65 & $67-64-1$ & Acetone & $1.9 \mathrm{E}+01$ & $1.1 \mathrm{E}+02$ & $3.1 \mathrm{E}+02$ & $2.1 \mathrm{E}+03$ \\
\hline 4.95 & $78-79-5$ & Isoprene* & $3.0 \mathrm{E}+01$ & $8.3 \mathrm{E}+02$ & $6.0 \mathrm{E}+03$ & $4.4 \mathrm{E}+04$ \\
\hline 5.19 & $2511-95-7$ & 1,2-Dimethylcylopropane & $1.2 \mathrm{E}+01$ & $1.3 \mathrm{E}+02$ & $7.5 \mathrm{E}+02$ & $3.9 \mathrm{E}+03$ \\
\hline 5.75 & $591-93-5$ & 1,4-Pentadiene & $8.2 \mathrm{E}-02$ & $2.5 \mathrm{E}+00$ & $2.3 \mathrm{E}+02$ & $8.7 \mathrm{E}+01$ \\
\hline 6.44 & $78-84-2$ & Isobutyraldehyde & $3.9 \mathrm{E}-01$ & $1.4 \mathrm{E}+00$ & $2.9 \mathrm{E}+00$ & $1.6 \mathrm{E}+02$ \\
\hline 6.61 & $563-78-0$ & 2,3-Dimethylbutene, & $\mathrm{ND}$ & $1.6 \mathrm{E}+00$ & $1.3 \mathrm{E}+02$ & $4.0 \mathrm{E}+01$ \\
\hline 6.84 & $78-85-3$ & Methacrolein* & $5.6 \mathrm{E}+00$ & $3.2 \mathrm{E}+01$ & $1.9 \mathrm{E}+02$ & $1.2 \mathrm{E}+04$ \\
\hline 7.54 & $625-27-4$ & 2-Methyl-2-pentene & ND & ND & $1.3 \mathrm{E}+02$ & $8.8 \mathrm{E}+01$ \\
\hline 7.69 & $78-94-4$ & Methyl vinyl ketone & $4.8 \mathrm{E}+00$ & $2.8 \mathrm{E}+01$ & $4.6 \mathrm{E}+01$ & $9.7 \mathrm{E}+02$ \\
\hline 7.79 & $123-72-8$ & Butyraldehyde & $9.0 \mathrm{E}-01$ & $4.6 \mathrm{E}+00$ & ND & $4.8 \mathrm{E}+02$ \\
\hline 8.45 & $674-76-0$ & 4-Methyl-2-pentene & $2.0 \mathrm{E}+00$ & $3.7 \mathrm{E}+01$ & $7.1 \mathrm{E}+02$ & $5.8 \mathrm{E}+02$ \\
\hline 8.71 & $7319-00-8$ & 1,4-Hexadiene & ND & $4.1 \mathrm{E}+00$ & $2.0 \mathrm{E}+02$ & $3.7 \mathrm{E}+02$ \\
\hline 8.98 & $1118-58-7$ & 2-Methyl-1,3-pentadiene & $3.0 \mathrm{E}-01$ & $5.4 \mathrm{E}-05$ & $1.7 \mathrm{E}+02$ & $6.6 \mathrm{E}+02$ \\
\hline 9.21 & $922-62-3$ & 3-Methyl-2-pentene & $\mathrm{ND}$ & $1.0 \mathrm{E}+00$ & $8.8 \mathrm{E}+01$ & $2.5 \mathrm{E}+01$ \\
\hline 10.53 & $926-56-7$ & 4-Methyl-1,3-pentadiene & ND & $4.0 \mathrm{E}+00$ & $1.1 \mathrm{E}+02$ & $2.5 \mathrm{E}+02$ \\
\hline 10.72 & $542-92-7$ & 1,3-Cyclopentadiene & $5.7 \mathrm{E}-01$ & $1.6 \mathrm{E}+01$ & $2.9 \mathrm{E}+02$ & $5.4 \mathrm{E}+02$ \\
\hline 10.86 & $592-48-3$ & 1,3-Hexadiene & $4.4 \mathrm{E}+00$ & $7.6 \mathrm{E}+01$ & $5.1 \mathrm{E}+02$ & $1.1 \mathrm{E}+03$ \\
\hline 11.00 & $592-57-4$ & 1,3-Cyclohexadiene & ND & $6.8 \mathrm{E}-05$ & $3.0 \mathrm{E}+02$ & $1.4 \mathrm{E}+03$ \\
\hline 12.07 & $71-43-2$ & Benzene* & $9.9 \mathrm{E}-01$ & $2.7 \mathrm{E}+00$ & $3.6 \mathrm{E}+01$ & $3.6 \mathrm{E}+02$ \\
\hline 12.26 & $96-39-9$ & Methyl-1,3-cyclopentadiene & $1.7 \mathrm{E}-01$ & $5.7 \mathrm{E}+00$ & $7.3 \mathrm{E}+01$ & $1.1 \mathrm{E}+03$ \\
\hline 12.93 & $1838-94-4$ & Isoprene epoxide & ND & $1.1 \mathrm{E}+00$ & $3.2 \mathrm{E}+00$ & $2.7 \mathrm{E}+02$ \\
\hline 13.47 & $110-62-3$ & Valeraldehyde & ND & ND & ND & $1.8 \mathrm{E}+02$ \\
\hline 13.64 & $2738-19-4$ & 2-Methyl-2-hexene & $1.3 \mathrm{E}-01$ & $9.1 \mathrm{E}+00$ & $2.8 \mathrm{E}+02$ & $7.2 \mathrm{E}+01$ \\
\hline 14.83 & $4125-18-2$ & 5,5-Dimethylcyclopentadiene & $8.3 \mathrm{E}-02$ & $2.5 \mathrm{E}+00$ & $9.7 \mathrm{E}+01$ & $3.1 \mathrm{E}+02$ \\
\hline 15.39 & $4313-57-9$ & 1-Methyl-1,4-cyclohexadiene & $1.1 \mathrm{E}-01$ & $2.3 \mathrm{E}+00$ & $1.2 \mathrm{E}+02$ & $1.2 \mathrm{E}+02$ \\
\hline 15.45 & $497-03-0$ & 2,3-Dimethylacrolein & ND & ND & ND & $7.5 \mathrm{E}+01$ \\
\hline 15.68 & $4784-86-5$ & 1,2-Dimethylcyclopentadiene & ND & $2.7 \mathrm{E}+00$ & $7.5 \mathrm{E}+01$ & $1.9 \mathrm{E}+02$ \\
\hline 15.93 & $3404-78-2$ & 2,5-Dimethyl-2-hexene & ND & $5.3 \mathrm{E}+00$ & $1.5 \mathrm{E}+02$ & $1.5 \mathrm{E}+02$ \\
\hline 16.03 & $41233-72-1$ & 2-Methyl-1,3,5-hexatriene & ND & $2.4 \mathrm{E}+00$ & $9.2 \mathrm{E}+01$ & $5.5 \mathrm{E}+02$ \\
\hline 16.21 & $1489-57-2$ & 2-Methyl-1,3-cyclohexadiene & ND & $2.9 \mathrm{E}+01$ & $1.5 \mathrm{E}+02$ & $9.7 \mathrm{E}+02$ \\
\hline 16.44 & $108-88-3$ & Toluene* & 7.0E-01 & $1.0 \mathrm{E}+01$ & $1.6 \mathrm{E}+02$ & $1.3 \mathrm{E}+03$ \\
\hline 16.81 & $13643-0606$ & 2-Methyl-1,6-heptadiene & ND & $4.4 \mathrm{E}+00$ & $6.6 \mathrm{E}+01$ & $1.8 \mathrm{E}+02$ \\
\hline 18.32 & $\mathrm{NA}$ & $\begin{array}{l}\text { 1,2,5,5-Tetramethyl-1,3- } \\
\text { cyclopentadiene }\end{array}$ & ND & $3.1 \mathrm{E}+00$ & $1.6 \mathrm{E}+02$ & $2.3 \mathrm{E}+02$ \\
\hline 18.46 & NA & $\begin{array}{l}\text { 5-tert-Butyl-1,3- } \\
\text { cyclopentadiene }\end{array}$ & ND & $1.8 \mathrm{E}+00$ & $1.1 \mathrm{E}+02$ & $1.3 \mathrm{E}+02$ \\
\hline 19.11 & $100-41-4$ & Ethylbenzene* & $3.7 \mathrm{E}-02$ & $2.5 \mathrm{E}-01$ & $2.7 \mathrm{E}+00$ & $5.5 \mathrm{E}+01$ \\
\hline 19.32 & $6709-39-3$ & 2,6-Dimethyl-1,5-heptadiene & $2.1 \mathrm{E}+00$ & $2.6 \mathrm{E}+01$ & $2.0 \mathrm{E}+02$ & $2.0 \mathrm{E}+02$ \\
\hline 19.43 & $\begin{array}{l}106-42-3 \quad \& \\
95-47-6\end{array}$ & $p$ - and $o$-Xylenes* & $1.0 \mathrm{E}+00$ & $1.4 \mathrm{E}+01$ & $178 \mathrm{E}+02$ & $8.3 \mathrm{E}+02$ \\
\hline 19.91 & $100-42-5$ & Styrene* & 9.3E-02 & $2.7 \mathrm{E}-01$ & NQ & $2.7 \mathrm{E}+01$ \\
\hline 20.017 & $108-38-3$ & $m$-Xylene* & $3.2 \mathrm{E}-02$ & $3.4 \mathrm{E}-01$ & $48 \mathrm{E}+00$ & $2.3 \mathrm{E}+01$ \\
\hline 20.56 & $98-82-8$ & Isopropylbenzene* $^{*}$ & ND & ND & ND & $3.3 \mathrm{E}+01$ \\
\hline \multirow[t]{2}{*}{23.96} & $1195-32-0$ & alpha- $p$-Dimethylstyrene & $6.6 \mathrm{E}+00$ & $2.2 \mathrm{E}+01$ & $1.9 \mathrm{E}+01$ & $1.2 \mathrm{E}+02$ \\
\hline & & Total VOCs & 9.4E-02 & $1.5 \mathrm{E}+00$ & $1.2 \mathrm{E}+01$ & $7.7 \mathrm{E}+01$ \\
\hline
\end{tabular}

Table 9.1: Gas phase components tentatively identified and quantified by non-target analysis for vaping and dabbing THC + terpenes. Results for $\mathrm{THC}+$ terpenes dabbing are averaged between the duplicate measurements and are based on a $40 \mathrm{mg}$ dab; values for vaping are based on single measurements. All measurements are in ng, except for Total VOCs, in $\mu g$. *: These components were quantified using IS calibration for dabbing, for using RF analysis for dabbing; all other components were quantified by non-target analysis. 


\begin{tabular}{|c|c|c|c|}
\hline $\begin{array}{l}\text { RT } \\
\text { (min) }\end{array}$ & $\begin{array}{l}\text { CAS } \\
\text { Number }\end{array}$ & Name & $\begin{array}{l}\text { THC } \\
\text { dabbing }\end{array}$ \\
\hline 3.293 & $115-11-7$ & Isobutylene & $4.5 \mathrm{E}+02$ \\
\hline 3.997 & $563-46-2$ & 2-Methylbutene & $6.1 \mathrm{E}+01$ \\
\hline 4.521 & $646-04-8$ & 2-Pentene & $3.1 \mathrm{E}+02$ \\
\hline 4.65 & $67-64-1$ & Acetone & $1.6 \mathrm{E}+03$ \\
\hline 4.954 & $78-79-5$ & Isoprene* & $9.6 \mathrm{E}+03$ \\
\hline 5.199 & $2511-95-7$ & 1,1-Dimethylcyclopropane & $3.9 \mathrm{E}+02$ \\
\hline 5.452 & $2004-70-8$ & 1,3-Pentadiene & $7.1 \mathrm{E}+01$ \\
\hline 5.766 & $591-93-5$ & 1,4-Pentadiene & $3.8 \mathrm{E}+01$ \\
\hline 6.264 & 763-29-1 & 2-Methylpentene & $1.3 \mathrm{E}+01$ \\
\hline 6.44 & $78-84-2$ & Isobutyraldehyde & $1.8 \mathrm{E}+01$ \\
\hline 6.71 & $625-27-4$ & 2-Methyl-2-pentene & $3.4 \mathrm{E}+01$ \\
\hline 6.835 & $78-85-3$ & Methacrolein* & $2.7 \mathrm{E}+03$ \\
\hline 7.689 & $78-94-4$ & Methyl vinyl ketone & $4.3 \mathrm{E}+02$ \\
\hline 7.792 & $123-72-8$ & Butyraldehyde & $8.4 \mathrm{E}+02$ \\
\hline 8.758 & $1759-81-5$ & 4-Methylcyclopentene & $3.4 \mathrm{E}+01$ \\
\hline 9.007 & $764-35-2$ & 2-Hexyne & $2.0 \mathrm{E}+02$ \\
\hline 9.38 & $592-46-1$ & 2,4-Hexadiene & $1.8 \mathrm{E}+01$ \\
\hline 9.857 & $123-72-8$ & Tetrahydrofuran & $3.8 \mathrm{E}+01$ \\
\hline 10.737 & $96-39-9$ & Methyl-1,3-cyclopentadiene & $4.0 \mathrm{E}+02$ \\
\hline 10.861 & $926-56-7$ & 4-Methyl-1,3-pentadiene & $5.9 \mathrm{E}+02$ \\
\hline 11.011 & $592-57-4$ & 1,3-Cyclohexadiene & $3.4 \mathrm{E}+02$ \\
\hline 12.067 & $71-43-2$ & Benzene* & $3.3 \mathrm{E}+01$ \\
\hline 12.265 & $96-47-9$ & 2-Methyltetrahydrofuran & $2.0 \mathrm{E}+02$ \\
\hline 12.548 & $814-78-8$ & Isopropenyl methyl ketone & $2.0 \mathrm{E}+01$ \\
\hline 12.934 & $1838-94-4$ & Isoprene epoxide & $4.4 \mathrm{E}+01$ \\
\hline 13.471 & $110-62-3$ & Valeraldehyde & $1.0 \mathrm{E}+02$ \\
\hline 13.591 & $630-19-3$ & Trimethylacetaldehyde & $1.7 \mathrm{E}+01$ \\
\hline 14.025 & $630-19-3$ & 2,5-Dimethylfuran & $8.3 \mathrm{E}+00$ \\
\hline 14.372 & $591-47-9$ & 4-Methylcyclohexene & $3.5 \mathrm{E}+01$ \\
\hline 14.836 & $4125-18-2$ & 5,5-dimethylcyclopentadiene & $8.1 \mathrm{E}+01$ \\
\hline 15.454 & $497-03-0$ & 2,3-Dimethylacrolein & $2.3 \mathrm{E}+01$ \\
\hline 15.965 & $3404-78-2$ & 2,5-dimethyl-2-hexene & $9.6 \mathrm{E}+00$ \\
\hline 16.042 & $41233-72-1$ & 2-methyl-1,3,5-hexatriene & $1.3 \mathrm{E}+02$ \\
\hline 16.218 & $1489-57-2$ & 2-methyl-1,3-cyclohexadiene & $2.5 \mathrm{E}+02$ \\
\hline 16.437 & $108-88-3$ & Toluene* & $4.4 \mathrm{E}+02$ \\
\hline 18.33 & NA & 1,2,5,5-Tetramethyl-1,3-cyclopentadiene & $1.8 \mathrm{E}+02$ \\
\hline 18.468 & NA & 5-tert-Butyl-1,3-cyclopentadiene & $8.8 \mathrm{E}+01$ \\
\hline 19.107 & $100-41-4$ & Ethylbenzene* & $1.4 \mathrm{E}+00$ \\
\hline 19.318 & $6709-39-3$ & 2,6-Dimethyl-1,5-heptadiene & $1.2 \mathrm{E}+01$ \\
\hline 19.425 & $\begin{array}{l}106-42-3 \quad \& \\
95-47-6\end{array}$ & $p$ - and $o$ - Xylenes* & $3.3 \mathrm{E}+02$ \\
\hline 19.618 & $20185-16-4$ & 3,3-Dimethyl-6-methylenecyclohexene & $3.8 \mathrm{E}+01$ \\
\hline 19.910 & $100-42-5$ & Styrene* & $8.8 \mathrm{E}-01$ \\
\hline 20.017 & $108-38-3$ & $m$-Xylene* & $4.2 \mathrm{E}+00$ \\
\hline 20.563 & $98-82-8$ & Isopropylbenzene* & $2.1 \mathrm{E}+00$ \\
\hline 21.846 & $\mathrm{NA}$ & 1,6-Dimethylhepta-1,3,5-triene & $2.6 \mathrm{E}+01$ \\
\hline 22.249 & NA & 2,5,5-Trimethyl-1-hexen-3-yne & $1.6 \mathrm{E}+01$ \\
\hline 22.614 & $99-87-6$ & $p$-Cymene & $6.5 \mathrm{E}+01$ \\
\hline 23.966 & $1195-32-0$ & alpha- $p$-Dimethylstyrene & $2.3 \mathrm{E}+01$ \\
\hline
\end{tabular}

Table 9.2: Gas phase components identified and quantified (ng) for dabbing THC. Results are averaged between the duplicate measurements and are based on a $40 \mathrm{mg}$ dab. All measurements are in ng, except for Total VOCs, in $\mu g$. *: These components were quantified using IS calibration for dabbing; all other components were quantified by non-target analysis. 


\begin{tabular}{|c|c|c|c|c|c|c|c|c|}
\hline Compound & $\begin{array}{l}\text { CAS } \\
\text { RN }\end{array}$ & $\begin{array}{l}\text { IUR } \\
\left(\boldsymbol{\mu g} / \mathbf{m}^{3}\right)^{-1}\end{array}$ & $\begin{array}{l}\text { REL } \\
\left(\mu \mathrm{g} / \mathrm{m}^{3}\right)\end{array}$ & $\begin{array}{ll}\text { Target } & \text { sys- } \\
\text { tem } & \text { for } \\
\text { REL } & \end{array}$ & $\begin{array}{l}\text { ELCR }_{i} \\
\text { Dabbing } \\
\left(\% \text { (ELCR }_{\mathrm{T}}\right)\end{array}$ & $\begin{array}{l}\text { ELCR }_{i} \\
\text { Vaping } \\
\text { at } 4.0 \mathrm{~V} \\
\left(\% \mathrm{ELCR}_{\mathrm{T}}\right)\end{array}$ & $\begin{array}{l}\text { HQ } \\
\text { Dabbing } \\
(\% \mathrm{HI})\end{array}$ & $\begin{array}{l}\text { HQ } \\
\text { Vaping } \\
\text { at 4.0V } \\
(\% \mathrm{HI})\end{array}$ \\
\hline Methacrolein & $78-85-3$ & NA & $\begin{array}{l}8.1 \mathrm{E}+00, \\
\text { TCEQ }\end{array}$ & Respiratory & NA & NA & $\begin{array}{l}1 \mathrm{E}-1 \\
(91 \%)\end{array}$ & $\begin{array}{l}4 \mathrm{E}-3 \\
(62 \%)\end{array}$ \\
\hline Benzene & $71-43-2$ & $\begin{array}{l}2.2 \mathrm{E}-06, \\
\text { IRIS* }\end{array}$ & $\begin{array}{l}3.0 \mathrm{E}+01, \\
\text { IRIS }\end{array}$ & Immune & $\begin{array}{l}6 \mathrm{E}-8 \\
(42 \%)\end{array}$ & $\begin{array}{l}5 \mathrm{E}-9 \\
(24 \%)\end{array}$ & $1 \mathrm{E}-3$ & $\begin{array}{l}9 \mathrm{E}-5 \\
(1.4 \%) \\
\end{array}$ \\
\hline Xylenes & $\begin{array}{l}1330-20- \\
7\end{array}$ & NA & $\begin{array}{l}1.0 \mathrm{E}+02, \\
\text { IRIS }\end{array}$ & Neurological & NA & NA & $9 \mathrm{E}-4$ & $\begin{array}{l}\mathrm{E}-4 \\
(2.2 \%) \\
\end{array}$ \\
\hline Styrene & $100-42-5$ & NA & $\begin{array}{l}1.0 \mathrm{E}+03, \\
\text { IRIS }\end{array}$ & Neurological & NA & NA & $3 \mathrm{E}-6$ & $3 \mathrm{E}-7$ \\
\hline Ethylbenzene & $100-41-4$ & $\begin{array}{l}2.5 \mathrm{E}-06, \\
\text { OEHHA }\end{array}$ & $\begin{array}{l}1.0 \mathrm{E}+03, \\
\text { IRIS }\end{array}$ & Developmental & $\begin{array}{l}1 \mathrm{E}-8 \\
(7.3 \%)\end{array}$ & $\begin{array}{l}5 \mathrm{E}-10 \\
(2.5 \%)\end{array}$ & $6 \mathrm{E}-6$ & $3 \mathrm{E}-7$ \\
\hline Isoprene & $78-79-5$ & $\begin{array}{l}2.2 \mathrm{E}-08, \\
\text { Haney et } \\
\text { al }\end{array}$ & $\begin{array}{l}3.9 \mathrm{E}+02, \\
\text { TCEQ }\end{array}$ & NA & $\begin{array}{l}8 \mathrm{E}-8 \\
(51 \%)\end{array}$ & $\begin{array}{l}1 \mathrm{E}-8 \\
(74 \%)\end{array}$ & $\begin{array}{l}1 \mathrm{E}-2 \\
(7.2 \%)\end{array}$ & $\begin{array}{l}2 \mathrm{E}-3 \\
(32.7 \%)\end{array}$ \\
\hline
\end{tabular}

Table 9.3: Dabbing and CV gas phase components used for QRA. REL and IUR values with sources used, their non-cancer target systems according to IRIS, and the $\mathrm{ELCR}_{i}$ and $\mathrm{HQ}$ for each component are listed. Percentage contributions to ELCR $\mathrm{T}_{\mathrm{T}}$ and HI are shown for components that contribute greater than $1 \%$ to the total of each, which collectively make up $>98 \% \mathrm{ELCR}_{\mathrm{T}}$ and HI. ${ }^{*}$ The lower bound of the range reported for benzene is used. 


\begin{tabular}{|c|c|c|c|c|c|c|c|}
\hline Compound & $\begin{array}{l}\text { CAS } \\
\text { RN }\end{array}$ & $\begin{array}{l}\mathrm{CY} \\
\text { (pg/grams } \\
\text { cannabis) }\end{array}$ & $\begin{array}{l}\text { IUR } \\
\left(\mathbf{\mu g} / \mathbf{m}^{3}\right),-1 \\
\text { source }\end{array}$ & $\begin{array}{l}\text { REL } \\
\left(\mu \mathrm{g} / \mathbf{m}^{3}\right), \\
\text { source }\end{array}$ & $\begin{array}{l}\text { Target sys- } \\
\text { tem for REL }\end{array}$ & 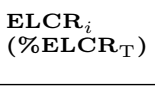 & $\begin{array}{l}\text { HQ } \\
(\% \mathbf{H I})\end{array}$ \\
\hline 4-Aminobiphenyl & $92-67-1$ & $1.6 \mathrm{E}-02$ & $\begin{array}{l}\text { 6.0E-03, } \\
\text { OEHHA }\end{array}$ & NA & NA & $3 \mathrm{E}-6$ & NA \\
\hline Acetaldehyde & $75-07-0$ & $6.2 \mathrm{E}+02$ & $\begin{array}{l}2.2 \mathrm{E}-06, \\
\text { IRIS }\end{array}$ & $\begin{array}{l}9.0 \mathrm{E}+00, \\
\text { IRIS }\end{array}$ & Respiratory & $4 \mathrm{E}-5(10 \%)$ & $\begin{array}{l}3 \mathrm{E}+0 \\
(1.1 \%)\end{array}$ \\
\hline Acetone & $67-64-1$ & $2.1 \mathrm{E}+02$ & NA & $\begin{array}{l}1.6 \mathrm{E}+04, \\
\text { TCEQ }\end{array}$ & Neurological & NA & $5 \mathrm{E}-4$ \\
\hline Acrolein & $107-02-8$ & $9.0 \mathrm{E}+01$ & $\overline{\mathrm{NA}}$ & $\begin{array}{l}2.0 \mathrm{E}-02, \\
\text { IRIS }\end{array}$ & Respiratory & NA & $\begin{array}{l}2 \mathrm{E}+2 \\
(75 \%)\end{array}$ \\
\hline Acrylonitrile & $107-13-1$ & $8.2 \mathrm{E}+01$ & $\begin{array}{l}6.8 \mathrm{E}-05 \\
\text { IRIS }\end{array}$ & $\begin{array}{l}2.0 \mathrm{E}+00 \\
\text { IRIS }\end{array}$ & Respiratory & $2 \mathrm{E}-4(40 \%)$ & $2 \mathrm{E}+0$ \\
\hline Ammonia & $\begin{array}{l}7664-41- \\
7\end{array}$ & $8.0 \mathrm{E}+02$ & NA & $\begin{array}{l}5.0 \mathrm{E}+02, \\
\text { IRIS }\end{array}$ & Respiratory & NA & $6 \mathrm{E}-2$ \\
\hline Benzene & $71-43-2$ & $1.0 \mathrm{E}+02$ & $\begin{array}{l}2.2 \mathrm{E}-06 \\
\text { IRIS* }\end{array}$ & $\begin{array}{l}3.0 \mathrm{E}+01, \\
\text { IRIS }\end{array}$ & Immune & $\begin{array}{l}7 \mathrm{E}-6 \\
(1.6 \%)\end{array}$ & $1 \mathrm{E}-1$ \\
\hline Benzo[b]fluoranthene & $205-99-2$ & $2.1 \mathrm{E}-02$ & $\begin{array}{l}1.1 \mathrm{E}-4, \\
\text { OEHHA }\end{array}$ & NA & NA & $7 \mathrm{E}-8$ & NA \\
\hline Benzo[a]pyrene & $50-32-8$ & $1.9 \mathrm{E}-02$ & $\begin{array}{l}6.0 \mathrm{E}-04, \\
\text { IRIS }\end{array}$ & $\begin{array}{l}\text { 2.0E-03, } \\
\text { IRIS }\end{array}$ & Developmental & $3 \mathrm{E}-7$ & $4 \mathrm{E}-1$ \\
\hline Benzo[j]fluoranthene & $205-82-3$ & $1.5 \mathrm{E}-02$ & $\begin{array}{l}1.1 \mathrm{E}-4, \\
\text { OEHHA }\end{array}$ & NA & $\overline{\mathrm{NA}}$ & $5 \mathrm{E}-8$ & $\overline{\mathrm{NA}}$ \\
\hline Benzo[k]fluoranthene & 207-08-9 & $5.6 \mathrm{E}-03$ & $\begin{array}{l}1.1 \mathrm{E}-4, \\
\text { OEHHA }\end{array}$ & NA & NA & $2 \mathrm{E}-8$ & NA \\
\hline Butadiene & $106-99-0$ & $1.7 \mathrm{E}+02$ & $\begin{array}{l}3.0 \mathrm{E}-05 \\
\text { IRIS }\end{array}$ & $\begin{array}{l}2.0 \mathrm{E}+00, \\
\text { IRIS }\end{array}$ & Reproductive & $2 \mathrm{E}-4(37 \%)$ & $\begin{array}{l}3 \mathrm{E}+0 \\
(1.4 \%)\end{array}$ \\
\hline Cadmium & $\begin{array}{l}7440-43- \\
9\end{array}$ & $1.8 \mathrm{E}-02$ & $\begin{array}{l}1.8 \mathrm{E}-03 \\
\text { IRIS }\end{array}$ & NA & Renal & $9 \mathrm{E}-7$ & NA \\
\hline Chrysene & $218-01-9$ & $6.9 \mathrm{E}-02$ & $\begin{array}{l}1.1 \mathrm{E}-5 \\
\text { OЕНHA }\end{array}$ & $\overline{\mathrm{NA}}$ & NA & $2 \mathrm{E}-8$ & $\overline{\mathrm{NA}}$ \\
\hline Cresol & $\begin{array}{l}1319-77- \\
3\end{array}$ & $1.2 \mathrm{E}+01$ & NA & $\begin{array}{l}6.0 \mathrm{E}+02, \\
\text { OEHHA }\end{array}$ & NA & NA & $8 \mathrm{E}-3$ \\
\hline Formaldehyde & $50-00-0$ & $8.1 \mathrm{E}+01$ & $\begin{array}{l}1.3 \mathrm{E}-05 \\
\text { IRIS }\end{array}$ & NA & $\begin{array}{l}\text { Respiratory/ } \\
\text { ophthalmologi- } \\
\text { cal }\end{array}$ & $\begin{array}{l}3 \mathrm{E}-5 \\
(7.7 \%)\end{array}$ & $3 \mathrm{E}-1$ \\
\hline $\mathrm{HCN}$ & $74-90-8$ & $1.0 \mathrm{E}+03$ & NA & $\begin{array}{l}\text { 8.0E-01, } \\
\text { IRIS }\end{array}$ & Endocrine & NA & $\begin{array}{l}5 \mathrm{E}+1 \\
(21 \%)\end{array}$ \\
\hline $\begin{array}{l}\text { Indeno[1,2,3- } \\
\text { cd]pyrene }\end{array}$ & $193-39-5$ & $1.1 \mathrm{E}-02$ & $\begin{array}{l}1.1 \mathrm{E}-4, \\
\text { OEHHA }\end{array}$ & NA & NA & $3 \mathrm{E}-8$ & NA \\
\hline Isoprene & $78-79-5$ & $1.1 \mathrm{E}+02$ & $\begin{array}{l}2.2 \mathrm{E}-08, \\
\text { Haney et al }\end{array}$ & $\begin{array}{l}1.0 \mathrm{E}+03 \\
\mathrm{TCEQ}\end{array}$ & NA & $7 \mathrm{E}-8$ & $1 \mathrm{E}-2$ \\
\hline Mercury & $\begin{array}{l}7439-97- \\
6\end{array}$ & $4.3 \mathrm{E}-03$ & NA & $\begin{array}{l}\text { 3.0E-01, } \\
\text { TCEQ }\end{array}$ & Neurological & NA & $5 \mathrm{E}-4$ \\
\hline $\begin{array}{l}\text { Methyl ethyl ke- } \\
\text { tone }\end{array}$ & $78-93-3$ & $1.7 \mathrm{E}+02$ & NA & $\begin{array}{l}5.0 \mathrm{E}+03, \\
\text { IRIS }\end{array}$ & Developmental & NA & $1 \mathrm{E}-3$ \\
\hline Naphthalene & $91-20-3$ & $1.0 \mathrm{E}+01$ & $\begin{array}{l}3.4 \mathrm{E}-05 \\
\text { OEHHA }\end{array}$ & $\begin{array}{l}3.0 \mathrm{E}+00, \\
\text { IRIS }\end{array}$ & Respiratory & $\begin{array}{l}\mathrm{E}-5 \\
(2.5 \%)\end{array}$ & $1 \mathrm{E}-1$ \\
\hline Phenol & $108-95-2$ & $3.2 \mathrm{E}+02$ & NA & $\begin{array}{l}2.0 \mathrm{E}+02, \\
\text { OЕHHA }\end{array}$ & NA & NA & $6 \mathrm{E}-2$ \\
\hline Propionaldehyde & $123-38-6$ & $9.0 \mathrm{E}+01$ & NA & $\begin{array}{l}8.0 \mathrm{E}+00, \\
\text { IRIS }\end{array}$ & Respiratory & NA & $4 \mathrm{E}-1$ \\
\hline Styrene & $100-42-5$ & $5.5 \mathrm{E}+01$ & NA & $\begin{array}{l}1.0 \mathrm{E}+03, \\
\text { IRIS }\end{array}$ & Neurological & NA & $2 \mathrm{E}-3$ \\
\hline Toluene & $108-88-3$ & $2.4 \mathrm{E}+02$ & NA & $\begin{array}{l}5.0 \mathrm{E}+03, \\
\text { IRIS }\end{array}$ & Neurological & NA & $2 \mathrm{E}-3$ \\
\hline
\end{tabular}

Table 9.4: Smoke components from the literature used for cannabis smoking QRA. $\mathrm{CY}$ in $\mu \mathrm{g} /$ joint (for a $0.75 \mathrm{~g}$ joint), as well as their associated REL and IUR with sources used, their non-cancer target systems according to IRIS, and the ELCR $\mathrm{EL}_{i}$ and HQ for each component. Percentage contributions to $\mathrm{ELCR}_{\mathrm{T}}$ and HI are shown for components that contribute greater than $1 \%$ to the total of each, which collectively make up $99 \% \mathrm{ELCR}_{\mathrm{T}}$ and HI. ${ }^{*}$ The lower bound of the range reported for benzene is used. 


\section{Appendix D: Supporting Information to The influence of terpenes on the release of volatile organic compounds and active ingredients to cannabis vaping aerosols}

\subsection{Scheduled substance usage}

Research activities involved THC were performed in accordance with 21 C.F.R. $\S 1301.18$ and safely stored in accordance with $\S 1301.75$. THC was purchased from Cayman Chemical (Ann Arbor, MI) as a solution in acetonitrile at $50 \mathrm{mg} / \mathrm{mL}$. The solvent was removed in vacuo before use in experiments. Cannabinol was graciously donated by Floraworks Holdings Inc.
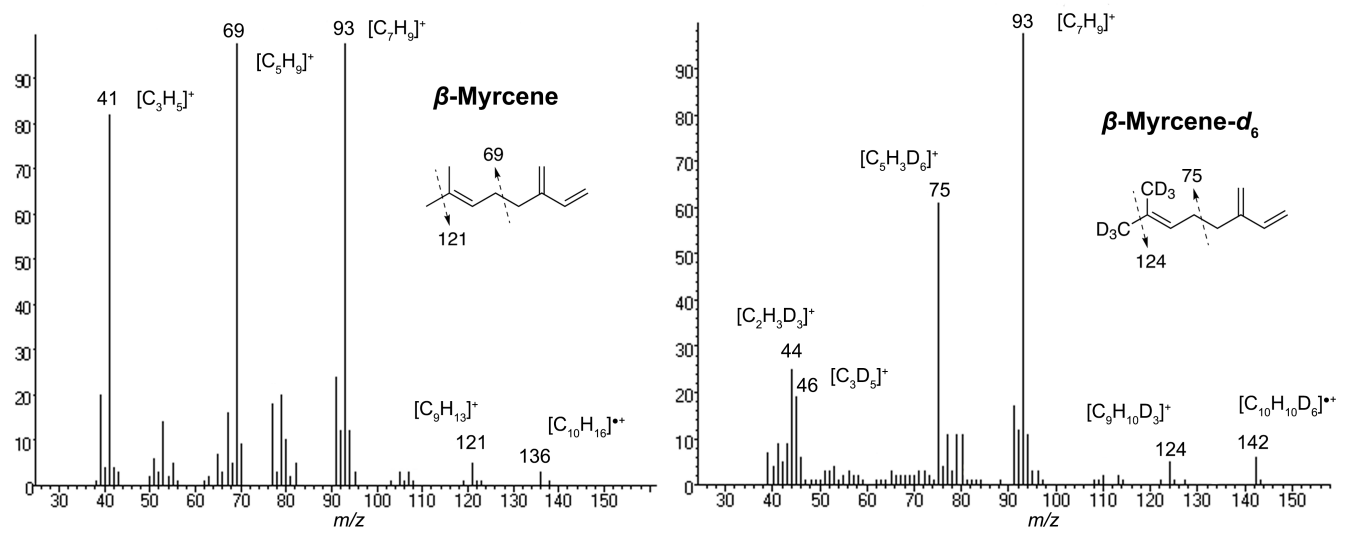

Figure 10.1: EIMS spectra of $\beta$-myrcene $\beta$-myrcene- $d_{6}$ 


\subsection{Synthesis of $\beta$-myrcene- $d_{6}$}

To a solution of hexadeutero isopropyl triphenylphoshine iodide salt (420 mg, 1.0 mmol, $1.1 \mathrm{eq})$ in $\operatorname{THF}(9 \mathrm{~mL}, 0.1 \mathrm{M})$ at $0{ }^{\circ} \mathrm{C}$ was added n-butyllithium $(1.6 \mathrm{M}, 620$ $\mu \mathrm{L}, 1.0 \mathrm{mmol}, 1.1 \mathrm{eq})$. This solution was allowed to stir at $0{ }^{\circ} \mathrm{C}$ for $30 \mathrm{~min}$ before a solution of 4-methylenehex-5-enal (100 mg, $0.90 \mathrm{mmol}, 1.0 \mathrm{eq})$ in THF (0.50 mL) was added dropwise. The ice bath was removed and the reaction was permitted to stir at room temperature for 2 hours before being quenched with saturated aqueous ammonium chloride and extracted with pentane. The combined organic fractions were dried over anhydrous magnesium sulfate, concentrated under reduced pressure, and purified via flash chromatography (100\% pentane) to provide the title compound in $54 \%$ yield in a 6:1 ratio with pentane. As expected, NMR analysis shows a spectrum identical to that of myrcene except for the absence of six proton signals associated with the geminal dimethyl olefin, and confirming the presence of 7 -(methyl- $\left.d_{3}\right)-3-$ methyleneocta-1,6-diene-8,8,8- $d_{3}\left(\beta\right.$-myrcene- $\left.d_{6}\right) .{ }^{1} \mathrm{H}$ NMR $\left(500 \mathrm{MHz}, \mathrm{CDCl}_{3}\right): \delta$ $6.38(\mathrm{dd}, J=17.6,10.8 \mathrm{~Hz}, 1 \mathrm{H}), 5.25(\mathrm{~d}, J=17.6 \mathrm{~Hz}, 1 \mathrm{H}), 5.16(\mathrm{t}, J=6.7 \mathrm{~Hz}, 1 \mathrm{H})$, $5.03(\mathrm{~m}, 3 \mathrm{H}), 2.20(\mathrm{~m}, 4 \mathrm{H}) \cdot{ }^{1-4}$

\subsection{Synthetic cannabis oil}

THC (Cayman Chemical, Ann Arbor, MI) was acquired as a $10 \mathrm{mg} / \mathrm{mL}$ solution in acetonitrile, which was concentrated in vacuo. Pure THC was assessed for purity by HPLC-UV and NMR. THC was used alone in vaping or dabbing experiments, or mixed with $\beta$-myrcene (Sigma Aldrich) or $\beta$-myrcene- $d_{6}$ for studies using synthetic cannabis oil. THC and $\beta$-myrcene mixtures were homogenized in scintillation vials 
using a rotary evaporator slowly spinning at atmospheric pressure with the vial partially submerged in a $50{ }^{\circ} \mathrm{C}$ water bath for $1-2$ hours. THC content was assessed by HPLC-UV on 5-point standard addition calibration curves by first creating analyte stock solutions. of the mixes at $1-1.3 \mathrm{mg} / \mathrm{mL}$ in $1: 1 \mathrm{CH}_{3} \mathrm{CN}: \mathrm{H}_{2} \mathrm{O} .400 \mu \mathrm{L}$ of 1.0 $\mathrm{mg} / \mathrm{mL}(-)-\Delta^{9}-\mathrm{THC}$ in methanol certified reference material standard soln. (Cerilliant Corporation, Round Rock, TX) were added to a $2 \mathrm{~mL}$ vol. flask, and the methanol was evaporated under a gentle stream of Ar, then brought up to volume in 1:1 $\mathrm{CH}_{3} \mathrm{CN}: \mathrm{H}_{2} \mathrm{O}$ for a final conc. of $200 \mu \mathrm{g} / \mathrm{mL}$ (THC spike soln.). $50 \mu \mathrm{L}$ of analyte stock soln. and 100, 150, 200, 300, or $400 \mu \mathrm{L}$ of THC spike soln. were added and to $2 \mathrm{~mL}$. vol. flasks and brought up to volume in $1: 1 \mathrm{CH}_{3} \mathrm{CN}: \mathrm{H}_{2} \mathrm{O}$, and immediately analyzed by HPLC-UV monitoring at $254 \mathrm{~nm}$.

\subsection{Cartridge vaping experiments}

Pure THC, THC with $7.2 \%$ myrcene, THC with $14 \%$ myrcene, and pure CBN were added to CCELL TH2 oil vape atomizer (CCELL) and warmed in a $40{ }^{\circ} \mathrm{C}$ oven for 3-4 hours oven to allow the oil to saturate the internal wick, and then used the following day in vaping experiments. The atomizers were connected to an iStick PICO (eLeaf) battery that was set to the wattage required for each experiment. The aerosol collection apparatus (Figure 10.2) consisted of: the CEC atomizer/battery for aerosol generation, a $47 \mathrm{~mm}$ glass fiber filter pad (i.e. Cambridge filter pad [CFP], Healthcare) for aerosol particulate matter collection, a $\frac{1}{4}$ ” $\mathrm{x} 3.5$ " ATD sorbent tube containing $100 \mathrm{mg}$ 35/60 mesh Tenax TA and $200 \mathrm{mg}$ 60/80 mesh Carbograph 1 TD (Camsco Inc., Houston, TX), a 0 -10 L/min GFM Mass Flowmeter (Aalborg, Orangeburg, NY), and a Cigarette Smoking Machine CSM-STEP (CH Technologies). 


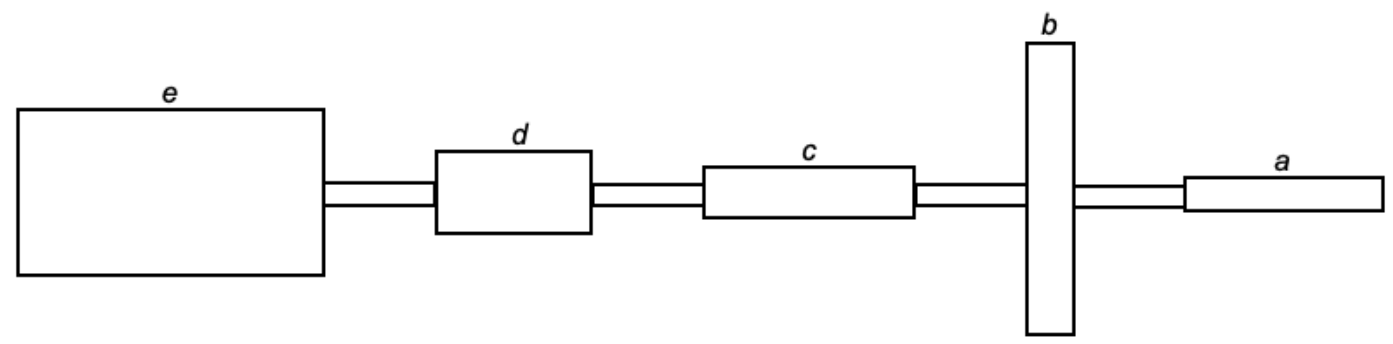

Figure 10.2: Aerosol collection apparatus for CEC vaping. $a$ : CEC/battery; $b$ : CFP holder; $c$ : sorbent tube; $d$ : mass flowmeter; $e$ : CSM.

Given the variability of sorbent material packing in each ATD sorbent tube, each tube was calibrated on a 5-point calibration curve (CSM puff depth [V] vs. flowmeter flowrate $[\mathrm{L} / \mathrm{min}])$ in order to determine the puff depth setting on the CSM to match, as closely as possible, the CORESTA recommended setting for e-cigarette puffing: 50 $\mathrm{mL}$ puff volume in $3 \mathrm{~s}^{5}$ Knowledge of the exact puff volume facilitated air blank VOC correction. After calibration, VOC emissions from a single puff from the vaporizer were collected on the ATD sorbent tube, and the atomizer was massed before and after each puff. Air blanks were collected in triplicate in the exact same manner on the days experiments were performed and used to account for background levels of target VOCs in the samples. Benzene and toluene were the only target VOCs (Table $5.1)$ detectable. Air levels of benzene $(4.3 \pm 0.2 \mathrm{ng} / \mathrm{L})$ and toluene $(2.0 \pm 0.4 \mathrm{ng} / \mathrm{L})$ were taken as the mass of analyte collected on the sorbent tube vs. the total sampled air volume, including the calibration draws. Background contributions of benzene and toluene were subtracted from measured benzene and toluene levels in ATD sorbent tubes for vaping samples by accounting for the total sampled air volume for each (including calibration draws). 


\subsection{THC delivery analysis}

Cambridge filter pads from CEC vaping experiments were extracted in $20 \mathrm{~mL}$ 1:1 $\mathrm{CH}_{3} \mathrm{CN}: \mathrm{H}_{2} \mathrm{O}$ added with $1 \mathrm{~mL}$ of an internal standard solution $(5.574 \mathrm{mg} / \mathrm{mL}$ olivetol in 1:1 $\left.\mathrm{CH}_{3} \mathrm{CN}: \mathrm{H}_{2} \mathrm{O}\right)$. Olivetol was chosen as an internal standard due to its similar solubility to THC, and its favorable retention time on the chromatogram relative to THC. Extraction solutions were stored at $-20{ }^{\circ} \mathrm{C}$ for $<2$ days prior to analysis by HPLC-UV. THC concentration loss under these storage conditions was monitored, and concentration loss as monitored by HPLC-UV was only detectable after 5 days. $\mathrm{THC}_{T}$ was quantified using a freshly-prepared six-point internal standard calibration curve with $0.0,4.5,9.1,18.2,36.4$, and $59.1 \mu \mathrm{g} / \mathrm{mL}$ THC with $50.7 \mu \mathrm{g} / \mathrm{mL}$ olivetol in each.

\subsection{HPLC-UV methodology}

The following method was adapted from Protti et al. (2019). ${ }^{6}$ A Waters 1525 Binary HPLC Pump with a Waters 2996 Photodiode Array Detector were used for the analysis. A $5 \mu \mathrm{L}$ loop was loaded with $5 \mathrm{x}$ sample volume and copious wash solvent between injections to avoid contamination. Sample injection were separated over an Acclaim $^{\text {TM }}$ RSLC Polar Advantage II 3um $20 \AA 3.0 \times 75$ mm stationary phase. Mobile phase consisted of: solvent A, $0.1 \%$ formic acid (Fisher Scientific) in HPLC-grade water (Honeywell, Morris Plains, NJ); solvent B $0.1 \%$ formic acid (Fisher Scientific) in HPLC-grade acetonitrile (Honeywell, Morris Plains, NJ). The gradient separation was as follows: initially $50 \% \mathrm{~A}$, ramping down to $5 \%$ A after 7 min., maintaining

for $1 \mathrm{~min}$., then ramping back to $50 \% \mathrm{~A}$ for $1 \mathrm{~min}$., with a re-equilibration time of 
$4 \mathrm{~min}$. at $50 \% \mathrm{~A}$, for a total run time of $13 \mathrm{~min}$. with combined flowrate of 0.3 $\mathrm{mL} / \mathrm{min} .3-4$ injections of a check standard $(200 \mu \mathrm{g} / \mathrm{mL}$ THC) were performed prior to analysis to ensure retention time stability.

\subsection{ATD-GC-MS methodology}

Sorbent tubes were stored at $-20{ }^{\circ} \mathrm{C}$ for not more than seven days before analysis. ATD sorbent tubes were thermally desorbed with a TurboMatrix 650 automated thermal desorber (ATD) unit. $20 \mathrm{ng}$ fluorobenzene, $18.6 \mathrm{ng}$ toluene- $d_{8}$, $21.7 \mathrm{ng} 4$ bromofluorobenzene, and $20.3 \mathrm{ng}$ 1,2-dichlorobenzene- $d_{4}$ were added automatically to all ATD sorbent tubes prior to desorption as internal standards. The ATD unit thermally desorbed tubes for $8 \mathrm{~min}$. at $285{ }^{\circ} \mathrm{C}$ with a He desorption flow of 40 $\mathrm{mL} / \mathrm{min}$ and a split flow of $100 \mathrm{~mL} / \mathrm{min}$, and the desorption stream was trapped at $-5{ }^{\circ} \mathrm{C}$ on an intermediate "Tenax trap." This intermediate trap was desorbed at 295 ${ }^{\circ} \mathrm{C}$ at a constant pressure of $35 \mathrm{psi}$ on a split flow of $20 \mathrm{~mL} / \mathrm{min}$ for $6 \mathrm{~min}$. Through a $1 \mathrm{~m}$ long and $0.25 \mathrm{~mm}$ i.d. deactivated, fused silica transfer line maintained at 235 ${ }^{\circ} \mathrm{C}$, the sample stream was passed along to a $60 \mathrm{~m}, 0.25 \mathrm{~mm}$ i.d., and $1.4 \mu \mathrm{m}$ film thickness Agilent (Santa Clara, CA) DB-VRX capillary GC column mounted in an Agilent 7890 A GC. The GC was interfaced with an Agilent 5975C MS in electron impact ionization at $70 \mathrm{eV}$ in the positive ion mode, with an MS scan range of $34-600$ amu, and an electron multiplier voltage of $1725 \mathrm{~V}$. GC oven temperature was held at $45{ }^{\circ} \mathrm{C}$ for $10 \mathrm{~min}$, raised to $190{ }^{\circ} \mathrm{C}$ at $12{ }^{\circ} \mathrm{C} / \mathrm{min}$ and held for $2 \mathrm{~min}$, then raised to $240{ }^{\circ} \mathrm{C}$ at $6{ }^{\circ} \mathrm{C} / \mathrm{min}$ and held for $5 \mathrm{~min}$, then programmed down to $210{ }^{\circ} \mathrm{C}$ at 10 ${ }^{\circ} \mathrm{C} / \min$. 


\subsection{VOC quantification by ATD-GC-MS}

For all samples excluding those generated from the THC- $\beta$-myrcene- $d_{6}$ mixes, VOCs in the aerosol GP were quantified using the non-target analysis method from MeehanAtrash et al. (2019). ${ }^{7}$ Where selected HPHCs were quantified, an ionizaton cross section is calculated to provide a more accurate result. When total the yield of total VOCs $\left(\mathrm{VOC}_{\mathrm{T}}\right)$ were calculated, the ionization cross section of all components of the chromatogram was assumed to be equal to that of a chosen internal standard, fluorobenzene. In GP samples generated from THC- $\beta$-myrcene- $d_{6}$ mixes, the coeluting deuterated and non-deuterated compounds prevented these from being estimated using the above non-target analysis method, which requires integration on the total ion chromatogram. To overcome this, response factors for HPHCs of interest were determined from previously collected quantitative $\mathrm{ATD}-\mathrm{GC}-\mathrm{MS}$ chromatograms. The mass of each HPHC in the sample $\left(m_{H P H C}\right.$, sample, ng) per mg particulate matter collected $\left(m_{P M}\right)$ was determined using equation 10.1:

$$
\frac{m_{H P H C, \text { sample }}}{m_{P M}}=\frac{\frac{A_{H P L C}}{A_{F B}} \times \frac{R F_{F B}}{R F_{H P H C}} \times m_{F B}-m_{H P H C, \text { blank }}}{m_{P M}}
$$

where $\mathrm{A}_{H P H C}$ is the area of HPHC's ion of interest in the selected ion chromatogram (SIC), AFB is the $m / z=96$ SIC area of the fluorobenzene internal standard, RFFB fluorobenzene's response factor for $m / z=96$ calculated from a blank run $\left(\mathrm{A}_{m / z=96} / \mathrm{m}_{F B}\right), R F_{H P H C}$ is the response factor of the HPHC's ion of interest calculated from an injection of pure standards, $m_{F B}$ is the mass of fluorobenzene added (20 ng) to each sample, and $m_{H P H C \text {,blank }}$ is the mass of HPHC present in the 
laboratory air blank. The response factor for a specific ion of interest of an HPHC was used for the equivalent ion in a deuterium isotopologue. For example, the RF for isoprene's $m / z=67 \mathrm{amu}$ ion was assumed to be equal to isoprene- $d_{5}$ 's $m / z=71 \mathrm{amu}$ ion, because these both occur after loss of a methyl hydrogen.

\subsection{Chemical mechanism modelling}

A gas-phase oxidation mechanism for $\beta$-myrcene was derived using the SAPRC ${ }^{8-9}$ mechanism generation system, MechGen ${ }^{10}$, and product formation was predicted using a SAPRC box model. MechGen uses experimentally derived rate constants and branching ratios if data are available and otherwise uses estimated rate constants and branching ratios based on group additivity and other estimation methods. MechGen has been used previously in the development of the SAPRC-18 mechanism ${ }^{11}$ and in development of a detailed SAPRC furans mechanism for atmospheric modeling. ${ }^{12}$ In this work, MechGen was used to derive a $\beta$-myrcene oxidation mechanism under vaping conditions (significantly higher VOC levels and temperature than atmospheric conditions); the MechGen-derived mechanism was then implemented into a SAPRC box model to simulate vaping of a $\beta$-myrcene (300 ppm) and THC (700 ppm) mixture at $643 \mathrm{~K}$ and $1 \mathrm{~atm}$ with $5 \mathrm{ppb}$ of NO. The SAPRC simulation duration was $10 \mathrm{~min}-$ utes with a time step of $0.1 \mathrm{~min}$, and the $\mathrm{OH}$ level was controlled between $2 \times 10^{-8}$ and $5 \times 10^{-7} \mathrm{ppm}$ throughout the simulations. The SAPRC modeling was used to investigate observed ratios of product formation as a function of temperature and NO level. To further investigate product formation mechanisms, a second gas-phase chemical mechanism generator, GECKO-A, was used to derive a $\beta$-myrcene oxidation mechanism under vaping conditions. GECKO-A is a nearly explicit chemical mecha- 
nism generator that relies on experimental data, structure-activity relationships, and a predefined protocol to generate detailed oxidation reaction schemes for organic compounds under atmospheric conditions (Aumont et al., 2005). Detailed descriptions of mechanism generation in GECKO-A can be found in Aumont et al. (2005) and Camredon et al. (2007). In this work, the GECKO-A-generated reaction mechanism for $\beta$-myrcene at $643 \mathrm{~K}$ demonstrated that MVK (a $1^{\text {st }}$ generation product) and MACR (a $2^{\text {nd }}$ generation product) formed via $\mathrm{OH}$ and $\mathrm{NO}_{3}$ pathways.

\subsection{Mass spectra}
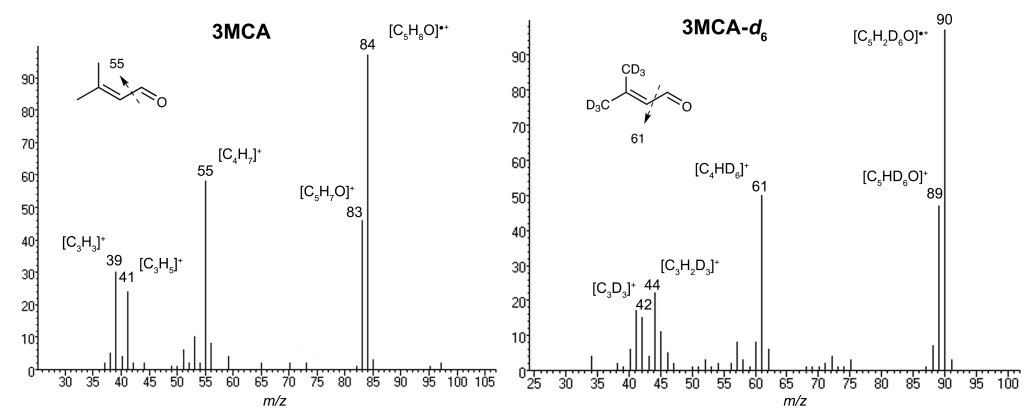

Figure 10.3: EIMS spectra for 3-methylacrolein (3MCA) and its deuterium isotopologue 4,4,4-trideutero-3-(1,1,1-trideuteromethyl)-prop-2-enal (3MCA- $\left.d_{6}\right)$ that are formed when $\beta$-myrcene- $d_{6}$ is subjected to dabbing. $3 \mathrm{MCA}-d_{6}$ elutes immediately before $3 \mathrm{MCA}$ on the GC-MS chromatogram, and the structure was proposed primarily on the observation of a +6 amu mass shift on the molecular ion and a +6 amu mass shift on the isobutenyl cation. 

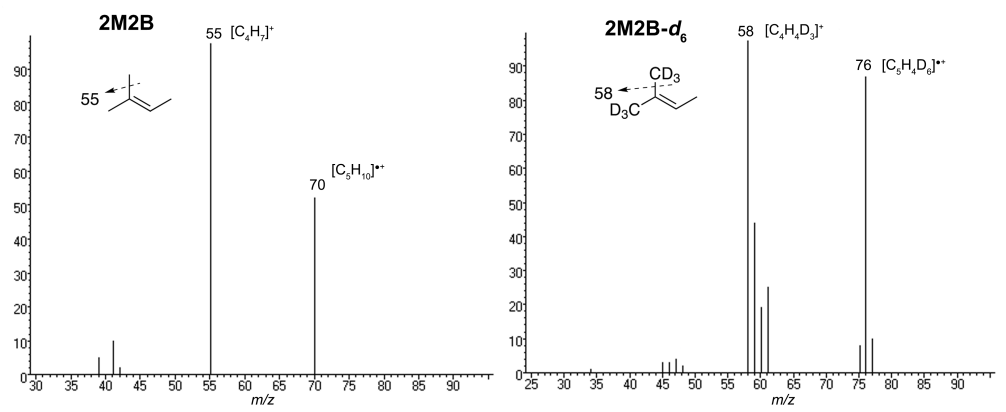

Figure 10.4: The EIMS spectra for 2-methyl-2-butene (2M2B) and its deuterium isotopologue 1,1,1-trideutero-2-(1,1,1-trideuteromethyl)-but-2-ene $\left(2 \mathrm{M} 2 \mathrm{~B}-d_{6}\right)$ that are formed when $\beta$-myrcene- $d_{6}$ is subjected to dabbing. $2 \mathrm{M} 2 \mathrm{~B}-d_{6}$ elutes immediately before 2M2B on the GC-MS chromatogram, and the structure was proposed primarily on the observation of a +6 amu mass shift on the molecular ion and a +3 amu mass shift on its base peak.
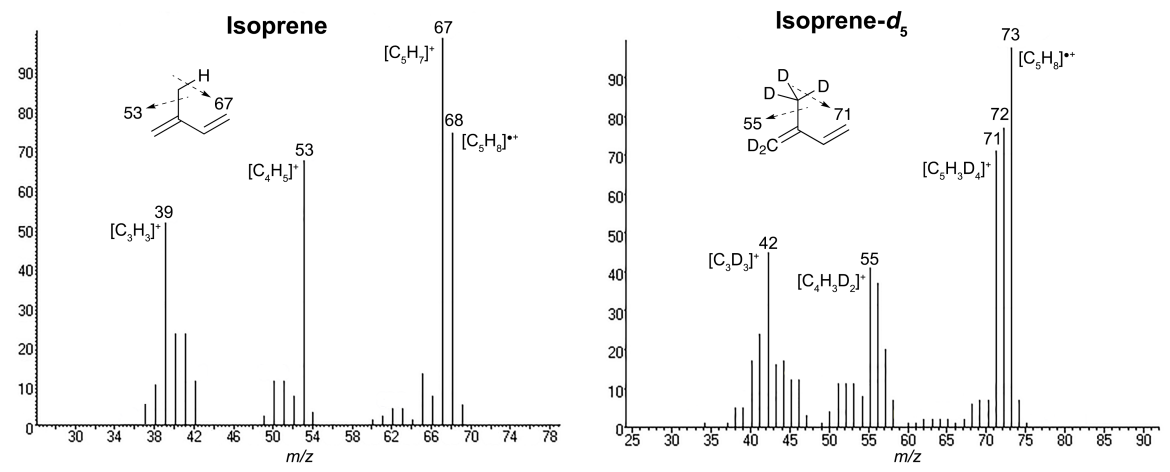

Figure 10.5: The EIMS spectra for isoprene and 1,1-dideutero-2-(1,1,1trideuteromethyl)-1,3-butadiene (isoprene- $d_{5}$ ) that are formed when $\beta$-myrcene- $d_{6}$ is subjected to dabbing. Isoprene- $d_{5}$ elutes immediately before isoprene on the GC-MS chromatogram, and the structure was proposed primarily on the observation of a +6 amu mass shift on the molecular ion and a +2 amu mass shift on the butadienyl cation. The presence of other ions such as $m / z=72,56$, and 57 suggest that another isoprene- $d_{5}$ isotopomer may be present, but the relatively higher abundance of $m / z=73,71,55$, and 42 suggest that the proposed structure is the most abundant isotopomer. 

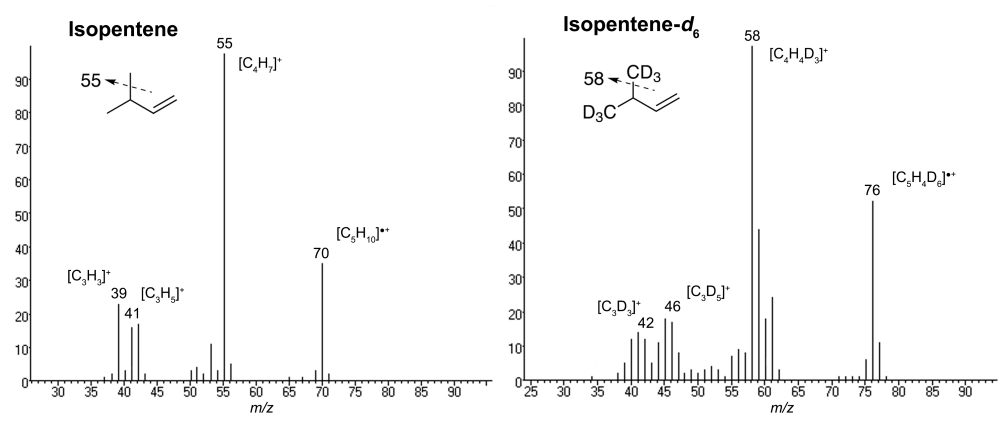

Figure 10.6: The EIMS spectra for isopentene and its deuterium isotopologue 4,4,4trideutero-3-(1,1,1-trideuteromethyl)-but-1-ene (isopentene- $d_{6}$ ) that are formed when $\beta$-myrcene- $d_{6}$ is subjected to dabbing. Isopentene- $d_{6}$ elutes immediately before isopentene on the GC-MS chromatogram, and the structure was proposed primarily on the observation of a +6 amu mass shift on the molecular ion and a +3 amu mass shift on its base peak.
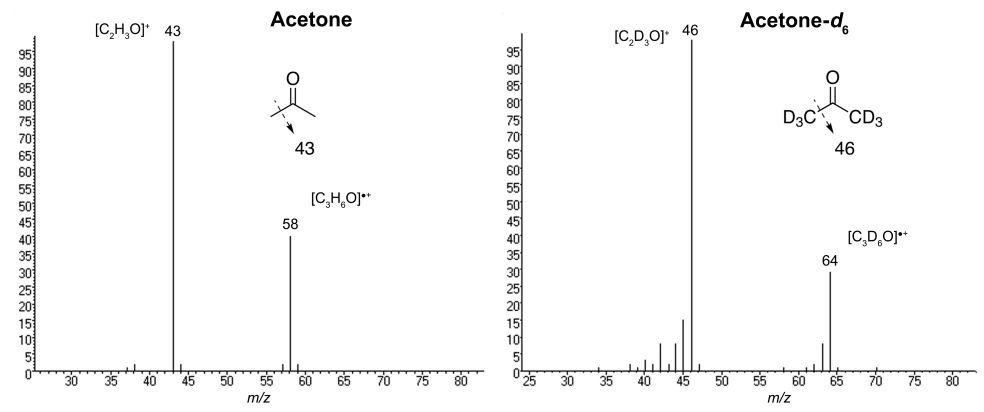

Figure 10.7: The EIMS spectra for acetone and its deuterium isotopologue 1,1,1,3,3,3hexadeutero-2-propanone (acetone- $d_{6}$ ) that are formed when $\beta$-myrcene- $d_{6}$ is subjected to dabbing. Acetone- $d_{6}$ elutes immediately before acetone on the GC-MS chromatogram, and the structure was proposed primarily on the observation of a +6 amu mass shift on the molecular ion and a +3 amu mass shift on its base peak. 

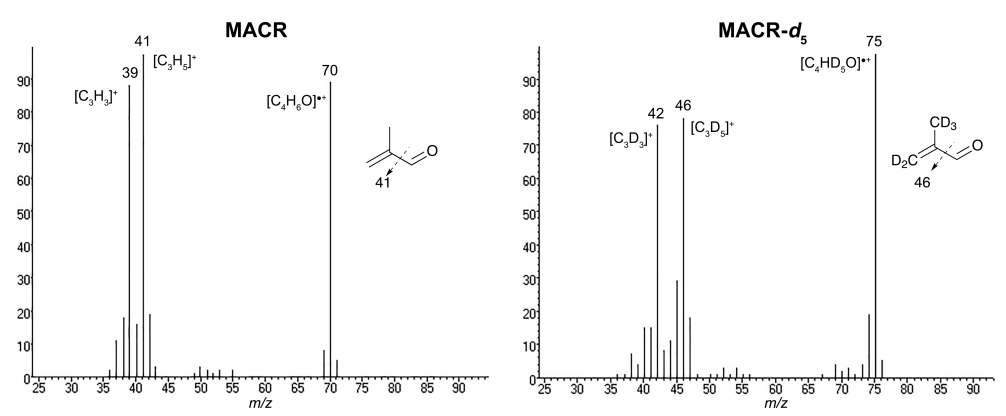

Figure 10.8: The EIMS spectra for methacrolein (MACR) and its deuterium isotopologue 3,3-dideutero-2-(1,1,1-trideuteromethyl)-prop-2-enal (MACR- $\left.d_{5}\right)$ that are formed when $\beta$-myrcene- $d_{6}$ is subjected to dabbing. MACR- $d_{5}$ elutes immediately before MACR on the GC-MS chromatogram, and the structure was proposed primarily on the observation of a +5 amu mass shift on the molecular ion and a +5 amu mass shift on its base peak.
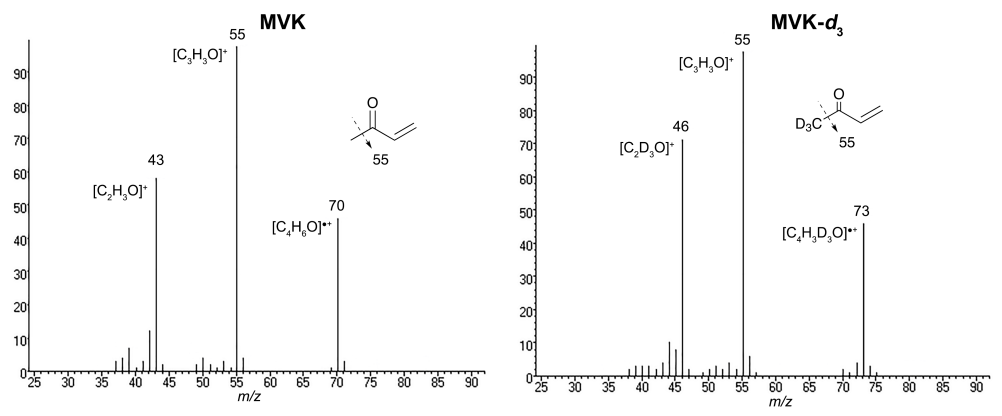

Figure 10.9: The EIMS spectra for methyl vinyl ketone (MVK) and its deuterium isotopologue 1,1,1-trideuterobut-3-en-2-one $\left(\mathrm{MVK}-d_{3}\right)$ that are formed when $\beta$-myrcene$d_{6}$ is subjected to dabbing. MVK- $d_{3}$ elutes immediately before MVK on the GC-MS chromatogram, and the structure was proposed primarily on the observation of a +3 amu mass shift on the molecular ion, an identical base peak which results from loss of the methyl group, and a +3 amu mass shift on the acetyl radical. 


\subsection{Chromatograms}

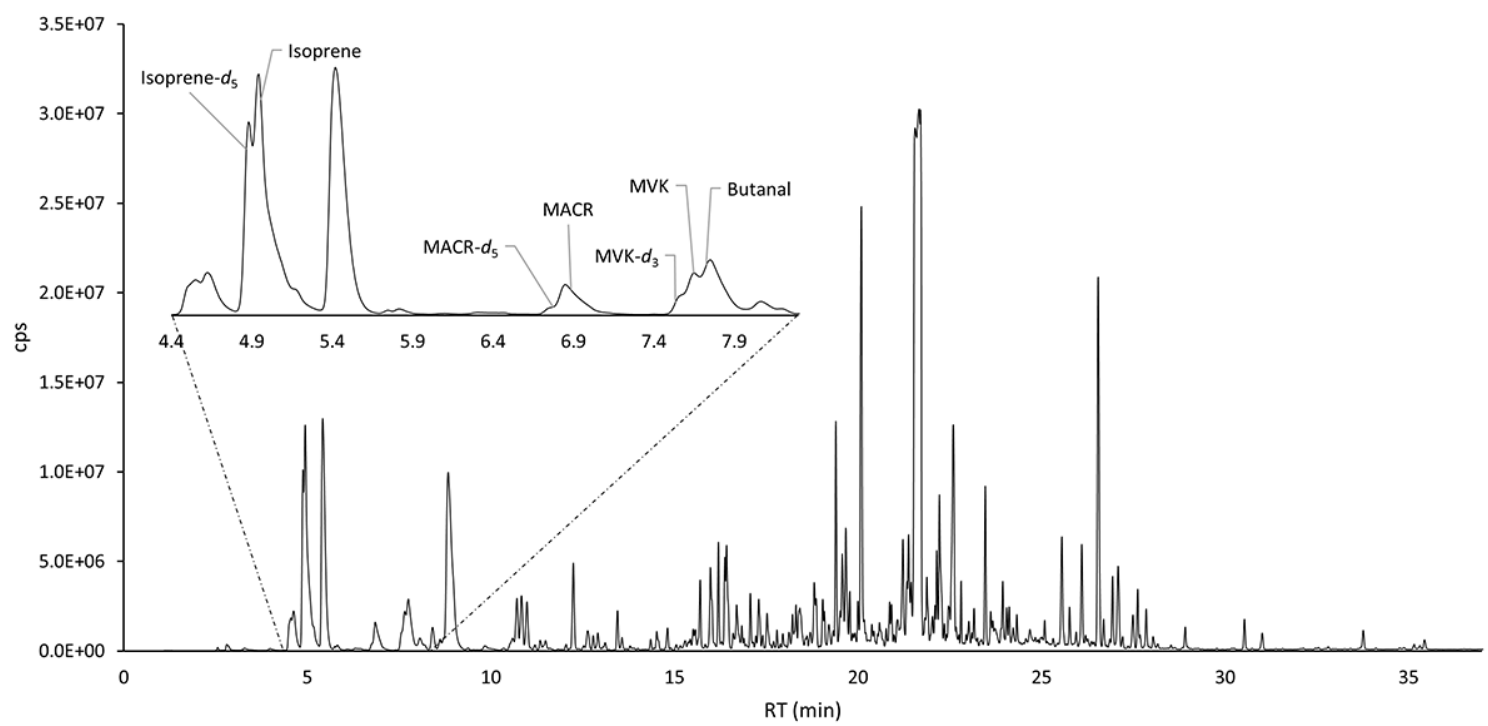

Figure 10.10: ATD-GC-MS chromatogram obtained from dabbing $\beta$-myrcene- $d_{6}$. The inlay highlights the presence of D-isotopologues identifiable in the chromatogram by examination of their mass spectra.

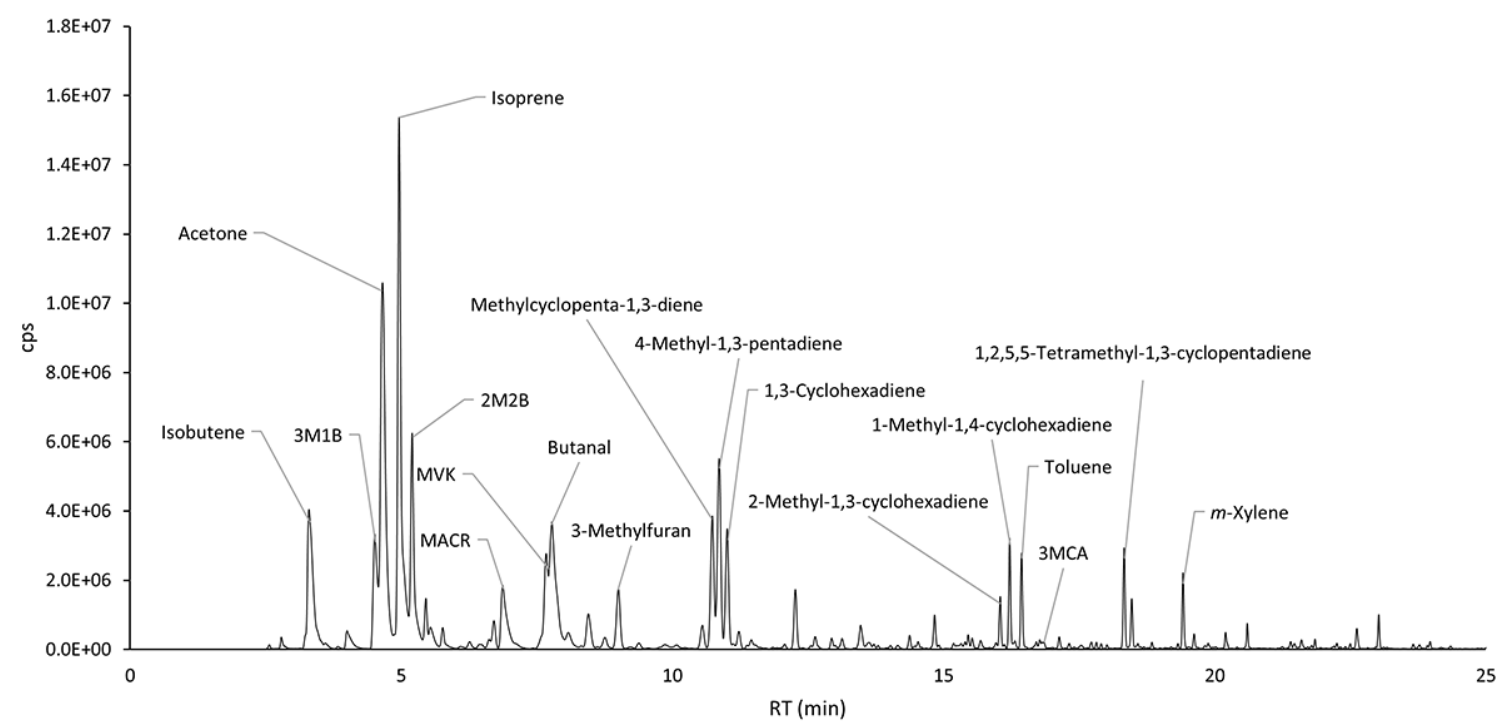

Figure 10.11: ATD-GC-MS chromatogram obtained from vaping pure THC. 


\subsection{Identified compounds}

\begin{tabular}{|c|c|c|c|c|}
\hline $\begin{array}{l}\text { Retention time } \\
(\min )\end{array}$ & Name & CAS \# & Match quality (\%) & ng analyte \\
\hline 3.021 & methylethene & 000115-07-1 & 90 & 2 \\
\hline 3.586 & isobutene & $000115-11-7$ & 90 & 54 \\
\hline 4.171 & ethanol & $000064-17-5$ & 72 & 3 \\
\hline 4.351 & 1,2-dimethylcyclopropane & 002402-06-4 & 91 & 37 \\
\hline 4.743 & (3Z)-1,3-pentadiene & 001574-41-0 & 96 & 2 \\
\hline 5.084 & acetone & $000627-20-3$ & 55 & 128 \\
\hline 5.444 & isoprene & $000078-79-5$ & 96 & 1296 \\
\hline 5.546 & 4-methyl-2-pentene & 000691-38-3 & 87 & 82 \\
\hline 5.713 & 2-methyl-2-butene & 000513-35-9 & 91 & 198 \\
\hline 6.343 & 1,4-pentadiene & 000591-93-5 & 97 & 64 \\
\hline 7.32 & 2,3-dimethyl-2-butene & $000563-79-1$ & 81 & 62 \\
\hline 7.538 & methacrolein & $000078-85-3$ & 91 & 34 \\
\hline 8.348 & 2-methyl-1-pentene & 000763-29-1 & 90 & 8 \\
\hline 8.425 & methyl vinyl ketone & $000078-94-4$ & 90 & 31 \\
\hline 8.541 & butanal & $000123-72-8$ & 94 & 10 \\
\hline 9.081 & 3-vinyl-1-cyclobutene & $006555-52-8$ & 95 & 3 \\
\hline 9.351 & 4-methyl-2-pentene & $000674-76-0$ & 91 & 357 \\
\hline 9.646 & (E)-3-methyl-2-pentene & 000616-12-6 & 93 & 55 \\
\hline 9.961 & 4-methyl-1,3-pentadiene & 000926-56-7 & 95 & 94 \\
\hline 10.231 & (2Z)-3-methyl-2-pentene & $000922-62-3$ & 95 & 38 \\
\hline 10.366 & (1-methylethylidene) cyclopropane & 004741-86-0 & 91 & 5 \\
\hline 10.951 & 3,3-dimethyl-1-pentene & 003404-73-7 & 91 & 17 \\
\hline 11.574 & 1-methyl-1,3-cyclopentadiene & 000096-39-9 & 76 & 216 \\
\hline 11.67 & 4-methyl-1,3-pentadiene & 000926-56-7 & 95 & 346 \\
\hline 12.037 & 1-methyl-1-cyclopentene & 000693-89-0 & 76 & 18 \\
\hline 12.229 & 4-methylpenta-1,3-diene & 000926-56-7 & 93 & 10 \\
\hline 12.319 & (3E)-3-methyl-3-hexene & 003404-65-7 & 93 & 3 \\
\hline 12.39 & 2,3-dimethyl-1-pentene & $003404-72-6$ & 95 & 12 \\
\hline
\end{tabular}

Table 10.1: All GP products from vaping THC with a CEC tentatively identified by GC-MS presenting a match quality of $>70 \%$ with the NIST/Wiley mass spectral library. 


\begin{tabular}{|c|c|c|c|c|}
\hline $\begin{array}{l}\text { Retention time } \\
(\min )\end{array}$ & Name & CAS \# & Match quality (\%) & ng analyte \\
\hline 12.486 & hexahydrobenzene & $000110-82-7$ & 95 & 53 \\
\hline 12.808 & benzene & $000071-43-2$ & 95 & 12 \\
\hline 13.007 & 1,3-cyclohexadiene & $000592-57-4$ & 87 & 55 \\
\hline 13.617 & isoprene epoxide & $000000-00-0$ & 78 & 6 \\
\hline 13.701 & (2E)-5-methyl-2-hexene & $003404-62-4$ & 74 & 2 \\
\hline 14.029 & (Z)-3-methyl-3-hexene & 004914-89-0 & 95 & 6 \\
\hline 14.119 & pentanal & $000110-62-3$ & 72 & 6 \\
\hline 14.305 & 2-methyl-2-hexene & 002738-19-4 & 91 & 96 \\
\hline 14.639 & (E)-4-methyl-2-hexene & $003683-22-5$ & 83 & 14 \\
\hline 14.819 & 1,5-dimethylcyclopentene & 016491-15-9 & 70 & 4 \\
\hline 15.012 & 3-methylcyclohexene & $000591-48-0$ & 81 & 19 \\
\hline 15.821 & 3-methylcyclohexene & 000591-48-0 & 91 & 12 \\
\hline 16.008 & 2,5-dihydrotoluene & 004313-57-9 & 94 & 51 \\
\hline 16.297 & 2,5-dihydrotoluene & 004313-57-9 & 94 & 39 \\
\hline 16.438 & 2-methyl-1,3,5-hexatriene & 019264-50-7 & 95 & 12 \\
\hline 16.663 & 2,5-dihydrotoluene & 004313-57-9 & 94 & 36 \\
\hline 16.74 & 1,5-dimethyl-1,4-cyclohexadiene & 004190-06-1 & 74 & 7 \\
\hline 16.83 & 1-methyl-1,4-cyclohexadiene & $004313-57-9$ & 94 & 81 \\
\hline 17.036 & toluene & $000108-88-3$ & 95 & 141 \\
\hline 17.12 & 2-methyl-1,3-cyclohexadiene & $001489-57-2$ & 97 & 9 \\
\hline 17.209 & $\begin{array}{l}\text { tetramethylmethylene- } \\
\text { cyclopropane }\end{array}$ & $054376-39-5$ & 83 & 4 \\
\hline 17.287 & $(3 \mathrm{E}, 5 \mathrm{E})-1,3,5$-heptatriene & $017679-93-5$ & 90 & 22 \\
\hline 17.389 & 6-methyl-1,5-heptadiene & $007270-50-0$ & 76 & 58 \\
\hline 17.479 & 2-hexanone & $000591-78-6$ & 91 & 18 \\
\hline 17.711 & 2-methyl-2-heptene & $000627-97-4$ & 95 & 24 \\
\hline 17.916 & (3E)-3-methyl-1,3,5-hexatriene & $024587-26-6$ & 94 & 15 \\
\hline 18.09 & dimethylsiloxane cyclic trimer & 000541-05-9 & 97 & 30 \\
\hline 18.315 & $(\mathrm{E}, \mathrm{E}, \mathrm{E})-2,4,6$-octatriene & 015192-80-0 & 94 & 31 \\
\hline 18.912 & 5-tert-butyl-1,3-cyclopentadiene & $035059-40-6$ & 94 & 92 \\
\hline 19.054 & 5-tert-butyl-1,3-cyclopentadiene & 035059-40-6 & 91 & 53 \\
\hline 19.15 & 1,2-dimethyl-1,4-cyclohexadiene & 017351-28-9 & 87 & 10 \\
\hline 19.279 & 1,4-dimethylenecyclohexane & 004982-20-1 & 91 & 6 \\
\hline 19.426 & 2,3-dimethyl-1,3-cyclohexadiene & $004430-91-5$ & 91 & 22 \\
\hline
\end{tabular}

Table 10.2: Table 10.1 Continued 


\begin{tabular}{|c|c|c|c|c|}
\hline $\begin{array}{l}\text { Retention time } \\
(\min )\end{array}$ & Name & CAS \# & Match quality (\%) & ng analyte \\
\hline 19.574 & octa-2,4,6-triene & $999178-75-1$ & 95 & 7 \\
\hline 19.876 & 2,6-dimethyl-1,5-heptadiene & 006709-39-3 & 91 & 92 \\
\hline 19.979 & xylene & $000106-42-3$ & 97 & 333 \\
\hline 20.198 & $\begin{array}{l}\text { 1-methylene-3-(1- } \\
\text { methylethylidene)cyclopentane }\end{array}$ & 073913-74-3 & 93 & 31 \\
\hline 20.243 & 1,2-dimethylenecyclohexane & $002819-48-9$ & 90 & 18 \\
\hline 20.442 & 3,3,6-trimethyl-1,5-heptadiene & $035387-63-4$ & 80 & 173 \\
\hline 20.59 & o-xylene & $000095-47-6$ & 87 & 19 \\
\hline 20.699 & 3-methylene-1-vinyl-1-cyclopentene & 061142-07-2 & 76 & 8 \\
\hline 21.187 & 2,3,6-trimethyl-1,5-heptadiene & 033501-88-1 & 74 & 67 \\
\hline 21.399 & 2,4-dimethyl-2,3-heptadien-5-yne & 041898-89-9 & 81 & 4 \\
\hline 21.457 & 4-methyl-1-heptene & 013151-05-8 & 78 & 22 \\
\hline 21.56 & $\begin{array}{l}\text { 1-ethylnyl-2,2,3,3- } \\
\text { tetramethylcyclopropane }\end{array}$ & $103304-20-7$ & 72 & 21 \\
\hline 21.926 & 2,4-dimethyl-2,3-heptadien-5-yne & 041898-89-9 & 91 & 9 \\
\hline 22.023 & 1,4-methylethylbenzene & $000622-96-8$ & 91 & 8 \\
\hline 22.151 & 2,7-dimethyl-1,6-octadiene & 040195-09-3 & 91 & 264 \\
\hline 22.196 & beta-myrcene & 000123-35-3 & 93 & 24 \\
\hline 22.325 & 2,3,6-trimethyl-1,5-heptadiene & 033501-88-1 & 90 & 65 \\
\hline 22.402 & $\begin{array}{l}\text { 1,2,5,5-tetramethyl-1,3- } \\
\text { cyclopentadiene }\end{array}$ & $004249-12-1$ & 90 & 84 \\
\hline 22.762 & 2,4-dimethyl-2,3-heptadien-5-yne & 041898-89-9 & 70 & 27 \\
\hline 22.845 & allylbenzene & $999243-49-8$ & 86 & 16 \\
\hline 22.89 & 1,2,4-trimethylenecyclohexane & 014296-81-2 & 93 & 7 \\
\hline 23.019 & alpha-terpinolen & $000586-62-9$ & 76 & 6 \\
\hline 23.102 & p-cymene & $000099-87-6$ & 97 & 24 \\
\hline 23.231 & m-cymene & $000535-77-3$ & 93 & 55 \\
\hline 23.327 & ocimene & 000502-99-8 & 96 & 12 \\
\hline 23.391 & eucalyptol & $000470-82-6$ & 93 & 6 \\
\hline 23.584 & m-ethyltoluene & $000620-14-4$ & 83 & 11 \\
\hline 23.648 & $\begin{array}{l}(3 \mathrm{E}, 5 \mathrm{E}) \text {-2,6-dimethyl-1,3,5,7- } \\
\text { octatetraene }\end{array}$ & 000460-01-5 & 95 & 5 \\
\hline 24.426 & 4-methylbenzaldehyde & 000104-87-0 & 94 & 12 \\
\hline v 24.644 & alpha-4-dimethylstyrene & $001195-32-0$ & 98 & 13 \\
\hline 25.043 & 1,3,8-para-menthatriene & 018368-95-1 & 94 & 8 \\
\hline
\end{tabular}

Table 10.3: Table 10.1 Continued 


\begin{tabular}{|c|c|c|c|c|}
\hline $\begin{array}{l}\text { Retention } \\
\text { time } \\
(\min )\end{array}$ & Name & CAS \# & $\begin{array}{l}\text { Match } \\
\text { quality } \\
(\%)\end{array}$ & $\begin{array}{l}\text { ng ana- } \\
\text { lyte }\end{array}$ \\
\hline 2.872 & propene & 000115-07-1 & 86 & 3 \\
\hline 3.297 & isobutylene & 000115-11-7 & 90 & 184 \\
\hline 3.821 & ethanol & $000064-17-5$ & 83 & 5 \\
\hline 4.001 & isopentene & 001630-94-0 & 90 & 34 \\
\hline 4.525 & isopentene & $000627-20-3$ & 87 & 175 \\
\hline 4.654 & acetone & $000067-64-1$ & 72 & 661 \\
\hline 4.963 & isoprene & 000591-95-7 & 95 & 857 \\
\hline 5.457 & (3Z)-1,3-pentadiene & 001574-41-0 & 97 & 44 \\
\hline 5.766 & 1,4-pentadiene & 000591-93-5 & 97 & 27 \\
\hline 6.092 & 1-propanol & $000071-23-8$ & 64 & 8 \\
\hline 6.44 & 2-methylpropanal & $000078-84-2$ & 87 & 13 \\
\hline 6.629 & 2,3-dimethylbut-1-ene & $000563-78-0$ & 91 & 7 \\
\hline 6.71 & 2-methyl-2-pentene & $000625-27-4$ & 91 & 20 \\
\hline 6.878 & methacrolein & $000078-85-3$ & 94 & 238 \\
\hline 7.689 & methyl vinyl ketone & $000078-94-4$ & 83 & 224 \\
\hline 7.792 & butanal & $000123-72-8$ & 70 & 541 \\
\hline 8.457 & 2,3-dimethylbut-2-ene & 000563-79-1 & 76 & 75 \\
\hline 8.762 & 4-methyl-1-cyclopentene & $001759-81-5$ & 91 & 26 \\
\hline 9.007 & 2-methylfuran & $000513-81-5$ & 80 & 127 \\
\hline 9.38 & 2,4-hexadiene & $000592-46-1$ & 94 & 14 \\
\hline 9.565 & 2,3-dihydro-4-methylfuran & $034314-83-5$ & 87 & 4 \\
\hline 9.861 & tetrahydro-furan & 000109-99-9 & 91 & 39 \\
\hline 10.552 & 2,4-hexadiene & 005194-51-4 & 94 & 43 \\
\hline 10.737 & methylcyclopenta-1,3-diene & 026519-91-5 & 93 & 262 \\
\hline 10.865 & 4-methyl-1,3-pentadiene & $000926-56-7$ & 95 & 339 \\
\hline 11.011 & 1,3-cyclohexadiene & 026519-91-5 & 93 & 229 \\
\hline 11.226 & 1-methylcyclopentene & 000693-89-0 & 93 & 28 \\
\hline 11.372 & 2-butenal & 004170-30-3 & 95 & 12 \\
\hline 11.458 & (E)-3-methyl-1,3-pentadiene & $002787-43-1$ & 90 & 16 \\
\hline 11.509 & 2-butenal & 004170-30-3 & 93 & 11 \\
\hline 11.625 & 2,5-dihydrofuran & $001708-29-8$ & 80 & 6 \\
\hline 12.072 & benzene & $000071-43-2$ & 95 & 12 \\
\hline 12.269 & 2-methyltetrahydrofuran & $000096-47-9$ & 60 & 165 \\
\hline 12.398 & 5-methyl-1,4-hexadiene & $000763-88-2$ & 92 & 3 \\
\hline 12.552 & methyl vinyl ketone & $000814-78-8$ & 90 & 12 \\
\hline 12.939 & isoprene epoxide & 000000-00-0 & 91 & 37 \\
\hline 13.132 & 1-heptene & $000592-76-7$ & 70 & 31 \\
\hline 13.471 & pentanal & $000110-62-3$ & 91 & 82 \\
\hline 13.595 & 2-(butoxymethyl)oxirane & 002426-08-6 & 43 & 36 \\
\hline 13.716 & 2,4-dimethyl-1,3-pentadiene & 001000-86-8 & 95 & 8 \\
\hline 13.793 & (2e)-2-heptene & $000592-77-8$ & 97 & 6 \\
\hline 13.874 & oxane & $000142-68-7$ & 81 & 1 \\
\hline 13.943 & cyclopropanecarboxylic acid & 001759-53-1 & 72 & 3 \\
\hline 14.025 & 2,5-dimethylfuran & $000625-86-5$ & 93 & 9 \\
\hline
\end{tabular}

Table 10.4: All GP products from dabbing THC tentatively identified by GC-MS presenting a match quality of $>70 \%$ with the NIST/Wiley mass spectral library. 


\begin{tabular}{|c|c|c|c|c|}
\hline $\begin{array}{l}\text { Retention } \\
\text { time } \\
(\mathrm{min})\end{array}$ & Name & CAS \# & $\begin{array}{l}\text { Match } \\
\text { quality } \\
(\%)\end{array}$ & $\begin{array}{l}\text { ng ana- } \\
\text { lyte }\end{array}$ \\
\hline 14.154 & 1,5-dimethylcyclopentene & 016491-15-9 & 70 & 8 \\
\hline 14.377 & 1-methylcyclohexene & 000591-49-1 & 87 & 35 \\
\hline 14.527 & methyl butanoate & $000623-42-7$ & 81 & 3 \\
\hline 14.591 & (Z)-cycloheptene & $000628-92-2$ & 89 & 4 \\
\hline 14.836 & 1-methylcyclohexa-2,4-diene & 999131-00-1 & 93 & 66 \\
\hline 14.913 & 2,3-dimethyl-1,3-pentadiene & 001113-56-0 & 94 & 5 \\
\hline 15.184 & 1-methylcyclohexene & $000591-49-1$ & 78 & 13 \\
\hline 15.394 & 1,2-dimethyl-1,3-cyclopentadiene & 004784-86-5 & 94 & 15 \\
\hline 15.454 & (2E)-2-methyl-2-butenal & 001115-11-3 & 91 & 23 \\
\hline 15.527 & (2E)-2-methyl-2-butenal & 000497-03-0 & 93 & 29 \\
\hline 15.682 & (3E)-2-methyl-1,3,5-hexatriene & 019264-50-7 & 90 & 26 \\
\hline 15.849 & (3E)-3-methyl-1,3,5-hexatriene & $024587-26-6$ & 94 & 5 \\
\hline 15.969 & 2,5-dihydrotoluene & 004313-57-9 & 83 & 16 \\
\hline 16.047 & 2-methyl-1,3-cyclohexadiene & 001489-57-2 & 94 & 106 \\
\hline 16.12 & 5,6-dimethyl-1,3-cyclohexadiene & $002417-81-4$ & 91 & 7 \\
\hline 16.218 & 2-methyl-1,3,5-hexatriene & 019264-50-7 & 94 & 243 \\
\hline 16.441 & toluene & $000108-88-3$ & 95 & 226 \\
\hline 16.708 & 2-methyl-1-heptene & 015870-10-7 & 93 & 22 \\
\hline 16.776 & 3-methyleneheptane & 001632-16-2 & 94 & 17 \\
\hline 16.854 & Methylcholanthrene & $000107-86-8$ & 94 & 12 \\
\hline 17.133 & 2-methyl-2-heptene & $000627-97-4$ & 91 & 35 \\
\hline 17.24 & (E)-4-octene & 014850-23-8 & 70 & 3 \\
\hline 17.317 & 2,5-dihydrotoluene & 004313-57-9 & 93 & 18 \\
\hline 17.643 & 2,5-dimethyl-1,3-hexadiene & 000927-98-0 & 93 & 3 \\
\hline 17.725 & 1,5,5-trimethyl-1,3-cyclopentadiene & 999178-77-9 & 91 & 22 \\
\hline 17.815 & biisobutenyl & $000764-13-6$ & 92 & 5 \\
\hline 17.905 & 1-methylene-2-methylcyclohexane & 002808-75-5 & 91 & 13 \\
\hline 18.013 & 3,5-dimethylcyclohexene & $000823-17-6$ & 96 & 11 \\
\hline 18.159 & (3E)-3-ethylidene-1-methyl-1-cyclopentene & 062338-00-5 & 93 & 5 \\
\hline 18.33 & 1,2,5,5-tetramethyl-1,3-cyclopentadiene & 004249-12-1 & 91 & 257 \\
\hline 18.472 & 5-tert-butyl-1,3-cyclopentadiene & $035059-40-6$ & 91 & 110 \\
\hline 18.584 & 2,5-dimethylhex-5-en-3-yn-2-ol & $999226-91-1$ & 90 & 31 \\
\hline 18.841 & 1,5,5-trimethyl-1,3-cyclopentadiene & 999178-77-9 & 95 & 25 \\
\hline 18.987 & $(\mathrm{E}, \mathrm{E}, \mathrm{E})-2,4,6$-octatriene & 015192-80-0 & 94 & 4 \\
\hline 19.197 & 5,5-dimethyl-2-ethyl-1,3-cyclopentadiene & 999221-33-9 & 64 & 6 \\
\hline 19.322 & 2,6-dimethyl-1,5-heptadiene & 006709-39-3 & 91 & 18 \\
\hline 19.416 & p-xylene & $000106-42-3$ & 97 & 247 \\
\hline 19.622 & 3,3-dimethyl-6-methylenecyclohexene & 020185-16-4 & 94 & 52 \\
\hline 19.82 & 1,2-dimethyl-1,4-cyclohexadiene & 017351-28-9 & 86 & 14 \\
\hline
\end{tabular}

Table 10.5: Table 10.4 continued 


\begin{tabular}{|c|c|c|c|c|}
\hline $\begin{array}{l}\text { Retention } \\
\text { time } \\
(\min )\end{array}$ & Name & CAS \# & $\begin{array}{l}\text { Match } \\
\text { quality } \\
\text { (\%) }\end{array}$ & $\begin{array}{l}\text { ng ana- } \\
\text { lyte }\end{array}$ \\
\hline 19.966 & 1,6-dimethylhepta-1,3,5-triene & 999221-34-1 & 95 & 7 \\
\hline 20.017 & m-xylene & 000108-38-3 & 60 & 11 \\
\hline 20.21 & 1,5-dimethyl-1,4-cyclohexadiene & 004190-06-1 & 90 & 4 \\
\hline 20.309 & 1-methylene-3-vinylcyclohexane & $999131-40-0$ & 58 & 3 \\
\hline 20.412 & alpha-pyrone & $000514-94-3$ & 94 & 6 \\
\hline 20.893 & hexanoic acid & $000142-62-1$ & 72 & 6 \\
\hline 21.017 & 1-phenylethanol & $000098-85-1$ & 76 & 6 \\
\hline 21.399 & $1(7), 5,8$-o-menthatriene & 000000-00-0 & 91 & 35 \\
\hline 21.46 & 1,2,3-trimethylbenzene & $000526-73-8$ & 70 & 11 \\
\hline 21.545 & 2,4-dimethyl-2,3-heptadien-5-yne & 041898-89-9 & 83 & 6 \\
\hline 21.606 & 2,6-dimethyl-2,7-octadiene & $016736-42-8$ & 81 & 24 \\
\hline 21.713 & 3-isopropenyl-6-methyl-1-cyclohexene & 005113-87-1 & 96 & 10 \\
\hline 21.79 & 3-isopropenyl-6-methyl-1-cyclohexene & 005113-87-1 & 98 & 12 \\
\hline 21.85 & 1,6-dimethylhepta-1,3,5-triene & 999221-34-1 & 94 & 37 \\
\hline 21.953 & octanal & $000124-13-0$ & 93 & 4 \\
\hline 22.408 & alpha-terpinene & 000099-86-5 & 98 & 10 \\
\hline 22.498 & o-cymene & $000527-84-4$ & 97 & 17 \\
\hline 22.619 & o-cymene & $000527-84-4$ & 97 & 99 \\
\hline 22.76 & $(+)$-sabinene & $003387-41-5$ & 96 & 3 \\
\hline 22.82 & 1,2,3-trimethylbenzene & $000526-73-8$ & 90 & 4 \\
\hline 22.962 & 2,4-dimethyl-2,3-heptadien-5-yne & 041898-89-9 & 90 & 7 \\
\hline 23.657 & 3-methyl-5-methylene-norbornylene & 000000-00-0 & 81 & 5 \\
\hline 23.846 & terpinolene & $000586-62-9$ & 96 & 3 \\
\hline 23.971 & 1-methyl-2-isopropenylbenzene & 001587-04-8 & 97 & 36 \\
\hline 24.048 & 3-methylbenzaldehyde & $000620-23-5$ & 80 & 1 \\
\hline 24.147 & 2-methoxy-4-methylphenol & $000093-51-6$ & 86 & 3 \\
\hline 24.353 & 1,3,8-p-menthatriene & 021195-59-5 & 93 & 12 \\
\hline 24.447 & 1-methylcyclooctene & 000933-11-9 & 94 & 1 \\
\hline 25.057 & $\begin{array}{l}\text { methyl-6-methyl-8,9,10-trinorborn-5-en-2- } \\
\text { endo-yl ketone }\end{array}$ & 092356-41-7 & 91 & 17 \\
\hline 25.181 & $\begin{array}{l}\text { methyl-6-methyl-8,9,10-trinorborn-5-en-2- } \\
\text { endo-yl ketone }\end{array}$ & 092356-41-7 & 91 & 9 \\
\hline 26.276 & (4-methylphenyl)ethanone & $000122-00-9$ & 94 & 5 \\
\hline 26.645 & naphthalene & 000091-20-3 & 97 & 5 \\
\hline 26.735 & alpha-phellandren-8-ol & 001686-20-0 & 70 & 2 \\
\hline 28.942 & 2-methyl-2-norbornene & $000694-92-8$ & 83 & 1 \\
\hline 29.324 & 2-methyl-2-propenoic acid & 007779-31-9 & 72 & 3 \\
\hline 30.564 & $\begin{array}{l}\text { 3,4-dimethyl-7-exo-methylene- } \\
\text { bicyclo[4.3.0]non-3-ene }\end{array}$ & $999134-71-8$ & 90 & 11 \\
\hline 31.054 & 2-methylenenorbornane & $000694-92-8$ & 86 & 4 \\
\hline
\end{tabular}

Table 10.6: Table 10.4 continued 


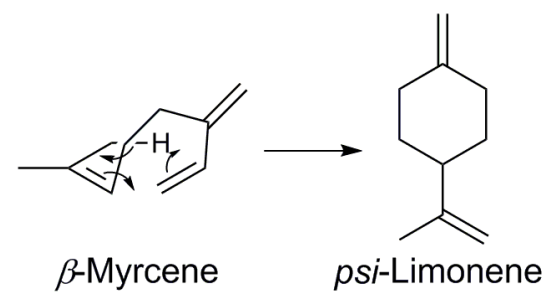

Figure 10.12: Proposed mechanism for the conversion of $\beta$-myrcene to psi-limonene. psi-Limonene formation may occur as an intramolecular ene reaction of $\beta$-myrcene or via a radical mechanism.

\subsection{1a and $1 \mathrm{~b}$ product distribution as a function of applied power}

In order to determine the influence of applied electrical power on the product distribution of the four products deriving from radical 1 (3MCA and 2M2B from resonance structure $\mathbf{1 a}$, and isoprene and 3M1B from resonance structure $\mathbf{1 b}$ ), relative ratios of integrations of the molecular ion of each were graphed as a function of power. The increase in isoprene:3M1B ratio ( $\mathbf{1} \mathbf{b}$ oxidation and reduction products) with respect to power and the decrease in $3 \mathrm{MCA}: 2 \mathrm{M} 2 \mathrm{~B}$ ratio (1a oxidation and reduction products) is mirrored by a decreasing 3MCA:isoprene ratio with respect to power. The static 2M2B:3M1B ratio signals that the decreasing $\mathbf{1 a}: \mathbf{1 b}$ ratio with power is largely governed by a decreasing 3MCA:isoprene ratio. 


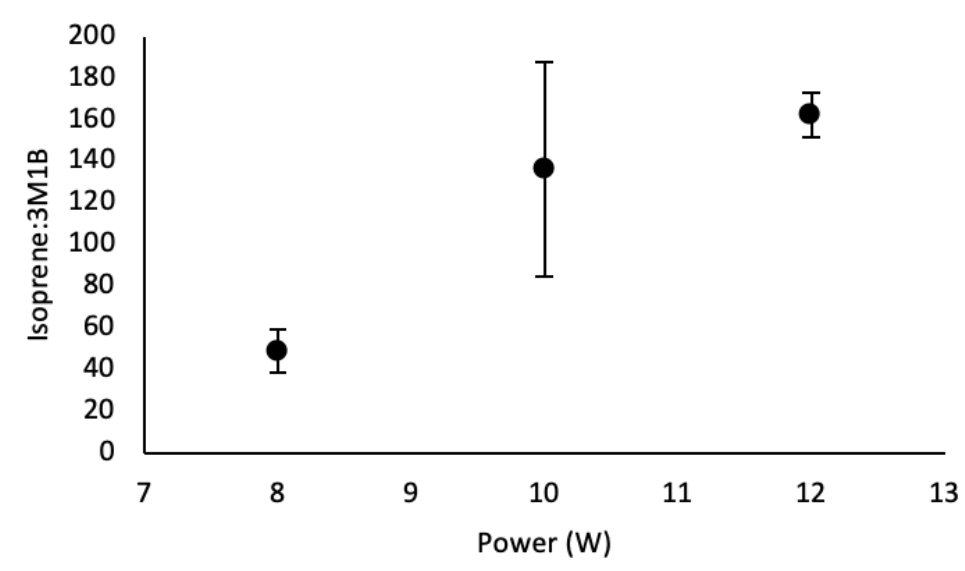

Figure 10.13: Relative levels of the isoprene base peak $(m / z=67 \mathrm{amu})$ to the 3M1B molecular ion $(\mathrm{m} / z=70 \mathrm{amu})$ as a function of applied power. Note the linear increase in the isoprene:3M1B ratio with increasing power.

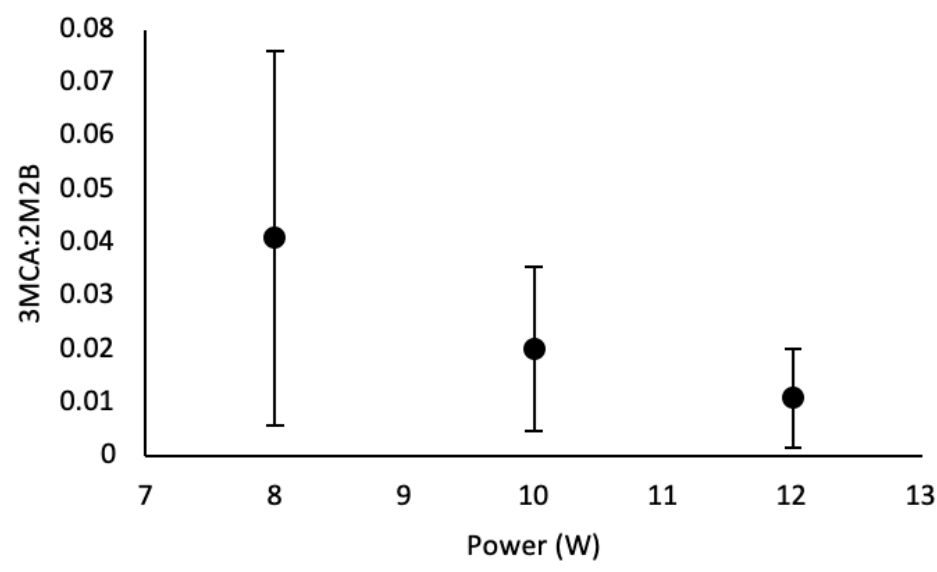

Figure 10.14: Relative levels of the 3MCA molecular ion $(m / z=84 \mathrm{amu})$ to the 2M2B molecular ion $(m / z=70 \mathrm{amu})$ as a function of applied power. Note the small linear decrease in the $3 \mathrm{MCA}: 2 \mathrm{M} 2 \mathrm{~B}$ ratio with increasing power. 


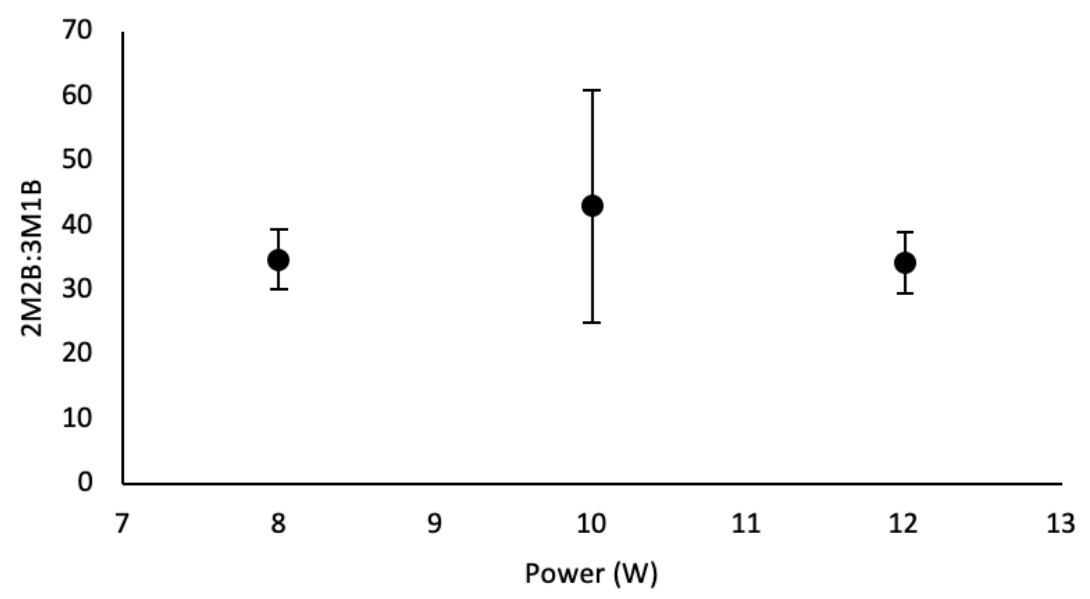

Figure 10.15: Relative levels of the 2M2B molecular ion $(m / z=70 \mathrm{amu})$ to the 3M1B molecular ion $(\mathrm{m} / z=70 \mathrm{amu})$ as a function of applied power. Note this ratio does not change in a statistically significant manner with increasing power.

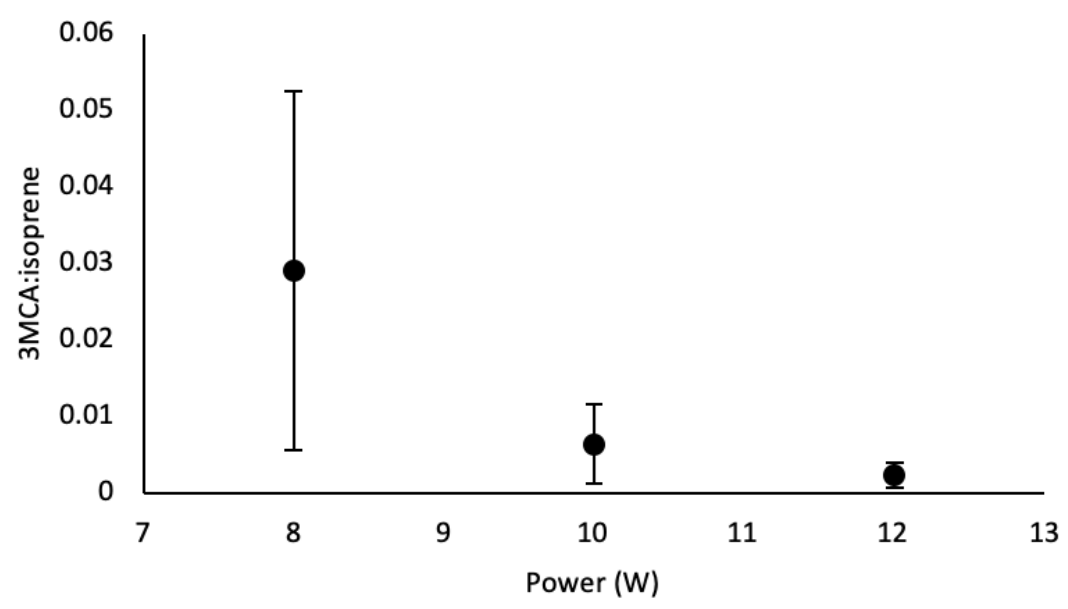

Figure 10.16: Relative levels of the 3MCA molecular ion $(m / z=84 \mathrm{amu})$ to the isoprene base peak $(m / z=67 \mathrm{amu})$ as a function of applied power. Note the significant decrease in the $3 \mathrm{MCA}$ :isoprene ratio with increasing power.

\subsection{References}

(1) S. M. Stevenson, R. F. Higgins, M. P. Shores and E. M. Ferreira, Chem Sci, 2017, 8, 654-660. 
(2) K. Sun, C. Fang, W. Yang, Z. Xu, H. Wang, W. Sun, Y. Luo and Y. Xu, J. Label. Compd. Radiopharm., 2016, 59, 552-556.

(3) W. Liu, L. Li and C. J. Li, Nat Comm, 2015, 6, 6526.

(4) D. J. Comesky, D. D. Rowan and A. J. Matich, J. Label. Compd. Radiopharm, 2006, 49, 47-54.

(5) Cooperation Centre for Scientific Research Relative to Tobacco, Routine Analytical Machine for E-Cigarette Aerosol Generation and Collection - Definitions and Standard Conditions. CORESTA Recommended Method No.81, CORESTA, Paris, France, 2015.

(6) M. Protti, V. Brighenti, M. R. Battaglia, L. Anceschi, F. Pellati and L. Mercolini, ACS Med. Chem. Lett., 2019, 10, 539-544.

(7) J. Meehan-Atrash, W. Luo, K. J. McWhirter and R. M. Strongin, ACS Omega, 2019, 4, 16111-16120.

(8) Carter, W. P. L. The SAPRC-18 Atmospheric Chemical Mechanism. https://intra. engr.ucr.edu/ carter/SAPRC/18/ (accessed February, 2, 2020).

(9) Carter, W. P. L. Documentation of the SAPRC Chemical Mechanism Modeling Software and Files. https://intra.engr.ucr.edu/ carter/SAPRC/ModelPgm.pdf (accessed February 2, 2020).

(10) Carter, William P.L. (2020b). Estimates and Assignments used in the SAPRC-18 Mechanism Generation System; Report to California Air Resources Board Contract No. 11-761. In preparation. When completed, will be available at http://intra.engr. ucr.edu/ carter/SAPRC/18.

(11) W. P. L. Carter, Documentation of the SAPRC Chemical Mechanism Modeling Software and Files, https://intra.engr.ucr.edu/ carter/SAPRC/ModelPgm.pdf, (ac- 
cessed February 2, 2020, 2020).

(12) J. Jiang, W. P. L. Carter, D. R. Cocker and K. C. Barsanti, ACS Earth Space Chem., 2020, 4, 1254-1268. 